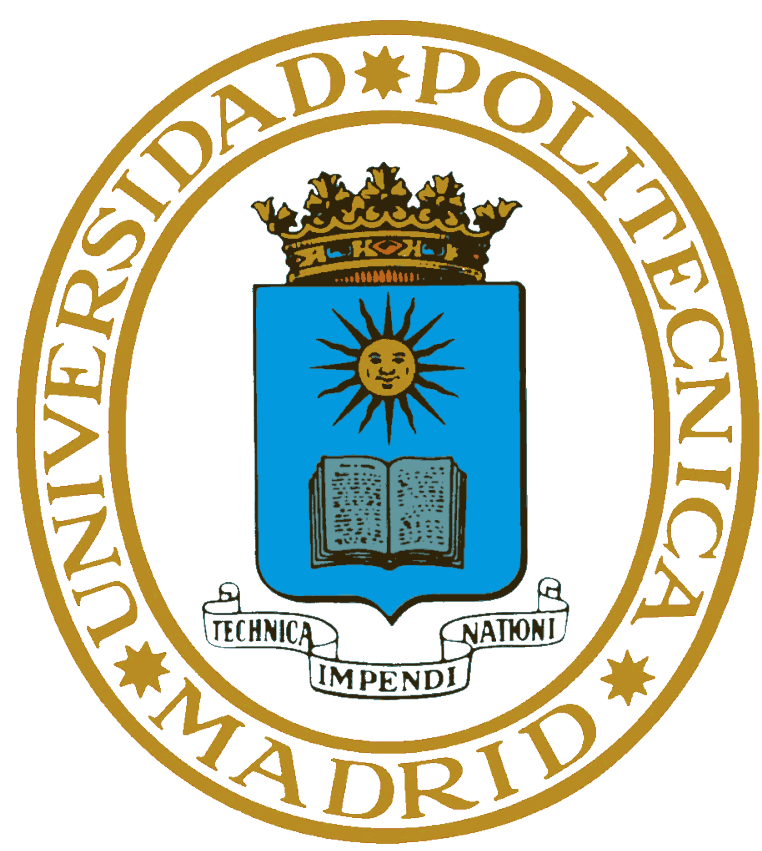

CONTROLES DE SEXO, GÉNERO, HORMONALES Y LA INELEGIBILIDAD DE LAS MUJERES CON HIPERANDROGENISMO EN EL DEPORTE FEMENINO DE ALTO NIVEL

TESIS DOCTORAL

JONATHAN ANDRÉS OSPINA BETANCURT

LICENCIADO EN CIENCIAS DE LA ACTIVIDAD FÍSICA Y DEL DEPORTE 

FACULTAD CIENCIAS DE LA ACTIVIDAD FÍSICA Y DEL DEPORTE

\title{
CONTROLES DE SEXO, GÉNERO, HORMONALES Y LA INELEGIBILIDAD DE LAS MUJERES CON HIPERANDROGENISMO EN EL DEPORTE FEMENINO DE ALTO NIVEL
}

\author{
JONATHAN ANDRÉS OSPINA BETANCURT \\ LICENCIADO EN CIENCIAS DE LA ACTIVIDAD FÍSICA Y DEL DEPORTE
}

\section{Directores:}

Dr. D. Carlos A. Cordente Martínez. Doctor en Ciencias del la Actividad Física y del Deporte. Universidad Politécnica de Madrid.

Dra. Dña. María José Martínez Patiño. Doctora en Ciencias del la Actividad Física y del Deporte. Universidad de Vigo. 

Tribunal nombrado por el Magfco. Y Excmo. Sr. Rector de la Universidad Politécnica de Madrid, el día de de 2017.

Presidente D./Dña.

Vocal D./Dña.

Vocal D./Dña.

Vocal D./Dña.

Secretario/a D./Dña.

Realizado el acto de defensa y lectura de tesis el día, en la Facultad de Ciencias de la Actividad Física y del Deporte (INEF) - Madrid.

Calificación:

EL PRESIDENTE

LOS VOCALES

EL SECRETARIO 

A mi abuela, Fanny

A mi madre, Clara

A mi hermana, Isabella

A mi sobrina, Elena

Y a ti, José

Las personas que más quiero y querré en mi vida 

Siempre me he fijado en el apartado de agradecimientos de todas las tesis doctorales que he leído en este tiempo de doctorado, y han sido unas cuantas. Me parece un pequeño testimonio de quién se encuentra en realidad detrás de un gran trabajo que, la mayoría de las veces, puede parecer frío y poco humano. Ahora me toca a mí: aunque veía el momento muy lejano, ya no hay, por fin, marcha atrás. Son tantas las palabras de agradecimiento que tengo para el mundo entero, para las personas que me han ayudado y me rodean, que voy a intentar ordenarlas.

Mis primeras palabras de agradecimiento son para la persona que me dio la vida, la que luchó y dio su vida por mi futuro y mi bienestar: mi MADRE. Por ella estoy aquí, escribiendo este apartado que cierra una etapa muy larga y difícil, pero en último término exitosa. Gracias, mamá, por tanto amor que me ofreciste y por darme todo lo que necesité para llegar hasta aquí. Sin ti no hubiera sido igual; de hecho, sin ti ya nada es igual. Aunque pasen los años, siempre guardo tu último beso y tu último abrazo como los tesoros más preciados de mi vida. Estarás en mi mente y en mi corazón para siempre.

Mis directores de tesis han sido las personas que me han guiado, ayudado y alentado para no desfallecer.

Carlos ha sido la persona que confió ciegamente en mí y nunca dudó de mi compromiso y capacidad. A ti, Carlos, te debo mi seguridad en la tesis, el orden y el saber hacer. Gracias por permitirme trabajar contigo desde el primer momento en que te lo sugerí. Gracias por haber sido mi director en el Máster y por ser mi director en el Doctorado. Mi estancia en la Facultad de Ciencias de la Actividad Física y el Deporte (INEF) fue diferente y se hizo amable gracias a una persona como tú. Nunca olvidaré y siempre intentaré reproducir tu compromiso y solidaridad con los alumnos. Ellos son los que realmente hacen grande a los profesores, y no al contrario. Para mí, eres el mejor ejemplo para llevar en el camino que me espera después de terminar esta etapa de mi vida.

Igual que Carlos, María José también confió en mí de igual manera. Ella es para mí la mejor prueba de que, cuando algo se quiere, hay que intentarlo. Nunca pensé que una mujer con tanto prestigio a nivel mundial llegara a ser mi directora de tesis y se convirtiera no solo en mi mentora, sino en mi amiga. María José confió en mí con tan solo un email, aquel correo electrónico que escribí muchas veces y no me atrevía a enviar. Todas las veces que lo intenté pensaba: "Recibirá más de cien mensajes al día. ¿Por qué habría de considerar el mío diferente?". Pero fue diferente y aquí estamos, juntos, presentado una tesis doctoral que estoy seguro de que a ella la llena tanto de orgullo como a mí. Gracias, María José, por abrirme tu mundo, tu casa; por dejarme entrar en tu familia y confiar como lo haces a diario. Hoy cerramos una tesis, pero mañana abriremos un nuevo camino. Será largo y espero seguirlo a tu lado. 
María Zakynthinaki, no fuiste mi directora de tesis, pero te considero como tal. Gracias, María, por tu dedicación, generosidad y ayuda. Esta tesis llega a su final por ti; si es grande, lo es por tu cariño y grandeza. Gracias por tu tiempo y por compartir tu sabiduría conmigo. Siempre estará en mi memoria nuestro café de las 10 en el MAICH y tu banda sonora, melodías que tantas risas nos produjo. Roberto nunca más será Roberto: será Roberto-to-to-to. Al escuchar esa risa contagiosa y sincera, supe entender la admiración que le guardas y ese amor incondicional que permanecerá en ti.

Mil gracias a todos aquellos que hicieron que mi camino en la vida universitaria fuera fácil y amena. Gracias a la Facultad Ciencias de la Salud de la Universidad Tecnológica de Pereira. Gracias a la Facultad de Ciencias de la Actividad Física y el Deporte (INEF) de la Universidad Politécnica de Madrid. Gracias a cada uno de sus profesores y trabajadores. Gracias a Ángela por haber sido mi profesora, por ser mi amiga, por ser mi mejor animadora y porque estoy seguro que ella se siente tan feliz como lo estoy yo. Gracias a Javier Durán por su sensibilidad y por haber formado parte de mi tesis. Y gracias a Gador por ayudarme en la facultad a lo largo de tantos años.

Quiero agradecer a toda mi familia, que siempre me ha apoyado y confiado en mí en cuantos proyectos emprendiera. Aunque ellos a menudo no entendieran qué estaba haciendo y por qué tardaba tantos años en terminar, siempre tenían presente que era para un mejor futuro. Gracias a cada integrante de mi familia por transmitirme su amor: abuela, tíos, hermana, primos, sobrina. Y gracias de igual manera a mi familia política, cuyo apoyo siempre he sentido en todas mis decisiones.

Gracias a todos y cada uno de mis amigos, de aquí y de Colombia. Cuando me sentía desanimado, siempre había quien se ofreciera a brindarme compañía y cariño. Por eso agradezco tanto los cafés, las copas, las cenas, las llamadas, los mensajes, los entrenamientos compartidos. Katty, Ana, Mónica, Lorena, Isa, Yeny, Mai, María, Guille, Javi, Isa, Marina, Belén, Miguel, Carlos, Juan Ele, Bea, Fer, Fede, Yaiza, Eva, Fredy y todos que dejo sin nombrar: me habéis ayudado mucho en este proceso. Gracias también a ti, Carlos A., porque sé que era tu sueño y lo estoy haciendo realidad yo. Serás mi amigo por siempre.

Por último, quiero agradecer a la persona que cada día está a mi lado, quien más me ha animado en todo el camino y mejor me ha entendido. José, gracias por ayudarme, aguantar y soportar toda esa presión que te transmitía y tú me ayudabas a canalizar. Gracias por jamás juzgarme y por animarme siempre. Gracias por tantos consejos, por tantas horas y días dedicados. Gracias por ese beso sincero de cada mañana y el abrazo de cada noche. Sin ti, esto que hoy termina no hubiera sido posible. Literalmente. Gracias por tu amor y tu compañía. Te quiero. 


\section{ÍNDICE GENERAL}

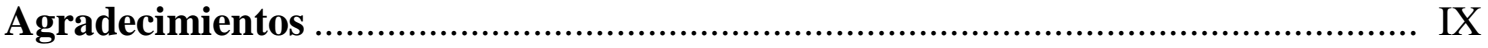

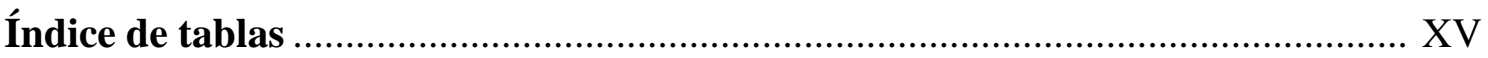

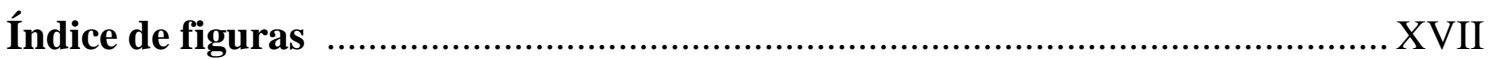

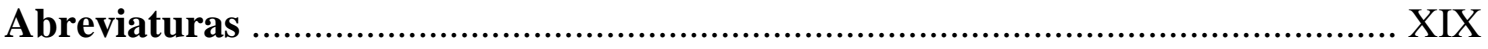

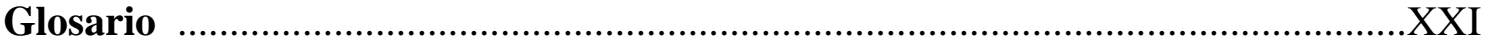

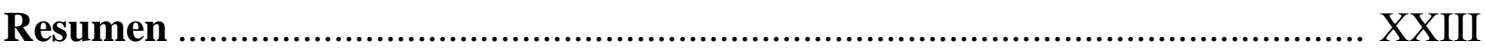

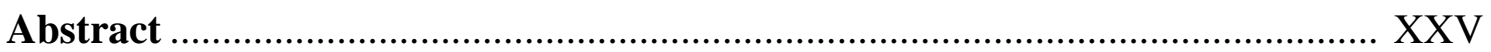

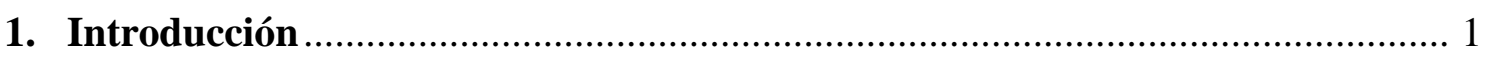

1.1. Diferenciación de sexos en el ser humano ……………………………………. 3

1.1.1. Categorización de la diferenciación de los sexos....................................... 3

1.1.1.1. Sexo Cromosómico.......................................................................... 3

1.1.1.2. Sexo cromatínico ............................................................................. 4

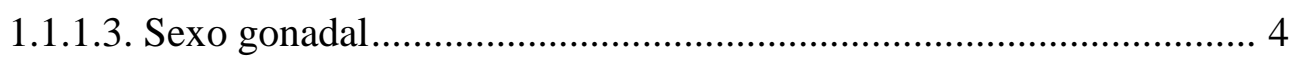

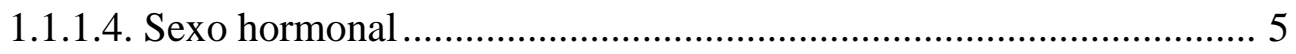

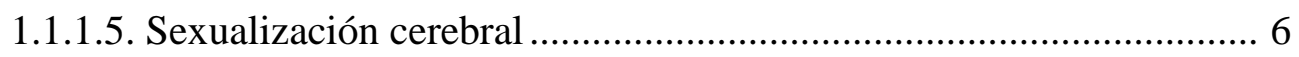

1.1.2. Orígenes de los Estados Intersexuales ……...................... 7

1.1.2.1. Evolución de los Estados Intersexuales.............................................. 8

1.1.3. Anomalías de la Diferenciación Sexual (ADS)...................................... 10

1.1.3.1. Anomalías de la diferenciación sexual con cariotipo 46,XY ......... 12

1.1.3.1.1. Anomalías del desarrollo gonadal (testículo) ............................ 13

1.1.3.1.2. Anomalías de la síntesis de la acción de los andrógenos ............16

1.1.3.1.3. Anomalías en la síntesis o la acción del factor inhibidor de los conductos de Müller (ADS 46,XY interno)......................... 20

1.1.3.1.4. Otras ADS con cariotipo 46,XY ………………….................. 21

1.1.3.2. Anomalías de la diferenciación sexual con cariotipo 46,XX ......... 21

1.1.3.2.1. Anomalías del desarrollo gonadal (ovario) ............................... 21

1.1.3.2.2. Exceso de andrógenos ............................................................ 23 
1.2. Evolución de la normativa del Comité Olímpico Internacional y de la Federación Internacional de Atletismo Amateur (IAAF), en materia de regulación deportiva

1.2.1. Inicios de la verificación de sexo/género en el deporte femenino ......... 23

1.2.2. Certificado Médico ........................................................................... 25

1.2.3. Nude Parade .................................................................................. 26

1.2.4. Cromatina Sexual ó Corpúsculos de Barr ........................................... 28

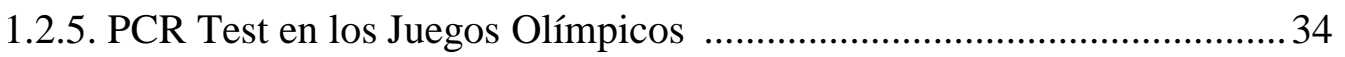

1.2.6. Santhi Soundarajan y Caster Semenya. Nombres propios de los nuevos controles de género del 2006 .................................................... 37

1.2.7. Normativa de Hiperandrogenismo ................................................... 39

1.3. La decisión del Tribunal de Arbitraje del Deporte sobre la normativa de

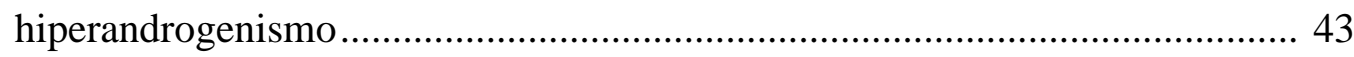

1.3.1. El fundamento fáctico del caso y las causas de impugnación................ 44

1.3.2. La discriminación por razón de la condición física o sexual ................ 47

1.3.2.1. Posición de la impugnante ............................................................ 47

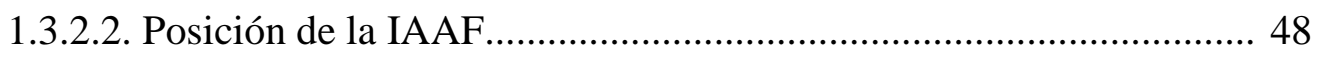

1.3.2.3. Valoración del TAS y sus conclusiones ......................................... 48

1.3.3. La vinculación entre los andrógenos y el rendimiento deportivo .......... 49

1.3.3.1. Posición de la impugnante ................................................................ 49

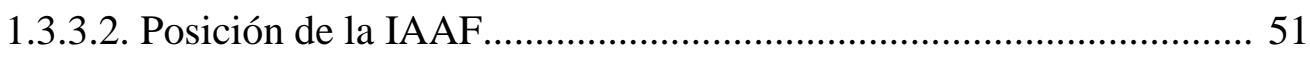

1.3.3.3. Posición del TAS ............................................................................ 53

1.3.4. La desproporcionalidad de la normativa sobre hiperandrogenismo ...... 54

1.3.4.1. Posición de la impugnante ............................................................. 54

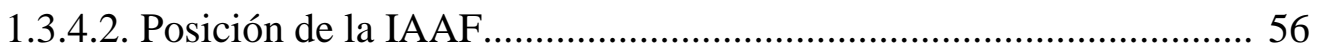

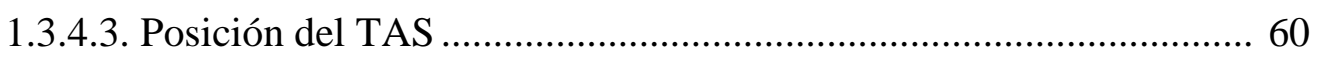

1.4. Estudios relacionados y planteamiento del problema .................................... 61

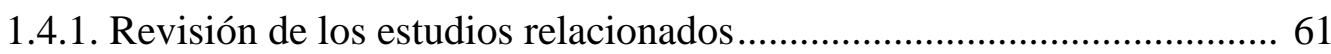

1.4.1.1. Diferencia utilizada en el caso Dutee Chand.................................. 61

1.4.1.2. Diferencias de género en el ciclismo - "Furnace Creek" ................ 62

1.4.1.3. Diferencias de género en triatlón olímpico - "Zürich Triathlon" ..... 63

1.4.1.4. Diferencias de género en los Juegos Olímpicos desde 1983 ............ 63

1.4.1.5. Diferencias de género en el Off-road triatlón ....................................64

1.4.1.6. Influencia del género en el ritmo adoptado por triatletas de élite..... 64

1.4.1.7. Diferencias relativas al género en la pruebas del Ironman de Hawái 65

1.4.1.8. ¿Las diferencias de género en el desempeño deportivo

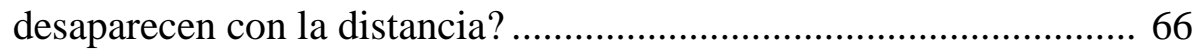

1.4.1.9. Diferencia de género en los eventos de carrera del atletismo........... 67 


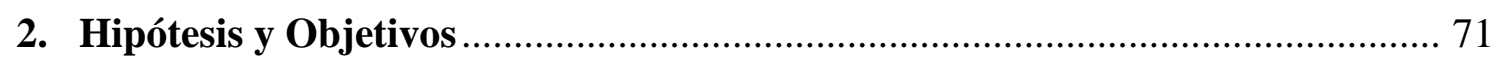

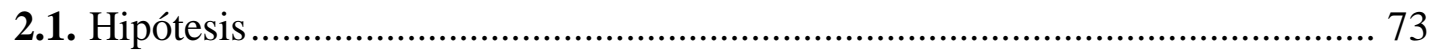

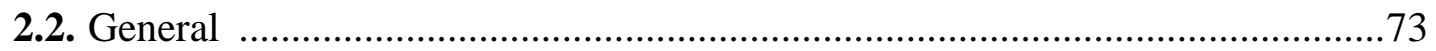

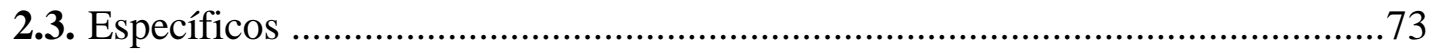

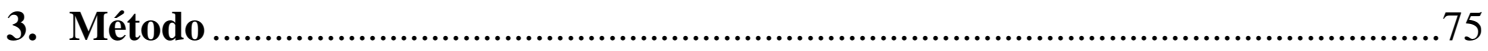

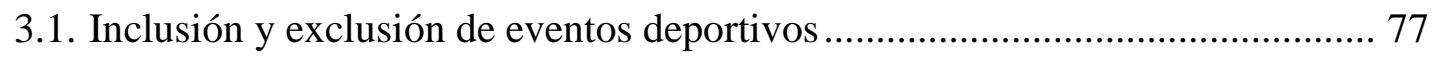

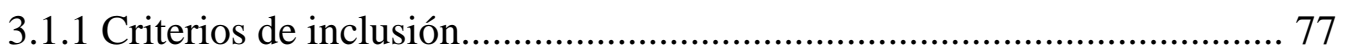

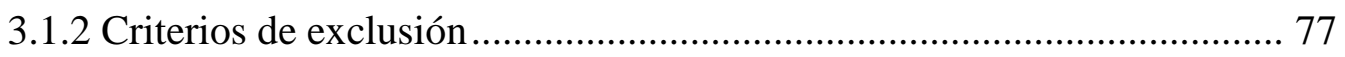

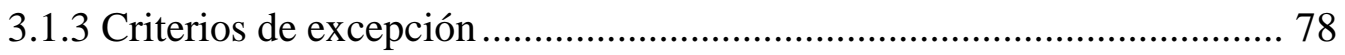

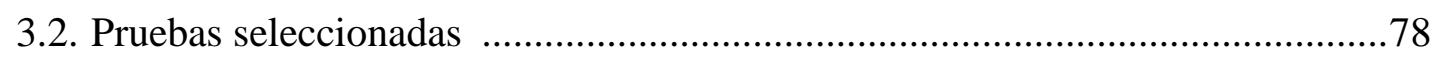

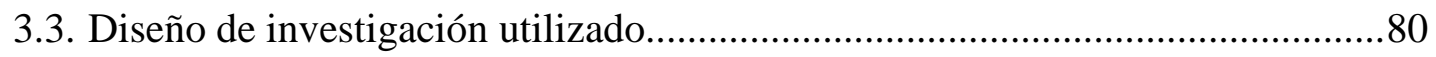

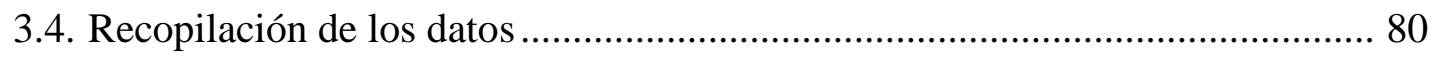

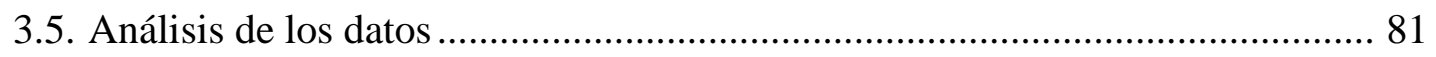

3.6. Justificación del análisis Matemático............................................................. 85

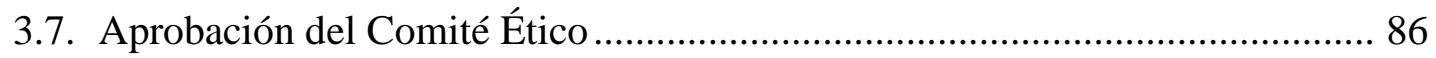

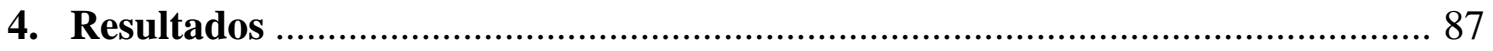

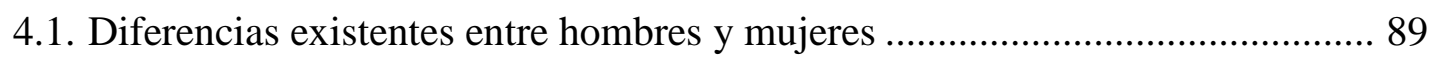

4.1.1. Ajuste de curvas y cálculo de los parámetros...................................... 89

4.1.2. Cálculo de las diferencias .............................................................. 94

4.2. Diferencias entre mujeres con y sin hiperandrogenismo................................ 96

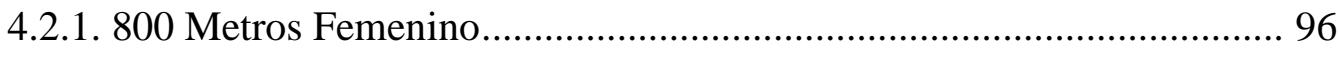

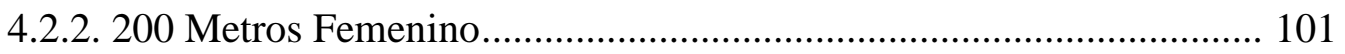

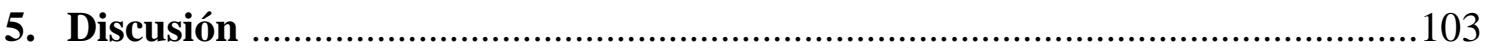


5.1. Novedad e importancia del presente estudio

5.2. Ajuste de curvas y cálculo de los parámetros .............................................. 106

5.3. Diferencias en el rendimiento deportivo entre hombres y mujeres ............... 107

5.3.1. Pruebas de velocidad .................................................................. 108

5.3.2. Pruebas de media y larga distancia ...................................................... 109

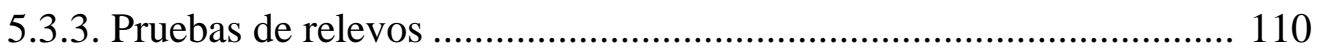

5.3.4. Pruebas de saltos .......................................................................... 111

5.4. Diferencias entre mujeres con hiperandrogenismo y mujeres sin

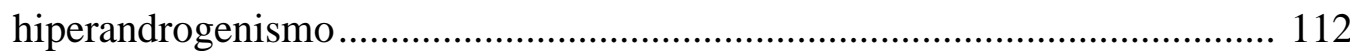

5.4.1. Caster Semenya - 800 Metros ....................................................... 112

5.4.2. Dutee Chand - 200 Metros Femenino.............................................. 115

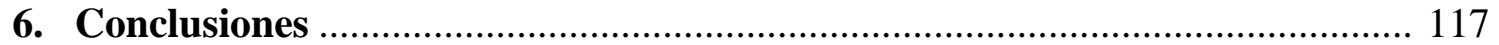

6.1. En relación con el objetivo de determinar la diferencias en el rendimiento deportivo entre hombres y mujeres .......................................................... 119

6.2. En relación con el objetivo de determinar la diferencia entre mujeres con hiperandrogenismo y mujeres sin hiperandrogenismo.

6.3. En relación con el objetivo de verificar si está justificada la normativa de hiperandrogenismo de la IAAF

7. Limitaciones y futuras líneas de investigación

7.1. Pruebas de 1500 metros y más metros

7.2. Número de casos

7.3. Futuras líneas de investigación 126

8. Referencias

9. Anexos

Anexo I. Informe Comité de Ética de la UPM

Anexo II. Resumen de las pruebas testificales y su valoración por el TAS 


\section{ÍNDICE DE TABLAS}

Tabla 1. Clasificación de las anomalías de la diferenciación sexual 10

Tabla 2. Etiología de las anomalías de la diferenciación sexual con cariotipo 46,XY.......11

Tabla 3. Etiología de las anomalías de la diferenciación sexual con cariotipo 46,XX.......12

Tabla 4. Evolución de los controles de sexo, género y hormonales en el deporte femenino

Tabla 5. Pruebas del Atletismo reguladas por la IAAF y pruebas incluidas en el estudio .79

Tabla 6. Número total de resultados deportivos analizados 82

Tabla 7. Parámetros encontrados para cada una de las pruebas, rangos de confianza del $95 \%$, unidades y valores de $\mathrm{R}^{2}$

Tabla 8. Diferencias en $\%$ entre los parámetros $a_{H}$ y $a_{M} \pm \mathrm{DS}$ .94

Tabla 9. Diferencias en $\%$ entre las medias de los tiempos de los ganadores \pm DS .95

Tabla 10. Diferencias en $\%$ entre las medias de los resultados totales \pm DS .95 


\section{ÍNDICE DE FIGURAS}

Figura 1. Clasificación de medallas de los Campeonatos Europeos de Atletismo por sexo en los años 1946 - 1958

Figura 2. Foto finish final 800 metros femenino, Mundial de Atletismo de Berlín 2009..38

Figura 3. Curva característica para las pruebas de velocidad 91

Figura 4. Curva característica para las pruebas de relevos .91

Figura 5. Curva característica para las pruebas de carrera de media y larga distancia ......92

Figura 6. Curva característica para las pruebas de Salto .93

Figura 7. Prueba de 800 metros femenino del Mundial de Atletismo Berlín 2009 .96

Figura 8. Prueba de 800 metros femenino del Mundial de Atletismo Daegu 2011 .97

Figura 9. Prueba de 800 metros femenino de los Juegos Olímpicos, Londres 2012 .97

Figura 10. Prueba de 800 metros femenino de los Juegos Olímpicos Río 2016 .98

Figura 11. Prueba de 800 metros femenino de la Liga Diamante IAAF, Mónaco 2016 ....98

Figura 12. Prueba de 200 metros femenino de 20th Asian Athletics Championship, Pune - India, 2013 101

Figura 13. Prueba de 200 metros femenino de 53rd Open National Championship, Calcuta - India, 2014 102

Figura 14. Prueba de 200 metros femenino de 16th Asian Junior Athletics Championship, Taipei - China, 2014 102 


\section{ABREVIATURAS}

ADS

AFI

$\mathrm{AMH}$

AR

CCES

$\mathrm{CM}$

COI

DHT

DNA

DSD

ESPE

FI

FISU

HSC

IAAF

IMM

JJOO

LH

LWPES

PCR

RFEA

SIA

SIA Parcial

SOP
Anomalías de la Diferenciación Sexual

Federación de Atletismo de la India (Siglas en inglés)

Hormona antimülleriana

Receptor androgénico

Centro canadiense para la ética en el deporte

Comisión Médica

Comité Olímpico Internacional

Dihidrotestosterona

Ácido desoxirribonucleico

Differences of Sex Development (Siglas en inglés)

European Society for Pediatric Endocrinology

Federaciones Internacionales

Federación Internacional de Deportes Universitarios

Hiperplasia suprarrenal congénita

Asociación Internacional de Federaciones de Atletismo

Índice de Masa Muscular

Juegos Olímpicos

Hormona luteinizante

Lawson Wilkins Pediatric Endocrinology Society

Reacción en Cadena de la Polimerasa

Real Federación Española de Atletismo

Insensibilidad completa a los andrógenos

Insensibilidad parcial a los andrógenos

Síndrome de Ovario Poliquístico 
(del inglés sex-determining region $Y$ )

TAS

Tribunal Arbitral du Sport (siglas en francés)

WADA

Agencia Mundial Antidopaje (Siglas en inglés) 


\section{GLOSARIO}

Ácido desoxirribonucleico (ADN o DNA, por sus siglas en inglés): Proteína compleja que se encuentra en el núcleo de las células y que es el principal constituyente del material genético de los seres vivos.

Anomalías de la Diferenciación Sexual (ADS o DSD, por sus siglas en inglés): Patologías originadas por anomalías en alguna de las etapas del desarrollo fetal imprescindibles para el desarrollo normal del sexo genético, gonadal y/o del sexo genital interno y/o externo.

Cromosoma: Filamento condensado de ácido desoxirribonucleico cuyo número es constante para las células de cada especie animal o vegetal y que contiene la mayor parte de la información genética de un individuo. El ser humano cuenta con 23 pares de cromosomas, correspondiendo los pares XY al sexo cromosómico masculino y los pares $\mathrm{XX}$ al femenino.

Género: Grupo al que pertenecen los seres humanos de cada sexo, entendido este desde un punto de vista sociocultural en lugar de exclusivamente biológico.

Hiperandrogenismo: Niveles excesivos de hormonas androgénicas que en las mujeres deportistas pueden determinar su inelegibilidad para las competiciones deportivas.

Hormona: Producto de secreción de ciertas glándulas que, transportado por el sistema circulatorio, excita, inhibe o regula la actividad de otros órganos o sistemas de órganos. Son las responsables de la diferenciación sexual.

(In)elegibilidad: Resultado del proceso de control al que se somete a las mujeres deportistas para verificar si cumplen las condiciones normativas exigidas en cada momento -desde una perspectiva, sexual, de género u hormonal- para poder competir en categoría femenina.

Medidas cautelares: Decisiones provisionales adoptadas por los órganos jurisdiccionales para garantizar la efectividad de una futura resolución definitiva sobre el asunto sometido a su conocimiento. 
Prueba de la cromatina sexual: Técnica utilizada en las pruebas de control del sexo en el deporte de alto nivel basada en la búsqueda de los cuerpos de Barr en muestras celulares obtenidas de las deportistas. Se debía obtener un resultado cromatin-positivo (dos cromosomas XX) para resultar elegibles para la competición femenina.

Reacción en Cadena de la Polimerasa (PCR, por sus siglas en inglés): Técnica de bilogía molecular para obtener un gran número de copias de un fragmento de ADN especifico. Esta técnica fue utilizada como prueba de control del sexo en el deporte de alto nivel.

Sexo: Condición orgánica, masculina o femenina, de los animales y las plantas.

Tribunal de Arbitraje Deportivo (TAS/CAS, por sus siglas en francés/inglés): Institución arbitral independiente con sede en Lausana (Suiza) creada en 1984 al que se someten la solución de conflictos relacionados con el deporte. 


\section{RESUMEN}

Introducción: La Federación de Atletismo de la India (AFI) suspendió en el año 2014 a la atleta Dutee Chand de las competiciones nacional e internacional en aplicación de la normativa de hiperandrogenismo de La Asociación Internacional de Federaciones de Atletismo (IAAF). Chand demandó a la AFI y a la IAAF ante el Tribunal de Arbitraje Deportivo (TAS). El TAS emitió la resolución CAS 2014/A/3759 en el 2015, en que acepta que existe una diferencia de rendimiento deportivo entre hombres y mujeres en el atletismo de élite del $10-12 \%$. Por el contrario, el TAS determina que la IAAF no ha probado que la normativa de hiperandrogenismo, cumpla su objetivo de mantener la equidad en la competición femenina. Por estas razones, el TAS insta no solo a la IAAF y a las Federaciones Internacionales, sino a la comunidad científica a aportar evidencias científicas para probar que el reglamento de hiperandrogenismo de la IAAF cumple ese objetivo.

Objetivo: Verificar sí está justificada la normativa de inelegibilidad de las deportistas con hiperandrogenismo de la IAAF desde la perspectiva de los resultados deportivos en el atletismo de élite.

Material y Método: Se seleccionaron 13 pruebas del atletismo, que se desarrollaron en 15 ediciones del Campeonato del Mundo de Atletismo (1983-2015) y en 9 ediciones de los Juegos Olímpicos (1984-2016). 1 evento de la Liga Diamante y 3 eventos de la Asociación Asiática de Atletismo. Para cada una de las pruebas seleccionadas se ha ajustado una curva exponencial. Para estudiar el buen ajuste de cada curva, se calculó el coeficiente de determinación $R^{2}$ en combinación con el parámetro estadístico $F$. Se calculó los intervalos de confianza del 95\%, y el valor estadístico $t$ de student con sus correspondientes $p$ valores, para confirmar la hipótesis de que los valores encontrados de los tres parámetros $(a, b$ y $c)$ de la curva son adecuados y diferentes a 0 . Por último, se calculó el porcentaje de diferencia del rendimiento deportivo existente en cada una de las pruebas entre hombres y mujeres. Para estudiar el rendimiento deportivo de algunas atletas que han estado bajo investigación y suspendidas por la normativa de hiperandrogenismo de la IAAF, se calculó la curva característica de la prueba junto con las curvas correspondientes a los rangos de confianza del $95 \%$ y del $99 \%$.

Resultados: La diferencia encontrada entre hombres y mujeres en el rendimiento deportivo para las pruebas de velocidad fue: $8.23 \pm 1.02 \%$ - 11.76 $\pm 2.12 \%$; pruebas de media y larga distancia: $10.35 \pm 3.26 \%-12.76 \pm 4.02 \%$; pruebas de relevos: $9.75 \pm 2.93 \%$ 13.14 $\pm 2.98 \%$; pruebas de saltos: $14.21 \pm 2.17 \%$ - $25.04 \pm 4.36 \%$. La diferencia encontrada entre atletas que han estado suspendidas por la normativa y las demás atletas, están en el rango de $1.24 \%-1.39 \%$ utilizando la curva característica de la prueba y de $0.78 \%-2.08 \%$ 
comparando sus resultados con la segunda clasificada en las pruebas específicas analizadas.

Conclusiones: El presente estudio confirma que el porcentaje de diferencia del 10\% - 12\% en el rendimiento deportivo entre hombres y mujeres aceptado por el TAS, puede ser establecido como un porcentaje que indique la mínima diferencia en el rendimiento deportivo del atletismo de élite. Por el contrario, los rangos de diferencia encontrados del rendimiento deportivo entre atletas que han estado suspendidas por la normativa y las demás atletas respecto a la curva característica no alcanzan el 3\% citado en las medidas cautelares del TAS. Por tanto, no está justificada la inelegibilidad de las mujeres con hiperandrogenismo con fundamento en una supuesta ventaja competitiva similar a la condición masculina.

Palabras clave: Atletismo, Rendimiento Deportivo, Diferencias de Género, Hiperandrogenismo, IAAF, COI, TAS 


\section{ABSTRACT}

Introduction: In 2014, the Athletics Federation of India (AFI) suspended the Indian sprinter Dutee Chand from participating in national and international competitions in application of the "IAAF Regulations Governing Eligibility of Females with Hyperandrogenism to Compete in Women's Competition". Chand brought the case against the AFI and the International Association of Athletics Federations (IAAF) to the Court of Arbitration for Sport (CAS). On July 24th, 2015 the CAS delivered the Interim Arbitral Award -CAS 2014/A/3759 2-. On the contrary, the CAS determined that the IAAF has not proved that the hyperandrogenism regulation fulfills its objective of maintaining fairness in women's competition. For these reasons, the CAS urges not only the IAAF and the International Federations, but also the scientific community to provide scientific evidence to prove that the IAAF hyperandrogenism regulation meets that objective.

Objective: To verify the justification of regulation the eligibility of female athletes with hyperandrogenism by the IAAF, from the perspective of sports results in elite track and field.

Material and methods: The results of the finals of all IAAF World Championships from 1983 to 2015 and all Olympic Games from 1984 to 2016 were analyzed in the study. In addition, 1 Diamond League event and 3 events of the Asian Athletics Association have also been selected. An exponential function was chosen, as it was one that best fitted the data, in accordance with the criterion of least square error. To study the goodness of fit of each exponential curve to the data, the coefficient of determination $\mathrm{R}^{2}$ was calculated, in combination with the statistical parameter F (Fisher's test), as well as the statistical values of the student's $t$ test, with their corresponding $p$-values. In addition, for each curve the 95\% confidence intervals were calculated. The percentage difference between male and female athletic performance for each one of the events was calculated. To study the athletic performance of some athletes who have been under investigation and temporarily suspended by the IAAF hyperandrogenism regulation, the characteristic curve has been calculated along with the corresponding $95 \%$ and $99 \%$ confidence intervals.

Results: The difference found between males and females in athletic performance for sprints events is $8.23 \pm 1.02 \%$ - $11.76 \pm 2.12 \%$; for middle and long distance events: $10.35 \pm 3.26 \%-12.76 \pm 4.02 \%$; for relay events: $9.75 \pm 2.93 \%-13.14 \pm 2.98 \%$; for jumps events: $14.21 \pm 2.17 \%-25.04 \pm 4.36 \%$. The difference found between athletes who have been suspended by the hyperandrogenism regulation and the other athletes, are in the range 
of $1.24 \%-1.39 \%$ using the characteristic curve of the test and of $0.78 \%-2.08 \%$ comparing their results with the second athlete classified in the event analyzed.

Conclusions: The present study, via analysis of track and field results of all IAAF World Championships from 1983 to 2015 and all Olympic Games from 1984 to 2016, confirms that the percentage difference of $10 \%$ - $12 \%$ between male and female athletic performance accepted by CAS, can be established as a percentage indicating the minimum difference in athletic performance between elite track and field male and female athletes. On the contrary, the differences found in athletic performance between athletes who have been suspended by the hyperandrogenism regulation and the other athletes with respect to the characteristic curve do not reach the 3\% mentioned in the Interim Arbitral Award by the CAS. Therefore, there is no justification for the ineligibility of women with hyperandrogenism based on an alleged competitive advantage similar to the male condition.

Keywords: Track and Field, Athletic performance, Gender difference, Hyperandrogenism, IAAF, IOC, CAS 
1. INTRODUCCIÓN 



\subsection{Diferenciación de sexos en el ser humano.}

\subsubsection{Categorización de la diferenciación de los sexos.}

La "Guerra Fría" fue una época de batallas larvadas. La escenificación de la hegemonía de cada uno de los bloques en pugna -el comunista y el capitalista- se extendía a lo largo y ancho de todas las actividades sociales. El deporte y, sobre todo, las competiciones de alto nivel fueron uno más de esos campos de batalla. El éxito deportivo era vendido como el éxito del régimen (Guttmann, 1988; Riordan, 1988). El caldo de cultivo perfecto para propiciar todo tipo de ventajas competitivas. Fue el origen de las ayudas farmacológicas y biológicas para la maximización del rendimiento impulsadas a nivel de políticas de estado (Hunt, 2007) (Hunt et al., 2014). También fue el origen de otros intentos, menos sutiles pero muy eficientes, de alterar la equidad de las competiciones femeninas mediante la infiltración de deportistas masculinos en las categorías femeninas. Así nacieron los controles de sexo en el deporte femenino de alto nivel. Esto explica que los primeros sistemas de verificación quedaran limitados a un examen de los caracteres sexuales secundarios. Desde entonces, estos controles han evolucionado mucho tanto en su finalidad como en su metodología. Su premisa principal, alejada ya de la pretensión de evitar un fraude consciente en la competición femenina, es garantizar la igualdad de trato y el principio de competencia leal, tal como se enuncia en el último consenso de la Comisión Médica (CM) del Comité Olímpico Internacional (COI) de noviembre de 2015 (International Olympic Committe, 2015). La metodología transcurrió desde los análisis cromosómicos hasta el de los niveles hormonales imperantes en la actualidad.

Una mejor comprensión de la evolución de los sistemas de verificación y control del sexo o género en el deporte femenino de élite exige remontarse al origen de la identidad sexual y definir los conceptos básicos de esa identidad. Solo así resultará más fácil la interpretación de cada una de las normativas que han existido y su razón de ser.

\subsubsection{Sexo Cromosómico.}

El sexo cromosómico establece la diferenciación sexual tomando en consideración las combinaciones resultantes de los cromosomas $\mathrm{X}$ e $\mathrm{Y}$ que tienen todos los seres humanos. De ese modo, hay un sexo cromosómico femenino compuesto por la combinación XX y otro sexo cromosómico masculino compuesto por la combinación XY, ya que "al unirse un 
espermio portador de un cromosoma $Y$ con un ovocito, siempre dará lugar a un sexo cromosómico masculino, mientras que, si se reúnen un espermio portador de $X$ con un ovocito, siempre dará lugar a un sexo cromosómico femenino” (Campos Merlo, 2007, pág. $57)$.

\subsubsection{Sexo cromatínico.}

El sexo cromatínico establece la diferenciación sexual tomando en consideración la presencia en las células de los llamados corpúsculos de Barr. En 1949 los investigadores Barr y Bertram descubren la cromatina sexual o, como es popularmente conocida, los corpúsculos de Barr (Barr \& Bertram, 1949). Estos investigadores descubrieron en sus experimentos con gatos que en las células de las gatas hembras existía una masa densa de cromatina que no existía en los gatos machos. Estos corpúsculos son una masa que se apoya en la membrana nuclear de las células con un tamaño triangular o en forma de disco. Este experimento evolucionó hasta resultar aplicable a los seres humanos y de ahí que las mujeres con cromosomas XX eran consideradas "cromatin-positivo" y los hombres XY “cromatin-negativo" (Pujol Amat, 1992).

El sexo cromatínico se configura como una forma de confirmación del sexo cromosómico. Es, por tanto, más bien una técnica de análisis del sexo, por lo que ha sido muy utilizada durante finales del siglo XX para la verificación del sexo. Las definiciones de sexo cromosómico y cromatínico están escalonadas. Primero debe existir una diferenciación cromosómica para posteriormente llevar a cabo una clasificación de los seres humanos según la técnica de Barr y Bertram.

\subsubsection{Sexo gonadal.}

El sexo gonadal establece la diferenciación sexual tomando en consideración los órganos sexuales reproductores. Estos caracteres sexuales comienzan a desarrollarse y a evidenciarse desde la fase embrionaria.

Todos los seres humanos son potencialmente bi-gonadales pues en las etapas tempranas del desarrollo fetal la gónada es capaz de formar testículos u ovarios. La diferenciación gonadal masculina tiene como precursor el material genético contenido en la región SRY (del inglés sex-determining region $Y$ ) en el cromosoma $Y$. Se forman primero los senos urogenitales, aproximadamente en la cuarta semana de gestación. Durante la sexta y 
séptima semana de gestación se empiezan a desarrollar los testículos o testes. Es necesaria la presencia del gen SOX9, que ayuda a mantener la formación testicular, ya que los SRY por si solos no pueden llevar a cabo la función completa (Alemán Ramírez et al., 2013).

La diferenciación gonadal femenina corresponde a los conductos de Müller. A partir de ellos se formará la parte interior del sistema reproductor femenino. El proceso de formación se puede evidenciar alrededor de la novena semana de gestación, gracias al proceso de regresión de los conductos de Wolff, consecuencia de la ausencia de hormonas masculinas. Al mismo tiempo que se está desarrollando la parte interna de ese sistema reproductor femenino, evoluciona la parte externa, diferenciándose los labios mayores y menores que se forman a partir del seno urogenital y los tubérculos genitales (Alemán Ramírez et al., 2013).

En conclusión, puede decirse que el sexo gonadal queda definido por la formación de testículos u ovarios, lo que deja fuera de esta definición a las gónadas mixtas, conocidas como ovotestículos, sobre las que se volverá más adelante. El proceso de formación de los órganos reproductores externos es el factor más determinante y más utilizado por los facultativos y padres para diferenciar la identidad sexual de los recién nacidos.

Resulta relevante hacer incidencia en la región SRY del cromosoma Y a la que, como ya se ha señalado, se atribuye el desarrollo testicular en los seres humanos. Es una región que ha sido descubierta recientemente, en el año 1990, pero que tiene gran relevancia en lo que se refiere a los controles verificación de sexo, ya que, propiciado por este avance científico, en la década de los años 90 del siglo XX se utilizó en la aplicación de alguno de los controles que son motivo de la presente investigación.

\subsubsection{Sexo hormonal.}

El sexo hormonal establece la diferenciación sexual tomando en consideración la presencia/ausencia de determinadas sustancias hormonales. En la actualidad todas o casi todas las diferenciaciones sexuales entre varones y mujeres se atribuyen a las hormonas. El diccionario de la Real Academia Española define hormona como "producto de secreción de ciertas glándulas que, transportado por el sistema circulatorio, excita, inhibe o regula la actividad de otros órganos o sistemas de órganos". Esta diferenciación se hace radicar especialmente en la testosterona, una hormona masculina, producida por los testículos, que 
provoca que el feto se desarrolle en sentido masculino y, en su ausencia, que el feto se desarrolle en sentido femenino.

El sexo hormonal se fundamenta en dos palabras: andrógenos y estrógenos. La presencia o ausencia de estas sustancias determina que el feto se desarrolle en un sentido u otro. No obstante, a lo largo de la vida y de la carrera deportiva de las mujeres, no solo es importante la ausencia o la presencia de testosterona sino el nivel de esta hormona. Este nivel, como se expondrá más adelante, es el factor determinante en las últimas normativas sobre elegibilidad en las competiciones femeninas.

\subsubsection{Sexualización cerebral.}

Es uno de los conceptos que se utilizan frecuentemente, pero que no cuenta con una definición consensuada. Hay múltiples factores que intervienen en el desarrollo de esta sexualización, como son los factores ambientales, sociales, hormonales, etc. Así, se ha señalado que "aunque no se sabe con exactitud cuáles son los mecanismos responsables de la sexualización del cerebro, se puede afirmar que la principal causa es la diferenciación sexual masculina o femenina de cada persona. El desarrollo del cerebro es posterior al de las gónadas sexuales, y son las hormonas que éstas segregan, junto a otros estímulos ambientales, las que van conformando el cerebro de acuerdo con la sexualidad de la persona” (Campos Merlo, 2007, pág. 67).

La definición de todos los conceptos de los diferentes tipos de "sexos" que se manejan en la actualidad en la literatura científica tiene una relación directa con los cromosomas y las hormonas, respecto de lo que existe un consenso científico.

Ahora bien, a nivel cromosómico no todo es X ni Y, ni mucho menos XX ni XY. Lo mismo sucede a nivel hormonal. Aunque los estrógenos se identifiquen con las hormonas sexuales femeninas y los andrógenos con las masculinas, las mujeres tienen presencia de andrógenos, si bien en los hombres lo es en una proporción 10 veces superior. Este panorama dibuja una situación biológica subyacente de múltiples variantes que, aun no siendo objeto específico de este estudio, si es la razón fundamental para que no pueda establecerse de una manera tan sencilla una categorización sexual binaria cerrada que extrapolar al mundo de la competición deportiva. 


\subsubsection{Orígenes de los Estados Intersexuales.}

El Dr. Gregorio Marañón y Posadillo, considerado el fundador de la endocrinología en España, en su obra "Los estados intersexuales del hombre y la mujer” (1951), detalla y describe los caracteres sexuales de los seres humanos, que finalmente son los determinantes del sistema binario sexual que se ha consagrado a lo largo de la historia y sigue siendo el imperante en la actualidad, ya que en las categorías sexuales femenino o masculino han de encuadrarse todos los seres humanos.

Marañón refiere en su estudio a John Hunter y su obra de 1870 como el primer autor en dividir los caracteres sexuales en primarios y secundarios. "Los primarios se referían a las glándulas, reproductoras mismas y a los órganos accesorios de dichas glándulas, que constituyen el conjunto del aparato genital. Los secundarios se refieren a aquellos caracteres generales, extragenitales, que permiten, sin necesidad del examen directo de los órganos de la generación la diferenciación, a simple vista, del macho y de la hembra" (Marañón, 1951, pág. 7). Marañón discrepó de esta clasificación, por no tener "sentido ni utilidad", proponiendo un cambio de terminología por la de "caracteres genitales y caracteres sexuales", debido a que los primarios hacían referencia a órganos y la función generadora y los secundarios al dimorfismo sexual externo.

Los caracteres sexuales diferenciados, descritos por Marañón, los desglosa en anatómicos y funcionales. Los anatómicos (genitales y sexuales) están constituidos por los ovarios, útero, vagina, vulva, mamas, testículos, conductos seminales, próstata, pene, morfología corporal femenina y masculina, vello femenino y masculino y el desarrollo pelviano sobre el escapular, sistema locomotor, la distribución de la grasa, el sistema piloso y el desarrollo de la laringe. Los funcionales (genitales y sexuales) serían el instinto a la maternidad, la sensibilidad a los estímulos afectivos, la aptitud para la impulsión motora, defensa de la familia y del hogar por parte del hombre, etc.

Esta clasificación dada por Marañón siguió evolucionando y fue ampliada a primarios, secundarios y terciarios por Havellock Alleis (Ellis, 1904). Un discípulo del propio Gregorio Marañón, José Botella Llusía, amplió esta clasificación hasta los cuaternarios en el año 1961, estableciendo: a) primarios: cromosómico (fecundación); b) secundarios: gonadales $\left(5^{\mathrm{a}}-6^{\mathrm{a}}\right.$ semana embrión $)$; c) terciarios: aparato genital $\left(7^{\mathrm{a}}-12^{\mathrm{a}}\right.$ semana de 
embrión); d) cuaternarios: somáticos (pubertad) (Botella Llusía, 1998, pág. 80). En el año 1995 el propio Botella Llusía amplió la clasificación y añadió un orden más, llegando a los de quinto orden, quedando de la siguiente manera: a) primarios: cromosómico (fecundación); b) secundarios: gonadales $\left(5^{\mathrm{a}}-6^{\mathrm{a}}\right.$ semana embrión); c) terciarios: aparato genital ( $7^{\mathrm{a}}$ - $12^{\mathrm{a}}$ semana embrión); d) cuaternarios: somáticos (pubertad); y e) de quinto orden: psíquicos (pubertad y después) (Botella Llusía, 1998, pág. 81).

La frase de Hunter en 1870 "la diferenciación, a simple vista del macho y de la hembra" (recogida anteriormente) puede presumirse que sirvió como fundamento teórico para la verificación de sexo, llevada a cabo en el mundo deportivo durante la década de los 60's, sobre la que se volverá más adelante en este estudio.

\subsubsection{Evolución de los Estados Intersexuales.}

Las Anomalías de la Diferenciación Sexual (ADS) -popularmente conocidas en el ámbito clínico por sus siglas en inglés (DSD) de "Differences of Sex Development"-, antiguamente conocidas como Estados Intersexuales, plantean una de las cuestiones capitales para sustentar una categorización binaria sexual.

Las ADS tienen una tradicional identificación en la literatura científica con el hermafroditismo ${ }^{1}$. Este concepto se ha utilizado a través de la historia y en la actualidad se sigue usando ${ }^{2}$, sorprendentemente, ya que no está recogido en ningún consenso medico actual. En todo caso, hay que destacar que el término hermafrodita ha sido utilizado también para la identificación de una tercera categoría sexual ${ }^{3}$.

El hermafroditismo, por tanto, fue la primera clasificación existente para los cuerpos diferentes o con genitales ambiguos. No era infrecuente que se les considerada monstruos, tal como lo hacía Gregorio Marañón en su obra en la década de los años 30 del siglo XX.

Gregorio Marañón aborda por primera vez de manera sistematizada la cuestión de los estados intersexuales en su libro "La evolución de la sexualidad y los estados intersexuales" publicado en 1930. Sin embargo, será en 1951 cuando con la publicación de su trabajo "Estados Intersexuales del hombre y la mujer" se exponga de forma más acabada su análisis y categorización de los estados intersexuales. Aunque lejos del 
tratamiento y la clasificación que actualmente se da a estas consideraciones, Marañón logra plasmar y abordar de una manera renovadora y con datos clínicos una categorización de los estados intersexuales.

Los caracteres primarios y secundarios o genitales y sexuales, como los denominaba Marañón, no son iguales en hombre y mujeres. Por esta razón y porque, en palabras del autor, la mezcla de estos caracteres exceden a lo imaginario, Marañón creó un esquema atendiendo solamente a la pauta clínica, estableciendo la diferencia entre "hermafrodíticos verdaderos y falsos". Este esquema lo desarrolló en dos grupos:

I. "En un primer grupo de casos, la intersexualidad se refiere a los órganos germinales mismos, que aparecen como netos ovario-testes; y por lo tanto, a la totalidad de los demás caracteres sexuales primarios y secundarios. Son los casos de hermafroditismo"

II. En un segundo grupo, las glándulas germinales conservan aparentemente su diferenciación sexual; y la intersexualidad se refiere principalmente a un orden determinado de los demás caracteres sexuales... pudiendo distinguir, las siguientes subclasificaciones:

a. Si la intersexualidad afecta profundamente a los órganos genitales externos e internos tendremos el pseudohermafroditismo masculino y femenino.

b. Dentro de esta intersexualidad de los genitales externos puede aislarse un grupo formado por dos formas típicas de retraso en la evolución sexual masculina: el hipospadias y la criptorquidia.

c. Si la intersexualidad se refiere principalmente a los órganos mamarios se producirá la Ginecomastia.

d. Si se refiere principalmente a los caracteres sexuales anatómicos secundarios se producirá la Virilización y Feminización.

e. Si se refiere principalmente a los caracteres sexuales funcionales dará lugar al Homosexualismo y otras inversiones del carácter, de la conducta, etc ${ }^{4}$.

f. En ciertos casos, la intersexualidad no aparece como estado permanente, sino episódico, en relación con las crisis sexuales: Intersexualidades críticas” (Marañón, 1951, pág. 68).

La clasificación actual y la terminología utilizada para describir estos estados intersexuales han evolucionado y no tienen nada que ver con los descritos en la obra de Marañón. 


\subsubsection{Anomalías de la Diferenciación Sexual (ADS).}

En la actualidad las diferentes anomalías o trastornos de la diferenciación sexual y los diferentes estados intersexuales existentes aparecen recogidas en el consenso alcanzado por los grupos de trabajo de la European Society for Pediatric Endocrinology (ESPE) y la Lawson Wilkins Pediatric Endocrinology Society (LWPES) acerca de la terminología que se debe aplicar a las diferentes patologías de la diferenciación (o desarrollo) sexual humano, su diagnóstico y tratamiento, que es desarrollado por el Grupo de Trabajo sobre Anomalías de la Diferenciación Sexual de la Sociedad Española de Endocrinología Pediátrica (Audí Parera et al., 2011). De ese modo las ADS responden a la categorización expuesta en las siguientes tablas (tabla 1, 2 y 3 ).

Tabla 1. Clasificación de las anomalías de la diferenciación sexual (Audí Parera et al., 2011).

\begin{tabular}{|l|}
\hline Anomalías de la diferenciación sexual con anomalías de los cromosomas sexuales: \\
\hline$\bullet \quad 45, \mathrm{X}$ y mosaico $45, \mathrm{X} / 46, \mathrm{XX}$ (síndrome de Turner y variantes) \\
• $\quad 47, \mathrm{XXY}$ (síndrome de Klinefelter y variantes) \\
• Mosaico 45,X/46,XY (disgenesia gonadal mixta) \\
- Mosaico 46,XX/46,XY (quimerismo, ADS ovotesticular) \\
Anomalías de la diferenciación sexual con cariotipo 46,XX (anteriormente pseudohermafroditismo \\
femenino) \\
Anomalías de la diferenciación sexual con cariotipo $\mathbf{4 6 , X Y}$ (anteriormente pseudohermafroditismo \\
masculino)
\end{tabular}


Tabla 2. Etiología de las anomalías de la diferenciación sexual con cariotipo 46,XY (Audí Parera et al., 2011).

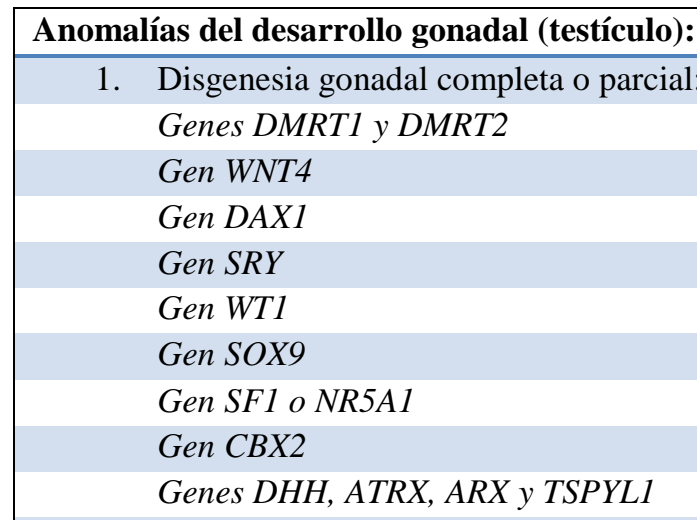

2. Quimera ovotesticular

3. Regresión testicular

Anomalías de la síntesis de la acción de los andrógenos:

1. Mutaciones del gen LH-beta (síntesis de LH anómala)

2. Mutaciones del gen LHCGR (aplasia o hipoplasia de las células de Leydig)

3. Déficits enzimáticos en la biosíntesis de testosterona:

- Afectan a las glándulas suprarrenales y a los testículos:

- Mutaciones del gen 7-dehidro-colesterol desmolasa(sindrome de Smith-LemliOpit)

- Mutaciones del gen StAR

- Mutaciones del gen colesterol-desmolasa

- Mutaciones 3- $\beta$-hidroxiesteroide-deshidrogenasa (gen HSD3B2)

- Mutaciones P450 oxido-reductasa (gen POR)

- Mutaciones 17- $\alpha$-hidroxilasa (gen CYP17)

- Afectan solo a los testículos:

- Mutaciones 17,20-desmolasa (gen CYP17)

- Mutaciones 17-ceto-reductasa (gen HSD17B3)

4. Anomalías en la acción de los andrógenos:

- Déficit de 5- $\alpha$-reductasa (gen SRD5A2)

- Insensibilidad a los andrógenos (gen $A R$ )

- Iatrogenia materna o contaminantes ambientales

Anomalías en la síntesis o la acción del factor inhibidor de los conductos de Müller (ADS 46,XY interno):

1. Déficit de hormona anti-mulleriana (mutaciones del gen $A M H$ )

2. Resistencia a la hormona anti-mulleriana (gen $A M H R$ )

Otros:

1. Síndromes malformativos que asocian anomalías del desarrollo genital:

- Anomalías cloacales

- Síndrome de Robinow

- Síndrome de Aarskog

- Síndrome pie-mano-genital

2. Hipospadias aislado

3. Criptorquidia 
Tabla 3. Etiología de las anomalías de la diferenciación sexual con cariotipo 46,XX (Audí Parera et al., 2011).

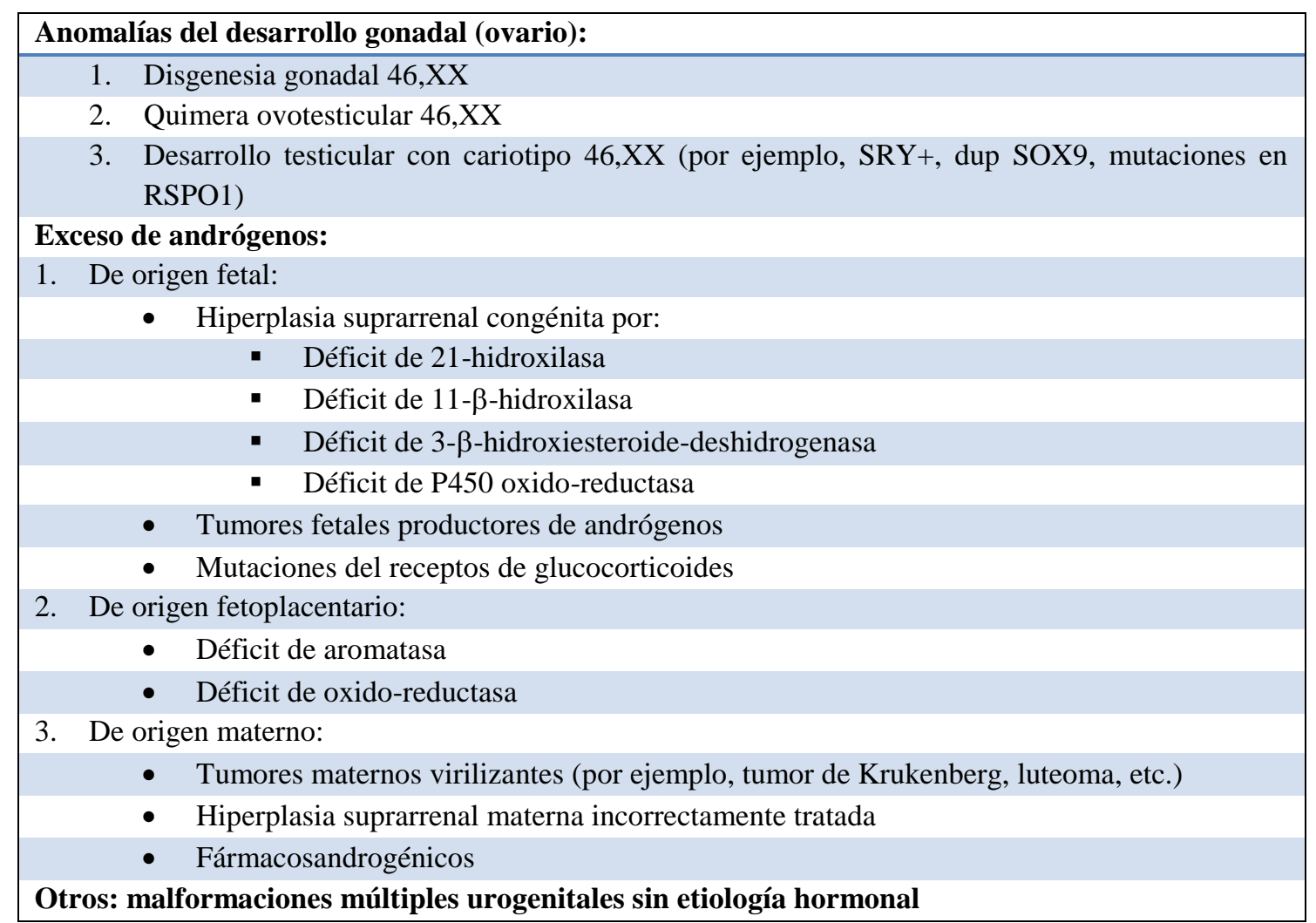

\subsubsection{Anomalías de la diferenciación sexual con cariotipo 46,XY.}

La siguiente exposición de las ADS con cariotipo 46,XY se realiza siguiendo los trabajos desarrollados por los equipos de trabajo dirigidos por la Dra. Laura Audí, investigadora senior de la unidad de investigación endocrinología pediátrica del Vall d' Hebron Institut de Recerca, Barcelona y la Dra. Berenice Bilharinho Mendonça, profesora del Departamento de Medicina Interna, área de Endocrinología de la Facultad de Medicina de la Universidad de São Paulo. Ambos equipos han trabajado en el estudio clínico y molecular de los trastornos de determinación y diferenciación sexual, el crecimiento y la pubertad y la zona de hipo e hiperfunción suprarrenal centrado en la esteroidogénesis y la tumorogénesis (Audí Parera et al., 2011; Mendonça et al., 2009). 


\subsection{Anomalías del desarrollo gonadal (testículo):}

\section{a) Disgenesia gonadal completa o parcial:}

La disgenesia parcial es una ADS que va asociada a las anomalías del desarrollo gonadal dando ambigüedad genital variable en personas con cariotipo 46,XY. Es variable porque depende de la capacidad del testículo disgenético para sintetizar testosterona y la hormona antimülleriana. En la disgenesia gonadal completa hay presencia de genitales externos e internos femeninos, aunque el cariotipo del paciente sea 46,XY. Esta disgenesia completa, también es conocida como disgenesia gonadal pura completa o síndrome de Swyer. Este tipo de disgenesia, ya sea completa o parcial, están relacionadas con las alteraciones o mutaciones de diferentes genes de los 23 pares de cromosomas del cuerpo humano. A continuación se exponen las alteraciones más comunes.

\section{- Gen SRY}

La disgenesia gonadal completa puede ser producto de mutaciones puntuales en el gen SRY o la supresión del mismo. Se han encontrado alrededor de 53 mutaciones dentro del propio gen $S R Y$. Como ha sido expuesto anteriormente, el gen $S R Y$ es el gen de la determinación sexual, ubicado en el brazo corto del cromosoma Y. Un ejemplo típico de una ADS 46,XY completa es el de una mujer con fenotipo femenino y cariotipo $46, \mathrm{XY}$, pero con una deleción del gen $S R Y$ y por ende $S R Y$ negativo.

\section{- Genes DMRT1 y DMRT2}

Los genes DMRTI Y DMRT2, son dos genes que se encuentran en el cromosoma 9 y están directamente relacionados con la diferenciación sexual. Además, se encuentran relacionados con algunas causas de discapacidad cognitiva. Estos dos genes se encuentran ubicados en la región 9p243 del cromosoma 9 y la pérdida de estos dos genes, puede ocasionar la falta de desarrollo testicular.

\section{- Gen WT1: "Wilms tumor protein"}

El gen supresor del tumor de Wilms (WT1) está implicado fundamentalmente en la formación de los riñones y las gónadas de los seres humanos, además en la tumorogénesis. Este gen se encuentra ubicado en el brazo corto del cromosoma 11. Existe un tipo de cáncer renal que es homónimo al gen "tumor de Wilms", pero para los efectos de este 
estudio hay que detenerse en 3 síndromes que causan la mutación del gen WT1: síndrome de WAGR, síndrome de Denys-Drash y síndrome de Frasier.

Síndrome de WAGR: también es llamado "Síndrome de Wilms-aniridia", ya que está caracterizado por el tumor de Wilms, causando aniridia (ausencia del iris en el ojo), anormalidades en el aparato genitourinario, obesidad y discapacidad mental. Las principales causas de este síndrome es la mutación del cromosoma 11 en su región 11p13, incluyendo principalmente a los genes PAX6 y WT1.

Síndrome de Denys-Drash: este síndrome es caracterizado por ADS 46,XY, tumor de Wilms e insuficiencia renal temprana. Su causa principal es una mutación en el gen supresor del WT1 del cromosoma 11. El desarrollo genital es ambiguo y por esta razón se presenta la ADS 46,XY.

Síndrome de Frasier: es un síndrome especialmente caracterizado por ADS 46,XY, enfermedad renal crónica y disgenesia gonadal. El síndrome de Frasier es originado por una mutación heterocigótica del gen supresor del tumor de Wilms, WT1.

\section{- Gen SF1 o NR5A1}

El factor esteroidogénico 1 (SF1) ó Receptor Nuclear de la subfamilia 5, grupo A, miembro 1 (NR5A1), controlan el desarrollo sexual en la etapa embrionaria y en la pubertad. Además, es el encargado de la transcripción de los genes implicados en el desarrollo sexual y la reproducción. Se han presentado casos de mutaciones del gen SF1/NR5A1 con ADS 46,XY, con presencia de órganos sexuales femeninos y conductos Müllerianos derivados, asociados a la insuficiencia suprarrenal. Pero también hay documentados casos de pacientes con ADS 46,XY, sin presencias de conductos de Müller derivados y sin órganos sexuales ambiguos.

\section{- Gen SOX9}

El gen SOX9se encuentra ubicado en el cromosoma 17 del cariotipo humano, está altamente involucrado en la determinación sexual. Las mutaciones de este gen causan graves malformaciones esqueléticas, que en una proporción de tres cuartos (3/4) están 
asociadas a la disgenesia 46,XY. Por lo tanto, se considera que no se debe asociar al gen SOX9 como el precursor de la ADS 46,XY en los casos que no exista una displasia ósea.

\section{- Gen DAX1}

El gen DAX1 se encuentra contenido en el locus ${ }^{5}$ denominado DSS (Dosage Sensitive Sex reversal), específicamente en la región Xp21.2 del cromosoma $\mathrm{X}$. se ha demostrado que su duplicación en personas con cariotipo 46.XY impedía la normal diferenciación testicular, aunque tengan un $S R Y$ normal.

\section{- Gen WNT4}

El WNT4 es un gen que se ubica en el cromosoma 1 en la posición 35 (1p35). Desarrolla su acción en las gónadas en etapas primarias, favoreciendo el desarrollo sexual femenino y reprimiendo el masculino. Se dice que una duplicación del 1p31-35 deriva en un ADS 46,XY. "La hipótesis actual sería que en el sexo femenino 46,XX, WNT4 regularía la expresión de DAX-1 el cual suprimiría la expresión de SOX-9 y/o de otros genes masculinizantes de la gónada indiferenciada (siendo fundamental en el desarrollo del ovario), mientras que en el sexo masculino 46,XY, SRY suprimiría la expresión de WNT4 y por lo tanto la de DAX-1, pudiendo entonces actuar el/los genes determinantes de la diferenciación testicular” (Audí et al., 2006).

\section{b) Quimera ovotesticular}

La quimera ovotesticular se puede definir como la coexistencia en una o en las dos gónadas de tejido ovárico y testicular, aunque el fenotipo y el cariotipo son variables y su incidencia desconocida. Se puede confundir con la disgenesia parcial 46,XY. La quimera ovotesticular 46,XY, no es tan frecuente como en personas con cariotipo 46,XX, haciendo de esta una ADS poco frecuente. Según las autoras que estamos siguiendo para estas definiciones, no hay descripciones de quimera ovotesticular en un paciente adulto con cariotipo 46,XY como si ocurre en pacientes adultos con cariotipo 46,XX. 


\section{c) Regresión testicular}

También es conocido como síndrome de regresión testicular, se caracteriza por la regresión del tejido testicular de uno o de los dos lados, con genitales externos ambiguos o micropenes y un cariotipo 46,XY. Generalmente el útero y las trompas de falopio no existen, pero sí estructuras de tubos rudimentarios que se pueden interpretar como conductos de Müller o de Wolff.

\subsection{Anomalías de la síntesis de la acción de los andrógenos:}

\section{a) Mutaciones del gen LHCGR (aplasia o hipoplasia de las células de Leydig)}

De acuerdo con (Mendonca, Domenice, Arnhold, \& Costa, 2009) y (Audí Parera, y otros, 2011), las características de la aplasia de las células de Leydig o síndrome completo son: (i) genitales externos femeninos que conducen a la reasignación de sexo femenino; (ii) falta de desarrollo de las características sexuales en la pubertad; (iii) testículos criptorquídicos y ligeramente más pequeños con tubos seminíferos parcialmente conservados y ausencia de células Leydig maduras; (iv) presencia de epidídimo y conducto deferente rudimentario, pero con ausencia de útero y trompas de falopio; (v) niveles de testosterona bajos, a pesar de los niveles elevados de gonodatropina, con niveles elevados de $\mathrm{LH}$ predominante sobre los niveles de FSH; (vi) falta de respuesta testicular a la estimulación de gonodatropina; y (vii) no existe aumento anormal de los precursores de la biosíntesis de testosterona.

\section{b) Déficits enzimáticos en la biosíntesis de testosterona:}

\section{Afectan a las glándulas suprarrenales y a los testículos:}

- Mutaciones del gen 7-dehidro-colesterol desmolasa (síndrome de Smith-LemliOpitz).

El síndrome de Smith Lemli-Opitz (SLO) se caracteriza por múltiples malformaciones y anomalías congénitas, entre las que se encuentran la ambigüedad de los genitales, hipotonía, fusión de dos o tres dedos de los pies, retardo mental y una apariencia facial caracterizada por una nariz corta, fosas nasales antevertidas, caída parcial o total del parpado superior (blefaroptosis), microcefalia y fotosensibilidad. 
La ambigüedad de los genitales en las personas de cariotipo 46,XY con este síndrome es bastante frecuente, situándose alrededor del $71 \%$. Los rangos entre hipospadia y la apariencia de genitales femeninos es bastante amplia, a pesar del cariotipo 46,XY y la secuencia normal del gen SRY.

El síndrome de Smith Lemli-Opitz está provocado por la mutación del gen $D C H R 7$ el cual se encuentra ubicado en el cromosoma 11q12-q13. Este gen contiene la enzima 7-dehidrocolesterol reductasa, que cataliza la última etapa en la biosíntesis del colesterol. Los niños afectados por este síndrome presentan bajos niveles de colesterol en plasma y elevados niveles de 7-dehidro-colesterol en plasma.

\section{- Mutaciones del gen StAR}

A la mutación de este gen StAR (gen de la proteína reguladora de la síntesis rápida de esteroides ó Steroidogenic Acute Regulatory protein) se asocia la hiperplasia suprarrenal lipoidea, que no es otra cosa que la incapacidad de transformar colesterol en pregnenolona, que es la que da lugar a la progesterona. En un principio esta hiperplasia suprarrenal lipoidea se atribuía al gen P450scc, pero a través de estudios moleculares se pudo identificar que en la mayoría de casos este gen se encontraba intacto y sí existían mutaciones en el gen StAR.

Los pacientes con esta mutación tienen un fenotipo femenino con una ligera virilización de los genitales externos y todos los esteroides suprarrenales y testiculares se encuentran disminuidos. No es común encontrar casos en América o Europa, pero si en Japón y Palestina.

\section{- Mutaciones 3-ß-hidroxiesteroide-deshidrogenasa (gen HSD3B2)}

Los pacientes masculinos con ADS por HSD3B2 ó $3 \beta$-HSD tipo II, presentan genitales externos ambiguos, caracterizados por micro penes, hipospadias perinatal, escroto bífido y una vagina ciega que puede estar asociado o no a la perdida de sal. La mayoría de las personas que presentan esta anomalía son criados como hombres y mantienen la condición después de la pubertad. 
Las personas con cariotipo 46,XY y una ADS debido a $H S D 3 B 2$ pero sin pérdida de sal, pueden tener características similares a las que se presentan en la ADS debido a 7 $\beta$-HSD3 y $5 \alpha$-reductasa.

\section{- Mutaciones 17- $\alpha$-hidroxilasa (gen CYP17)}

La mayoría de las personas con la mutación de este gen son criadas como mujeres, pero solo se percatan o buscan ayuda profesional por la ausencia de la primera menstruación o la falta del desarrollo mamario. El fenotipo es similar al de una persona 46,XX o 46,XY con disgenesia gonadal completa. Aunque la presencia de hipertensión arterial sistémica y la ausencia del vello puberal, sugiera un diagnostico de 17- $\alpha$-hidroxilasa.

El gen CYP17, contiene las enzimas 17- $\alpha$-hidroxilasa y 17,20 desmolasa, se encuentra ubicado en el cromosoma 10q24.3.

\section{Afectan solo a los testículos:}

\section{- Mutaciones 17,20-desmolasa (gen CYP17)}

La mutación de este gen $C Y P 17$, específicamente la enzima que contiene 17,20 desmolasa, genera una hiperplasia suprarrenal congénita, caracterizada por genitales masculinos ambiguos o femeninos debido a una producción disminuida de esteroides. La primera vez que se diagnosticó esta mutación, fue en dos pacientes brasileños con cariotipo 46,XY y una ADS debido al déficit de 17,20 desmolasa.

\section{- Mutaciones 17-ceto-reductasa (gen HSD17B3)}

Las personas que tienen la mutación de 17-ceto-reductasa ó17 $\beta$-hidroxiesteroide deshidrogenasa, que se encuentra en el gen $H S D 17 B 3$, son personas que presentan órganos femeninos ambiguos en el momento del nacimiento, vagina ciega y testes inguinales o intra-abdominales. La virilización viene en el momento de la pubertad y es la razón por la cual la mayoría de mujeres que han sido criadas como mujeres, deciden dar el cambio hacia lo masculino después de la pubertad.

La falta de capacidad de convertir la androstenediona en testosterona en los tejidos extragonadales del feto, puede explicar el deterioro de la virilización de los órganos sexuales externos en el recién nacido. 


\section{c) Anomalías en la acción de los andrógenos}

\section{- Déficit de 5- $\alpha$-reductasa (gen SRD5A2)}

Las mutaciones del gen $S R D 5 A 2$, que se encuentra ubicado en el cromosoma 2 p23 y a la vez es el que contiene la isoenzima5- $\alpha$-reductasa 2, son los causantes de la ADS 46,XY para este caso. Las personas que presentan un déficit de 5 - $\alpha$-reductasa pasan por 2 fenotipos en diferentes etapas de su vida. En la etapa previa a la pubertad presentan genitales externos ambiguos, micropene, genitales masculinos internos normales, hiperplasia de próstata, testículos con espermatogénesis normal o reducida, escaso vello facial o corporal, ausencia de acné y calvicie masculina temporal. Por lo general los testes están situados en el canal inguinal, siendo sensibles al tacto. Después de la pubertad, existe una virilización significativa, pero sin ginecomastia, el vello facial y pubiano sigue siendo escaso y el acné no aparece.

Hay que tener en cuenta que una de las funciones de la enzima 5- $\alpha$-reductasa es la transformación de la testosterona en dihidrotestosterona, a través de la isoenzima 1 y 2 (5$\alpha$-reductasa 1 -2), para después esta dihidrotestosterona unirse al receptor androgénico. Al fallar alguno de estos procesos, se frustra la interacción con los genes y por ende se produce la nula o, en su caso, insuficiente virilización del feto, con cariotipo 46,XY y gónadas masculinas, teniendo como resultado el déficit de 5- $\alpha$-reductasa y la insensibilidad a los andrógenos.

\section{- Insensibilidad a los andrógenos}

Este tipo de anomalía es una de la más frecuentes de las ADS 46,XY y a su vez se divide en 2: insensibilidad completa a los andrógenos (SIA) e insensibilidad parcial a los andrógenos (SIA Parcial) ${ }^{6}$. Estas dos divisiones básicamente se diferencian en la resistencia a los andrógenos de manera total o parcial.

El síndrome de insensibilidad completa a los andrógenos (SIA) puede ser identificado desde la edad fetal por medio de una prueba de ultrasonido y una análisis genético, ya que un feto con cariotipo 46,XY que presenta genitales femeninos en la prueba de ultrasonido es sospechoso de un posible SIA. En todo caso, lo más frecuente es descubrirlo durante la pubertad, cuando una hernia inguinal pone al descubierto la existencia de testes, además de 
la falta de aparición del vello pubiano y axilar y el normal desarrollo de las mamas. Los genitales externos son de desarrollo normal y de carácter femenino. La literatura y los expertos recomiendan la gonadectomía, antes o durante la pubertad, por el elevado riesgo de tumores testiculares. El SIA determina una falta total de respuesta a los andrógenos que no permite una regulación normal a nivel hipotálamo-hipofisiario de la secreción de LH, lo que puede desencadenar en unos niveles elevados de testosterona a partir de la pubertad.

En los diferentes casos en que concurre el síndrome de insensibilidad parcial a los andrógenos (SIA Parcial) se muestra una disminución en la densidad mineral ósea en la columna lumbar. Al no existir una insensibilidad total a los andrógenos, los fenotipos son variables y fácilmente confundibles con las diferentes ADS 46,XY existentes. Solo al llegar a la pubertad puede existir una virilización marcada o una feminización variable, dependiendo del grado de insensibilidad, existiendo el desarrolla mamario normal en el caso de feminización o ginecomastia en el caso de la virilización.

El receptor androgénico o "androgen receptor (AR) gen" se encuentra localizado en el cromosoma Xq11-12. En la mayoría de los casos de SIA y en un alto porcentaje de los casos de SIA parcial, existen mutaciones de este gen.

Es de destacar que las personas que han sido diagnosticadas con SIA y han sido criadas en el sexo femenino se mantienen con esa misma asignación sexual después de la pubertad. Lo mismo sucede con las personas con SIA Parcial a pesar de la virilización parcial y el crecimiento del clítoris.

\subsection{Anomalías en la síntesis o la acción del factor inhibidor de los conductos de Müller (ADS 46,XY interno).}

El desarrollo de genitales internos femeninos en una persona con cariotipo 46,XY es debido a la incapacidad de las células de Sertoli de secretar y sintetizar la hormona antimülleriana $(\mathrm{AMH})$ o debido a alteraciones del receptor de la AMH. Las células de Sertoli son las encargadas de la regresión del conducto de Müller y este conducto es el que se convierte en útero y parte interna de la vagina. 
Una anomalía en cualquiera de estos mecanismos da origen al síndrome del conducto mülleriano persistente. En la literatura este síndrome se clasifica en tipo I y II, según su origen. De ese modo el tipo I es causado por un déficit de la hormona (mutaciones del gen $A M H)$ y el de tipo II por la resistencia a la hormona (gen $A M H R$ ).

Todas las personas afectadas por este síndrome tienen un fenotipo masculino, acompañado de criptorquidia bilateral y hernia inguinal

\subsection{Otras ADS con cariotipo 46,XY.}

\section{a) Hipospadias aislado}

La hipospadias tiene gran prevalencia clínica y el $40 \%$ de ellas vienen asociadas a otros problemas del sistema urogenital. La hipospadia es una anomalía congénita de nacimiento, en la que la abertura de la uretra se encuentra en la parte inferior del pene. La presencia de esta anomalía en el momento del nacimiento puede ser indicativa de una posible alteración de la acción o secreción de la testosterona en el feto. Por lo general, conlleva tratamiento quirúrgico y hormonal.

\subsubsection{Anomalías de la diferenciación sexual con cariotipo $46, X X$}

\subsection{Anomalías del desarrollo gonadal (ovario).}

\section{a) Disgenesia gonadal 46,XX}

Al igual que en las disgenesias 46,XY existen las disgenesias parciales y completas en las personas con cariotipo 46,XX. En las dos formas de esta ADS, los niveles de gonadotropinas son elevados. En ambos casos presentan genitales externos femeninos normales, no hay presencia de órganos derivados del conducto de Wolff y todos los órganos derivados del conducto de Müller son normales. Las diferencias se pueden encontrar en las gónadas, que en el caso de disgenesia completa son de carácter bilateral, atróficas y en cintilla. En el caso de disgenesia parcial existe ovario hipoplásico y, adicionalmente, ovarios en cintilla. 


\section{b) Quimera ovotesticular 46,XX}

Esta clasificación de ADS 46,XX es la que antiguamente se conocía como hermafroditas verdaderos. Dentro de la clasificación de esta ADS se ubican personas con cariotipo 46,XX/46,XY (cariotipo alterado) y diferentes mosaicismos cromosómicos 45,X/46,XY; 46,XX/47,XXY; 46,XX/47,XYY; 46,XX/48,XXYY; 46,XX/47,XXY y algunas combinaciones más.

Las personas con esta ADS se pueden clasificar según el tipo y localización de las gónadas en: a) lateral (20\%) con un teste en un lado y un ovario en el otro; b) bilateral (30\%), con presencia de tejido ovárico y testicular en ambos lados (ovotestes); y c) unilateral $(<50 \%)$, con tejido ovárico y testicular en un lado (ovotestes) y un teste o un ovario en el otro lado.

Las manifestaciones clínicas son diversas con personas con hernia inguinal que contiene una gónada o el útero. En la mayoría de los casos se encuentra presente el útero, aunque casi siempre es rudimentario, hemiútero o hipoplasico. Durante la pubertad, como se mencionó anteriormente, es visible la ginecomastia y la virilización. Por último, en la mayoría de los casos hay desarrollo normal de la menstruación y en un alto porcentaje el ciclo de ovulación es posible.

\section{c) Desarrollo testicular con cariotipo $46, \mathrm{XX}$.}

Desarrollo testicular con cariotipo 46,XX (por ejemplo, SRY+, dup SOX9, mutaciones en RSPO1) son personas con fenotipo masculino, pero con cariotipo femenino 46, XX o, como se conocen, varones XX. Esto quiere decir que hasta la pubertad son criados y viven socialmente bajo la apariencia sexual masculina, pero al llegar a la pubertad suelen consultar por una ginecomastia y retraso puberal.

Las diferentes causas del desarrollo testicular con cariotipo 46,XX son atribuidas en su $80 \%$ de los casos a las translocación del gen SRY desde el cromosoma Y paterno al X materno. En el 10-12\% a los demás genes que son inductores de la diferenciación testicular, como son el SOX9 y el RSPO1. 


\subsection{Exceso de andrógenos.}

\section{a) De origen fetal:}

\section{- Hiperplasia suprarrenal congénita}

La virilización de una niña con cariotipo 46,XX en un $95 \%$ de los casos es por la producción excesiva de andrógenos asociada a la hiperplasia suprarrenal congénita (HSC).

La HSC es el resultado de un defecto en la biosíntesis de cortisol, que determina un descenso del cortisol $\mathrm{y}$, de forma compensatoria, la elevación de la hormona adrenocorticotropina (ACTH), que es la que estimula la síntesis esteroidal y lleva a un aumento de la producción de esteroides cuya síntesis no está bloqueada.

Las formas causantes son la deficiencia de 21-hidroxilasa ( $>90 \%$ de los casos); déficit de 11- $\beta$-hidroxilasa (5-8\% de los casos); déficit de 3- $\beta$-hidroxiesteroide-deshidrogenasa; por último y de manera excepcional también se considera el déficit de P450 oxido-reductasa.

\subsection{Evolución de la normativa del Comité Olímpico Internacional y de La} Asociación Internacional de Federaciones de Atletismo (IAAF), en materia de regulación deportiva.

\subsubsection{Inicios de la verificación de sexo/género en el deporte femenino.}

La historia de la mujer en el deporte no se ha escrito de forma paralela a la del hombre. Como en muchos otros ámbitos sociales, culturales, científicos y técnicos, la mujer siempre ha encontrado obstáculos y ha tenido que luchar para ganar el lugar que le corresponde. En el mundo deportivo ha tenido que enfrentarse a los estereotipos y a la dualidad de lo masculino y lo femenino. Ha tenido que superar los prejuicios sociales por su participación en una actividad históricamente reservada al hombre. Ha tenido que alzarse contra los prejuicios médicos y científicos, que todavía afirmaban a principios del siglo XX que el deporte perjudicaba la salud de las mujeres y dañaba su figura femenina, 
haciendo principal énfasis en su capacidad virilizante, rompiendo el estereotipo de mujer frágil, delicada y sensible (Valdivia Moral et al., 2003; Vázquez, 2002).

A pesar de ello, las mujeres consiguieron abrir un camino en el mundo deportivo y en la alta competición. La primera vez que una mujer pudo participar en unos JJOO fue en los de Paris 1900, participando en 2 deportes (tenis y golf) con un total de 22 deportistas (2.2\% de participación total). Su presencia fue incrementándose paulatinamente en el evento deportivo más importante del mundo y ya en la edición de los JJOO de Londres 2012, participaron en 26 deportes, un total de 4676 mujeres (44.2\% de participación total) ${ }^{7}$. No obstante, la participación femenina en el deporte de alta competición se ha visto acompañada de grandes escándalos en los principales medios de comunicación de todas las épocas ante las dudas sobre la feminidad de una u otra deportista. Esa presión, en última instancia, ha servido de justificación para que las autoridades deportivas desarrollaran pruebas de verificación de sexo. Además, como el atletismo fue el deporte en el que principalmente se cuestionó la feminidad de las mujeres, la IAAF junto el COI son los organismos deportivos que han liderado las políticas deportivas en esta materia y las demás Federaciones Internacionales (FI) en la mayoría de las ocasiones se han limitado a seguir sus lineamientos.

Uno de los primeros casos sobre dudas de feminidad con repercusión mediática fue el de la atleta japonesa Hitomi Kinue, que ganó la medalla de oro en la prueba de 800 metros durante los JJOO de Ámsterdam 1928, aunque nunca se pudo comprobar que hubiera sido sometida a ninguna exploración médica para la verificación sexual (Pieper, 2016, pág. 19). Lo mismo sucedió con la atleta polaca Stela Walsh, quien también se vio envuelta en la duda y se presume que debió superar las inspecciones médicas visuales previas a su participación en los JJOO de 1932 y 1936. A pesar de ello, los periodistas de la época alimentaban las dudas sobre su condición de mujer por sus características físicas, su estatura y su voz profunda (Pieper, 2016, pág. 26). En el año 1980, después de su muerte en la ciudad de Cleveland y su posterior autopsia, se descubrió que tenía caracteres sexuales ambiguos (Heggie, 2010). Este descubrimiento sirvió como argumento para que las autoridades deportivas justificaran políticas de verificación del sexo para luchar contra el fraude en el deporte femenino. 
Del mismo modo, la velocista estadounidense de origen polaco Helen Stephens protagonizó grandes titulares de prensa durante los JJOO de Berlín de 1936. El motivo fue las dudas generadas por la gran marca conseguida en la final de los 100 metros lisos, 11.5 segundos, que resultaba ser record mundial ${ }^{8}$. El Comité Organizador y las autoridades deportivas correspondientes tuvieron que hacer público que la atleta había pasado previamente un examen físico para poder competir, lo que lo convierte en el primer caso en que existe un reconocimiento oficial y documentado de que se había desarrollado una prueba de sexo en el deporte femenino de alta competición (Pieper, 2016, pág. 12).

Los JJOO de Berlín 1936 fueron unos juegos marcados por la sospecha. Las mujeres no llevaban mucho tiempo compitiendo en los JJOO, en la ediciones anteriores su representación había sido mínima y llena de controversias y resistencias. El fundador de los JJOO de la era moderna, el barón Pierre de Coubertin fue el principal opositor a la participación femenina en los JJOO. El año 1928 en la ciudad de Ámsterdam, las mujeres llegan al atletismo y con ellas la sospecha y la duda. Para la edición del año 1936, los principales periódicos ya hablaban de las cirugías de cambio de sexo de algunas de las figuras femeninas del atletismo (Revista TIME August 24, 1936| Vol. XXVIII No. 8). La realidad fue que al menos dos campeonas, Zdenka Koubková y Mary Edith Louise Weston, habían hecho la transición de mujer a hombre, adoptando los nombres de Zdenek Koubek y Mark Edward LoisWeton. Ambas deportistas fueron retiradas del mundo deportivo y a su vez sus títulos y sus records fueron borrados (Pieper, 2016, pág. 29).

\subsubsection{Certificado Médico.}

Los controles de verificación de sexo comentados anteriormente se produjeron ante la presencia de sospechas y dudas sobre la feminidad de las atletas, no porque existiera la obligación deportiva de pasar un control sistemático para competir en categoría femenina. La IAAF fue la primera FI en instaurar una norma de obligatorio cumplimiento en todos sus campeonatos internacionales. Para el año 1946, todas las atletas que fueran a competir en un evento reglado por la IAAF debían presentar la carta de un médico donde asegurara el sexo al que pertenecía, haciéndolas elegibles para competir. Lo mismo hizo el COI para los JJOO de Londres 1948 (Heggie, 2010). Estas medidas, a priori, no parecían muy 
rigurosas, pero sentaban un precedente e iniciaban el camino de la regulación en materia de verificación de género en el deporte femenino.

Este requisito se mantuvo por un periodo prolongado de tiempo (alrededor de dos décadas), requisito al que todas las delegaciones se sometían, pero que no estuvo exento de polémicas. El caso con más repercusión de la época fue el de la atleta neerlandesa Foekje Dillema, quien participó en los JJOO de Londres 1948 ganando la prueba de 200 metros lisos con una marca de 24.1 segundos estableciendo un nuevo record nacional. Todas las marcas de Dillema fueron borradas y fue apartada de las pistas en el año 1950 por la Federación Holandesa de Atletismo ${ }^{9}$ después de los resultados de una prueba de sexo, que nunca fueron revelados. En el año 2012 se publicó un artículo científico en la revista British Journal of Sports Medicine, donde se detalla que décadas después de su muerte y con autorización de sus herederos, se realizó una prueba de ADN utilizando métodos forenses, revelando que la atleta tenía un mosaicismo 46,XX/46,XY de origen raro. En dicho artículo los investigadores sugieren que se debe a un caso de hiperandrogenismo en su pubertad, constituyendo seguramente un caso de ADS ovotesticular (Ballantyne, Kayser, \& Grootegoed, 2012).

\subsubsection{Nude Parade.}

La primera prueba de verificación de sexo estrictamente deportivo que puede ser considerada como tal se implantó en el año 1966 por parte de la IAAF para el Campeonato Europeo de Atletismo celebrado en la ciudad de Budapest. Un total de 243 atletas posaron desnudas frente a un panel de médicos, quienes realizaban una inspección visual de sus genitales y decidían si eran elegibles para competir o no (Ferguson-Smith \& Ferris, 1991), (Ljungqvist et al., 2006). Este método de verificación fue posteriormente utilizado por la IAAF en los Juegos de la Commonwealth en el año 1966 en Kingston, Jamaica, en que se llevaron a cabo exploraciones ginecológicas manuales a las deportistas (Ljungqvist et al., 2006) y en los Juegos Panamericanos de 1967 en la ciudad canadiense de Winnipeg.

La razón principal para implantar un análisis de estas características fue lo que se valoraba como una pérdida de la feminidad de las mujeres deportistas en comparación con los estereotipos sociales. Los rumores y las dudas aumentaron después de la primera aparición de la antigua Unión Soviética en los Campeonatos Europeos de Atletismo, donde las 
mujeres ganaban más medallas que sus connacionales masculinos. Esta situación generó el rumor de que existían hombres enmascarados en las competiciones femeninas. La supremacía de las mujeres en el medallero en los diferentes Campeonatos de Atletismo, se puede comprobar en el siguiente gráfico (Pieper, 2016, pág. 47).
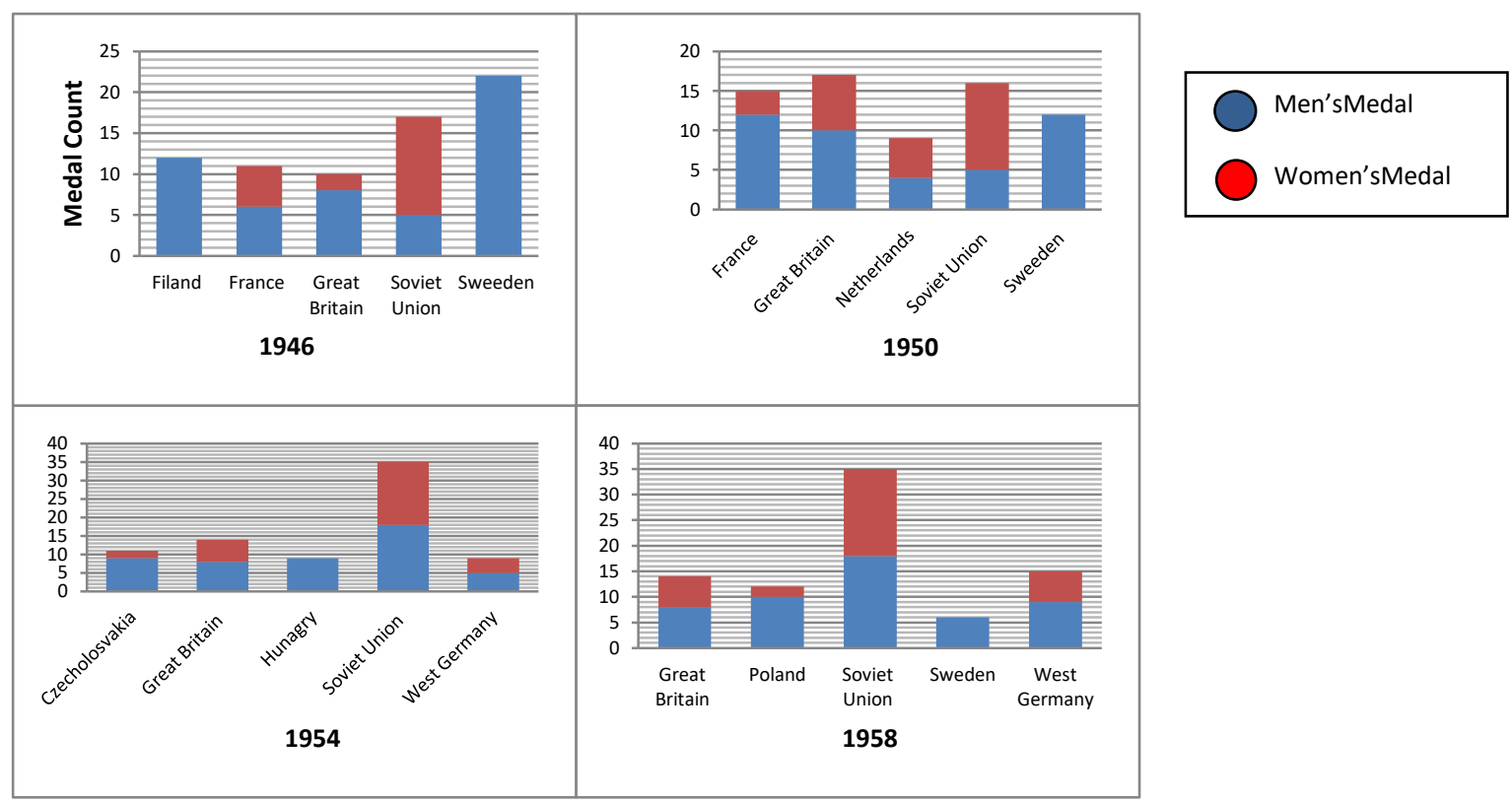

Figura 1. "European Athletics Championships medal breakdown by sex, 1946-1958" (Clasificación de medallas de los Campeonatos Europeos de Atletismo por sexo en los años 1946 - 1958). fuente (GBR Athletics, European Championships http://www.gbrathletics.com/iclecw.htm) (Pieper, 2016, pág. 47).

El ex Presidente de la CM de la IAAF y ex Presidente de la CM del COI, Arne Ljungqvist, ha reconocido que los rumores de años atrás condujeron a la creación de esta primera normativa. Así señala que: "La historia de las pruebas de género se remonta a la década de 1960. Habían existido rumores durante años de que había atletas que competían en eventos femeninos que eran más masculinos que femeninos, lo que constituía una competencia desleal para las mujeres "reales" ${ }^{\prime \prime 10}$ (Lager, 2011, pág. 183). Este comentario fue ratificado en entrevista personal con el autor de esta tesis doctoral en la ciudad de Estocolmo en abril de 2016.

Las experiencias vividas por las deportistas sometidas a este tipo de verificaciones de género han sido objeto de diversas valoraciones poniendo de manifiesto lo humillante y denigrante que esta práctica significaba para las atletas. Así, se puede destacar el relato de la lanzadora de peso norteamericana Maren Sidler que narra que "recuerdo que nos organizaron en una fila justo fuera de una habitación, donde al entrar nos esperaban 3 
médicos detrás de un escritorio. Debíamos subirnos la camiseta y bajarnos los pantalones, esperar hasta que ellos decidieran para poder luego salir..." (Heggie, 2010), (Teetze \& Torres, 2016).

Este método de verificación también implicó que algunas deportistas que estaban en la gloria de su carrera deportiva decidieran "ceder" su lugar a deportistas más jóvenes o simplemente no volvieron a competir, como es el caso de las atletas soviéticas, las hermanas Tamara e Irina Press. Tamara Press había sido ganadora de la medalla de oro en la modalidad de lanzamiento de peso en los JJOO de 1960 y 1964, oro en lanzamiento de disco en JJOO de 1964 y plata en JJOO de 1960¹ . Irina Press había sido ganadora de la medalla de oro en la modalidad 80 metros vallas en los JJOO de 1960 y también ganadora de la medalla de oro en pentatlón en los JJOO de $1964^{12}$. Ambas hermanas desparecieron de la competición deportiva con la introducción de la normativa "nude parade". También hubo casos en que las atletas se negaron a pasar la inspección visual o el análisis ginecológico $\mathrm{y}$, por tanto, fueron retiradas de las competiciones por parte de la organización o la IAAF.

\subsubsection{Cromatina Sexual o Corpúsculos de Barr.}

Las críticas y el desacuerdo de las deportistas con el método de verificación del sexo de la "nude parade" precipitaron que la IAAF cambiara su método de evaluación por uno más sofisticado, poco invasivo y con mayor eficiencia. Durante el Campeonato de Europa de Atletismo en 1967 de Kiev (antigua Unión Soviética), la IAAF estableció la prueba de la cromatina sexual (Corpúsculos de Barr) aprovechando un reciente avance científico en la materia.

En 1949 los científicos Barr y Bertran lograron identificar que en las células de las gatas (hembras) existía una masa densa de cromatina que no existía en los gatos (machos). Demostraron la presencia de esta cromatina sexual en todos los órganos de los gatos (excepto en el páncreas e hígado), apareciendo estas en un ratio del 50-60 \% en las gatas (hembra) y siendo prácticamente ausente en los gatos (macho). A partir de este descubrimiento se desarrolló la prueba de la cromatina sexual, una prueba de tinción rápida, que dejaba al descubierto una mancha (cuerpo de Barr) en las muestras celulares 
de las mujeres, que no aparecía en las células de los hombres. Esta técnica se fue perfeccionando hasta lograr en el año 1960 explicar la correlación entre los cuerpos de Barr visibles y el número de cromosomas $\mathrm{X}$ presentes en el cariotipo del ser humano (Lacadena, 1996, pág. 374). En efecto, uno de los aspectos más importantes de la cromatina sexual y los cromosomas X es: "el número de cuerpos de Barr observables es igual al de cromosomas $X$ menos uno; por eso en las células somáticas del varón normal $(X Y)$ no aparecen y en el de las mujeres normales $(X X)$ aparece uno. Incluso se ha observado una correlación entre el tamaño del cuerpo de Barr y anomalías estructurales de los cromosomas X” (Lacadena, 1996, pág. 374).

Una vez que se pudo aplicar esta técnica en seres humanos, se convirtió en una prueba rápida, económica y útil para la determinación del sexo. Con un simple frotis de la mucosa bucal, se obtenían muestras celulares por rascado de la cara interna del carrillo de las que, teñidas adecuadamente en el laboratorio, se podía obtener el corpúsculo anteriormente descrito. El resultado de esta prueba era establecido para las mujeres con cromosomas XX como “cromatin-positivo” y los hombres XY “cromatin-negativo” (Pujol Amat, 1992).

Una de las primeras deportistas en no superar este test fue la polaca Ewa Kłobukowska, quien durante el Campeonato de Europa de Atletismo de 1966 no había tenido problemas con el control mediante la inspección visual. Kłobukowska tenía un mosaicismo XX/XXY y perdió la condición de elegibilidad para competiciones femeninas y, según determinados autores, le fueron también retirados todos sus títulos y anulados sus records (Pieper, 2016, pág. 55; Heggie, 2010; Ritchie \& Reynard, 2008) ${ }^{13}$.

Una vez más, el caso de una deportista se convertía en el mejor argumento para justificar y mantener una normativa rodeada de polémicas y detractores ${ }^{14}$.

Hasta ese momento solo la IAAF había aprobado una regulación en materia de verificación de sexo. El COI demoraría el establecimiento de una normativa de estas características hasta los JJOO de Invierno de 1968 en Grenoble ${ }^{15}$. El objetivo final de esta técnica de control, tal como se reconoce en el estudio desarrollado para el análisis de 155 atletas durante la Universiada de Invierno de 1991 en Sapporo City - Japón, no era otra que "excluir "hombres" que habían sido reconocidos erróneamente como mujeres en el 
nacimiento" (Yamaguchi et., 1992), destacando que era una normativa cuya finalidad era diferenciar los hombres de las mujeres y determinar con certeza quién era hombre y quien era mujer.

La técnica de los corpúsculos de Barr se mantuvo en los JJOO de México 1968, Munich1972, y Montreal 1976, y en los JJOO de Invierno de Sapporo 1972. En estos eventos solo resultaban elegibles para competiciones deportivas femeninas aquellas atletas con cromosomas 46,XX. Los mosaicimos no eran aceptados y tampoco las diversas condiciones de ADS expuestas anteriormente.

La IAAF y el COI continuaron aplicando la técnica de la cromatina sexual para evaluar la elegibilidad de las deportistas, definiendo quienes eran hombres y quienes mujeres. La superación de la prueba de verificación determinaba la obtención de un certificado denominado por la IAAF "Certificado Oficial de la IAAF" y por el COI "Tarjeta de Identidad"-, que se constituía como un documento acreditativo de que no existía ninguna anormalidad en la prueba de la cromatina sexual y, por tanto, que se era una mujer con cromosomas 46,XX. La leyenda que se incluía en el certificado de la IAAF era "The above mentioned athlete underwent an approved medical test. The result of which was sex chromatin positive. This satisfies the IAAF requirements for competition in women's athletic events" "16 (Martinez-Patiño, 2005).

El mundo médico y científico pronto empezó a mostrarse crítico con la utilización de esta técnica como prueba de verificación de sexo en el deporte femenino. El genetista escocés Malcon Ferguson-Smith en diferentes cartas remitidas a los organizadores de los Juegos de la Commonwelth de 1970 ya informaba de las razones para oponerse a la prueba de la cromatina sexual en el deporte, señalando que: i) "la composición cromosómica de una persona no siempre concuerda con el sexo social o legal de las personas"; ii) "siete de cada 1000 personas poseen una "cromatina sexual anormal"; iii) "las inspecciones visuales podrían ser más adecuadas para identificar hombres enmascarados en las categorías femeninas" (Pieper, 2016, pág. 138).

También fueron detractores de esta técnica de verificación un grupo de médicos daneses denominado "The Danish Protest" (Pieper, 2016, pág. 82) ${ }^{17}$. Este grupo de médicos 
(psiquiatras, genetistas y ginecólogos) escribieron al COI un memorado en 1972, criticando el uso de la cromatina sexual y solicitando el abandono de esta técnica. En ese memorando concluían que "los controles de sexo llevados a cabo por el COI son irresponsables desde el punto de vista médico y conllevan un comportamiento antiético" (Pieper, 2016, pág. 82).

El propio Murray Barr, padre de esta técnica, había reiterado sus protestas e informado que su técnica era errónea y no debía ser usada para los fines pretendidos por los organismos deportivos. En 1987, escribió al Presidente del Comité Olímpico Canadiense pidiéndole que el COI abandonara el uso de la cromatina sexual como método de control. En su carta afirmaba que "la prueba del raspado bucal en el ámbito deportivo es completamente inapropiada", reconociendo que "su uso en este sentido me hace sentir completamente avergonzado" (Pieper, 2016, pág. 67).

Otro de los principales detractores y opositores a esta técnica fue el genetista finlandés Albert de la Chapelle. En sus múltiples artículos sobre el tema, defendió que la prueba de la cromatina sexual era poco fiable y no se debía usar en la pruebas de verificación de sexo en el deporte. Su argumento principal era que esta prueba no tenía en cuenta la existencia de ADS que no aportaban ninguna ventaja deportiva a las mujeres. Ejemplos de ello eran el SIA - SIA parcial; mujeres con cariotipo 45,X con Síndrome de Turner; o mujeres con cariotipo 46,XY que presenten el Síndrome de Feminización Testicular o Disgenesia Gonadal (Elsas et al., 2000; de la Chapelle A., 1986; de la Chapelle A., 1985).

A pesar de estas evidencias científicas la IAAF y el COI mantuvieron su programa de verificación de sexo y la técnica que la cromatina de Barr. Durante los JJOO de Los Ángeles 1984, la organización decidió cambiar el nombre de control de sexo -"Sex testing”- por el de verificación de género -“Gender Verification”-, pero la técnica utilizada era la misma que en las ediciones anteriores.

El principio del fin de las pruebas de control de sexo y verificación de género mediante la técnica de la cromatina de Barr por parte de los organismos deportivos internacionales comenzó un año después de los JJOO de Los Ángeles 1984. En el año 1985 la Federación Internacional de Deportes Universitarios (FISU) organizó la edición XIII de las 
Universiadas en la ciudad de Kobe - Japón. En este evento las deportistas todavía debían acreditar su femineidad mediante la prueba de la cromatina sexual. El procedimiento era rápido y sencillo: las atletas debían enjuagar su boca y se recogía una muestra de membrana mucosa bucal por medio de un raspado en la cara interna y se les solicitaba muestras de su cabello, arrancando desde la raíz (Sakamoto, Nakanoin, Komatsu, Michimoto, Takashima, \& Furuyama, 1988). Tres atletas no superaron la prueba. Una de ellas no se pudo establecer que cariotipo tenía. Las dos restantes tenían cariotipo 46,XY (Sakamoto et al., 1988).

Esas dos deportistas eran la atleta española María José Martínez Patiño y la nadadora estadounidense Kirsten Wengler. Wengler fue sometida a pruebas ginecológicas adicionales y se le permitió competir, convirtiéndose en el primer caso documentado en que, a pesar de no haber superado la prueba de la cromatina sexual, se le permitió participar en esa misma competición. Al regresar a los Estados Unidos se sometió a análisis más sofisticados que revelaron un falso positivo provocado por una proteína que se asemejaba en su estructura al cromosoma Y (Pieper, 2016, pág. 134; Carlson, 2007, pág. 108).

El caso de la atleta española Martínez Patiño fue distinto. Esta atleta había obtenido su certificado de feminidad de la IAAF en el $1^{\text {er }}$ Campeonato Mundial de Atletismo de Helsinki 1983. La IAAF y el COI aceptaban los certificados de feminidad expedidos en competiciones anteriores para futuros eventos reglados por la IAAF o por COI, indistintamente, de modo que cualquier deportista que hubiese obtenido dicho certificado de una u otra institución no debía repetir la prueba de la cromatina sexual. Martínez Patiño viajó hasta la ciudad de Kobe para participar en las Universiadas de 1985 pero no portaba el carnet de feminidad que le había sido expedido por la IAAF en 1983. Tuvo que volver a realizar la prueba para poder competir en 100 metros vallas. Su cariotipo, en esta ocasión, resultó ser 46,XY. Fue declarada inelegible y no pudo competir. Como ella misma relata, la Real Federación Española de Atletismo (RFEA) le sugirió que fingiera una lesión y se retirara del deporte (Martinez-Patiño, 2005). El 29 de enero de 1986 en uno de los periódicos más importante de España se publica una noticia titulada "La federación retira la licencia de atleta a María José Martínez Patiño por tener cromosomas masculinos" (Mora, 1986), provocando con esa publicidad no pocos problemas personales a la atleta. 
Martínez Patiño, aliada con la férrea oposición del mundo medico internacional a este procedimiento de verificación, provocó que la IAAF debiera reconsiderar su caso en el año 1988. La atleta encontró su principal apoyo en el genetista finlandés Albert de la Chapelle, que se convirtió en el abanderado de su caso, ayudado por Malcon Ferguson-Smith y Elizbeth Ferris, entre otros. De la Chapelle había trabajado en el Karolinska Institute de Estocolmo, donde conoció al también médico Arne Ljungqvist, quien entre los años 1981 y 2003 fue Presidente de la CM y Anti-Doping de la IAAF. de la Chapelle logró convencer a Ljungqvist en 1985 de que los controles de sexo en el deporte carecían completamente de rigor científico. La frase que utilizó Arne Ljungqvist para describir la situación fue " $m e$ pregunté a mí mismo, ¿qué estaba haciendo el mundo del deporte?” (Lager, 2011, pág. 185). Con el propio Presidente de la CM de la IAAF a favor, en el caso de Martínez Patiño se asomaba a ver una luz al final del camino para ver rehabilitada su carrera deportiva. La atleta obtuvo de nuevo su licencia federativa en el año 1988, después de la reunión de la CM del COI en los JJOO de Seúl, donde el propio Arne Ljungqvist autorizó a Martínez Patiño a volver a la competición femenina (Martinez-Patiño, 2005).

La normativa de verificación, a pesar de todo, siguió vigente. Ljungqvist, apoyado por de la Chapelle, emprendió el camino para persuadir a la IAAF y al COI de abandonar por completo la normativa de verificación de sexo (Lager, 2011, pág. 185). Ljungqvist, en su condición de Presidente de la CM y Anti-Doping de la IAAF, organizó una reunión en Montecarlo en 1990 para revisar las políticas de verificación de sexo vigente. Después de esa reunión y de otra más celebrada en Londres en 1992, el grupo de trabajo concluyó que: i) las personas que posean una anomalía genética relacionada con el sexo y que se hayan criado como mujeres y que no posean ninguna ventaja competitiva sobre otras mujeres, no deben ser excluidas de las competiciones deportivas. Esta recomendación incluye a las mujeres que presentan déficit de la enzima 21 hidroxilasa, deficiencia de la 5-alfa reductasa, SIA y SIA parcial; ii) la búsqueda del cromosoma Y en las mujeres a través de la cromatina sexual debe ser abandonada; iii) solo los hombres que han crecido y se han criado como hombres deben ser excluidos de las competiciones deportivas para mujeres (Elsas et al., 2000). 
Con las recomendaciones de la primera reunión en Montecarlo, la IAAF decidió no mantener la normativa de verificación de sexo mediante la técnica de la cromatina sexual para el Campeonato Mundial de Atletismo de 1991 en Tokio. Para esta competición se estableció una nueva normativa con una técnica de verificación denominada "health check" consistente en una simple inspección física a la que se sometía a la totalidad de los atletas con independencia de su sexo. Esta nueva técnica fue rechazada por las Federaciones Nacionales y por las propias deportistas. Los representantes médicos del equipo de Estados Unidos argumentaron que esta técnica era una reversión a las "nude parade" de la guerra fría y la Federación australiana señaló la inutilidad de los controles practicados a los hombres. Esta situación provocó que esta técnica de verificación fuera abandonada por la IAAF en el año 1992, suspendiéndose definitivamente todo control sistemático por esta Federación (Pieper, 2016, pág. 151).

\subsubsection{PCR Test en los Juegos Olímpicos.}

Aunque la IAAF había suspendido todo control sistemático de verificación sexual, el COI persistió en este tipo de pruebas. Anunció que para los JJOO de Invierno de Albertville de 1992 se utilizaría como técnica de verificación sistemática la reacción en cadena de la polimerasa (PCR, por sus siglas en inglés).

La Reacción en Cadena de la Polimerasa es un método que se utiliza para multiplicar fragmentos de ácido desoxirribonucleico (DNA), para cuya utilización no se requiere células y puede ser aplicado de manera rápida. El procedimiento se describe del siguiente modo "la PCR estándar es un procedimiento in vitro que permite ampliar secuencias de DNA definidas a partir de pequeñas cantidades de DNA de diferentes orígenes. Esta amplificación selectiva requiere alguna información previa acerca de las secuencias que flanquean al DNA blanco. Sobre la base de esta información se diseñan dos oligonucleótidos cebadores (primers) de alrededor de 15 a 25 pares de longitud. Los cebadores son complementarios de las secuencias por fuera de los extremos 3' del sitio blanco y se unen a ellas en forma específica. Durante la PCR las moléculas de DNA de cadena doble se desnaturalizan, cada cadena simple sirve como molde para la síntesis de una nueva cadena, y luego se renaturalizan (se vuelven a unir) con una cadena 
complementaria en condiciones controladas. La PCR es una reacción en cadena de 25 a 35 ciclos" (Passarge, 2010, pág. 62).

La técnica de la PCR se ha constituido como una herramienta fundamental en los ámbitos clínico y forense. En el ámbito clínico ayuda a diagnosticar enfermedades infecciosas y detectar episodios patológicos poco comunes. En el forense, la mayoría de los órganos judiciales acuden a ella al considerarse una identificación sin ambigüedad de los seres humanos. Además, la técnica de la PRC se puede realizar a partir de muestras de líquidos biológicos muy pequeñas (Voet, Voet, \& Pratt, 2007, pág. 68).

Esta técnica también ha sido utilizada como un método de determinación sexual rápido. La técnica de la PCR aporta la identificación del sexo mediante la presencia del gen SRY. Si este gen está presente, por estar ubicado en el cromosoma $\mathrm{Y}$, se interpreta como el de una persona con un cariotipo $46, \mathrm{XY}$ o con un mosaicismo con presencia de un cromosoma $\mathrm{Y}$ (Settin et al., 2008).

La utilización de la técnica PCR tampoco estuvo exenta de polémica y detractores. Al ser una prueba que solo busca el gen SRY, se considera que no es una prueba adecuada para los fines deportivos, al no tener en consideración las diferentes tipos de ADS que no confieren ninguna ventaja competitiva a las mujeres, aunque posean un cromosoma $\mathrm{Y}$ en su cariotipo (Marín Fernández, 1996, pág. 78).

Las primeras voces en alzarse contra el uso de esta técnica fueron la Comisión Ética de la Asociación de Médicos Franceses -país donde se realizaban los JJOO de invierno en 1992-, y la de un grupo de científicos franceses, dos de ellos ganadores del Premio Nobel. El principal reproche era que utilizar esta técnica en el deporte resultaba inadecuado y violaba la intimidad de las deportistas (Pieper, 2016, pág. 152). El COI mantuvo esta técnica de verificación de sexo en los JJOO de Barcelona 1992, Atlanta 1996, y en los JJOO de Invierno Lillehammer 1994 y Nagano 1998.

En los JJOO de Barcelona 1992 se vivió una situación similar a la de Albertville 1992. El genetista barcelonés Xavier Estivill se negó a realizar la prueba de PCR en los JJOO, 
cuestionando a la CM del COI su capacidad de explicar a las atletas lo que significaba y las consecuencias de una muestra positiva (Pieper, 2016, pág. 156).

El Gobierno Noruego en el año 1994 declaró las pruebas de verificación de género ilegales y no éticas. Ello motivó que la organización de los JJOO de Invierno en Lillehammer de 1994 tuviera serios problemas para llevar a cabo las pruebas que exigía el COI (Martínez Patiño etal., 2010). En el informe oficial de los JJOO de Invierno de 1994 se reconoció que fue muy difícil conseguir personal médico especializado en el norte de Europa para desarrollar estas pruebas, por lo que hubo que recurrir al equipo que las practicó en los JJOO de Invierno de Albertville 1992 (Mjelde, 1995).

En los JJOO de Atlanta 1996 y mediante la aplicación de la técnica del PCR se detectaron 8 casos anómalos en las 3387 participantes en categorías femeninas. 7 de esas 8 atletas tenían SIA, una de las ADS con las que se impedía participar cuando se utilizaba la técnica de cromatina sexual. Sin embargo, en aplicación de la reconsideración producida en el caso Martínez Patiño por la IAAF, estas 7 atletas resultaron elegibles para competir en los JJOO de Atlanta. El caso de la octava atleta, a la que se había practicado una gonadectomía previa, era un positivo al gen SRY, probablemente por una deficiencia de $5 \alpha$-reductasa, un trastorno en el que la testosterona no se puede convertir en dihidrotestosterona (Simpson et al., 2000).

El COI organizó la Primera Conferencia Mundial sobre Mujer y Deporte en Laussane en ese mismo año 1996. Como resultado de esta conferencia se aprobó un documento con 17 recomendaciones. En la décima "se insta al COI a suspender el actual proceso de verificación de sexo durante los Juegos Olímpicos" (International Olympic Committee, 1996). No obstante, la decisión del COI de suspender estas pruebas se demoró hasta 1999 durante la Sesión 109a del COI en Seúl. Los JJOO de Sídney 2000 serían un campeonato en que las deportistas ya no tendrían que someterse a este tipo de controles. La decisión fue aplaudida por el mundo medico internacional (Simpson et al., 2000). 


\subsubsection{Santhi Soundarajan y Caster Semenya. Nombres propios de los nuevos controles de género del 2006.}

En noviembre de 2006, la CM y Anti-doping de la IAAF aprobó una nueva política de verificación de género: "IAAF Policy on Gender Verification" (International Association of Athletics Federations, 2006). En su apartado A, puntos 4 y 6, se estipulan (i) las pautas a seguir y bajo qué condiciones deben hacerse las verificaciones; y (ii) que consideraciones se deben tomar en cuenta para declarar elegible a una deportista que sea susceptible de una verificación de género.

El punto A.4 establecía que solo si existe alguna sospecha hacia una deportista se le puede requerir que asista a una revisión con médicos especializados de las aéreas de ginecología, endocrinología, psicología y medicina interna para determinar su elegibilidad en las competiciones femeninas. Si la atleta era declarada inelegible, se le hacían recomendaciones tanto médicas como quirúrgicas para que pudiera solventar la situación y fuera declarada elegible. Ello implicaba que, después de muchos años, estos controles dejaban de tener un carácter sistemático.

El punto A.6, por su parte, determinaba las condiciones que pueden presentar las atletas, pero que no generan ninguna ventaja competitiva sobre otras mujeres, lo cual las hace elegibles sin ninguna recomendación. Estas son: i) síndrome de insensibilidad a los andrógenos (completo o parcial), antes llamado síndrome de feminización testicular; ii) disgenesia gonadal; y iii) síndrome de Turner. Además consideraban otras condiciones que generaban alguna ventaja competitiva, a pesar de las cuales la atleta debía ser declarada elegible como eran: i) hiperplasia suprarrenal congénita; ii) tumores productores de andrógenos; y iii) síndrome de ovario poliquístico.

En aplicación de esta nueva política de verificación de género, Santhi Soundurajan, atleta india que logró la medalla de plata en la prueba de 800 metros en los Juegos Asiáticos de Doha 2006 con una marca de 2:03.16 ${ }^{18}$ minutos, fue despojada de su medalla. En su perfil de la IAAF no aparecen registros después de Noviembre de 2006. Su mejor marca personal para la prueba de 800 metros aparece con el registro de 2:04.01minutos, con lo que su marca de Doha no es tenida en cuenta ${ }^{19}$. El caso nunca fue explicado oficialmente por parte 
de la IAAF ni por la Federación India de Atletismo (AFI, por sus siglas en inglés). Lo único que se conoce al respecto son las declaraciones recogidas por varios medios de comunicación, donde un portavoz de la AFI asegura que Soundarajan nunca se ha sometido a un cambio de sexo, pero al parecer la atleta tenía una composición cromosómica anormal (Associated Press, 2006).

Un nuevo caso estaba en ciernes. En el Mundial de Atletismo de Berlín 2009, la atleta sudafricana Caster Semenya marcó en la prueba de 800 metros un registro de 1:55.45 minutos. La segunda clasificada hizo un tiempo de 1:57.90 20

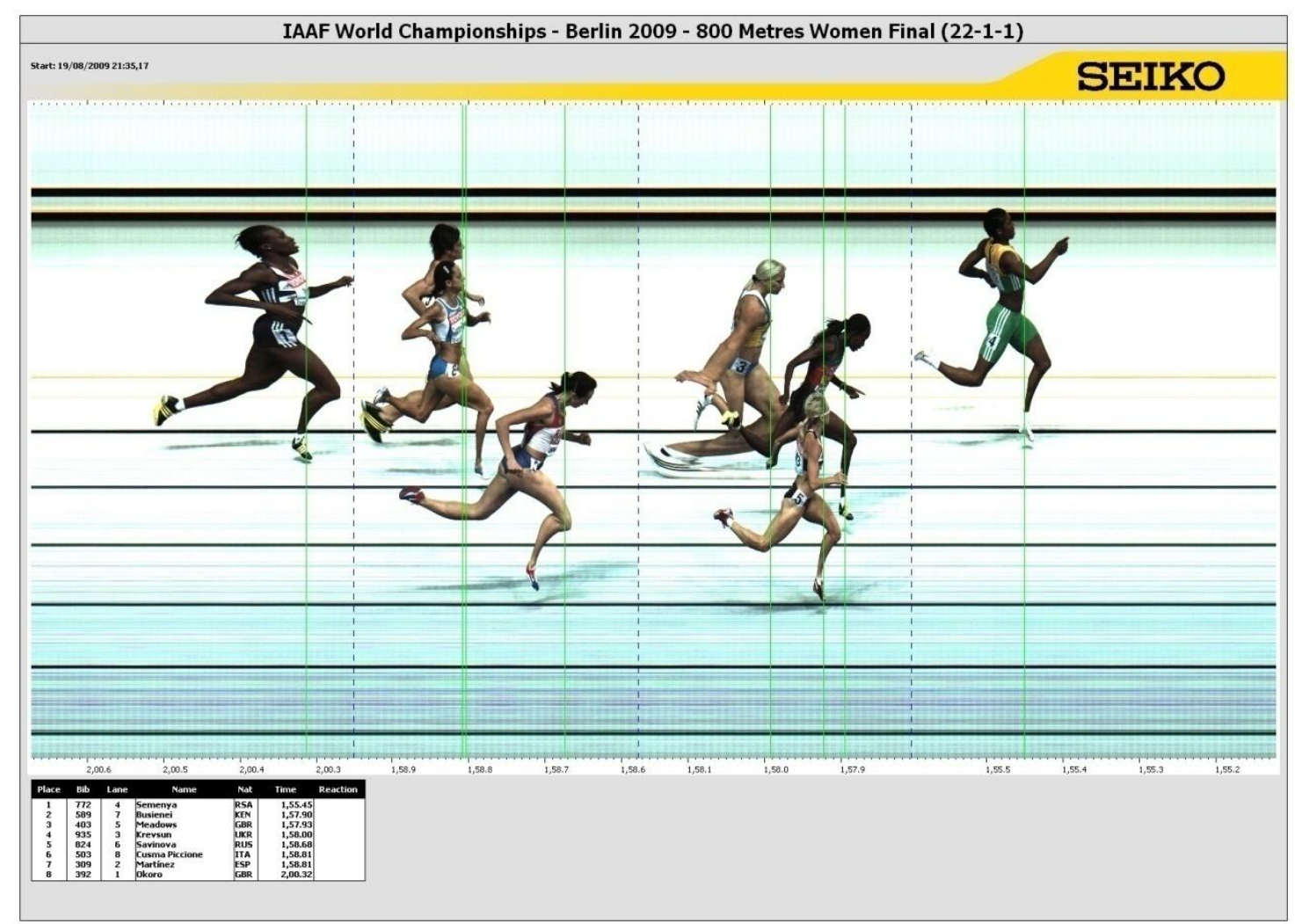

Figura 2. Foto finish final 800 metros femenino, Mundial de Atletismo de Berlín 2009. (Fuente IAAF). https://www.iaaf.org/results/iaaf-world-championships-in-athletics/2009/12th-iaaf-worldchampionships-in-athletics-3658/women/800-metres/final/result

En este caso, el registro no fue el detonante, se quedaba lejos del record mundial establecido en 1:53.28 minutos. Lo llamativo fue su apariencia física que determinó que fuera sometida a las pruebas de verificación de género. Hubo muchas especulaciones al respecto, pero ninguna confirmada por parte de la IAAF. Los resultados de su investigación no fueron revelados. Solo se conoce una filtración a los medios australianos, que afirmaron que la atleta sudafricana tenía características sexuales masculinas y 
femeninas y que, además, sus niveles de andrógenos estaban por encima del rango promedio de las mujeres. Semenya estuvo bajo investigación por parte de la IAAF diez meses. En ese tiempo fue sometida a diferentes pruebas médicas especializadas en Sudáfrica. En Junio de 2010 la IAAF anunció que su derecho a competir en la categoría femenina había sido reintegrado, pero sin revelar detalles de la investigación ${ }^{21}$ (Wells \& Darnell, 2014).

\subsubsection{Normativa de Hiperandrogenismo.}

Después de que la IAAF aceptara las conclusiones del panel de expertos que evaluó el caso de Caster Semenya, se preparó una nueva normativa. Esta regulación tomaba como elemento de referencia para la elegibilidad en categoría deportiva los niveles de testosterona activos en las mujeres.

Para consensuar esta nueva normativa, la IAAF, en colaboración con el COI, organizó siete reuniones de trabajo en que participaron expertos de diferentes ramas del conocimiento (derecho, ciencias, deportes, ética, grupos de mujeres intersexuales, atletas, etc). Estas reuniones tuvieron lugar en diciembre de 2009 -IAAF Expert Working Group; enero de 2010 -Mónaco IOC/IAF DSD Meeting; mayo de 2010 -Miami Working Group; septiembre de 2010 - Mónaco IOC/IAAF Working Session; octubre de 2010 -Estocolmo HA Expert Working Group; febrero de 2011 -Lausanne IOC/IAAF Working Session; y abril de 2011Daegu IAAF Council Meeting.

La reunión de mayo de 2010 en Miami, celebrada a puerta cerrada durante dos días, tuvo lugar en el marco de la conferencia convocada por el COI, denominada "2nd World Conference on the Hormonal and Genetic Basis of Sex Differentiation and Hot Topics in Endocrinology" abierta al público. Su desarrollo ha sido expuesto por la profesora Cassandra Wells, de la Universidad Dalhousieen Canada (Wells, 2010). Aunque esta reunión era convocada y organizada por el COI, gran parte de los participantes eran científicos involucrados con la IAAF, quienes a su vez estaban inmersos en el caso de Semenya, como Joe Leigh Simpson, Arne Ljungqvist, Heino Meyer-Bahlburg, Eric Vilain, Myron Genel, etc. 
Wells resume el desarrollo de los debates, destacando que los ponentes fueron preguntados por su opinión acerca de la posición que debía adoptar el COI en casos de deportistas con sexo ambiguo y la ambivalencia mostrada por los científicos acerca de esa cuestión. Uno de los aspectos que pone de relieve fue la oposición de los participantes a categorizar las mujeres con ambigüedad fuera de su condición femenina y a la realización de las pruebas de verificación de sexo. Ello generó un consenso en que no todas las ADS proporcionan una ventaja competitiva y que resultaba difícil definir lo que era una ventaja competitiva “injusta”, llegándose a señalar por alguno de los participantes la necesidad de realizar una investigación profunda para crear un mapa de las variaciones en las ADS que se podían considerar que proporcionaban una ventaja competitiva "injusta”. Situación que catalogó como "una tarea compleja y seguramente imposible" (Wells, 2010).

El 1 de Mayo de 2011 entró finalmente en vigor la normativa "IAAF Regulations Governing Eligibility of Females with Hyperandrogenism to Compete in Women's Competition" (International Association of Athletics Federations, 2011a). Esta reglamentación, que reemplazó la del 2006, compartía con ella el hecho de que no suponía un control sistemático de aplicación obligatoria para todas las deportistas, pero se diferenciaba en que su eje fundamental eran los niveles de testosterona activa en sangre. En una nota de explicaciones, la IAAF aclara el concepto que se utiliza para Hiperandrogenismo, señalando que "hiperandrogenismo es un término que se utiliza para describir la excesiva producción de andrógenos en las mujeres. El aspecto especifico de los andrógenos que interesa para la regulación en cuestión, es la mejora en el rendimiento que produce la testosterona" (International Association of Athletics Federations, 2011b).

La aplicación de esta nueva normativa era general para todas las atletas. Sin embargo, la posibilidad de ser sometidas a las concretas pruebas de verificación, de acuerdo con el capítulo 2 de esta regulación, quedaba limitada a aquellos casos en que el Director Médico de la IAAF decidiera iniciar una investigación confidencial ante la existencia de motivos razonables para creer que pudiera existir un caso de hiperandrogenismo. A esos efectos se consideraban fuentes confiables para considerar razonable dicha creencia i) que la atleta pusiera en conocimiento de las entidades deportivas una afección médica asociada al hiperandrogenismo; ii) la existencia de resultados en pruebas médicas realizadas 
previamente a la competición; iii) los resultados obtenidos de una prueba antidopaje o en los resultados del pasaporte biológico implementado en el año 2008; y iv) informaciones recibidas en una competición.

En el capítulo 6 de la normativa se establecen como criterios de elegibilidad para las competiciones femeninas: i) tener los niveles de andrógenos por debajo del nivel normal de los hombres; o, ii) si tiene niveles de andrógenos en el rango masculino, que exista una resistencia a esos andrógenos que impida adquirir la ventaja competitiva que le generaría ese alto nivel. Estos niveles de andrógenos son medidos por el total de testosterona en sangre y el rango normal de testosterona en sangre para los hombres se estableció en $\geq 10$ nmol/L. Ello determinaba que si una deportista arrojaba un resultado por encima de este valor y no se demostrara una resistencia a los andrógenos, no podía resultar elegible hasta que siguiera un tratamiento que restaurara sus niveles de andrógenos por debajo del rango masculino.

Por su parte, la CM del COI recomendó al COI que adoptara esta misma normativa para determinar la elegibilidad de los atletas para competir en las categorías femeninas. De ese modo se dio lugar en 2012 a los Reglamentos sobre hiperandrogenismo para los Juegos Olímpicos de 2012 en Londres y en 2013 para los Juegos Olímpicos de Invierno de 2014 en Sochi (International Olympic Committee, 2012), (International Olympic Committee, 2014). La normativa sobre hiperandrogenismo del COI hacía constar expresamente que no tiene por objeto la determinación del sexo y se limita a establecer un procedimiento para la apertura de las investigaciones sobre los presuntos casos de hiperandrogenismo en los Juegos Olímpicos. En tales casos, un grupo de expertos compuesto por un genetista, un ginecólogo y un endocrinólogo debían evaluar el caso para determinar: (i) si la atleta es hiperandrogénica; y (ii) en caso afirmativo, si esa condición confiere una ventaja competitiva. Al contrario que el Reglamento de la IAAF, los del COI no establecían un umbral de elegibilidad específica de $10 \mathrm{nmol} / \mathrm{L}$, ya que el COI consideraba que algunas atletas podían disfrutar de una ventaja de rendimiento incluso con concentraciones de testosterona endógena en suero inferior a $10 \mathrm{nmol} / \mathrm{L}$.

El caso más famoso y controvertido por la aplicación de esta normativa en el deporte, es el de la atleta india Dutee Chand, que se desarrolla en el siguiente capítulo. 
Tabla 4. Evolución de los controles de sexo, género y hormonales en el deporte femenino. (Elaboración propia)

\begin{tabular}{|c|c|c|c|}
\hline Año & Evento & Normativa & Descripción \\
\hline 1946 & IAAF & $\begin{array}{l}\text { Official IAAF } \\
\text { Certificate }\end{array}$ & $\begin{array}{l}\text { Todas las atletas que fueran a competir en un evento } \\
\text { reglado por la IAAF debían presentar una carta de su } \\
\text { médico donde asegurara el sexo al que pertenecía, } \\
\text { haciéndolas elegibles en el deporte. }\end{array}$ \\
\hline 1966 & $\begin{array}{l}\text { Campeonato } \\
\text { Europeo de } \\
\text { Atletismo }\end{array}$ & Nude Parade & $\begin{array}{l}\text { Todas las atletas debían posar desnudas en frente de un } \\
\text { panel de médicos, quienes a su vez realizaban una } \\
\text { inspección visual de sus genitales y decidían si eran } \\
\text { elegibles para competir o no }\end{array}$ \\
\hline 1967 & $\begin{array}{c}\text { Copa de Europa } \\
\text { de Atletismo }\end{array}$ & $\begin{array}{l}\text { Sex chromatin } \\
\text { test }\end{array}$ & \multirow{7}{*}{$\begin{array}{l}\text { Corpúsculo de Barr: } \\
\text { El examen de las células de la mucosa bucal muestra una } \\
\text { masa de cromatina, los cuerpos de Barr, que probablemente } \\
\text { representan un cromosoma X inactivo unido a la membrana } \\
\text { nuclear en la mayoría de las células femeninas }\end{array}$} \\
\hline 1968 & JJOO México & $\begin{array}{l}\text { Women's } \\
\text { Medical } \\
\text { Examination }\end{array}$ & \\
\hline 1972 & JJOO Múnich & Sex Control & \\
\hline 1976 & JJOO Montreal & $\begin{array}{l}\text { Femininity } \\
\text { Testing }\end{array}$ & \\
\hline 1980 & JJOO Moscú & $\begin{array}{l}\text { Femininity } \\
\text { Testing }\end{array}$ & \\
\hline 1984 & JJOO Los Ángeles & $\begin{array}{c}\text { Gender } \\
\text { Verification }\end{array}$ & \\
\hline 1988 & JJOO Seúl & $\begin{array}{c}\text { Gender } \\
\text { Verification }\end{array}$ & \\
\hline 1991 & IAAF & \multicolumn{2}{|c|}{ Finalización de los controles de sexo / genero por parte de la IAAF. } \\
\hline 1992 & JJOO Barcelona & $\begin{array}{l}\text { Gender } \\
\text { Control }\end{array}$ & \multirow{2}{*}{$\begin{array}{l}\text { Reacción en cadena de la polimerasa (PCR Test): } \\
\text { Para comprobar la presencia o ausencia del cromosoma Y }\end{array}$} \\
\hline 1996 & JJOO Atlanta & $\begin{array}{c}\text { Gender } \\
\text { Verification }\end{array}$ & \\
\hline 1999 & IOC & \multicolumn{2}{|c|}{ Finalización de los controles de sexo / genero por parte del COI. } \\
\hline 2006 & IAAF & \multicolumn{2}{|r|}{$\begin{array}{l}\text { IAAF Policy on Gender Verification // } \\
\text { Política de la IAAF sobre Verificación de Género }\end{array}$} \\
\hline 2011 & IAAF & $\begin{array}{r}\text { IAAF Regulati } \\
\text { Normativa } \\
\text { hipe }\end{array}$ & $\begin{array}{l}\text { ns Governing Eligibility of Females with Hyperandrogenism } \\
\text { to Compete in Women's Competition // } \\
\text { de la IAAF que regula la elegibilidad de las mujeres con } \\
\text { androgenismo para competir en la categoría femenina. }\end{array}$ \\
\hline 2012 & JJOO Londres & $\begin{array}{r}\text { IOC Regul } \\
\text { Normativa del }\end{array}$ & $\begin{array}{l}\text { tions on Female Hyperandrogenism. Games of the XXX } \\
\text { Olympiad in London, } 2012 \text { // } \\
\text { OI sobre el hiperandrogenismo femenino. Juegos de la XXX } \\
\text { Olimpiada en Londres, } 2012\end{array}$ \\
\hline 2014 & JJOO Sochi & $\begin{array}{r}\text { IC } \\
\text { Norm }\end{array}$ & $\begin{array}{l}\text { C Regulations on Female Hyperandrogenism // } \\
\text { tiva del COI sobre el hiperandrogenismo femenino. }\end{array}$ \\
\hline
\end{tabular}




\subsection{La decisión del Tribunal de Arbitraje del Deporte sobre la normativa de hiperandrogenismo.}

La nueva regulación sobre elegibilidad de las mujeres con hiperandrogenismo, tal como se ha expuesto anteriormente, no responde a una estrategia de verificar el sexo de la deportista con el fin de determinar en qué categoría, masculina o femenina, debe competir. La propia normativa no controvierte la asignación sexual de la deportista como mujer en los planos legal, social y/o personal. De ahí que se denomine Regulación sobre elegibilidad de las mujeres con hiperandrogenismo para participar en las competiciones femeninas (International Association of Athletics Federations, 2011a).

El nuevo objetivo de esta normativa es verificar el nivel de andrógenos producidos naturalmente por la deportista y su sensibilidad a esos andrógenos. Su finalidad expresa es la de mantener la equidad en la competición femenina al considerar que estos altos niveles activos de andrógenos "fuera del rango femenino" suponen una ventaja competitiva. A partir de ello, la deportista resulta inelegible para la competición hasta que consiga farmacológicamente una reducción de esos niveles de andrógenos dentro del rango estándar de feminidad establecido convencionalmente en esta regulación. Esta normativa no implica, por tanto, una prueba de sexo ni supone una imposibilidad jurídica de participar en competiciones femeninas. Es una verificación sobre la producción natural de un determinado elemento bioquímico y su sensibilidad al mismo y la obligación positiva de alterar ese elemento de su condición física natural por medios farmacológicos para reestablecer unos determinados niveles estandarizados de andrógenos.

Esta nueva filosofía parecía alejar la normatividad deportiva sobre hiperandrogenismo de las críticas de que había sido objeto la vieja estrategia de pruebas de determinación o verificación sexual en que, con independencia de la asignación sexual legal, social y/o personal, se imponía una categorización sexual a efectos de la competición deportiva. Sin embargo, esta nueva estrategia estaba muy lejos de poder acallar las muy serias objeciones que desde muy diversas perspectivas -medicas, bioéticas, deportivas, jurídicas, etc.- se le hacían. Muchas de esas objeciones fueron planteadas en el asunto Dutee Chand contra la Federación de Atletismo de la India (AFI, en sus siglas en inglés) y la Asociación Internacional de Federaciones de Atletismo (IAAF, en sus siglas en inglés), tramitado con 
el número CAS 2014/A/3759 por el Tribunal de Arbitraje del Deporte (TAS, en sus siglas en francés), y que dio lugar a la decisión arbitral cautelar de 24 de julio de 2015 (Court of Arbitration for Sports, 2015). En esta resolución, entre otras cuestiones, se decidió (i) suspender por un plazo no superior a dos años la normativa sobre hiperandrogenismo de la IAAF; e (ii) instar a la IAAF a que en ese periodo de dos años presentara nuevas pruebas e informes de expertos sobre el actual grado de ventaja en el rendimiento deportivo que tienen las mujeres con hiperandrogenismo por sus altos niveles de testosterona en relación con las que no lo tienen.

La más ordenada exposición de las cuestiones que fueron objeto de análisis y resolución en esta decisión y que son relevantes como marco teórico para esta investigación determinan que, a pesar de que no sea esa la sistematización seguida en la decisión arbitral ahora analizada, se expongan a modo introductorio, el fundamento fáctico del caso y los argumentos utilizados para impugnar esta normativa. Posteriormente, se describirá la posición sostenida por las partes intervinientes respecto de cada uno de esos argumentos y la opinión sustentada por el TAS sobre el particular. Un resumen amplio de los diferentes testimonios que se desarrollaron en la vista en defensa de cada una de las posiciones se han incluido en el Anexo II.

\subsubsection{El fundamento fáctico del caso y las causas de impugnación.}

La decisión arbitral desarrolla ampliamente los fundamentos fácticos del caso en sus parágrafos 7 a 31. De una manera extractada, estos fundamentos puede resumirse en que la atleta india Dutee Chand, nacida el 3 de febrero de 1996, comenzó a competir en las categorías inferiores del atletismo en 2007, ganando diversas competiciones nacionales atléticas en la India y del continente asiático. Una de ellas fue el campeonato "16th Asian Junior Athletics 2014" celebrado en mayo de 2014 en Taipéi, donde obtuvo la medalla de oro en las pruebas de 200 metros y de relevos de 4x400 metros. El 30 de junio de 2014 la AFI puso de manifiesto mediante una carta que durante el desarrollo de los mencionados Campeonatos asiáticos junior de atletismo la Asociación asiática de atletismo había expresados sus dudas en relación con el género de la atleta. Dutee Chand fue sometida a la normativa sobre elegibilidad de las mujeres con hiperandrogenismo para participar en las competiciones de mujeres concluyéndose que su nivel de andrógenos era demasiado alto 
por lo que fue declarada inelegible por la AFI para participar en competiciones atléticas nacionales e internacionales, incluyendo los inmediatos Campeonatos mundiales junior de atletismo a celebrar en julio de 2014 y los Juegos de la Commonwealth. Igualmente se determinó que, si bien por el momento la atleta no tendría la posibilidad de competir en categoría femenina, en el futuro podría hacerlo si con la ayuda de un tratamiento médico conseguía rebajar su nivel de andrógenos a un rango dentro de los límites permitidos.

La atleta Dutee Chand impugnó ante el TAS (i) la normativa sobre hiperandrogenismo, solicitando que fuera declarada inválida y nula; y (ii) la decisión de inelegibilidad adoptada por la AFI, con fundamento en la citada normativa sobre hiperandrogenismo de la IAAF, solicitando que fuera declarada elegible para competir; demandando para ello tanto a la AFI como a la IAAF.

La impugnación de la normativa sobre hiperandrogenismo de la IAAF -y, por extensión, de la decisión de inelegibilidad de la AFI- se fundamentó, a los efectos que resultan relevantes para esta investigación, en tres argumentos principales

a) Es una normativa discriminatoria (i) contra las mujeres deportistas y (ii) contra los deportistas que tienen características físicas naturales particulares.

b) Es una normativa que se basa en el error fáctico de asumir que existe una relación entre las testosterona y el rendimiento deportivo.

c) Es una normativa desproporcionada respecto de cualquier objetivo legítimo a perseguir.

Para una exposición sistematizada de cada uno de estos argumentos se analizará de una manera agrupada la posición sostenida por las partes intervinientes respecto de cada uno de ellos y la opinión sustentada por el TAS sobre el particular.

No obstante, antes de ello, es preciso destacar que, tal como se establece en el parágrafo 35 de la decisión arbitral, el debate que se estableció sobre estas cuestiones parte de una serie de aspectos que fueron comúnmente aceptados y que se pueden resumir en los siguientes puntos:

a) Las competiciones de atletismo están divididas, por razones de equidad, en competiciones para hombre y para mujeres. Por tanto, (i) los hombres solo 
pueden participar en las competiciones para hombre y nunca en las de mujeres y (ii) las mujeres solo pueden participar en las competiciones para mujeres y nunca en las de hombres.

b) Hay una sustancial diferencia en el rendimiento atlético de alta competición entre hombres y mujeres. Los atletas masculinos son, comparativamente, más rápidos y más fuertes que las atletas femeninas. Por tanto, la división de la competición según el sexo de los atletas resulta apropiada y es beneficiosa para la participación de las atletas femeninas en condiciones de igualdad.

c) Aunque las competiciones atléticas se dividan en categorías masculina y femenina, el género sexual en los humanos no es simplemente binario, ya que existen personas con diferencias en su desarrollo sexual que no encajan biológicamente en las tradicionales categorías de hombre y mujer.

d) No es adecuado someter a las atletas a una verificación de género o a un examen de sus genitales externos o a una prueba cromosómica para determinar su elegibilidad para competir como mujeres o con la finalidad de establecer su sexo o género.

e) La ventaja masculina sobre la femenina en el atletismo se atribuye primeramente al mayor índice de masa muscular (IMM) en los hombres, comenzado ese diferente desarrollo en la pubertad.

f) La mayoría de los hombres tiene un nivel de testosterona endógena significativamente más alto que las mujeres.

g) Los atletas masculinos y femeninos que toman testosterona exógena tienen una ventaja injusta ya que la testosterona exógena contribuye de forma significativa en aumentar el rendimiento deportivo, por lo que su prohibición está justificada para todos los deportistas.

h) Los criterios que determinan la inelegibilidad de una mujer para competir en categoría femenina en la regulación sobre hiperandrogenismo son (i) un nivel de testosterona endógena superior a los $10 \mathrm{nmol} / \mathrm{L}$ y (ii) un examen físico que incluya diversos criterios que establezca la existencia de sensibilidad a los andrógenos por la extensión de los rasgos de virilización. 


\subsubsection{La discriminación por razón de la condición física o sexual.}

\subsubsection{Posición de la impugnante.}

La impugnante, como se expone de manera detallada en los parágrafos 112 a 116 de la decisión arbitral, afirma que la normativa sobre hiperandrogenismo lesiona la prohibición de discriminación tanto por razones de la condición física como sexual establecida en la Carta Olímpica, la Carta de la IAAF y el Derecho internacional de los derechos humanos.

Considera que se produce una discriminación por razón de la condición física argumentando que la cantidad de testosterona que se establece en la normativa como causal de su inelegibilidad la produce su cuerpo de manera natural sin ninguna intervención artificial. Destaca que algunas de las ventajas competitivas de las que disfrutan los atletas son resultado de su configuración genética natural, lo que no debería ser considerado de una manera diferente a otro tipo de ventajas derivadas de mutaciones biológicas excepcionales. Así, pone de manifiesto que a los atletas no solo no se les prohíbe competir por poseer ventajas genéticas naturales como son su estatura, capacidad pulmonar o una agudeza visual por encima de un cierto límite; sino que, al contrario, sus éxitos deportivos se fundamentan normalmente en estas características que están fuera de los parámetros normales. De ello concluye que no existe ninguna razón especial para prohibir a las atletas competir por tener una condición genética natural inusual, incluso aunque ello les confiera una ventaja sobre otras competidoras que carezcan de esta singular condición.

La impugnante afirma que también se produce una discriminación por razón de sexo, al no existir un límite de testosterona aplicable a los atletas masculinos. Argumenta que los atletas masculinos con niveles de testosterona por encima del límite normal de testosterona masculina pueden competir sin tener que satisfacer ningún criterio médico o ser sometido a examen o tratamiento médico alguno como condición para su elegibilidad.

La impugnante pone de manifiesto que, tomando en consideración que la normativa sobre hiperandrogenismo tiene un evidente sesgo discriminatorio, corresponde a la IAAF establecer que esta discriminación está justificada. A esos efectos, si bien acepta que es un 
objetivo legítimo la consecución de una competición deportiva justa, discrepa que esta regulación esté diseñada para preservar la igualdad de condiciones en las competiciones atléticas femeninas, ya que existe multitud de factores biológicos, psicológicos, sociológicos y económicos que influyen en los resultados deportivos, siendo imposible singularizar un factor en particular.

\subsubsection{Posición de la IAAF.}

La IAAF, tal como se desarrolla en los parágrafos 116 y 117 de la decisión arbitral, acepta que la regulación sobre hiperandrogenismo implica una restricción a la elegibilidad basada en criterios sexuales, por lo que es discriminatoria. Por tanto, asume que le corresponde acreditar que está justificada por ser necesaria y proporcionada para la consecución de un objetivo legítimo. Considera que, si bien el principio de igualdad de trato exige que casos iguales sean tratados de la misma manera, también este principio permite un trato diferenciado cuando existen situaciones objetivamente diferentes en que resulta necesario proteger la equidad en la competición. La IAAF defiende que este es el principio conforme al cual debe ser evaluada esta normativa.

\subsubsection{Valoración del TAS y sus conclusiones.}

El TAS, como queda recogido en los parágrafos 448 a 450 de la decisión arbitral, constata que la normativa sobre hiperandrogenismo solo se aplica (i) a las atletas femeninas y (ii) con fundamento en características físicas naturales. Por tanto, considera que no es controvertible que, en principio, se trata de una regulación discriminatoria tanto (i) desde la perspectiva sexual, pues no resulta de aplicación a los atletas masculinos, como (ii) desde la perspectiva de la condición física, pues se refiere a una sustancia que el cuerpo produce naturalmente.

El TAS considera que al tratarse de una normativa, en principio, discriminatoria y, por tanto, contraria a los Carta del Comité Olímpico Internacional (COI) y a la Constitución de la IAAF debe ser considerada inválida, a no ser que se demuestre que es una normativa necesaria, razonable y proporcionada. 
El TAS concluye que, por su carácter discriminatorio, corresponde a la IAAF demostrar que la normativa es necesaria, razonable y proporcionada para mantener el principio de igualdad de condiciones de las atletas femeninas, cuyo análisis se remite a lo razonado en relación con el argumento sobre la proporcionalidad de la normativa.

\subsubsection{La vinculación entre los andrógenos y el rendimiento deportivo.}

\subsubsection{Posición de la impugnante.}

La impugnante, en una posición que aparece desarrollada en los parágrafos 119 a 125 de la decisión arbitral, afirma que la normativa sobre hiperandrogenismo se fundamenta en dos premisas principales como son que (i) un elevado nivel de testosterona endógena aporta a las atletas femeninas una ventaja competitiva; y (ii) la medicina es capaz en la actualidad de establecer un distinto nivel de testosterona para los atletas masculinos y femeninas. La impugnante considera que ambas premisas carecen de soporte científico. El presupuesto de que un elevado nivel natural de testosterona aporta una ventaja de rendimiento a las mujeres deportistas es rebatido por la impugnante con fundamento en que (i) no existe una relación de causalidad entre los niveles de testosterona y el rendimiento deportivo; y (ii) la testosterona endógena -producida naturalmente- no tiene el mismo efecto fisiológico que la testosterona exógena -aportada al cuerpo desde fuentes externas-. Igualmente rechaza que la medicina sea capaz en la actualidad de establecer un distinto nivel de testosterona para los atletas de ambos sexos.

\section{a) La testosterona no determina la diferencia de rendimiento deportivo entre ambos sexos.}

La impugnante sostiene, por lo que se refiere a la relación de causalidad entre la testosterona y el mayor rendimiento deportivo, que (i) no queda científicamente acreditada esa relación de causalidad; (ii) no hay estudios científicos publicados que vinculen los resultados atléticos con la concentración de testosterona en mujeres con hiperandrogenismo; y (iii) hay factores distintos a la testosterona endógena que pueden justificar la diferencia de rendimiento deportivo entre los atletas de ambos sexos. 
Destaca que existen evidencias científicas que acreditan que la testosterona endógena no puede ser el fundamento del éxito en el rendimiento deportivo. Aporta como ejemplos que (i) algunos atletas de alta competición tienen un muy bajo nivel de testosterona, los que sería indicativo de que la cantidad de testosterona no es necesaria ni suficiente para lograr un superior rendimiento deportivo; (ii) algunas mujeres atletas usan anticonceptivos hormonales que, aun teniendo un efecto reductor del nivel de andrógenos, no producen una disminución en su rendimiento deportivo; y (iii) algunas atletas femeninas tiene síndrome total o parcial- de insensibilidad a los andrógenos (SIA) que también les provoca -de manera total o parcial- una insensibilidad a la testosterona. Igualmente, existe una sobrerepresentación de mujeres atletas con cromosomas XY en la alta competición y un número de ellas tiene SIA, lo que significa que unos superiores niveles de testosterona no tienen efectos en su rendimiento deportivo. El hecho de que mujeres atletas con SIA puedan obtener importantes logros en las competiciones deportivas profesionales es indicativo de que la testosterona no tiene efectos -o son muy limitados- en la mejora del rendimiento deportivo.

\section{b) La testosterona endógena y exógena no tienen los mismos efectos.}

La impugnante sostiene que si bien no resulta controvertido que la testosterona exógena mejora el rendimiento deportivo, no ocurre lo mismo con la testosterona endógena, ya que el cuerpo humano responde de una manera diferente a una y otra. La testosterona exógena supone la introducción de un nuevo agente bioquímico que altera el equilibrio corporal modificando el nivel hormonal natural, lo que no sucede con la testosterona endógena. De ese modo, los datos referidos a una mejora del rendimiento provocado por la testosterona exógena no pueden ser aplicados a los supuestos de la testosterona endógena.

\section{c) No hay un distinto nivel de testosterona para los atletas de ambos sexos.}

La impugnante afirma que hay evidencia científica sobre que (i) los rangos de los niveles de testosterona en ambos sexos se superponen; (ii) las mujeres con niveles de testosterona superiores al umbral establecido por la IAAF de $10 \mathrm{nmol} / \mathrm{L}$ están dentro del rango normal femenino para los niveles de testosterona; (iii) el umbral de $10 \mathrm{nmol} / \mathrm{L}$ es arbitrario porque no hay un consenso científico sobre cuáles son los niveles de testosterona en individuos 
sanos y los niveles de testosterona son naturalmente dinámicos y varían en cada individuo en respuesta a una diversidad de factores ambientales, psicológicos y sociales.

\subsubsection{La posición de la IAAF.}

La posición de la IAAF es desarrollada en los parágrafos 126 a 132 de la decisión arbitral. La IAAF sostiene que hay evidencias científicas respecto de que (i) la testosterona es un elemento determinante del rendimiento deportivo y que la diferencia en el nivel de testosterona es el factor más relevante para explicar la diferencia de rendimiento en los deportistas masculinos y femeninas; (ii) los efectos fisiológicos de la testosterona endógena y exógena son los mismos; y (iii) es posible identificar un rango femenino para niveles normales de testosterona, ya que las atletas femeninas no tienen niveles de testosterona más allá del rango establecido a menos que sufran una anomalía ADS o hayan sido objeto de dopaje.

\section{a) La testosterona determina la diferencia de rendimiento deportivo entre ambos} sexos.

La IAAF afirma que hay un amplio consenso científico en que la principal causa de la ventaja de los atletas masculinos respecto de las femeninas en potencia, tamaño y fuerza radica en los niveles significativamente superiores de testosterona que los hombres generan durante y después de la pubertad. Esta es una evidencia que hace radicar, entre otros aspectos, en el número de deportistas de ambos sexos que se auto-administran ilegalmente testosterona exógena para aumentar su tamaño, fuerza y potencia. De ese modo, en los casos puntuales en que algunas mujeres deportistas producen de manera natural testosterona en niveles masculinos en vez de femeninos, cuentan con una ventaja de rendimiento deportivo sobre el resto de mujeres con niveles normales de testosterona semejante a la ventaja que tiene los deportistas masculinos sobre las femeninas. Así, la IAAF concluye que (i) el alto nivel de testosterona en los hombres es el factor más importante que explica la significativa diferencia en el rendimiento físico entre los atletas de ambos sexos; y (ii) no existen otros factores conocidos que permitan demostrar de una manera tan definida esa diferencia de rendimiento. 
La IAAF afirma que esta conclusiones están ampliamente asumidas en la comunidad científica, a cuyos efectos cita diversos estudios científicos como son los de (i) "Hormones and Sport: physiology, pharmacology \& forensic science" (Handelsman \& Gooren, 2008); (ii) "The science of sex verification and Athletic performance" (Tucker \& Collins, 2010); o (iii) "The new policy on hyperandrogenism in elite female athletes is not about 'sex testing "(Sánchez, Martínez-Patiño, \& Vilain, 2013).

\section{b) La testosterona endógena y exógena tienen los mismos efectos.}

La IAAF defiende establecer un umbral de testosterona de $10 \mathrm{nmol} / \mathrm{L}$ para determinar el nivel máximo de testosterona femenina endógena que permita la elegibilidad de las atletas femeninas para competir en la categoría femenina argumentando que (i) existen estudios que demuestran una correlación entre la testosterona endógena y el rendimiento deportivo; (ii) los probados efectos de mejora del rendimiento por la administración de testosterona exógena a las atletas femeninas en la República Democrática Alemana entre los años 60 y 80 del s. XX; (iii) el significativo número de mujeres deportistas que continúan dopándose con testosterona para beneficiarse de una mejora de rendimiento deportivo; (iv) la desproporcionada representación de atletas femeninas con hiperandrogenismo en la alta competición deportiva; (v) la acreditada bajada de rendimiento deportivo de las atletas femeninas con hiperandrogenismo cuando siguen tratamiento de reducción de la testosterona; y (vi) el umbral de $10 \mathrm{nmol} / \mathrm{L}$ es un nivel que, siendo considerada una magnitud por encima del rango normal para las mujeres, está dentro del rango normal para los hombre.

\section{c) Hay un distinto nivel de testosterona para los atletas de ambos sexos.}

La IAAF afirma la existencia de dos amplios estudios de población en competiciones de atletismo realizados en Moscú en 2013 -datos de Moscú- y en Daegu en 2011 -datos de Daegu-, conforme a los cuales se acredita que en condiciones de reposo, el rango normal en los niveles de testosterona en atletas femeninas de alta competición es el mismo que el de la población en general (entre 0.1 y $3.08 \mathrm{nmol} / \mathrm{L}$ ). 
La IAAF sostiene que no tiene conocimiento de ningún supuesto en que una mujer deportista no dopada con un normal funcionamiento gonadal y suprarrenal pudiera llegar a tener niveles de testosterona en sangre cercanos a $10 \mathrm{nmol} / \mathrm{L}$.

\subsubsection{La posición del TAS.}

El TAS concluye, con una argumentación desarrollada en los parágrafos 489 a 499 de la decisión arbitral, que la cuestión principal a resolver es (i) si existe una base científica que acredite que la testosterona es el marcador para diferenciar entre hombre y mujeres; y (ii) en caso afirmativo, si existe una diferencia en la respuesta fisiológica del cuerpo a la testosterona endógena y la exógena.

El TAS constata que existe una evidencia de que, al margen de algunas situaciones atípicas, hay una significativa diferencia en los niveles de testosterona en la población normal de hombres y mujeres; y que, si se incluyen esas situaciones atípicas, hay un significativo solapamiento en los niveles de testosterona entre hombre y mujeres. El TAS, sin embargo, acepta las razones aportadas por la IAAF para no tomar en consideración esas situaciones atípicas y concluye que hay tal diferencia de promedio en los niveles de testosterona masculina y femenina que este es un marcador que puede ser utilizado para diferencia a la población masculina y la femenina.

El TAS, partiendo de la base de que no era controvertido que la masa muscular fuera la clave que diferencia la capacidad atlética entre hombre y mujeres, establece que la cuestión es determinar si la testosterona es la causante de esa diferente masa muscular. A esos efectos, señala que, si bien no se ha establecido la base científica y médica de esa diferencia de desarrollo muscular y no se conoce completamente como el metabolismo de hombres y mujeres después de la pubertad dan como resultado esa diferencia de masa muscular, lo cierto es que la impugnante no ha negado la relevancia que en ello tiene la testosterona, limitándose a sugerir que pueden existir otras causas concurrentes con ella, pero que tampoco cuentan con el respaldo de datos científicos suficientes. Del mismo modo, el TAS considera que tampoco la impugnante ha cumplido con la carga probatoria 
suficiente para acreditar que la testosterona exógena tiene unos diferentes efectos en el rendimiento deportivo que la endógena.

Por tanto, el TAS concluye que de acuerdo con el estándar probatorio, hay una base científica para establecer que la testosterona es una circunstancia relevante para la consecución del objetivo propuesto en la normativa sobre hiperandrogenismo.

\subsubsection{La desproporcionalidad de la normativa sobre hiperandrogenismo.}

\subsubsection{Posición de la impugnante.}

La impugnante, como se expone de manera detallada en los parágrafos 231 a 241 de la decisión arbitral, imputa a la normativa sobre hiperandrogenismo que (i) persigue un objetivo ilegítimo como es la búsqueda de la igualdad de condiciones en la competición y (ii) causa daños desproporcionados en la consecución de cualquier objetivo legítimo.

\section{a) La normativa no tiene un fin legítimo.}

La impugnante acepta que es un objetivo legítimo la búsqueda de la equidad en el deporte. Discrepa, sin embargo, de que sea un objetivo legítimo la búsqueda de la igualdad de condiciones, pues este concepto es ilusorio y carece de sentido si se enfrenta a la extraordinaria amplitud de los diferentes factores que contribuyen al rendimiento deportivo.

Señala que es intrínsecamente injusta una normativa que impide a las atletas competir debido a una característica física natural que no es diferente de otros muchos factores físicos, psicológicos, sociales y económicos que contribuyen al rendimiento deportivo en la alta competición. La impugnante compara esta normativa con otra que impusiera un tamaño máximo de mano para las jugadoras de baloncesto, más allá de la cual se considerara dentro de un umbral masculino que determinara su inelegibilidad para competir en competiciones femeninas. Afirma que una regla de esa naturaleza sería claramente discriminatoria e injustificable. 
Del mismo modo, sostiene que si bien las reglas de elegibilidad referidas al peso o la edad siempre dan al deportista la oportunidad de competir en una categoría determinada, la normativa sobre hiperandrogenismo impide a algunas mujeres deportistas competir a menos que se someten a un tratamiento médico que lleve su nivel natural hormonal por debajo de un umbral determinado normativamente.

\section{b) La normativa causa perjuicios desproporcionados.}

La impugnante afirma que el daño causado por la aplicación del Reglamento sobre hiperandrogenismo es totalmente desproporcionado respecto de cualquier beneficio pretendido por esta normativa. En particular, señala que provoca los siguientes perjuicios:

i. La estigmatización de las atletas femeninas a las que se les aplica, quedando afectada la autoestima y la identidad de género de las atletas con hiperandrogenismo: la impugnante sostiene que esta normativa (i) incita al escrutinio, la sospecha y el miedo respecto de determinada tipología corporal y particulares formas de presentación de género; (ii) implica investigaciones invasivas que pueden afectar a la auto percepción y la identidad de un atleta como mujer y llevar a otras personas a que cuestionen esa identidad; y (iii) puede aumentar la presión sobre las atletas femeninas para cumplir con las expectativas estereotipadas de comportamiento y apariencia femeninas.

La impugnante también valora el hecho de que si bien la normativa establece que toda investigación debe ser confidencial, no existen garantías de ello. El proceso de evaluación puede tardar meses y durante ese tiempo no se puede participar en las competiciones, lo que es probable que despierte sospechas, existiendo un riesgo inevitable de especulación pública o de revelación de que la atleta está siendo investigada, propiciado, además, por la posibilidad prevista en la normativa de que cualquier atleta pueda suscitar dudas acerca de otra a un director médico de la IAAF. Cita diversos ejemplos en que ha existido esa filtración pública, refiriendo dos supuestos en que las atletas han experimentado tal situación de humillación y vergüenza pública como consecuencia de la divulgación mediática de la investigación que tuvieron tendencias suicidas. 
ii. Supone la práctica de pruebas médicas sin un consentimiento informado y la sumisión a tratamientos médicos innecesarios con graves efectos secundarios a largo plazo: La normativa sobre hiperandrogenismo establece que una atleta femenina que rechace someterse a la evaluación o que tenga un resultado con un nivel de testosterona funcional superior a los $10 \mathrm{nmol} / \mathrm{L}$ resulta inelegible a menos que sea capaz de bajar esos niveles por debajo de este umbral. La impugnante considera que esta normativa propicia el sometimiento a procedimientos médicos para reducir los niveles de testosterona que no son necesarios medicamente ni el resultado de un consentimiento libre e informado de la atleta. Afirma que existe un riesgo grave de que las atletas de alta competición que han dedicado toda su vida al deporte sentirán una presión abrumadora a someterse a cualquier tratamiento quirúrgico o farmacológico que les permita continuar compitiendo, independientemente de su necesidad médica o sus posibles efectos secundarios.

\subsubsection{Posición de la IAAF.}

La IAAF, como se expone de manera detallada en los parágrafos 242 a 250 de la decisión arbitral, argumenta que la normativa sobre hiperandrogenismo (i) persigue el objetivo legítimo de mantener la equidad en las competiciones deportivas, garantizando que las atletas femeninas puedan competir en igualdad de condiciones; y (ii) es necesaria y proporcionada para la consecución de ese objetivo, ya que sus beneficios superan cualquier daño y justifican el efecto discriminatorio que implica.

\section{a) La normativa persigue un fin legítimo.}

La IAAF identifica dos objetivos a perseguir por el Reglamento sobre hiperandrogenismo: (i) ayudará las atletas con hiperandrogenismo a la protección de su salud, facilitando un diagnóstico de su condición médica a cargo de la IAAF, lo que les permite obtener un tratamiento adecuado a su patología; y (ii) conciliar la preocupación de la mayoría de las atletas femeninas por la equidad deportiva con mantener la oportunidad de competir de las atletas con hiperandrogenismo, de modo tal que se incentive a las mujeres a seguir desarrollando los esfuerzos necesarios para conseguir la excelencia en el atletismo, a la vez que se desalienta la sensación de que deben doparse para ser competitivas. 
La IAAF sostiene que las atletas femeninas podrían considerar injusto tener que competir con otras mujeres en desigualdad de condiciones por sus niveles de testosterona. Destaca el razonamiento del profesor Murray según el cual si la categoría femenina se crea para su protección frente a la competición masculina por motivos de equidad, entonces la IAAF debe establecer una política que salvaguarde el fin perseguido por la división de la competición por sexos. De ese modo, a la vista del efecto de mejora del rendimiento que genera la testosterona, existe una obligación ética de asegurar que las atletas femeninas que desean competir contra otras mujeres no tengan que hacerlo contra aquellas que cuentan con ventajas de rendimiento producidas por hormonas comúnmente asociados con los hombres.

La IAAF rechaza la afirmación de que unos niveles endógenos de testosterona no son más injustos que otras ventajas naturales, con el argumento, también sustentado por el profesor Murray, de que cada deporte tiene derecho a determinar los factores que implican una situación de falta de equidad y adoptar unas líneas divisorias claras. También cita la IAAF el trabajo de Tucker y Collins titulado "The sciencie of sex verification and Athletic performance" (Tucker \& Collins, 2010), en que comparan los niveles elevados de testosterona y otros rasgos físicos a los efectos de la división competitiva por sexos, concluyendo que (i) existen categorías de género por la sencilla razón de que las diferencias de rendimiento entre sexos requieren dos categorías separadas de competición; (ii) las autoridades deportivas deben defender la igualdad de oportunidades en la competición femenina cuando la igualdad es cuestionada por factores fisiológicos que desafían la base primordial de la existencia de la división de las competiciones por sexos; y (iii) no excluir el hiperandrogenismo sería análogo a tener un sistema donde existen las clasificaciones de peso, pero renunciar a ellas para ciertos individuos que no pueden reducir su peso lo suficiente como para encajar en la categoría requerida. 


\section{b) El fin legítimo justifica los perjuicios.}

La IAAF niega que la normativa de hiperandrogenismo discrimine indebidamente a las mujeres deportistas por el hecho de que no exista una reglamentación equivalente para los atletas masculinos con niveles inusualmente altos de testosterona endógena. Argumenta, siguiendo de nuevo al profesor Murray, (i) que no existe evidencia de una correlación entre atletas masculinos con los niveles excepcionalmente altos de testosterona y un mejor rendimiento en el deporte; (ii) frente el apoyo que tiene entre las mujeres una regulación del hiperandrogenismo femenino, no existe nada parecido para las competiciones masculinas; y (iii) siendo la finalidad de esta normativa proteger a las mujeres de tener que competir contra atletas con las ventajas hormonales de los hombres, la igualdad de trato no exigiría una política análoga de protección de los hombres que compiten contra otros hombres.

La IAAF también rechaza la existencia de otros riesgos o la relevancia de los perjuicios derivados de esta regulación, poniendo de manifiesto que:

i. El Reglamento de hiperandrogenismo no implica que las atletas con hiperandrogenismo no son realmente mujeres. Al contrario esta normativa enfatiza y reconoce expresamente la feminidad de la atleta.

ii. El Reglamento de hiperandrogenismo no se aplican de la misma manera que las políticas de verificación de género anteriores, ya que (i) no se realizan pruebas para determinar el sexo de un atleta; (ii) solo el director médico de la IAAF puede iniciar una investigación y únicamente si hay motivos razonables derivados de una fuente fiables, no considerándose como tal una competidora o algún miembros de su delegación que se enfrentarían a sanciones disciplinaros en caso de intentar hacer uso con mala fe de esta normativa.

iii. El Reglamento de hiperandrogenismo no utiliza los indicadores de virilización asociados con definiciones subjetivas y estereotipadas de la feminidad en occidente. Son indicadores que (i) sólo se utilizan una vez que se ha decidido el desarrollo de la investigación; y (ii) se basan en la Medical Guidelines for the 
Clinical Practice for the Diagnosis and Treatment of Hyperandrogenic Disorders (American Association of Clinical Endocrinologists, 2001) y en el Consensus Document on the Management of Intersex Disorders (Hughe et al., 2006).

iv. No hay riesgos de estigmatización a no ser que se haga público el hecho de que una atleta está siendo investigada o ha sido diagnosticada como hiperandrogénica. El Reglamento de hiperandrogenismo incide en la necesidad de la confidencialidad del proceso médico, incluyendo un capítulo dedicado específicamente a la gestión confidencial de los casos con sanciones para su incumplimiento. La IAAF señala que más de 30 casos han sido investigados en aplicación de esa normativa y nadie fuera de la IAAF conoce la identidad, nacionalidad o cualquier información personal de esas atletas.

v. La disminución quirúrgica o farmacológica de los niveles de testosterona no producen graves efectos secundarios. En la medicina clínica habitual, las mujeres con hiperandrogenismo que desean prevenir la virilización generalmente tienen como opciones bien un tratamiento hormonal para suprimir los andrógenos, que implica un anticonceptivo oral con pocos efectos secundarios como el que toman muchas mujeres en el mundo; bien la gonadectomía o extirpación quirúrgica de la fuente de los andrógenos. Con carácter general se opta por la terapia hormonal ya que el Reglamento de hiperandrogenismo no obliga a someterse a la gonadectomía y si algunas atletas lo han hecho es por razones personales totalmente ajenas a la aplicación de la normativa. Por otro lado, se destaca que el hiperandrogenismo crea potencialmente graves riesgos para la salud, que hacen que el diagnóstico precoz y su tratamiento sean muy importantes, ya quela virilización puede causar ansiedad grave y puede haber un mayor riesgo de cáncer.

vi. El Reglamento de hiperandrogenismo establece normas muy claras sobre la necesidad de consentimiento informado, no estando la IAAF involucrada en los procesos de diagnóstico o tratamiento. 


\subsubsection{Posición del TAS.}

El TAS, con una argumentación desarrollada en los parágrafos 533 a 538 de la decisión arbitral, establece las siguientes conclusiones:

1. El TAS acepta las tres premisas siguientes: (i) la testosterona es un factor causal clave en el aumento de la masa muscular en los varones; (ii) el aumento del IMM confiere una ventaja competitiva que justifica la separación de la competición deportiva en categorías sexuales; y (iii) la ventaja competitiva de los hombres respecto de las mujeres es del orden de 10 - 12\%. De estas premisas concluye que (iv) solo está justificada la inelegibilidad en las competiciones femeninas cuando la atleta tenga un nivel de testosterona endógena funcional dentro del umbral masculino que le aporte un grado de ventaja competitiva en el mismo rango del que disfrutan los atletas masculinos respecto de las atletas femeninas.

2. El TAS considera que no existen suficientes evidencias sobre el concreto nivel de aumento de ventaja competitiva que aportan el nivel de testosterona. Las pruebas desarrolladas no acreditan que se produzca una ventaja del orden del $10-12 \%$ en lugar de, por ejemplo, el $1 \%$ o $3 \%$. De ese modo, una vez que se ha establecido que el nivel de ventaja competitiva de los hombres respecto de las mujeres es del 10$12 \%$, es preciso demostrar que los niveles de testosterona funcional establecidos para la inelegibilidad aportan una ventaja que no es esté por debajo del $12 \%$.

3. El TAS afirma que, aplicando la distribución de la carga de la prueba, es a la IAAF a la que corresponde demostrar que el grado de ventaja competitiva que confiere a una atleta un nivel de testosterona por encima de $10 \mathrm{nmol} / \mathrm{L}$ es similar al que justifica la segregación de la competición deportiva por sexos, convirtiendo en razonable y proporcionado ese nivel de testosterona para decretar la inelegibilidad de las atletas. Esa demostración no se ha producido en este procedimiento. Por tanto, la IAAF no ha satisfecho la carga de probar que los criterios establecidos en el Reglamento de hiperandrogenismo son necesarios y proporcionados para alcanzar el objetivo legítimo de regular la elegibilidad en la competición femenina sobre la base de garantizar su equidad. 


\subsection{Estudios relacionados y planteamiento del problema.}

\subsubsection{Revisión de los estudios relacionados.}

La diferencia del rendimiento deportivo entre hombres y mujeres ha sido analizada en varios estudios de la siguiente manera:

\subsubsection{Diferencia utilizada en el caso Dutee Chand}

La diferencia media para los resultados de atletismo entre hombre y mujeres que se cita en el auto de medidas cautelares del Tribunal de Arbitraje Deportivo (TAS) en el caso Dutee Chand, en el parágrafo 205 por el experto que dio testimonio a favor de La Asociación Internacional de Federaciones de Atletismo (IAAF) ante el tribunal, el Dr. Stéphane Bermon, es del 12,64\% (Court of Arbitration for Sports, 2015). Esta diferencia fue establecida usando registros de eventos directamente comparables del atletismo de élite.

La diferencia citada anteriormente y el método utilizado para su cálculo, no se encuentra publicada en revistas científicas. Sin embargo, en correspondencia mediante correo electrónico entre el autor de esta tesis doctoral y el Dr. Bermon, con fechas 20 y 22 de agosto de 2016 se conocieron detalles de cómo se realizó el cálculo. El Dr. Bermon expuso que los cálculos se realizaron utilizando los resultados de los Records Mundiales establecidos en cada una de las pruebas del atletismo comparables, hasta el 7 de enero de 2015. Sus resultados fueron obtenidos utilizando la siguiente fórmula para hallar el porcentaje de la diferencia entre hombres y mujeres:

$$
\% \text { diferencia }=\frac{W R h-W R m}{W R h} * 100
$$

Donde WRh se refiere al resultado del Record Mundial masculino y WRm se refiere al resultado del Record Mundial femenino en la prueba específica. 
En la bibliografía se encuentran estudios que analizan la diferencia del rendimiento deportivo entre hombres y mujeres, utilizando los resultados de los mejores cinco clasificados, los mejores diez clasificados, las mejores marcas del año, los records mundiales, etc. Todas estas diferencias que exponemos a continuación son expresadas en porcentaje y no son exclusivas del atletismo, el deporte que analizamos en nuestro estudio. A continuación, relacionamos cronológicamente uno a uno los estudios encontrados con su respectivo objetivo (acorde al del presente estudio), el método utilizado y los resultados encontrados:

\subsubsection{Diferencias de género en el ciclismo - "Furnace Creek".}

La "Furnace Creek" es una carrera de ultra maratón ciclista, que consiste en recorrer 508 millas $(818 \mathrm{~km})$ en el estado de California y para poder ser considerado finalista, el deportista debe cruzar la meta dentro del límite de 48 horas.

El estudio de Rüst et al., (Rüst et al., 2015) presenta un análisis de esta carrera, que hace parte del evento mundialmente conocido "Race across America". Para el análisis, que tenía como objetivo investigar las diferencias de género en la velocidad alcanzada por los ganadores en la prueba, se tuvieron en cuenta los datos de todos los finalistas desde el año 1983 hasta el año 2012, para un total de 836 atletas (750 hombres y 86 mujeres). Las diferencias entre hombres y mujeres, se calculó utilizando la siguiente fórmula:

$$
\begin{gathered}
\% \text { diferencia }= \\
\frac{[\text { Valor (velocidad)en Mujeres }]-[\text { Valor (velocidad) en hombres }]}{[\text { Valor (velocidad) en hombres }]} * 100
\end{gathered}
$$

Los autores, encontraron la diferencia de la diferencia de la velocidad alcanzada de los ganadores entre géneros a través del tiempo, en el periodo de tiempo analizado. Esta diferencia fue constante a lo largo de los años estudiados, siendo igual a $14.3 \pm 8.2 \%$. Sin embargo, al analizar la velocidad de los tres primeros finalistas de la prueba, la diferencia entre géneros disminuyó de manera lineal de $26.2 \pm 0.5 \%$ en el año 1984 a $10.7 \pm 1.9 \%$ en el año 2012.

Otro análisis que hicieron en el estudio fue comparar la velocidad alcanzada por el hombre más rápido y la mujer más rápida de todos los años estudiados; los 3 mejores hombres y las 
3 mejores mujeres de todos los años estudiados; y la velocidad alcanzada de los 10 mejores hombres y las 10 mejores mujeres de todos los años estudiados. Los resultados encontrados para los más rápidos de todo el periodo analizado dieron una diferencia de 5.3\% superior para los hombres; para los 3 mejores de todos los años, una diferencia de $7.2 \pm 1.7 \%$ superior para los hombres; y para los 10 mejores de todos los años, una diferencia de $11.3 \pm 3.1 \%$ superior para los hombres.

\subsubsection{Diferencias de género en triatlón olímpico - "Zürich Triathlon".}

En el estudio de Etter et al., (Etter et al., 2013) uno de los objetivos era analizar los cambios longitudinales en la diferencia de género en una carrera de triatlón olímpica, en triatletas de élite durante los años 2000 al año 2010. La carrera analizada fue el "Zürich Triathlon", donde la natación son $1.5 \mathrm{~km}$, el ciclismo $40 \mathrm{~km}$ y la carrera $10 \mathrm{~km}$. Para el análisis de los cambios en la diferencia de género, los autores tuvieron en cuenta la media de los tiempos de los cinco primeros clasificados de la prueba durante cada año tanto en hombres como en mujeres en cada categoría tras segmentar la muestra en grupos de edad $(18-24 ; 25-29 ; 30-34 ; 35-39 ; 40-44 ; 45-49 ;$ y 50-54). Para valorar si los cambios en las diferencias encontradas eran estadísticamente significativos, se aplicó un análisis de varianza (ANOVA) de una vía.

Según este estudio, la diferencia media del rendimiento deportivo entre hombres y mujeres, para las pruebas de natación, ciclismo, carrera y para el total de la prueba de los 5 primeros clasificados de cada año fue de $15.2 \pm 4.6 \%, 13.4 \pm 2.3 \%, 17.1 \pm 2.5 \%$, y $14.8 \pm 1.8 \%$, respectivamente.

\subsubsection{Diferencias de género en los Juegos Olímpicos desde 1983.}

El estudio de Thibault et al., (Thibault et al., 2010) compara la mejora en los registros masculinos y femeninos a lo largo de la era de los Juegos Olímpicos de la era moderna. Los autores analizan datos de cuatro deportes: atletismo, natación, patinaje y levantamiento de pesas. Para el deporte del atletismo, se tuvieron en cuenta los resultados de los 10 primeros clasificados en cada prueba para cada edición, en el periodo comprendido desde el año $1891^{22}$ hasta el año 2008 y los records mundiales establecidos. Para el cálculo de las diferencias entre hombres y mujeres utilizando los records mundiales para cada año se 
utilizó la siguiente fórmula: $\Delta i=W R w i-W R m i$ donde $W R w i$ es el record del mundo femenino para el año establecido y WRmi es el record del mundo masculino para el año establecido. Adicionalmente, calcularon la diferencia para cada posición entre hombres y mujeres para los 10 mejores clasificados de cada año.

Los resultados reportados por los autores en el caso del atletismo fueron que la diferencia entre hombres y mujeres, teniendo en cuenta los records mundiales, disminuyó en las pruebas de carrera desde el $30.0 \pm 6.48 \%$ hasta el $10.7 \pm 1.85 \%$ para estabilizarse después; para las pruebas de salto esta diferencia disminuyó desde el $30.1 \pm 8.52 \%$ hasta el $17.5 \pm 1.11 \%$, valor alrededor del cual se estabilizó a continuación. Teniendo en cuenta los resultados de los diez mejores clasificados, la diferencia entre hombres y mujeres disminuyó inicialmente para después estabilizarse desde el $25.3 \pm 4.46 \%$ al $11.2 \pm 1.25 \%$ en las pruebas de carrera y desde el $30.0 \pm 3.86 \%$ al $19.0 \pm 2.57 \%$ en el caso de las pruebas de salto.

\subsubsection{Diferencias de género en el Off-road triatlón.}

El estudio de Lepers \& Stapley (2010) se realizó en la modalidad de Off-road triatlón que engloba las pruebas de natación $1.5 \mathrm{~km}$, mountain bike $30 \mathrm{~km}$ y trail running $11 \mathrm{~km}$. Los autores de este estudio tenían dentro de sus objetivos analizar el rendimiento y las diferencias de género en las pruebas de la natación, la carrera, el ciclismo y la diferencia global de la prueba. Los datos utilizados fueron de los 10 mejores de la competición “Xterra World Championship" desde el año 2005 al año 2009 para hombres y mujeres. Para calcular el porcentaje de diferencia entre hombres y mujeres por cada prueba, utilizaron un análisis de varianza (ANOVA) de dos vías.

Los autores encontraron que, la diferencia media entre los tiempos de la prueba de la natación fue de $15.1 \pm 4.4 \%$; para la prueba de ciclismo fue $19.6 \pm 1.4 \%$; para la prueba de carrera fue de $19.8 \pm 3.7 \%$; y para la prueba global de off-road triatlón fue $19.2 \pm 1.5 \%$.

\subsubsection{Influencia del género en el ritmo adoptado por triatletas de élite.}

El estudio de Le Meur et al., (2009) presenta un análisis de diferencias entre hombres y mujeres, de una prueba de triatlón olímpico (natación: $1.5 \mathrm{~km}$; ciclismo: 40 km; y carrera $10 \mathrm{~km}$ ) que se llevó a cabo en el circuito de los Juegos Olímpicos de Beijing 2008 a manera de test en el año 2007. Del total de participantes en la prueba (75 mujeres y 85 
hombres), el estudio solo tuvo en cuenta a 12 triatletas (6 mujeres y 6 hombres) de los equipos nacionales de Francia y Suiza. Aunque el objetivo principal del estudio no fue cuantificar el porcentaje de diferencia en el rendimiento deportivo entre los hombres y las mujeres, sino, comparar las estrategias utilizadas por los hombres y las mujeres en una prueba de Copa Mundial ITU de Triatlón, nos sirve como referencia ya que hace un análisis de las diferencias existentes en cada una de las pruebas y particularmente para nuestro estudio, en la prueba de la carrera $(10 \mathrm{~km})$.

Los autores encontraron en la prueba global del triatlón que la media de los tiempos de los triatletas participantes en el estudio fue de 125:43 $\pm 2: 07$ minutos para las mujeres y 111:05 1:08 minutos para los hombres. Se halló una diferencia estadísticamente significativa entre hombres y mujeres en la prueba específica de la carrera $(10 \mathrm{~km})$, siendo esta diferencia superior a los 5 minutos, donde la media del tiempo para las mujeres fue de

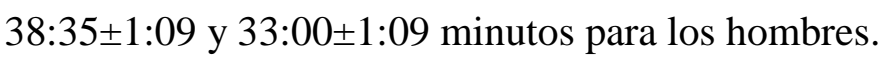

Posteriormente, en el año 2011 los mismos autores revelaron que en el informe que se publicó en la revista European Journal of Applied Physiology en el año 2009, había una errata en el número de participantes, corrigiendo de un total de 12 participantes a 9 participantes ( 3 mujeres y 6 hombres) (Le Meur, Hausswirth, Dorel, Bignet, Brisswalter, \& Bernard, 2011). Después de revisar, pudimos comprobar que esta errata no afectaba y no hizo falta realizar ninguna corrección a los valores que nos interesan para el presente estudio.

\subsubsection{Diferencias relativas al género en la pruebas del Ironman de Hawái.}

La prueba del Iron man de Hawái que consiste en $3.8 \mathrm{~km}$ nadando, $180 \mathrm{~km}$ en bicicleta y $42,195 \mathrm{~km}$ de carrera, fue analizada por Lepers (2008), con el objetivo de analizar las diferencias relativas al género en cada una de las disciplinas que conforman la prueba en el periodo del año 1981 al año 2007. Para este análisis se tuvieron en cuenta los tiempos de los 10 primeros clasificados de cada año tanto en la categoría femenina como en la masculina. El autor utilizó una regresión lineal de forma $(y=a x+b)$ y calculó los porcentajes de diferencia para cada una de las disciplinas, para el global de la prueba y la diferencia en porcentaje del ganador y el decimo clasificado. 
Según el estudio, la diferencia media del rendimiento deportivo entre hombres y mujeres, teniendo en cuenta la media de los 10 mejores triatletas de cada año, para las pruebas de natación, ciclismo, carrera y la media total de la prueba fue de 9.8\% $\pm 2.9,12.7 \% \pm 2.0$, $13.3 \% \pm 3.1$ y $12.6 \% \pm 1.3$ respectivamente.

La diferencia media entre el primer y el décimo clasificado de la prueba fue de $4.8 \pm 1.3 \%$ (25 \pm 7 minutos) para hombres y $7.1 \pm 2.3 \%$ (42 \pm 14 minutos) para las mujeres.

Uno de los datos interesantes del estudio, es que la diferencia entre hombres y mujeres en el periodo comprendido entre el año 1988 y 2007 se mantuvo estable y prácticamente idéntica para la natación $(+0.1 \%$ por década), incrementándose un poco en el tramo de ciclismo $(+0.8 \%$ por década) y disminuyendo más claramente en el tramo de la carrera ($2.8 \%$ por década).

\subsubsection{8. ¿Las diferencias de género en el desempeño deportivo desaparecen con la distancia?}

El estudio de Coast et al., ( 2004) es un estudio que tenía por objetivo validar una hipótesis existente en la época, que consistía en que a medida que aumentaba la distancia de la carrera, disminuía la diferencia en tiempo entre hombres y mujeres especialmente en eventos que comprendían distancias mayores de la maratón. Por esa misma razón utilizaron las mejores marcas a nivel mundial de aproximadamente 25 años, de las pruebas de 100, 200, 400, 800 y 1500 metros; 5, 10, 50, 100 y 200 kilómetros; y las pruebas de la media maratón, maratón, 50 y 100 millas, publicadas por la IAAF y la Amateur Athletic Federation.

Los resultados encontrados en el estudio fueron que en términos de la diferencia media en la velocidad (resultados) los hombres eran un $12.4 \%$ más rápidos que las mujeres. Pero, los datos desglosados en el estudio de las pruebas analizadas, muestran que en la prueba de 100 metros se encontró una diferencia de 7.2\%, en la prueba de la maratón de 9.3\%; en la prueba de los 5000 metros fue del 15.2\%; en la prueba de las 50 millas fue del 17\%; en la prueba de las 100 millas fue del $14 \%$ y en la prueba de los $200 \mathrm{~km}$ fue del $19.1 \%$, siendo los hombres siempre más rápidos que las mujeres.

Con los resultados encontrados, los autores determinan que existe un rango del $7-19 \%$ en los resultados entre hombres y mujeres en las pruebas analizadas y sugieren que a medida 
que aumentan las distancias, aumenta la diferencia en el rendimiento deportivo entre hombres y mujeres.

\subsubsection{Diferencia de género en los eventos de carrera del atletismo.}

En el estudio de Sparling et al., (1998) uno de los objetivos era determinar si la diferencia de género en eventos de carrera estaba completamente estabilizada. Se analizaron las pruebas de los 1500 metros y la prueba de la maratón $(42 \mathrm{~km})$ llevadas a cabo en el periodo comprendido entre el año 1980 al año 1996, utilizando los resultados de los "World best" y los resultados de los 100 mejores clasificados para cada prueba, durante cada año. El cálculo del porcentaje en la diferencia de género, se encontró hallando la diferencia de los "World best" de cada año, aplicando la siguiente fórmula:

$$
\% \text { diferencia }=\frac{W R h-W R m}{W R m} * 100
$$

Donde $W R h$ es World best hombre y $W R m$ es World best mujeres. Los resultados obtenidos para la prueba de 1500 metros, después de aplicar la fórmula señalaron que los hombres de media son un $11.1 \pm 1.1 \%$ más rápidos que las mujeres durante los 17 años analizados. Para la prueba de maratón $(42 \mathrm{~km})$ se estableció que los hombre de media son un $11.2 \pm 0.9 \%$ más rápidos que las mujeres.

En este mismo estudio se ajustaron líneas rectas a los resultados (regresión lineal), para establecer si los resultados de hombres y mujeres en las pruebas de 1500 metros y maratón se mantenían constantes y la diferencia de igual manera era constante. Para la prueba de los 1500 metros, se pudo establecer que los resultados y la diferencia entre hombres y mujeres se mantuvieron constantes a través de los años en el periodo de tiempo analizado. Para la prueba de la maratón, establecieron que la diferencia en los resultados y en la diferencia entre hombres y mujeres en el periodo comprendido entre el año 1980 y 1988 fue significativamente mayor, a partir del año 1988 hasta el año 1996 se mantuvo contante y no sufrió variaciones significativas. 


\subsubsection{Planteamiento del problema}

Después de analizar y explicar las razones, el alcance y las consecuencias de las medidas cautelares del caso de la atleta Dutee Chand (ver apartado 1.3) emitida el 24 de julio de 2015 por el TAS, quedan varias cuestiones por resolver.

El TAS en las cuestiones finales de estas medidas cautelares, insta a la IAAF en un plazo no mayor de dos años a presentar evidencias científicas e informes de expertos que puedan avalar el porcentaje de diferencia del rendimiento deportivo existente entre las mujeres con y sin hiperandrogenismo.

Para el desarrollo de esta tesis doctoral, se recogió esta cuestión y se plantearon los objetivos descritos en el apartado 2. Para poder llegar a la pregunta planteada por el TAS a la comunidad científica y en especial a la IAAF, debíamos estudiar en primer lugar el porcentaje de diferencia existente entre hombres y mujeres en el atletismo de élite. Se debe abordar primero esta cuestión en el estudio ya que como se expuso anteriormente, la evidencia aportada por parte del experto de la IAAF, el Dr. Bermon al tribunal, no era avalada por un estudio riguroso, ni publicado en una revista científica. De igual manera, en el parágrafo 526 de las medidas cautelares, se cita una diferencia del 10\% del rendimiento deportivo entre hombres y mujeres por los expertos de la IAAF el Dr. Ritzen y la Dra. Hirschberg. En correspondencia del autor de esta tesis doctoral con la Dra. Hirschberg el día 13 de junio de 2016, se pudo comprobar que esta diferencia fue obtenida utilizando los tiempos de los ganadores, poniendo como ejemplo en la correspondencia los tiempos de los ganadores de las medallas de oro en las pruebas de atletismo de los Juegos Olímpicos de Londres 2012, lo que tampoco estaba respaldado por una publicación científica.

Aunque el TAS en el auto del caso Dutee Chand aceptara los porcentajes de diferencia del rendimiento deportivo entre hombres y mujeres en el atletismo de élite presentados por los expertos que dieron testimonio oral y escrito por parte de la IAAF, consideramos que para llegar a la segunda cuestión del presente estudio debíamos analizar las diferencias en el rendimiento deportivo entre hombres y mujeres de una manera más detallada y rigurosa.

La segunda cuestión del TAS a la comunidad científica y en especial a la IAAF, era que el porcentaje de la diferencia deportiva del $3 \%$ entre mujeres con y sin hiperandrogenismo, presentada por el Dr. Bermon en su informe al tribunal del caso Dutee Chand, es 
significativamente menor que el porcentaje del 10-12\% que se aceptó por parte del tribunal en la diferencia deportiva entre hombres y mujeres en el atletismo de élite.

Entonces, planteadas las cuestiones anteriores, se estableció que desde las ciencias del deporte solo se puede dar respuesta a estas preguntas utilizando datos directamente proporcionados por el deporte, como son los resultados deportivos, dejando de lado los aspectos médicos y fisiológicos de la cuestión. 

2. HIPÓTESIS Y OBJETIVOS 



\section{HIPÓTESIS Y OBJETIVOS}

\subsection{Hipótesis}

La inelegibilidad de las mujeres con hiperandrogenismo para las competiciones femeninas de atletismo de élite solo se justifica, según el Tribunal de Arbitraje Deportivo, si el rendimiento deportivo de estas atletas es equiparable al de los atletas masculinos.

Las mujeres con hiperandrogenismo no tienen un rendimiento deportivo en las competiciones de atletismo de élite equiparable al que tienen los hombres en comparación con el resto de mujeres. Por tanto, la normativa de hiperandrogenismo de la IAAF no tiene una justificación razonable.

\subsection{Objetivo General}

Verificar sí está justificada la normativa de inelegibilidad de las deportistas con hiperandrogenismo de la IAAF desde la perspectiva de los resultados deportivos en el atletismo de élite.

\subsection{Objetivos Específicos}

2.3.1. Comprobar que existe una diferencia del rendimiento deportivo del orden del 10 $12 \%$ entre hombre y mujeres desde el punto de vista de los resultados deportivos en el atletismo de élite.

2.3.2. Estudiar la diferencia de rendimiento deportivo entre mujeres con y sin hiperandrogenismo desde el punto de vista de los resultados deportivos en el atletismo de élite, para verificar si las deportistas con hiperandrogenismo consiguen un rendimiento del $10-12 \%$ superior al de las mujeres sin hiperandrogenismo. 

3. MÉTODO 



\section{Método}

El deporte del atletismo es regulado internacionalmente por la Asociación Internacional de Federaciones de Atletismo (IAAF) que tiene catalogada cada una de las pruebas en 4 categorías diferentes, que a su vez se dividen en 15 sub-categorías:

Categoría 1 - Carreras: i) velocidad; ii) media distancia; iii) larga distancia; iv) vallas y obstáculos; v) marcha; vi) relevos.

Categoría 2 - Saltos: i) longitud; ii) triple salto; iii) altura; iv) con pértiga.

Categoría 3 - Lanzamientos: i) peso; ii) jabalina; iii) disco; iv) martillo.

Categoría 4 - Pruebas Combinadas: i) decatlón / heptatlón.

Los criterios elegidos para que cada una de las 30 pruebas del atletismo reguladas por la IAAF a fecha 1 de agosto de 2016, entrara a ser parte del análisis empírico de la tesis doctoral fueron los siguientes:

\subsection{Inclusión y exclusión de eventos deportivos}

\subsubsection{Criterios de inclusión:}

- La prueba debe haberse llevado a cabo en las ediciones del Campeonato Mundial de Atletismo desde el año 1983 hasta el año 2015 y en las ediciones de los Juegos Olímpicos de verano desde 1984 hasta 2016.

- La prueba debe haberse realizado en categoría masculina y femenina.

- La prueba debe ser directamente comparable y no pueden existir diferencias en los elementos utilizados y en las distancias recorridas.

\subsubsection{Criterios de exclusión:}

- La prueba no se llevó a cabo en los Campeonatos Mundiales de Atletismo desde 1983 o en los Juegos Olímpicos de verano desde 1984.

- La prueba solo se realizó en la categoría femenina o en la categoría masculina. 
- La prueba no es directamente comparable y existen diferencias en los elementos utilizados y en las distancias recorridas.

\subsubsection{Criterios de excepción:}

- La prueba se llevó a cabo en el Campeonato del Mundo de Atletismo y en los Juegos Olímpicos de verano, pero al haber pruebas que han sido implementadas a posteriori para la categoría femenina y no al mismo tiempo en los Campeonatos del Mundo de Atletismo y en los Juegos Olímpicos estas pruebas específicas se analizaran desde el año en que existan datos para los dos eventos en las dos categorías analizadas.

\subsection{Pruebas seleccionadas}

Después de aplicar los criterios de inclusión, los criterios de exclusión y los criterios de excepción, de las 30 pruebas se seleccionaron 13 (ver tabla 5).

Como se explicó anteriormente, para realizar el análisis del porcentaje de diferencia en el rendimiento deportivo entre hombre y mujeres, se tienen en cuenta las 13 pruebas seleccionadas para el estudio ya que se llevan a cabo en los Campeonatos del Mundo de Atletismo desde el año 1983 hasta el año 2015 y en los Juegos Olímpicos de Verano desde el año 1984 hasta el año 2016. Para poder realizar la comparación de las deportistas que han estado bajo investigación por la Normativa de hiperandrogenismo de la IAAF o porque hayan sido sospechosas de tener valores de andrógenos por encima de los valores permitidos, se tuvieron en cuenta datos de la prueba de 800 metros femenino en la Liga Diamante (IAAF Diamond League) de la reunión de Mónaco 2016. En este evento tuvo un rendimiento destacado la atleta Caster Semenya, que, tal y como se explicó en el apartado 1.2.6, estuvo bajo investigación y suspendida por la IAAF para competir. Por último, también se tuvieron en cuenta los resultados de las finales de la prueba de 200 metros del 16th Asian Junior Athletics 2014; 53rd Open National Athletcis Championship 2013 y 20th Asian Athletics Championship 2013. En estos eventos tuvo un rendimiento destacado la atleta Dutee Chand, quien es la que impugna ante el TAS la normativa de hiperandrogenismo de la IAAF. 
Tabla 5. Pruebas del Atletismo reguladas por la IAAF y pruebas incluidas en el estudio. (Elaboración propia).

\begin{tabular}{|c|c|c|c|c|c|}
\hline Prueba & Hombres & Mujeres & Diferencias & Observación & Estudio \\
\hline $100 \mathrm{~m}$ & $X$ & $\mathrm{X}$ & No & & $\mathrm{Si}$ \\
\hline $200 \mathrm{~m}$ & $X$ & $X$ & No & & $\mathrm{Si}$ \\
\hline $400 \mathrm{~m}$ & $X$ & $X$ & No & & $\mathrm{Si}$ \\
\hline $800 \mathrm{~m}$ & $X$ & $X$ & No & & $\mathrm{Si}$ \\
\hline $1500 \mathrm{~m}$ & $X$ & $X$ & No & & $\mathrm{Si}$ \\
\hline $5000 \mathrm{~m}$ & $\mathrm{X}$ & $\mathrm{X}$ & No & $\begin{array}{l}\text { En mujeres se realiza esta prueba en JJOO desde el año } \\
1996 .\end{array}$ & $\mathrm{Si}$ \\
\hline $10000 \mathrm{~m}$ & $\mathrm{X}$ & $\mathrm{X}$ & No & $\begin{array}{c}\text { En mujeres se realiza esta prueba en JJOO desde el año } \\
1988\end{array}$ & $\mathrm{Si}$ \\
\hline $\begin{array}{c}\text { 3000m } \\
\text { Obstáculos }\end{array}$ & $\mathrm{X}$ & $\mathrm{X}$ & $\mathrm{Si}$ & $\begin{array}{l}\text { Los obstáculos en la categoría masculina tienen una altura } \\
\text { de } 91.4 \mathrm{~cm} \text { y en la categoría femenina } 76.2 \mathrm{~cm} \text {. }\end{array}$ & No \\
\hline $\begin{array}{l}100 \mathrm{~m} \\
\text { Vallas }\end{array}$ & & $X$ & $\mathrm{Si}$ & & No \\
\hline $\begin{array}{l}110 m \\
\text { Vallas }\end{array}$ & $\mathrm{X}$ & & $\mathrm{Si}$ & & No \\
\hline $\begin{array}{l}400 \mathrm{~m} \\
\text { Vallas }\end{array}$ & $\mathrm{X}$ & $\mathrm{X}$ & $\mathrm{Si}$ & $\begin{array}{l}\text { Las vallas en la categoría masculina tienen una altura de } \\
\qquad 91.4 \mathrm{~cm} \text { y en la categoría femenina } 76.2 \mathrm{~cm} \text {. }\end{array}$ & No \\
\hline $\begin{array}{l}\text { Salto de } \\
\text { Altura }\end{array}$ & $\mathrm{X}$ & $X$ & No & & $\mathrm{Si}$ \\
\hline $\begin{array}{l}\text { Salto con } \\
\text { Pértiga }\end{array}$ & $\mathrm{X}$ & $\mathrm{X}$ & $\mathrm{Si}$ & $\begin{array}{l}\text { La prueba en mujeres se realizó por primera vez en los } \\
\text { JJOO de Sídney } 2000 \text { y se considera que aún no ha } \\
\text { alcanzado la madurez suficiente en la categoría } \\
\text { femenina como para ser objeto de una comparación } \\
\text { real con la categoría masculina. }\end{array}$ & No \\
\hline $\begin{array}{l}\text { Salto de } \\
\text { Longitud }\end{array}$ & $X$ & $X$ & No & & $\mathrm{Si}$ \\
\hline Triple salto & $\mathrm{X}$ & $X$ & No & $\begin{array}{c}\text { En mujeres se realiza esta prueba en JJOO desde el año } \\
\text { 1996. En campeonatos del mundo se realizó por } \\
\text { primera vez en } 1993 .\end{array}$ & $\mathrm{Si}$ \\
\hline $\begin{array}{l}\text { Lanzamiento } \\
\text { de Peso }\end{array}$ & $X$ & $\mathrm{X}$ & $\mathrm{Si}$ & $\begin{array}{l}\text { El peso de la bala para la categoría masculina es de } \\
7.26 \mathrm{kgy} \text { para la categoría femenina es de } 4 \mathrm{~kg} / 8.8 \mathrm{lb} \text {. }\end{array}$ & No \\
\hline $\begin{array}{l}\text { Lanzamiento } \\
\text { de Disco }\end{array}$ & $\mathrm{X}$ & $X$ & $\mathrm{Si}$ & $\begin{array}{c}\text { El peso del disco para la categoría masculina es de } 2 \mathrm{~kg} \text {, } \\
\text { con un diámetro de } 22 \mathrm{~cm} \text { y para la categoría } \\
\text { femenina es de } 1 \mathrm{~kg} \text {, con un diámetro de } 18 \mathrm{~cm} \text {. }\end{array}$ & No \\
\hline $\begin{array}{l}\text { Lanzamiento } \\
\text { de Martillo }\end{array}$ & $X$ & $\mathrm{X}$ & $\mathrm{Si}$ & $\begin{array}{l}\text { El peso del martillo para la categoría masculina es de } \\
7.26 \mathrm{kgy} \text { para la categoría femenina es de } 4 \mathrm{~kg} / 8.8 \mathrm{lb} \text {. }\end{array}$ & No \\
\hline $\begin{array}{l}\text { Lanzamiento } \\
\text { de Jabalina }\end{array}$ & $\mathrm{X}$ & $\mathrm{X}$ & $\mathrm{Si}$ & $\begin{array}{c}\text { La jabalina en la categoría masculina debe pesar como } \\
\text { mínimo } 800 \text { gramos y debe tener una longitud entre } \\
2.6 \text { y } 2.7 \text { metros. La jabalina en la categoría } \\
\text { femenina debe pesar } 600 \text { gramos y debe tener una } \\
\text { longitud entre } 2.2 \text { y } 2.3 \text { metros. }\end{array}$ & No \\
\hline Heptathlon & & $X$ & & & No \\
\hline Maratón & $X$ & $X$ & $\mathrm{NO}$ & & $\mathrm{Si}$ \\
\hline Decathlon & $X$ & & & & No \\
\hline $\begin{array}{l}20 \mathrm{Km} \\
\text { Marcha }\end{array}$ & $\mathrm{X}$ & $X$ & No & $\begin{array}{c}\text { La prueba en mujeres se realizó por primera vez en JJOO } \\
\text { de Barcelona 1992, pero solo } 10 \mathrm{~km} \text {. Los } 20 \mathrm{~km} \text { al } \\
\text { igual que los hombres, se realizó por primera vez en } \\
\text { Sídney } 2000\end{array}$ & No \\
\hline $\begin{array}{l}50 \mathrm{Km} \\
\text { marcha }\end{array}$ & $\mathrm{X}$ & & & & No \\
\hline $4 \times 100 m$ & $\mathrm{X}$ & $\mathrm{X}$ & No & & $\mathrm{Si}$ \\
\hline $4 \times 400 m$ & $\mathrm{X}$ & $\mathrm{X}$ & No & & $\mathrm{Si}$ \\
\hline Cross & $X$ & $X$ & & No es una prueba de Campeonato del mundo, ni de JJOO & No \\
\hline Ultra Running & $\mathrm{X}$ & $\mathrm{X}$ & & No es una prueba de Campeonato del mundo, ni de JJOO & No \\
\hline $\begin{array}{c}\text { Carreras de } \\
\text { montaña }\end{array}$ & $\mathrm{X}$ & $\mathrm{X}$ & & No es una prueba de Campeonato del mundo, ni de JJOO & No \\
\hline
\end{tabular}




\subsection{Diseño de investigación utilizado.}

En el diseño de la presente investigación, los datos se encuentran almacenados en las bases de datos de los eventos analizados, tal como se describe en el apartado 3.4. Por tanto, el presente estudio es una investigación de tipo cuantitativo de diseño retrospectivo, lo que "determina relaciones entre variables que se presentan en hechos ya ocurridos, sin deducir relaciones causales" (Lerma González, 2012, pág. 64).

En el diseño de investigación retrospectiva se utilizan dos variables (dependiente e independiente). En este estudio estas dos variables fueron: la variable dependiente " $Y$ ", correspondiente al resultado de la prueba analizada; y la variable independiente " $X$ ", correspondiente al ranking del atleta en la prueba estudiada.

\subsection{Recopilación de los datos}

Para el análisis de los datos se tuvieron en cuenta todos los resultados de las finales de las pruebas seleccionadas para el estudio. En total, de los eventos seleccionados, se obtuvieron los datos de 15 ediciones del Campeonato del Mundo de Atletismo, 9 ediciones de los Juegos Olímpicos de verano, 1 evento de la Liga Diamante y 3 eventos de la Asociación Asiática de Atletismo.

Los resultados de las finales de los Campeonatos del Mundo de Atletismo se obtuvieron de la página web oficial de la IAAF (International Association of Athletics Federations, 2016), en su sección de resultados y fueron corroborados con el libro oficial de resultados del campeonato del mundo de atletismo 2015 (Butler, 2015) que contiene todos los resultados históricos de los Campeonatos del Mundo de Atletismo desde el año 1983.

Los resultados de los Juegos Olímpicos de verano se obtuvieron de la página web oficial del COI (International Olympic Committee, 2016) en su sección de resultados. Los resultados de la Liga Diamante 2016 se obtuvieron de la página web de la IAAF (International Association of Athletics Federations, 2016) su sección de resultados. Los resultados del evento 20th Asian Athletics Championship 2013 (Asian Athletics Association, 2013) y 16th Asian Junior Athletics 2014 (Asian Athletics Association, 2014) 
se obtuvieron de la página web de la Asociación Asiática de Atletismo en su sección de resultados. Los resultados del 53rd Open National Athletcis Championship 2013 se obtuvieron de la página web de la Federación de Atletismo de la India (Athletics Federation of India, 2013).

\subsection{Análisis de los datos}

Todos los datos obtenidos de los 24 eventos analizados, se volcaron a una base de datos macro. La base de datos fue creada en el programa Excel para Microsoft Office Professional Plus 2007. No todas las pruebas analizadas tenían el mismo número de participantes. Para el análisis matemático se adecuó el número de participantes en cada una de las pruebas, quedando en igual número de participantes en todos los eventos estudiados (ver tabla 6). Para los eventos que tenían menor número de participantes en cada prueba, se utilizó como resultado 0.00 en las posiciones faltantes, hasta completar el número adecuado. Para los eventos con mayor número de participantes en cada prueba, se tuvieron en cuenta los resultados hasta el número de participantes establecido para cada una de las pruebas. El resultado de los atletas que fueron descalificados, no terminaron la prueba o no empezaron la prueba, era 0.00. Es importante señalar que los resultados 0.00 utilizados, no afectan al resultado de ninguno de los parámetros calculados, ya que en el momento del cálculo solo se tenían en cuenta los resultados diferentes a 0.00 y se dividía por el total de resultados que fueran diferentes a 0.00 . 
Tabla 6. Número total de resultados deportivos analizados. $N=$ número de atletas para cada evento (masculino y femenino). NA= número de atletas (resultados) total que se utilizó para el análisis.

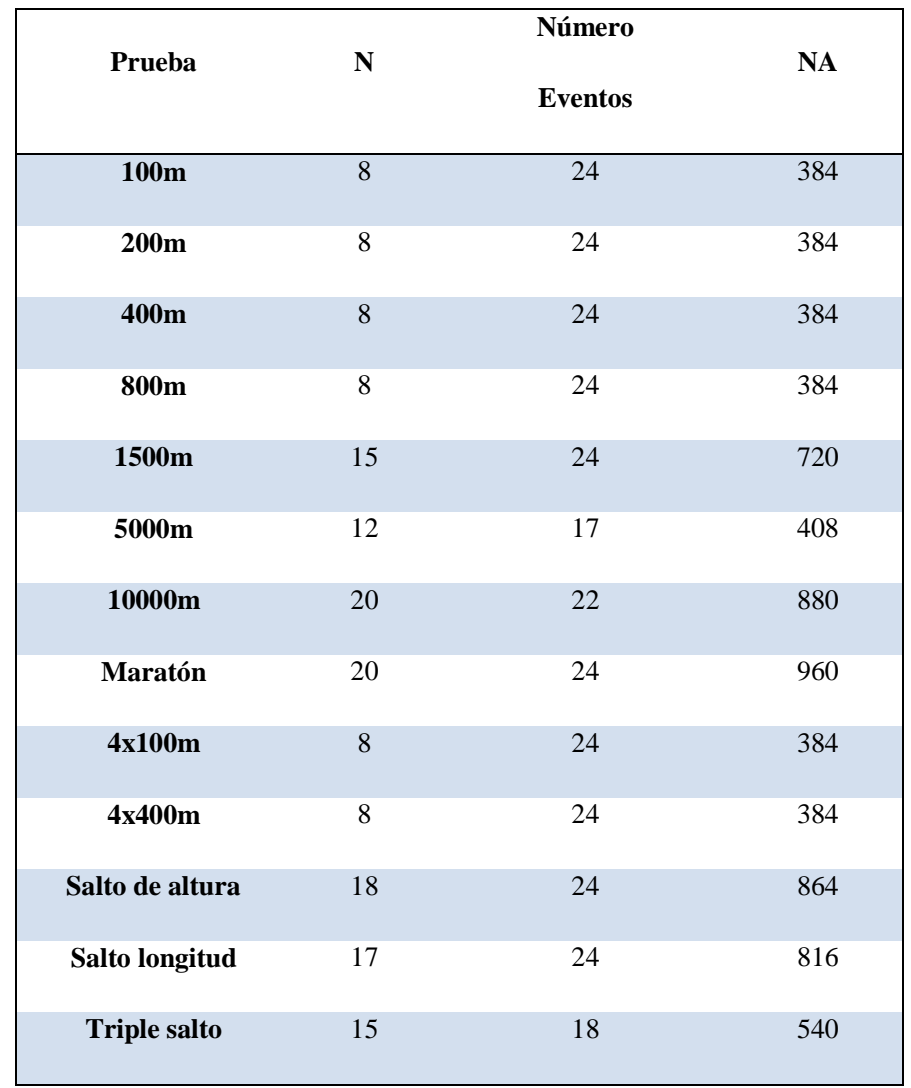

Después de realizar la adecuación de cada una de las pruebas, se crearon archivos para cada una de ellas (masculina y femenina) por separado, con el editor de texto Bloc de Notas para Microsoft Office Professional Plus 2007, para poder ser leídos por el software matemático Matlab R2016a. El formato de los resultados oficiales ha sido modificado, para poder ser analizado por el software utilizado; un ejemplo de esto es: el tiempo de Caster Semenya en la prueba de 800 metros en el Campeonato Mundial de Atletismo del 2009 fue 1:55.45 minutos, siendo este el formato utilizado en la página oficial de resultados de la IAAF. Para nuestro análisis, este resultado fue modificado a formato número con cifras decimales, obteniendo el resultado de 1,9242 minutos.

Para el análisis matemático se utilizó el programa Matlab versión R2016a para Microsoft. Para encontrar una curva que fuera característica para cada una de las pruebas se aplicó el método de ajuste de curvas de mínimos cuadrados no lineales. Este método se basa en que la dependencia entre dos variables ( $\mathrm{X}$ y “ $Y$ ”) puede ser tal que exista una relación 
funcional (matemática) exacta (como la existente entre la velocidad (=" $Y$ ”) y la distancia recorrida por un móvil (=“ $X$ ”). Pero esta dependencia puede también ser estadística. La dependencia estadística es un tipo de relación entre variables tal que, conocidos los valores de la variable independiente " $X$ ", no puede determinarse con exactitud el valor de la variable dependiente " $Y$ ”, aunque sí se puede llegar a determinar un cierto comportamiento (global) de la misma.

La finalidad última de la regresión (regresión= análisis de la dependencia estadística) es llegar a poder asignar el valor que toma la variable " $Y$ ” (dentro de los rangos de confianza del análisis estadístico) si se conoce el valor de la variable " $X$ ”.

Suponiendo una tendencia funcional entre las dos variables, se ajusta una curva (función) a los datos $\left(\mathrm{X}_{\mathrm{i}}, \mathrm{Y}_{\mathrm{i}}\right)$. La relación analítica (funcional) que mejor se ajusta al conjunto de los datos se halla por una técnica de optimización matemática llamada método de cuadrados mínimos. El ajuste de una curva (función) por este método de mínimos cuadrados se basa en la minimización del error cuadrático medio. Este criterio es una medida de la desviación total de los valores de la variable dependiente " $Y$ " (dados como datos) respecto a los valores calculados de Y por la curva ajustada. Su valor es la suma de la media de las diferencias cuadradas entre estos dos valores (Burden \& Douglas Faires, 2005, pág. 482), (Chapra \& Canale, 2010, pág. 481).

En el presente estudio, la variable " $Y$ " fue la variable dependiente del resultado de la prueba, expresada en formato tiempo en las pruebas de velocidad, media distancia, carrera y relevos; y distancia en las pruebas de salto. La variable " $X$ ” fue la variable independiente del ranking del atleta en la prueba (para la primera posición $X=1$; segunda posición $X=2$; etc.)

Se ajustaron funciones de forma diferente (lineal, de potencia, exponencial, logarítmicas), a las variables " $X$ ” y " $Y$ " para cada una de las pruebas seleccionadas y se eligió la función exponencial, que fue la que mejor se ajustaba a los datos, de acuerdo con el criterio de mínimo error cuadrático.

La curva exponencial que se eligió tiene la siguiente forma:

$$
\boldsymbol{Y}=\boldsymbol{a}+\boldsymbol{b} \boldsymbol{e}^{\boldsymbol{c X}}(\text { Ecuación 1) }
$$

donde los parámetros $a, b$ y $c$ fueron los parámetros de ajuste. 
Para estudiar el buen ajuste de cada curva, se calculó el coeficiente de determinación $R^{2}$ en combinación con el parámetro estadístico $F$, de la prueba de Fisher. El valor de $R^{2}$ oscila entre 0 y 1 , siendo 1 el valor que representa un mejor ajuste entre los valores de la variable dependiente " $Y$ " y los valores de " $Y$ " calculados por la curva ajustada.

Además, para cada uno de los ajustes se calcularon los intervalos de confianza del 95\%, y el valor estadístico $t$ de student con sus correspondientes $p$-valores a los datos linealizados, para confirmar la hipótesis que los valores encontrados de los tres parámetros $(a, b$ y $c)$ de la curva son adecuados y diferentes a 0 .

Por último se calculó el porcentaje de diferencia ( \pm desviación estándar) existente en cada una de las pruebas entre hombres y mujeres, dividiendo por el resultado de los hombres y también por el resultados de las mujeres, utilizando: i) el parámetro " $a$ " de ajuste de la curva encontrado para cada categoría (masculino - femenino) en cada una de las pruebas; ii) la media de los tiempos de los ganadores de cada evento en las pruebas seleccionadas; y iii) la diferencia de la media de los resultados totales de cada una de las pruebas.

Con el fin de estudiar el rendimiento deportivo de algunas atletas que han estado bajo investigación y suspendidas temporalmente por la normativa de hiperandrogenismo de la IAAF (Caster Semenya y Dutee Chand) en la prueba de 800 metros y en la prueba de 200 metros, hemos analizado con detalle las pruebas en las cuales han participado y han estado dentro de las primeras 8 posiciones de la prueba. Estas pruebas son: i) prueba de 800 metros del Campeonato del Mundo de Atletismo 2009; ii) prueba de 800 metros del Campeonato del Mundo de Atletismo 2011; iii) prueba de 800 metros de los Juegos Olímpicos de Londres 2012; iv) prueba de 800 metros de los Juegos Olímpicos de Rio 2016; v) prueba de 800 metros de la Liga Diamante Mónaco 2016; vi) prueba de 200 metros del 20th Asian Athletics Championship, Pune - India, 2013; vii) prueba de 200 metros del 53rd Open National Championship, Calcuta - India, 2013; y viii) prueba de 200 metros del 16th Asian Junior Athletics Championship, Taipei - China, 2014.

Para las pruebas de 200 y 800 metros mencionadas anteriormente, se encontraron sus curvas características junto con las curvas correspondientes a los rangos de confianza del 95\% y del $99 \%$. Se calcularon las diferencias entre el resultado de la atleta y el resultado correspondiente dado por la curva característica y las curvas de los rangos del 95 y $99 \%$ de confianza, solo cuando el resultado de la atleta se encontraba por fuera del rango del $99 \%$. 


\subsection{Justificación del análisis Matemático}

En el presente estudio hemos ajustado una curva a los datos de todos los resultados deportivos de las pruebas del atletismo seleccionadas desde el año 1983 para los Campeonatos del Mundo de Atletismo hasta el año 2015 y desde el año 1984 para los Juegos Olímpicos hasta el año 2016, para calcular la diferencia en porcentaje del rendimiento deportivo entre hombres y mujeres.

Para las pruebas de velocidad y relevos, no fue necesario descartar resultados deportivos, ya que se analizaron los datos de todos los participantes (8) en la final de cada prueba. En las demás pruebas, con el fin de adecuar los datos se eligió un número máximo de resultados, aunque algún evento analizado de la prueba tuviera mayor número de participantes. Este procedimiento se repite en los estudios de (Rüst et al., 2015; Etter et al., 2013; Lepers \& Stapley, 2010; (Le Meuret al., 2009; Lepers, 2008; Coast, Blevins, \& Wilson, 2004; y Sparling, O'Donnell, \& Snow, 1998), donde se eligen los 5 o los 10 mejores clasificados de todas las pruebas estudiadas. Es importante señalar que, en el presente estudio, se intentó tener en cuenta el mayor número posible de los resultados de las pruebas finales, de los eventos analizados para contar con la máxima información de la prueba.

Después de comprobar diferentes ajustes de curvas, elegimos la curva exponencial por el buen ajuste que esta curva presentaba a todos los conjuntos de datos, en comparación con otros estudios que utilizaron ajuste de líneas rectas, por ejemplo los publicados por (Lepers \& Stapley, 2010; y Sparling, O'Donnell, \& Snow, 1998). Observamos que la curva exponencial elegida seguía la tendencia de todos los datos para cada una de las pruebas analizadas, tanto para los hombres como para las mujeres. Hecho que se puede comprobar en los resultados que expondremos a continuación y que avalan la elección de la técnica matemática utilizada.

Por tanto, se ha alcanzado satisfactoriamente el cálculo de una curva característica que siga la tendencia de los resultados para cada prueba analizada de los Campeonatos del Mundo de Atletismo desde el año 1983 hasta el año 2015 y para los Juegos Olímpicos desde el año 1984 hasta el año 2016. 
Mediante un ajuste de curvas a los datos disponibles se ha encontrado que la tendencia de las pruebas sigue una curva exponencial, en la que la variable independiente era el ranking de los participantes de la prueba y la variable dependiente eran sus resultados correspondientes. Utilizando esta curva característica encontrada para cada prueba, se ha podido: i) cuantificar los rangos y porcentajes del rendimiento deportivo, así como las diferencias existentes en el rendimiento deportivo entre hombres y mujeres o entre mujeres con hiperandrogenismo y mujeres sin hiperandrogenismo; y ii) predecir los resultados de cada posición en cualquier prueba, asumiendo que esta prueba sigue la tendencia de la curva característica

\subsection{Aprobación del Comité Ético}

El Comité de Ética de la Universidad Politécnica de Madrid, donde se realizó la mayor parte de la presente investigación, aprobó el presente estudio, dado que el estudio incluyó el análisis de datos públicamente disponibles (ver anexo I). 
4. RESULTADOS 



\section{Resultados.}

\subsection{Diferencias existentes entre hombres y mujeres.}

\subsubsection{Ajuste de curvas y cálculo de los parámetros.}

Después de ajustar curvas exponenciales a los datos de cada una de las pruebas y estudiar los valores correspondientes de $R^{2}$, de $t$ de student y de $F$, se ha encontrado que el valor óptimo respecto al ajuste del parámetro “ $c$ ” era constante para todas las pruebas, siendo $c=$ -0.05 con un rango del $95 \%$ de confianza entre [-0.05271, -0.04449$]$.

El valor del parámetro $b$ hallado para hombres y para mujeres en cada una de las pruebas era igual dentro de sus correspondientes rangos de confianza del 95\%, variando en todas las pruebas, a diferencia del parámetro "c" que se mantuvo constante en todas las pruebas. Por esta razón, la diferencia entre hombres y mujeres en cada prueba está reflejada en la diferencia de los valores del parámetro “ $a$ ” correspondiente. Entonces, las curvas ajustadas tienen la siguiente forma:

$$
\begin{gathered}
\boldsymbol{Y}=\boldsymbol{a}_{\boldsymbol{H}}+\boldsymbol{b} \boldsymbol{e}^{\boldsymbol{c X}} \text {, para la categoría masculina (Ecuación 2) } \\
\boldsymbol{Y}=\boldsymbol{a}_{\boldsymbol{M}}+\boldsymbol{b} \boldsymbol{e}^{\boldsymbol{c X}} \text {, para la categoría femenina (Ecuación 3) }
\end{gathered}
$$

Donde $a_{H}$ es el parámetro “ $a$ ” para hombres y $a_{M}$ es el parámetro “ $a$ ” para mujeres.

En la tabla 7 se presentan los valores encontrados de los parámetros " $a_{H}$ ", " $a_{M}$ " $y$ " $b$ ", para cada una de las pruebas.

Los valores de $p$ para la $t$ de student y $F$ para la prueba de Fisher, fueron $p<0.0001$ y $F<0.0001$ respectivamente, para los valores de parámetros encontrados que se presentan en la tabla 7 y para todas las pruebas estudiadas. 
Tabla 7. Parámetros encontrados para cada una de las pruebas, rangos de confianza del 95\%, unidades y valores de $R^{2}$.

\begin{tabular}{|c|c|c|c|c|c|c|c|c|c|}
\hline Prueba & $\mathbf{a}_{\mathbf{H}}$ & $\begin{array}{c}\text { Rango de } \\
\text { Confianza } \\
95 \% \text { de } a_{H}\end{array}$ & $\mathbf{a}_{M}$ & $\begin{array}{c}\text { Rango de } \\
\text { Confianza } \\
95 \% \text { de } a_{M}\end{array}$ & b & $\begin{array}{c}\text { Rango de } \\
\text { Confianza } 95 \% \\
\text { de } b\end{array}$ & $\begin{array}{l}\text { Unidades } \\
\mathbf{a}_{\mathrm{H}}, \mathbf{a}_{\mathrm{M}}, \mathbf{b}\end{array}$ & $R_{\mathrm{H}}^{2}$ & $\boldsymbol{R}_{\mathrm{M}}^{2}$ \\
\hline $100 \mathrm{~m}$ & 11.085 & $(11.07,11.09)$ & 12.078 & $(12.05,12.10)$ & -1.296 & $(-1.319,-1.28)$ & Segundos & 0.9947 & 0.9969 \\
\hline $200 \mathrm{~m}$ & 22.317 & $(22.24,22.38)$ & 24.529 & $(23.08,24.61)$ & -2.592 & $(-2.670,-2.579)$ & Segundos & 0.9946 & 0.987 \\
\hline $400 \mathrm{~m}$ & 48.937 & $(48.89,48.98$ & 54.311 & $(54.26,54,36)$ & -5.184 & $(-5.09,-5.23)$ & Segundos & 0.9945 & 0.9948 \\
\hline $800 \mathrm{~m}$ & 1.872 & $(1.86,1.89)$ & 2.092 & $(2.08,2,11)$ & -0.151 & $(-0.152,-0.144)$ & Minutos & 0.965 & 0.954 \\
\hline $1500 \mathrm{~m}$ & 3.779 & $(3.777,3.780)$ & 4.251 & $(4.242,4.259)$ & -0.216 & $(-0.23,-0.20)$ & Minutos & 0.817 & 0.892 \\
\hline $5000 \mathrm{~m}$ & 14.028 & $(13.93,14.12)$ & 15.710 & $(15.66,15.75)$ & -0.864 & $(-0.999,-0.738)$ & Minutos & 0.856 & 0.863 \\
\hline $10000 \mathrm{~m}$ & 29.606 & $(29.56,29.64)$ & 33.379 & $(33.25,33.43)$ & -2.592 & $(-2.687,-2.52)$ & Minutos & 0.662 & 0.783 \\
\hline Maratón & 2.360 & $(2.363,2.371)$ & 2.642 & $(2.635,2.647)$ & -0.192 & $(-0.2044,-0.1788)$ & Horas & 0.870 & 0.699 \\
\hline $4 \times 100 \mathrm{~m}$ & 41.080 & $(41.01,41.15)$ & 45.450 & $(45.37,45.53)$ & -3.382 & $(-3.475,-3.288)$ & Segundos & 0.987 & 0.993 \\
\hline $4 \times 400 \mathrm{~m}$ & 3.572 & $(3.561,3.584)$ & 3.969 & $(3.96,3.978)$ & -0.695 & $(-0.7029,-0.6866)$ & Minutos & 0.9949 & 0.9946 \\
\hline $\begin{array}{c}\text { Salto } \\
\text { Altura }\end{array}$ & 2.056 & $(2.053,2.059)$ & 1.694 & $(1.14,1.295)$ & 0.326 & $(0.3051,0.3465)$ & Metros & 0.994 & 0.964 \\
\hline $\begin{array}{c}\text { Salto } \\
\text { Longitud }\end{array}$ & 6.827 & $(6.813,6.839)$ & 5.444 & $(5.427,5.46)$ & 1.714 & $(1.696,1.731)$ & Metros & 0.999 & 0.9981 \\
\hline $\begin{array}{c}\text { Salto } \\
\text { Triple }\end{array}$ & 14.910 & $(14.87,14.92)$ & 12.210 & $(12.18,12.25)$ & 3.000 & $(2.957,3.023)$ & Metros & 0.9991 & 0.9984 \\
\hline
\end{tabular}

Utilizando los valores encontrados para los parámetros “ $a_{H}$ ”, “ $a_{M}$ ”, " $b$ ” $y$ “c” se ajustó la curva correspondiente a los datos de cada prueba. Esta curva la denominaremos "curva característica de la prueba”. El buen ajuste de estas curvas características a los datos de cada prueba, se refleja en la figura 3 (pruebas de velocidad); figura 4 (pruebas de relevos); figura 5 (pruebas de carrera de media y larga distancia); y figura 6 (pruebas de saltos). 

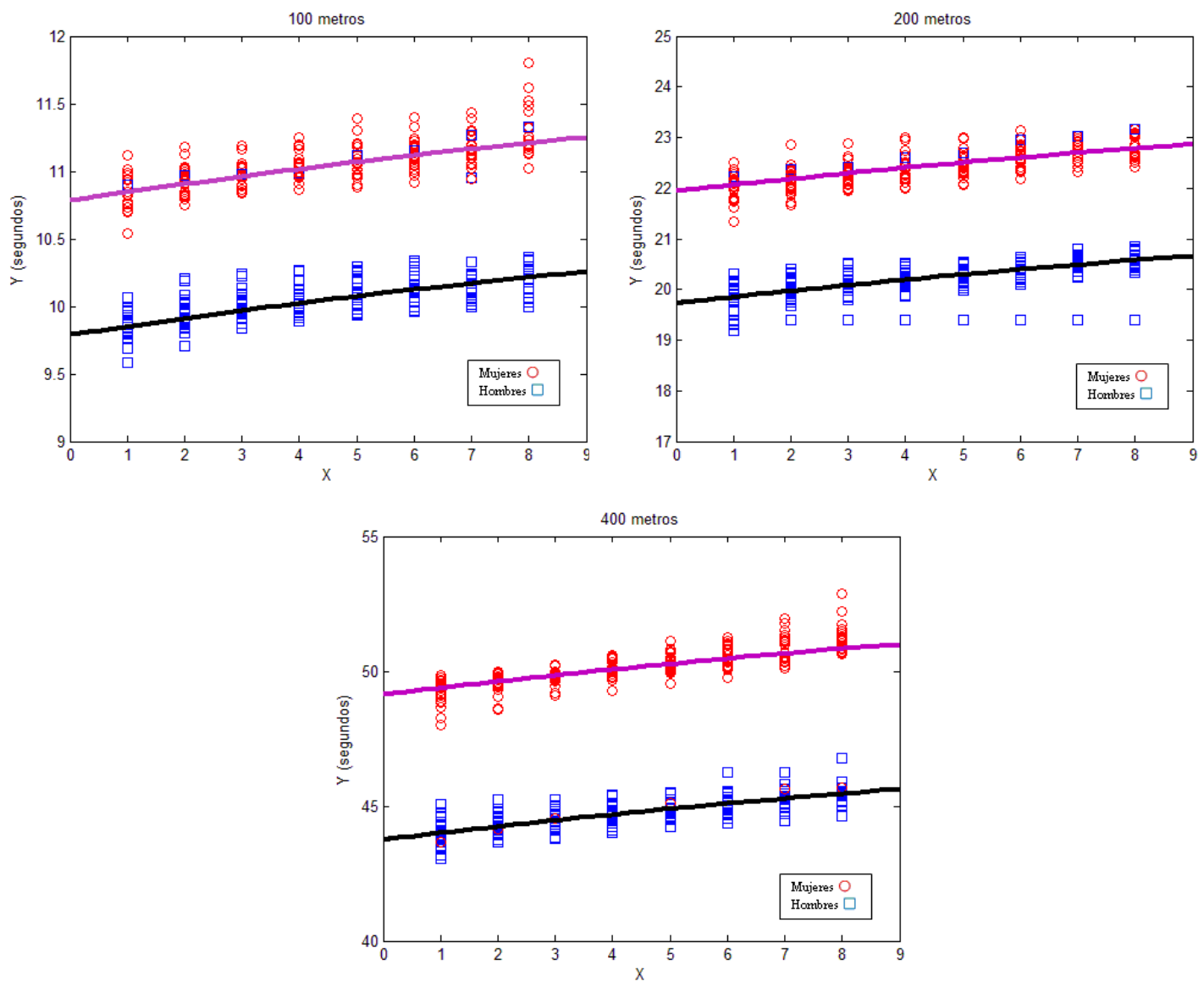

Figura 3. Curva característica para las pruebas de velocidad. Mundiales de Atletismo desde 1983 hasta 2015 y Juegos Olímpicos desde 1984 hasta 2016.
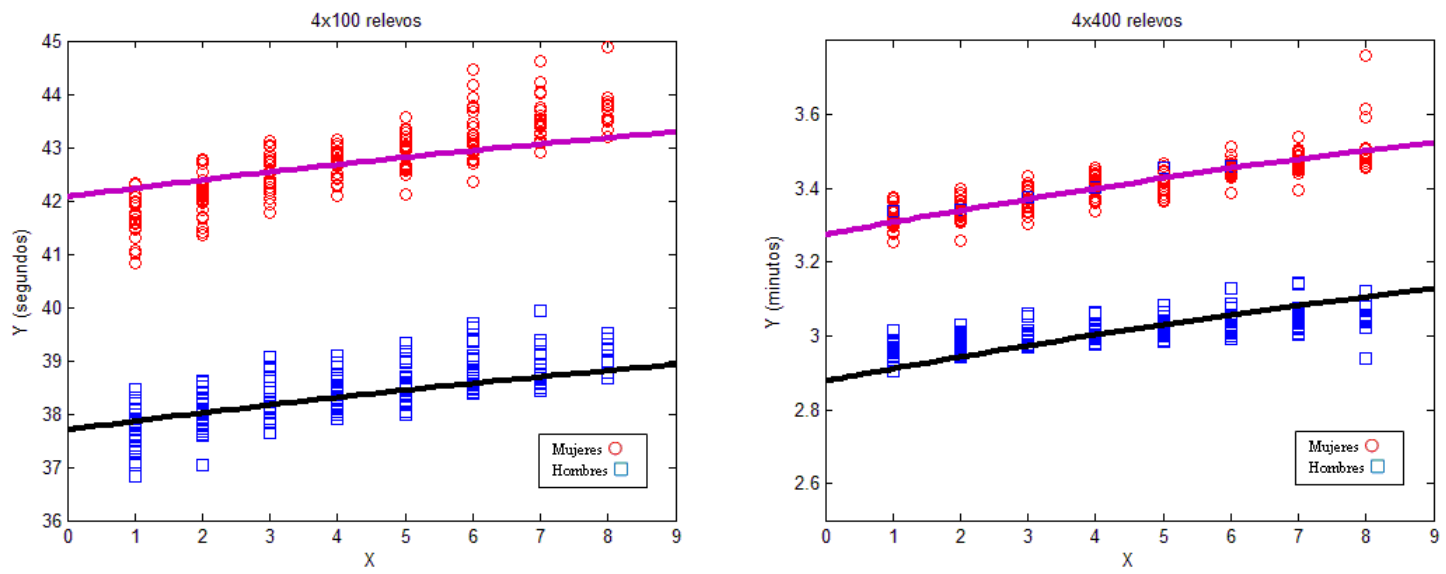

Figura 4. Curva característica para las pruebas de relevos. Mundiales de Atletismo desde 1983 hasta 2015 y Juegos Olímpicos desde 1984 hasta 2016. 

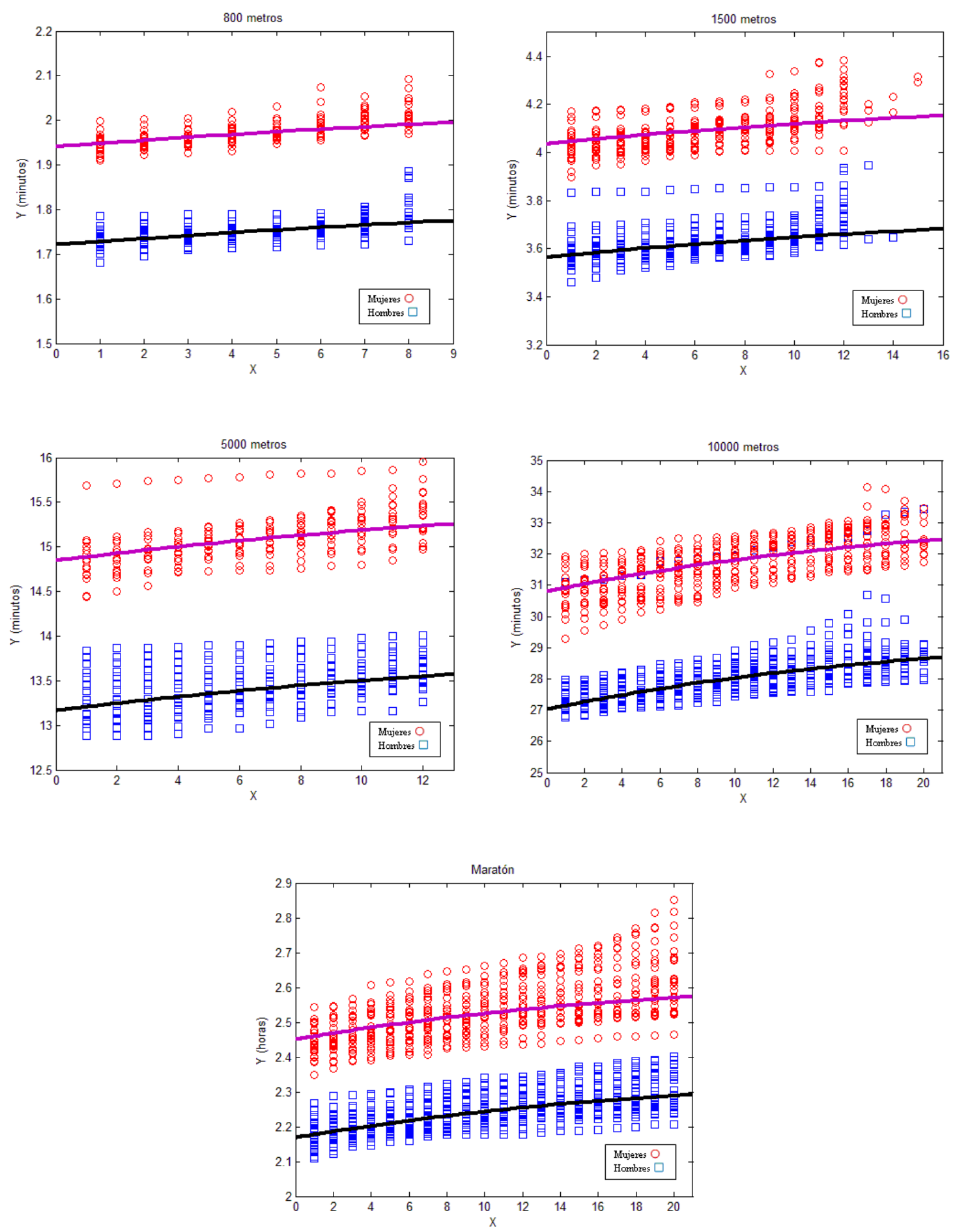

Figura 5. Curva característica para las pruebas de carrera de media y larga distancia. Mundiales de Atletismo desde 1983 hasta 2015 y Juegos Olímpicos desde 1984 hasta 2016. 

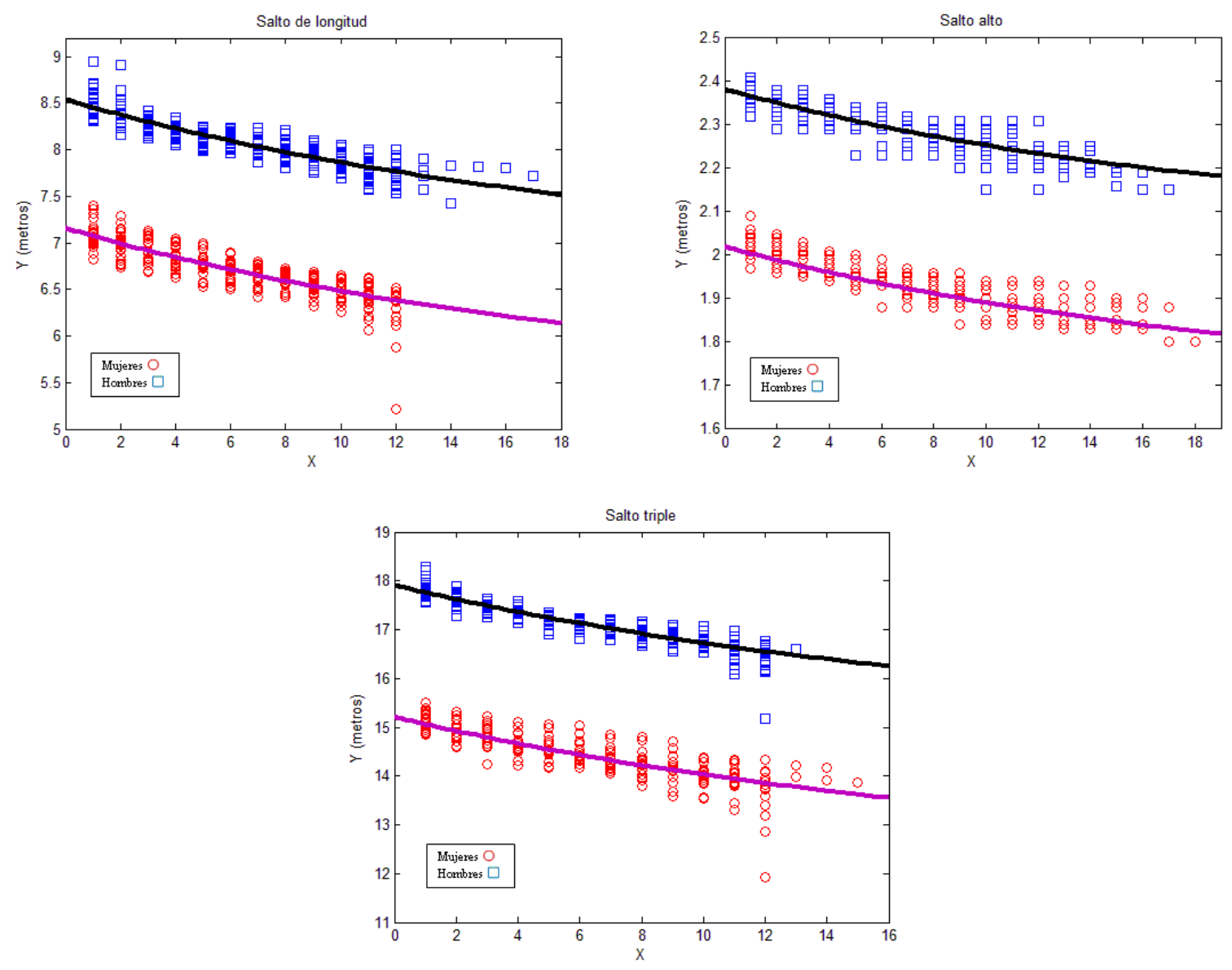

Figura 6. Curva característica para las pruebas de Salto. Mundiales de Atletismo desde 1983 hasta 2015 y Juegos Olímpicos desde 1984 hasta 2016. 


\subsubsection{Cálculo de las diferencias.}

Para cada una de las pruebas se calculó la diferencia en porcentaje de los resultados entre hombres y mujeres, utilizando los valores de los parámetros " $a_{H}$ ” y " $a_{M}$ " (véase tabla 8). Como hemos explicado anteriormente, estos parámetros reflejan la diferencia entre los resultados en cada prueba para hombres y mujeres.

Tabla 8. Diferencias en \% entre los parámetros $a_{H}$ (hombres) y $a_{M}$, (mujeres $) \pm D S$ (Desviación estándar).

\begin{tabular}{|c|c|c|c|c|c|c|}
\hline Prueba & $\left|a_{H}-a_{M}\right| / a_{H} * 100 \%$ & \pm & DS & $\left|a_{H}-a_{M}\right| a_{M} * 100 \%$ & \pm & DS \\
\hline $100 \mathrm{~m}$ & 8.96 & \pm & 1.12 & 8.23 & \pm & 1.02 \\
\hline $200 \mathrm{~m}$ & 9.91 & \pm & 1.92 & 9.02 & \pm & 1.58 \\
\hline $400 \mathrm{~m}$ & 10.98 & \pm & 1.43 & 9.90 & \pm & 1.27 \\
\hline $800 \mathrm{~m}$ & 11.77 & \pm & 1.98 & 10.53 & \pm & 2.53 \\
\hline $1500 \mathrm{~m}$ & 12.50 & \pm & 1.72 & 11.11 & \pm & 1.50 \\
\hline $5000 \mathrm{~m}$ & 11.99 & \pm & 2.97 & 10.71 & \pm & 2.69 \\
\hline $10000 \mathrm{~m}$ & 12.74 & \pm & 5.04 & 11.30 & \pm & 4.72 \\
\hline Maratón & 11.98 & \pm & 1.42 & 10.70 & \pm & 1.03 \\
\hline $4 \times 100 \mathrm{~m}$ & 10.64 & \pm & 1.75 & 9.62 & \pm & 1.36 \\
\hline $4 \times 400 \mathrm{~m}$ & 11.11 & \pm & 2.21 & 10.01 & \pm & 1.72 \\
\hline Salto de altura & 17.61 & \pm & 2.53 & 21.37 & \pm & 3.47 \\
\hline $\begin{array}{l}\text { Salto de } \\
\text { longitud }\end{array}$ & 20.26 & \pm & 3.85 & 25.04 & \pm & 4.36 \\
\hline Triple salto & 18.11 & \pm & 2.68 & 22.11 & \pm & 3.42 \\
\hline
\end{tabular}

Para completar el análisis de las diferencias entre hombres y mujeres, hemos calculado la diferencia entre las medias de los tiempos de los ganadores (véase tabla 9) y la diferencia entre las medias de los resultados totales (véase tabla 10), tal cual se realiza en los estudios de (Rüst et al., 2015; Etter et al., 2013; Lepers \& Stapley, 2010; Lepers, 2008; y Sparling, O'Donnell, \& Snow, 1998). 
Tabla 9. Diferencias en \% entre las medias de los tiempos de los ganadores \pm DS (Desviación estándar); $M G_{H}$ (Medias de los tiempos de los ganadores Hombres), $M G_{M}$ (Medias de los tiempos de los ganadores Mujeres).

\begin{tabular}{|c|c|c|c|c|c|c|}
\hline Prueba & $\left|\mathbf{M G}_{\mathrm{H}}-\mathbf{M G}_{\mathrm{M}}\right| \mathbf{M G}_{\mathrm{H}} * 100 \%$ & \pm & DS & $\left|\mathrm{MG}_{\mathrm{H}}-\mathrm{MG}_{\mathrm{M}}\right| \mathbf{M G}_{\mathrm{M}} * 100 \%$ & \pm & DS \\
\hline $100 \mathrm{~m}$ & 10.04 & \pm & 1.93 & 9.12 & \pm & 1.54 \\
\hline $200 \mathrm{~m}$ & 11.06 & \pm & 2.03 & 9.96 & \pm & 1.92 \\
\hline $400 \mathrm{~m}$ & 11.48 & \pm & 2.21 & 10.30 & \pm & 1.88 \\
\hline $800 \mathrm{~m}$ & 12.10 & \pm & 1.98 & 10.80 & \pm & 1.76 \\
\hline $1500 \mathrm{~m}$ & 12.28 & \pm & 3.26 & 10.94 & \pm & 2.87 \\
\hline $5000 \mathrm{~m}$ & 11.74 & \pm & 3.39 & 10.51 & \pm & 2.93 \\
\hline $10000 \mathrm{~m}$ & 11.54 & \pm & 3.87 & 10.35 & \pm & 3.26 \\
\hline Maratón & 11.88 & \pm & 3.92 & 10.62 & \pm & 3.34 \\
\hline $4 \times 100 \mathrm{~m}$ & 10.80 & \pm & 3.02 & 9.75 & \pm & 2.93 \\
\hline $4 \times 400 \mathrm{~m}$ & 12.50 & \pm & 2.87 & 11.11 & \pm & 2.26 \\
\hline $\begin{array}{c}\text { Salto de } \\
\text { altura }\end{array}$ & 14.21 & \pm & 2.17 & 16.56 & \pm & 2.78 \\
\hline $\begin{array}{l}\text { Salto de } \\
\text { longitud }\end{array}$ & 16.95 & \pm & 2.32 & 20.41 & \pm & 2.73 \\
\hline $\begin{array}{c}\text { Triple } \\
\text { salto }\end{array}$ & 15.23 & \pm & 2.04 & 17.96 & \pm & 2.84 \\
\hline
\end{tabular}

Tabla 10. Diferencias en \% entre las medias de los resultados totales \pm DS (Desviación estándar); MM $M_{H}$ (Hombres), $M_{M}$ (Mujeres).

\begin{tabular}{|c|c|c|c|c|c|c|}
\hline Prueba & $\left|\mathbf{M M}_{\mathrm{H}}-\mathbf{M M}_{\mathbf{M}}\right| \mathbf{M M}_{\mathrm{H}} * \mathbf{1 0 0} \%$ & \pm & SD & $\left|\mathbf{M M}_{\mathrm{H}}-\mathbf{M M}_{\mathrm{M}}\right| / \mathbf{M M}_{\mathbf{M}} * \mathbf{1 0 0} \%$ & \pm & SD \\
\hline $100 \mathrm{~m}$ & 9.82 & \pm & 1.87 & 8.94 & \pm & 1.57 \\
\hline $200 \mathrm{~m}$ & 10.89 & \pm & 1.92 & 9.82 & \pm & 1.83 \\
\hline $400 \mathrm{~m}$ & 11.76 & \pm & 2.12 & 10.53 & \pm & 1.91 \\
\hline $800 \mathrm{~m}$ & 12.60 & \pm & 1.95 & 11.19 & \pm & 1.67 \\
\hline $1500 \mathrm{~m}$ & 12.76 & \pm & 4.02 & 11.32 & \pm & 3.72 \\
\hline $5000 \mathrm{~m}$ & 11.75 & \pm & 3.93 & 10.51 & \pm & 3.84 \\
\hline $10000 \mathrm{~m}$ & 11.91 & \pm & 3.76 & 10.64 & \pm & 3.56 \\
\hline Maratón & 12.83 & \pm & 4.85 & 11.37 & \pm & 4.02 \\
\hline $4 \times 100 \mathrm{~m}$ & 11.29 & \pm & 2.74 & 10.14 & \pm & 2.56 \\
\hline $4 \times 400 \mathrm{~m}$ & 13.14 & \pm & 2.98 & 11.62 & \pm & 2.67 \\
\hline Salto altura & 15.29 & \pm & 2.46 & 18.05 & \pm & 3.02 \\
\hline $\begin{array}{c}\text { Salto } \\
\text { longitud }\end{array}$ & 16.93 & \pm & 2.87 & 20.38 & \pm & 3.45 \\
\hline Triple salto & 15.93 & \pm & 2.93 & 18.95 & \pm & 3.37 \\
\hline
\end{tabular}




\subsection{Diferencias entre mujeres con y sin hiperandrogenismo.}

\subsubsection{Metros Femenino}

En las figuras 7, 8, 9, 10 y 11 se presentan los datos de las pruebas específicas analizadas con sus correspondientes curvas características y las curvas de los rangos de confianza del 95\% y 99\%. La flecha en cada figura indica la posición de la atleta estudiada.

En las figuras 7, 10 y 11, la atleta Caster Semenya ocupó la primera posición, en las figuras 8 y 9 ocupó la segunda posición en la prueba de 800 metros.

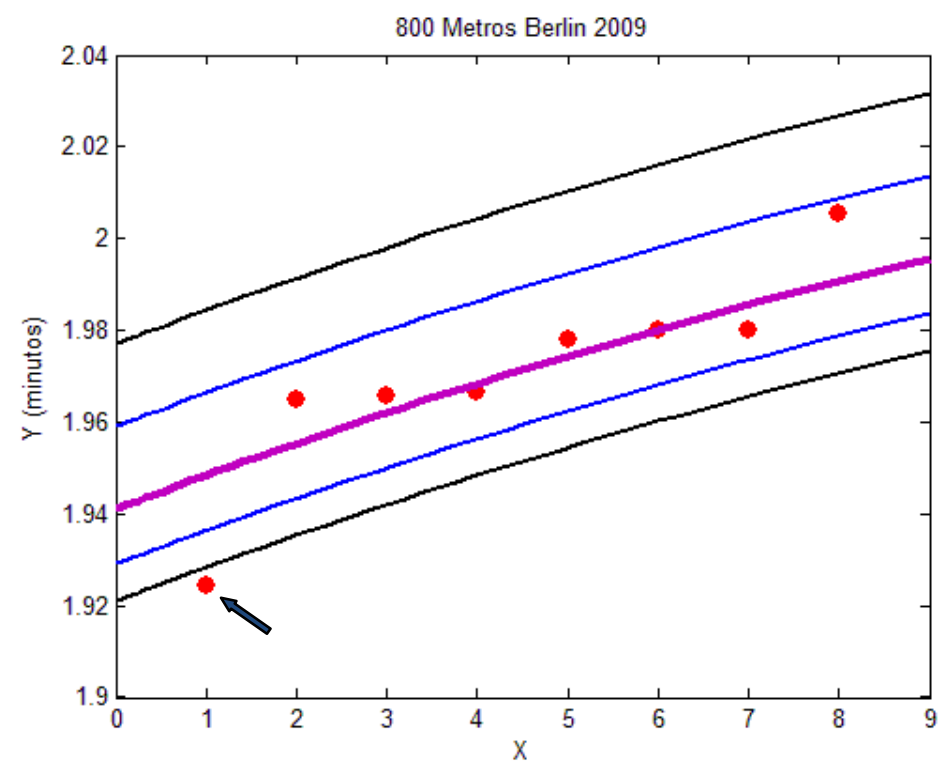

Figura 7. Prueba de 800 metros (rojo) femenino del Mundial de Atletismo Berlín 2009. Curva característica (morado) de la prueba y rangos de confianza del 95\% (azul) y 99\% (negro). 


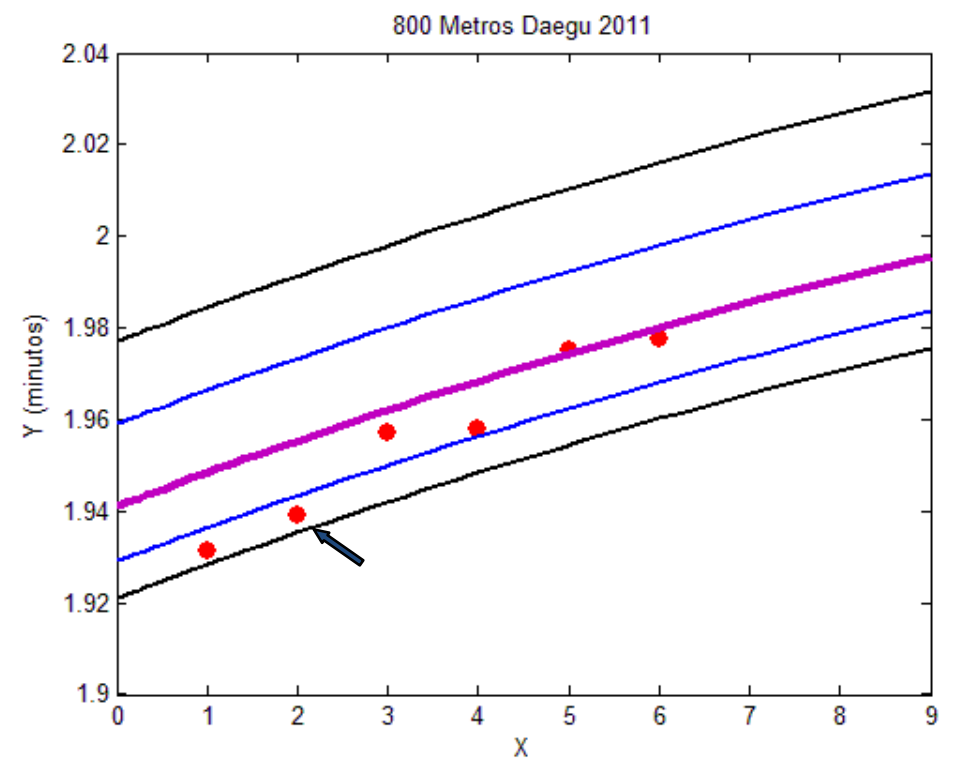

Figura 8. Prueba de 800 metros (rojo) femenino del Mundial de Atletismo, Daegu 2011.Curva característica (morado) de la prueba y rangos de confianza del 95\% (azul) y 99\% (negro).

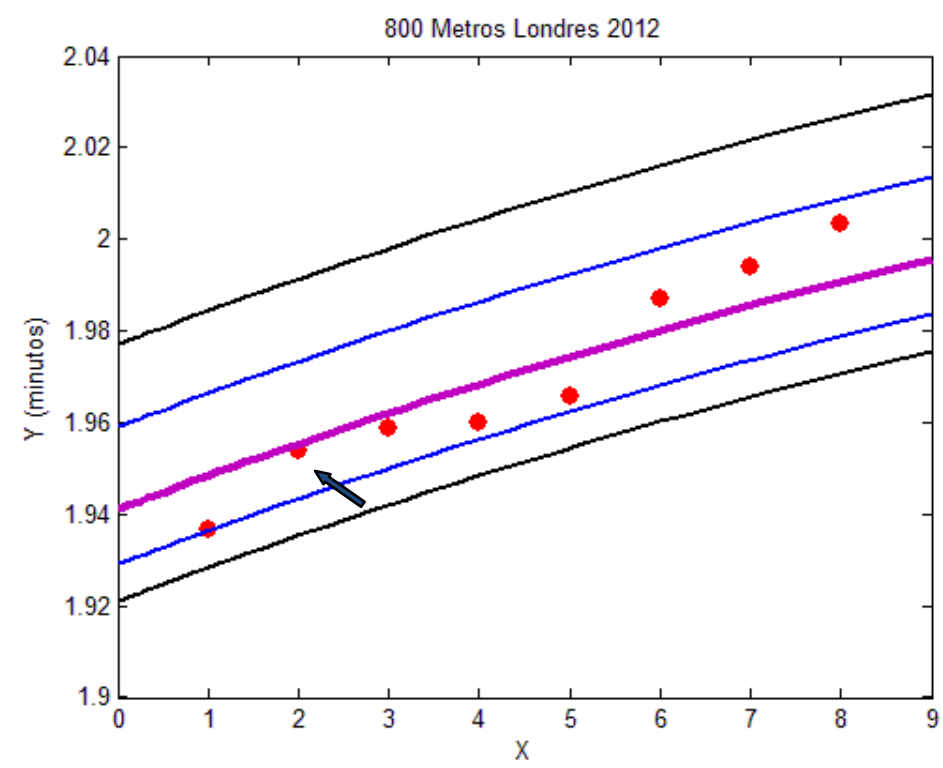

Figura 9. Prueba de 800 metros (rojo) femenino de los Juegos Olímpicos, Londres 2012.Curva característica (morado) de la prueba y rangos de confianza del 95\% (azul) y 99\% (negro). 


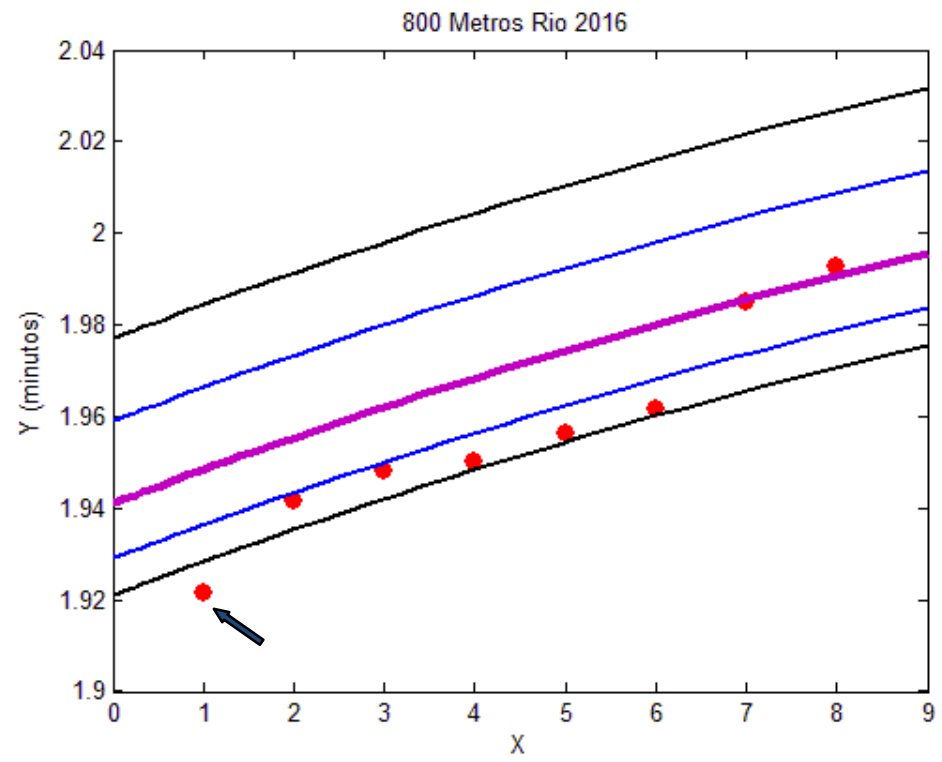

Figura 10. Prueba de 800 metros (rojo) femenino de los Juegos Olímpicos Río 2016.Curva característica (morado) de la prueba y rangos de confianza del 95\% (azul) y 99\% (negro).

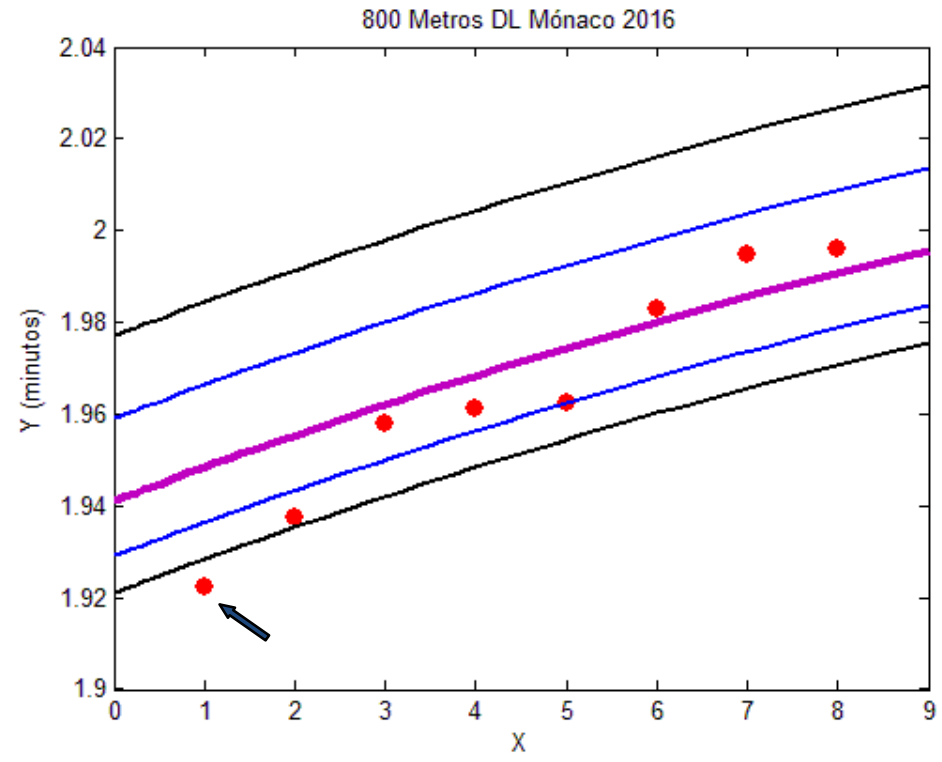

Figura 11. Prueba de 800 metros (rojo) femenino de la Liga Diamante IAAF, Mónaco 2016.Curva característica (morado) de la prueba y rangos de confianza del 95\% (azul) y 99\% (negro). 
El tiempo calculado por la curva característica de la prueba para la primera posición fue de 1:56.90 minutos. Los tiempos calculados para la primera posición en los rangos de confianza del 95\% por arriba y por abajo de la curva característica fueron 1:56.18 minutos y 1:57.98 minutos respectivamente. De igual manera, los tiempos calculados para la primera posición correspondientes a los rangos de confianza del $99 \%$ por arriba y por abajo de la curva característica fueron 1:55.70 minutos y 1:59.06 minutos respectivamente.

Para los hombres en la prueba de 800 metros el tiempo calculado por la curva característica de la prueba para la primera posición fue de 1:43.70 minutos. Los tiempos calculados para la primera posición en los rangos de confianza del $95 \%$ por arriba y por abajo de la curva característica fueron 1:42.98 minutos y 1:44.78 minutos respectivamente. De igual manera, los tiempos calculados para la primera posición correspondientes a los rangos de confianza del $99 \%$ por arriba y por abajo de la curva característica fueron 1:41.66 minutos y 1:45.68 minutos respectivamente.

En la prueba de 800 metros del Campeonato del Mundo de Atletismo, Berlín 2009 (véase fig. 7) Caster Semenya, obtuvo un resultado de 1:55.45 minutos. Este resultado muestra una diferencia de 1.45 segundos respecto al resultado correspondiente dado por la curva característica de la prueba de mujeres, lo que corresponde a un porcentaje de1.24\% y una diferencia de 11.75 segundos respecto al resultado correspondiente dado por la curva característica de la prueba de hombres, lo que corresponde a un porcentaje de $11.75 \%$; una diferencia de 0.73 segundos respecto al resultado correspondiente dado por la curva del 95\% de confianza por debajo de la curva característica de la prueba de mujeres, lo que corresponde a un porcentaje de $0.63 \%$ y una diferencia de 10.67 segundos respecto al resultado correspondiente dado por la curva del $95 \%$ de confianza por arriba de la curva característica de la prueba de hombres, lo que corresponde a un porcentaje de $10.18 \%$; y por último, una diferencia de 0.25 segundos respecto al resultado correspondiente dado por la curva del $99 \%$ de confianza por debajo de la curva característica de la prueba de mujeres, lo que corresponde a un porcentaje de $0.22 \%$ y una diferencia de 9.77 segundos respecto al resultado correspondiente dado por la curva del $99 \%$ de confianza por arriba de la curva característica de la prueba de hombres, lo que corresponde a un porcentaje de $9.77 \%$.

En la prueba de 800 metros de los Juegos Olímpicos de Rio 2016 (véase fig. 10) Caster Semenya, obtuvo un resultado de 1:55.28minutos. Este resultado muestra una diferencia de 
1.63 segundos respecto al resultado correspondiente dado por la curva característica de la prueba de mujeres, lo que corresponde a un porcentaje de $1.39 \%$ y una diferencia de 11.58 segundos respecto al resultado correspondiente dado por la curva característica de la prueba de hombres, lo que corresponde a un porcentaje de $11.17 \%$; una diferencia de 0.91 segundos respecto al resultado correspondiente dado por la curva del 95\% de confianza por debajo de la curva característica de la prueba de mujeres, lo que corresponde a un porcentaje de $0.77 \%$ y una diferencia de 10.50 segundos respecto al resultado correspondiente dado por la curva del $95 \%$ de confianza por arriba de la curva característica de la prueba de hombres, lo que corresponde a un porcentaje de $10.02 \%$; y por último, una diferencia de 0.43 segundos respecto al resultado correspondiente dado por la curva del $99 \%$ de confianza por debajo de la curva característica de la prueba de mujeres, lo que corresponde a un porcentaje de $0.36 \%$ y una diferencia de 9.60 segundos respecto al resultado correspondiente dado por la curva del $99 \%$ de confianza por arriba de la curva característica de la prueba de hombres, lo que corresponde a un porcentaje de $9.08 \%$.

En la prueba de 800 metros de la Liga Diamante, Mónaco 2016 (véase fig. 11) Caster Semenya, obtuvo un resultado de 1:55.33 minutos. Este resultado muestra una diferencia de 1.57 segundos respecto al resultado correspondiente dado por la curva característica de la prueba de mujeres, lo que corresponde a un porcentaje de $1.34 \%$ y una diferencia de 11.63 segundos respecto al resultado correspondiente dado por la curva característica de la prueba de hombres, lo que corresponde a un porcentaje de $11.21 \%$; una diferencia de 0.85 segundos respecto al resultado correspondiente dado por la curva del 95\% de confianza por debajo de la curva característica de la prueba de mujeres, lo que corresponde a un porcentaje de $0.73 \%$ y una diferencia de 10.55 segundos respecto al resultado correspondiente dado por la curva del $95 \%$ de confianza por arriba de la curva característica de la prueba de hombres, lo que corresponde a un porcentaje de $10.07 \%$; y por último, una diferencia de 0.37 segundos respecto al resultado correspondiente dado por la curva del $99 \%$ de confianza por debajo de la curva característica de la prueba de mujeres, lo que corresponde a un porcentaje de $0.32 \%$ y una diferencia de 9.65 segundos respecto al resultado correspondiente dado por la curva del $99 \%$ de confianza por arriba de la curva característica de la prueba de hombres, lo que corresponde a un porcentaje de $9.13 \%$. 


\subsubsection{Metros Femenino}

En las figuras 12, 13 y 14, se presentan los datos de las pruebas específicas de 200 metros analizadas con sus correspondientes curvas características. La flecha en cada figura indica la posición de la atleta estudiada. No se han calculado los rangos de confianza ya que todos los resultados de las pruebas analizadas, estaban muy alejados por encima de la curva característica. Tampoco se calculó la diferencia entre el resultado dado por la curva característica y el resultado de la atleta, por la razón expuesta anteriormente.

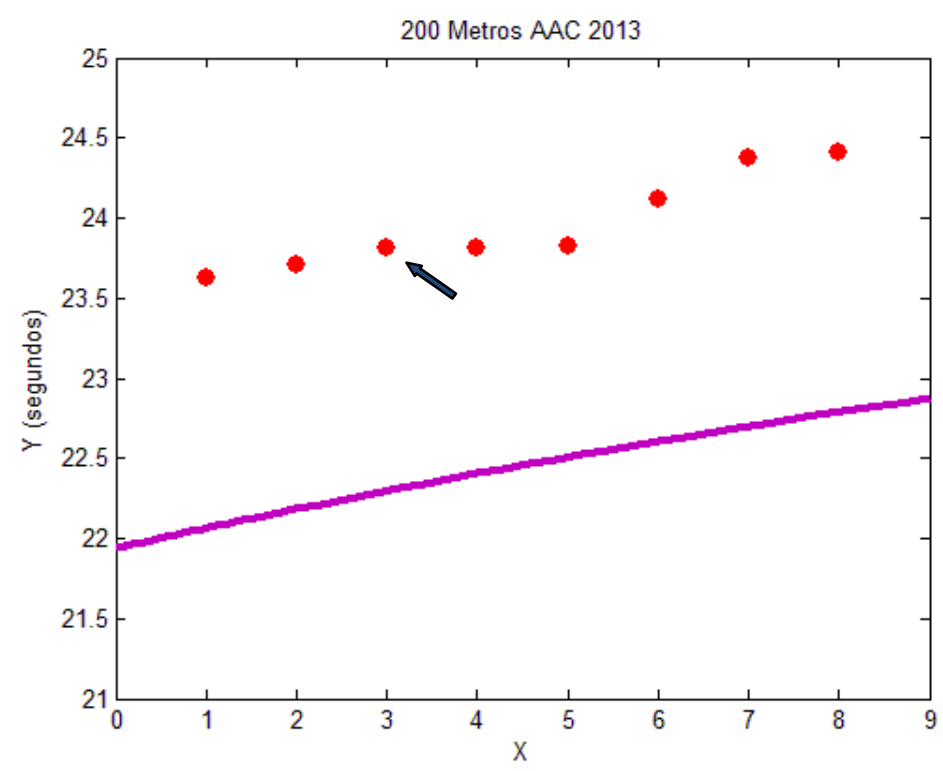

Figura 12. Prueba de 200 metros (rojo) femenino de 20th Asian Athletics Championship, Pune - India, 2013. Curva característica de la prueba (morado). 


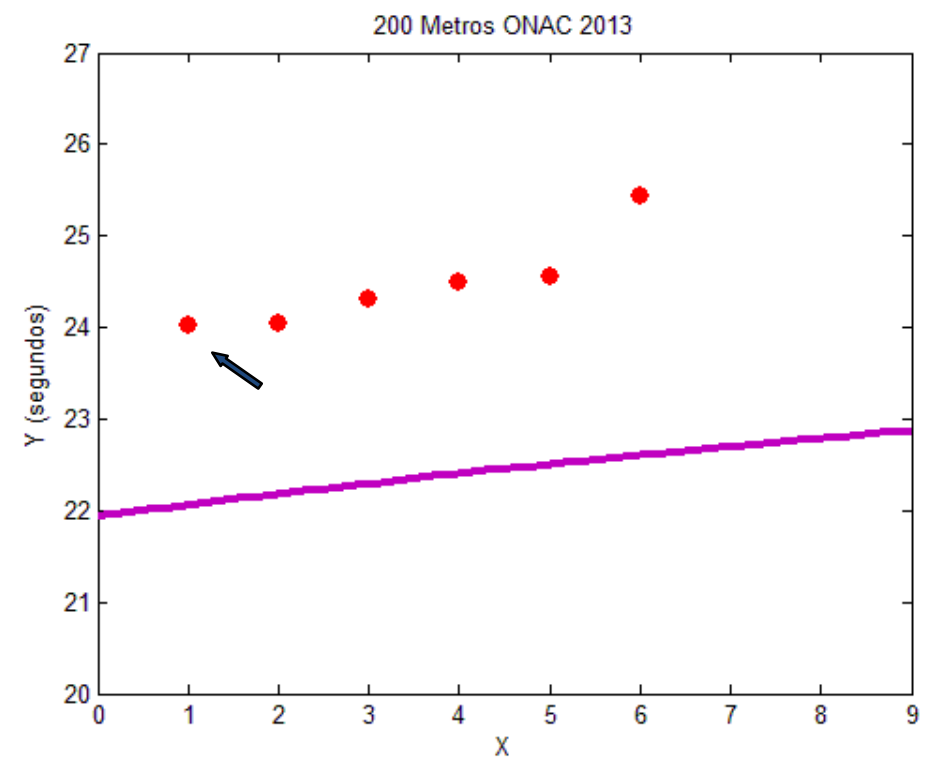

Figura 13. Prueba de 200 metros (rojo) femenino de 53rd Open National Championship, Calcuta - India, 2013. Curva característica de la prueba (morado).

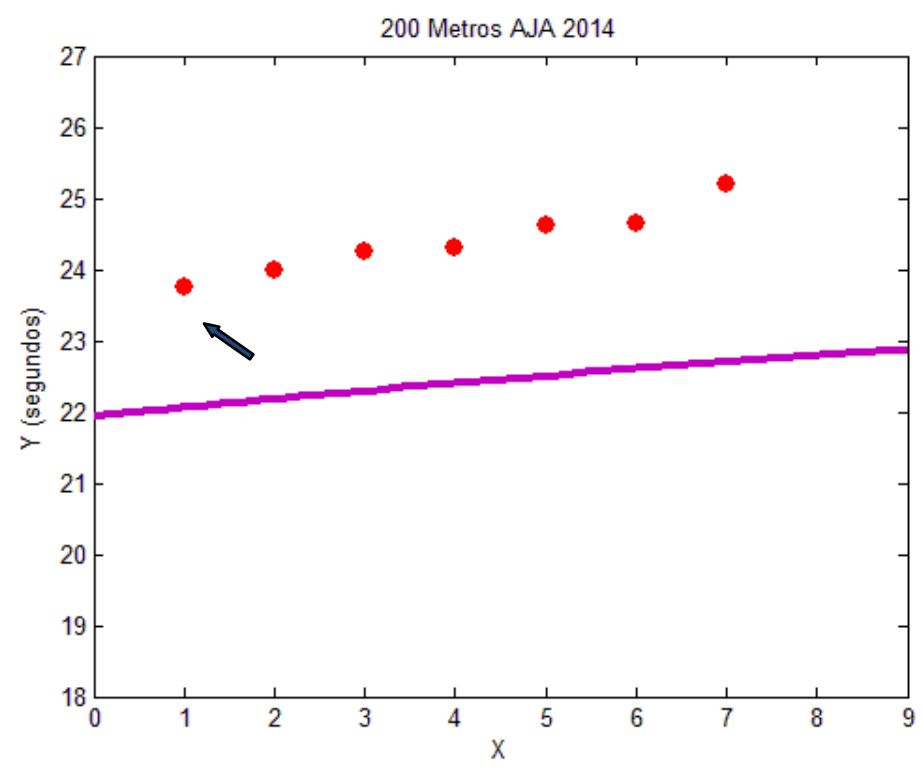

Figura 14. Prueba de 200 metros (rojo) femenino de 16th Asian Junior Athletics Championship, TaipeiChina, 2014. Curva característica de la prueba (morado). 
5. DISCUSIÓN 



\section{Discusión.}

\subsection{Novedad e importancia del presente estudio.}

La novedad del presente estudio es la utilización de ajuste de curvas para el cálculo de las diferencias en el rendimiento deportivo entre hombres y mujeres.

En la bibliografía, una de las técnicas utilizadas para calcular la diferencia en el rendimiento deportivo entre hombres y mujeres fue comparar los resultados de los records mundiales de una prueba específica, como se evidencia en el estudio presentando por Bermon ante el TAS para el caso Dutee Chand (Court of Arbitration for Sports, 2015) y en otros estudios encontrados como los de Thibault et al., (2010); Coast, Blevins, \& Wilson, (2004); y Sparling, O'Donnell, \& Snow, (1998).

Otra técnica utilizada para encontrar las diferencias entre hombres y mujeres fue comparar las medias de los resultados de los diez mejores clasificados (Rüst et al., 2015; Lepers \& Stapley, 2010; y Lepers, 2008); los doce mejores clasificados (Le Meur et al., 2009); los tres mejores clasificados (Rüst et al., 2015) y los cinco mejores clasificados (Etter et al., 2013).

Por último, el estudio de Rüst et al., (2015), ha calculado las diferencias entre hombres y mujeres, utilizando los tiempos de los ganadores de la prueba en el periodo de tiempo seleccionado en el estudio.

Para calcular el porcentaje de diferencia existente entre hombres y mujeres en cada una de las pruebas, los autores anteriormente citados han dividido las diferencias absolutas de los resultados por el resultado de los hombres o el resultado de las mujeres.

En nuestro estudio hemos observado que la curva exponencial elegida seguía la tendencia de todos los datos para cada una de las pruebas analizadas, tanto para los hombres como para las mujeres. En eso se basa la importancia y la novedad del presente estudio. Podemos decir que, mediante la utilización de la técnica matemática de ajuste de curvas, hemos conseguido encontrar una ecuación que simula la tendencia de los resultados deportivos durante una competición de alto nivel. Además de la información de los parámetros " $a_{H}$ " $y$ " $a_{M}$ ” que aquí se han utilizado para calcular las diferencias en el rendimiento, las curvas halladas pueden dar mucha más información respeto a la tendencia del rendimiento 
deportivo. Es importante señalar que ninguno de los métodos utilizados hasta ahora para hallar la diferencia en el rendimiento deportivo es capaz de proporcionar tal información sobre el rendimiento deportivo.

\subsection{Ajuste de curvas $y$ cálculo de los parámetros.}

Después de comprobar diferentes ajustes de curvas, en el estudio que se llevó a cabo en la presente tesis doctoral hemos elegido la curva exponencial por el buen ajuste que esta curva presentaba a todos los conjuntos de datos, en comparación con otros estudios que han utilizado ajuste de líneas rectas, por ejemplo, los publicados por Lepers \& Stapley, (2010); Sparling, O'Donnell, \& Snow, (1998). Hemos observado que la curva exponencial elegida seguía la tendencia de todos los datos para cada una de las pruebas analizadas, tanto para los hombres como para las mujeres. Este hecho se refleja en los valores elevados encontrados para el coeficiente de determinación $R^{2}$ que se encuentran en el rango de $(0.662,0.999)$ para hombres y $(0.699,0.998)$ para mujeres, véase tabla 7 . Es importante resaltar, que estos valores encontrados para el coeficiente de determinación no suelen ser tan elevados en estudios donde se utiliza un ajuste de curvas a datos. También este ajuste extraordinario de la curva elegida, se refleja en los valores hallados de $p$ para la $t$ de student y de $F$ para la prueba de Fisher, los cuales fueron $p<0.0001$ y $F<0.0001$ respectivamente, siendo valores muy bajos, representando una significancia estadística muy alta para los valores de los parámetros encontrados. Teniendo en cuenta todas las razones mencionadas anteriormente, la curva exponencial utilizada para cada una de las pruebas fue denominada "curva característica" de la prueba.

El buen ajuste anteriormente mencionado, puede ser observado en las figuras 3, 4, 5 y 6 . Como se puede comprobar en la tabla 7 los valores más bajos encontrados para el coeficiente de determinación $R^{2}$, se encuentran en la prueba de 10000 metros y en la prueba de la maratón femenina. Estos valores son debido a la tendencia del bajo rendimiento deportivo observada a partir de la posición 14 en los datos de la prueba de 10000 metros (figura 5), así como en los datos de la prueba de la maratón femenina (figura 5). Estas dos pruebas son una excepción, ya que para las demás pruebas los valores encontrados del coeficiente de determinación son mayores a 0.8. Respecto a la prueba de 10000 metros, Thibault et al., (2010) señalan que no pueden encontrar un punto de 
estabilización para la diferencia entre hombres y mujeres debido a la reciente introducción de la prueba en los JJOO, a diferencia de las demás pruebas del atletismo. Sin embargo, esta misma afirmación la hacen para la prueba de los 5000 metros y la $\mathrm{R}^{2}$ encontrada en nuestro estudio es de 0.863 , lo cual significa un buen ajuste.

Otro aspecto importante respecto a las curvas exponenciales ajustadas a los datos es que el valor óptimo del parámetro “c” encontrado (ecuación 1) fue constante (véase ecuación 2 y 3) e igual a $c=0.05$ dentro de los rangos de confianza, para todos los conjuntos de los datos y para todas las pruebas. Teniendo en cuenta que el parámetro “c” refleja la tasa de cambio de la variable dependiente (resultado "Y") respeto a la variable independiente (ranking "X"), el hecho que " $c$ " se pueda mantener constante significa que, en todas las pruebas, los datos muestran la misma tendencia de cambio en el resultado deportivo respecto a la posición del ranking de la prueba.

El valor del parámetro " $b$ " cambia para cada prueba, pero se mantiene constante dentro de un rango para la prueba femenina y masculina.

Al ser el parámetro " $c$ " constante en todas las pruebas estudiadas y el parámetro " $b$ " constante para cada prueba, la diferencia entre hombres y mujeres en el rendimiento deportivo está reflejada por la diferencia en los valores del parámetro " $a$ ". Por la razón anterior, no era suficiente utilizar una ecuación general (ecuación 1) para el análisis de las diferencias entre hombres y mujeres. Las ecuaciones 2 y 3, tienen la misma forma, donde el parámetro $c=0.05$ en todas las pruebas, el parámetro " $b$ " es igual en cada una de las pruebas y el parámetro " $a$ ” se diferencia siendo " $a_{H}$ ” para hombres y " $a_{M}$ ” para mujeres.

\subsection{Diferencias en el rendimiento deportivo entre hombres y mujeres.}

Uno de los objetivos de esta tesis doctoral es comprobar que desde el punto de vista de los resultados deportivos en el atletismo existe una diferencia del rendimiento deportivo del orden del $10-12 \%$ entre hombre y mujeres.

Para calcular las diferencias en el rendimiento deportivo entre hombres y mujeres, utilizando el método de ajuste de curvas exponenciales, se ha hallado el porcentaje de las diferencias entre los parámetros " $a_{H}$ " $y$ " $a_{M}$ " de ajuste de la curva, de las dos siguientes maneras: 


$$
\begin{aligned}
& \text { \%diferencia }=\frac{\boldsymbol{a}_{\boldsymbol{H}}-\boldsymbol{a}_{\boldsymbol{M}}}{\boldsymbol{a}_{\boldsymbol{H}}} * 100 \\
& \text { \%diferencia }=\frac{\boldsymbol{a}_{\boldsymbol{H}}-\boldsymbol{a}_{\boldsymbol{M}}}{\boldsymbol{a}_{\boldsymbol{M}}} * 100
\end{aligned}
$$

También, para seguir la bibliografía encontrada, se ha calculado el porcentaje de diferencia existente entre hombres y mujeres utilizando: i) la media de los tiempos de los ganadores de cada evento en las pruebas seleccionadas; y ii) la diferencia de la media de los resultados totales de cada una de las pruebas; dividiendo por el resultado de los hombres y por el resultado de las mujeres como se ha hecho para comparar los parámetros " $a_{H}$ " $y$ “ $a_{M}$ ”. Todos estos porcentajes los exponemos de manera específica a continuación, para poder compararlos con los estudios encontrados.

\subsubsection{Pruebas de velocidad}

En las pruebas de velocidad $(100 \mathrm{~m}, 200 \mathrm{~m}$ y $400 \mathrm{~m})$ el porcentaje de diferencia entre hombres y mujeres en se encuentra en un rango de: i) $8.96 \pm 1.12 \%-10.98 \pm 1.43 \%$ (rangos obtenidos al dividir por el resultado de los hombres) y $8.23 \pm 1.02 \%-9.90 \pm 1.27 \%$ (rangos obtenidos al dividir por el resultado de las mujeres), utilizando los parámetros " $a_{H}$ " y " $a_{M}$ "

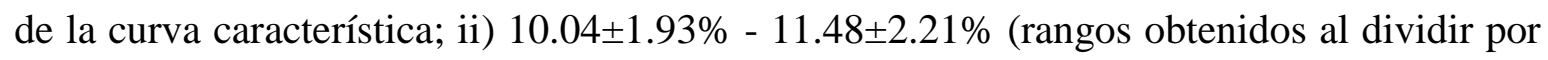
el resultado de los hombres) y $9.12 \pm 1.54 \%-10.30 \pm 1.88 \%$ (rangos obtenidos al dividir por el resultado de las mujeres), utilizando los tiempos de los ganadores; iii) $9.82 \pm 1.87 \%$ $11.76 \pm 2.12 \%$ (rangos obtenidos al dividir por el resultado de los hombres) y $8.94 \pm 1.57 \%$ $10.53 \pm 1.91 \%$ (rangos obtenidos al dividir por el resultado de las mujeres), utilizando la media de los resultados totales (véase tablas 8,9 y 10).

Con los valores de los porcentajes obtenidos en las pruebas de velocidad, se puede observar que el porcentaje de la diferencia hallado utilizando la curva característica es ligeramente inferior que los porcentajes encontrados utilizando las medias de los tiempos de los ganadores y las medias de los tiempos totales. Sin embargo, estadísticamente los porcentajes de diferencias encontrados se encuentran dentro de los mismos rangos para las 
3 técnicas utilizadas, teniendo en cuenta sus rangos de desviación estándar. Cabe resaltar que los porcentajes de diferencia hallados en el presente estudio se encuentran ligeramente por debajo del porcentaje (12.64\%) expuesto por Bermon en el caso Dutee Chand ante el TAS (Court of Arbitration for Sports, 2015), pero no se puede hablar de una diferencia estadísticamente significativa, ya que el resultado presentado por Bermon se encuentra dentro de los rangos de la desviación estándar de nuestros resultados. Lo hallado en el presente estudio está en concordancia con el porcentaje de diferencia $(11.1 \pm 1.1 \%)$ citado por Sparling, O'Donnell, \& Snow, (1998), para las pruebas de velocidad y el porcentaje de diferencia (12.4\%) citado por Coast, Blevins, \& Wilson, (2004). Por último, el estudio de Thibault et al., (2010) en las pruebas de velocidad señala un porcentaje de diferencia comprendido entre el $6.50 \%$ y el $9.98 \%$, lo que supone que el rango menor de ese porcentaje se encuentre por debajo del rango menor encontrado en el presente, sin embargo, se pude afirmar que los resultados de este estudio están en concordancia con los nuestros.

\subsubsection{Pruebas de media y larga distancia}

El porcentaje de diferencia entre hombres y mujeres en las pruebas de media y larga distancia se encuentra en un rango de: i) $11.77 \pm 1.98 \%-12.74 \pm 5.04 \%$ (rangos obtenidos al dividir por el resultado de los hombres) y $10.53 \pm 2.53 \%-11.30 \pm 4.72 \%$ (rangos obtenidos al dividir por el resultado de las mujeres), utilizando los parámetros " $a_{H}$ " y " $a_{M}$ " de la curva característica; ii) $11.54 \pm 3.87 \%$ - 12.28 $\pm 3.26 \%$ (rangos obtenidos al dividir por el resultado de los hombres) y $10.35 \pm 3.26 \%-10.94 \pm 2.87 \%$ (rangos obtenidos al dividir por el resultado de las mujeres), utilizando los tiempos de los ganadores; iii) $11.75 \pm 3.93 \%$ $12.76 \pm 4.02 \%$ (rangos obtenidos al dividir por el resultado de los hombres) y $10.51 \pm 3.84 \%$

$-11.37 \pm 4.02 \%$ (rangos obtenidos al dividir por el resultado de las mujeres), utilizando la media de los resultados totales (véase tablas 8,9 y 10).

Los valores porcentuales obtenidos en las pruebas de media y larga distancia, son ligeramente más altos que los encontrados para las pruebas de velocidad. Se puede observar que estadísticamente los porcentajes de diferencias encontrados se encuentran dentro de los mismos rangos para las 3 técnicas utilizadas, teniendo en cuenta sus rangos de desviación estándar. Estos porcentajes de diferencia se encuentran en concordancia con 
el porcentaje (12.64\%) expuesto por Bermon en el caso Dutee Chand ante el TAS (Court of Arbitration for Sports, 2015) y que fue aceptado por el tribunal como un porcentaje de diferencia en el rendimiento deportivo entre hombres y mujeres en el atletismo de élite, y lo hallado en el estudio de Sparling, O'Donnell, \& Snow, (1998) que cita un porcentaje de diferencia para la prueba de 1500 metros en $11.1 \pm 1.1 \%$ y para la prueba de maratón (42 $\mathrm{km})$ un $11.2 \pm 0.9 \%$, siendo estadísticamente casi iguales en esta prueba de media y larga distancia. En el estudio de Thibault et al.,( 2010) las diferencias específicas para las pruebas de media y larga distancia son el $10.98 \%$ para los 800 metros, $10.55 \%$ para los 1500 metros, $12.85 \%$ para los 5000 metros, $10.80 \%$ para los 10000 metros y $10.60 \%$ para la maratón, porcentajes que son similares entre sí y que no presentan grandes diferencias al igual que los encontrados por Sparling et al., (1998). Si nos referimos a los porcentajes específicos de nuestro estudio hallados por la diferencia del parámetro " $a$ " divido por el parámetro " $a$ " de mujeres, los valores son $10.53 \%$ para los 800 metros, $11.11 \%$ para los 1500 metros, $10.71 \%$ para los 5000 metros, $11,30 \%$ para los 10000 metros y $10,70 \%$ para la maratón. Podemos afirmar que son valores que están en completa concordancia con los estudios de Thibault et al., (2010) y Sparling et al., (1998). El porcentaje hallado en el presente estudio está en concordancia con el porcentaje de diferencia global de $12.4 \%$ citado por Coast, Blevins, \& Wilson, (2004) para todas las pruebas analizadas, pero para prueba específica de los 5000 metros el porcentaje de diferencia encontrado fue del $15.2 \%$ y en la prueba de la maratón de $9.3 \%$, siendo estos ligeramente más altos y más bajos que los porcentajes encontrados en el presente estudio.

\subsubsection{Pruebas de relevos}

El porcentaje de diferencia entre hombres y mujeres en las pruebas de relevos se encuentra en un rango de: i) $10.64 \pm 1.75 \%$ - $11.11 \pm 2.21 \%$ (rangos obtenidos al dividir por el resultado de los hombres) y $9.62 \pm 1.367 \%$ - 10.01 $\pm 1.72 \%$ (rangos obtenidos al dividir por el resultado de las mujeres), utilizando los parámetros " $a_{H}$ " y " $a_{M}$ " de la curva característica; ii) $10.80 \pm .3 .02 \%-12.50 \pm 2.87 \%$ (rangos obtenidos al dividir por el resultado de los hombres) y $9.75 \pm 2.93 \%-11.11 \pm 2.26 \%$ (rangos obtenidos al dividir por el resultado de las mujeres), utilizando los tiempos de los ganadores; iii) $11.29 \pm 2.74 \%-13.14 \pm 2.98 \%$ (rangos obtenidos al dividir por el resultado de los hombres) y $10.14 \pm 2.56 \%$ - 
$11.62 \pm 2.67 \%$ (rangos obtenidos al dividir por el resultado de las mujeres), utilizando la media de los resultados totales (véase tablas 8,9 y 10 ).

De todos los estudios consultados, el único que presenta datos para las pruebas de relevos es el de Thibault et al.,(2010), que señala que la diferencia entre hombres y mujeres para la prueba de 4x100 metros es de $13.96 \%$ y de $11,23 \%$ para la prueba de $4 \times 400$ metros, porcentajes que están ligeramente por encima de los encontrados en el presente estudio utilizando los parámetros " $\mathrm{a}_{\mathrm{H}}$ " y " $\mathrm{a}_{\mathrm{M}}$ ” de la curva característica,10,64\% para la prueba de $4 \times 100$ metros y $11,11 \%$ para la prueba de 4 x400 metros. Sin embargo, los resultados de Thibault et al., (2010) están en completa concordancia con los valores hallados por las otras dos técnicas utilizadas en la presente tesis doctoral. Adicionalmente, podemos decir que estos porcentajes de diferencia se encuentran en concordancia con el porcentaje (12.64\%) expuesto por Bermon en el caso Dutee Chand ante el TAS (Court of Arbitration for Sports, 2015), ya que está recogido en el auto de medidas cautelares del TAS como un porcentaje general para la diferencia existente entre hombres y mujeres en el atletismo de élite.

\subsubsection{Pruebas de saltos}

Para las pruebas de saltos en el atletismo el porcentaje de diferencia entre hombres y mujeres se encuentra en un rango de: i) $17.61 \pm 2.53 \%-20.26 \pm 3.85 \%$ (rangos obtenidos al dividir por el resultado de los hombres) y $21.37 \pm 3.47 \%-25.04 \pm 4.36 \%$ (rangos obtenidos al dividir por el resultado de las mujeres), utilizando los parámetros " $a_{H}$ " y " $a_{M}$ " de la curva característica; ii) $14.21 \pm 2.17 \%$ - $16.95 \pm 2.32 \%$ (rangos obtenidos al dividir por el resultado de los hombres) y $16.56 \pm 2.78 \%-20.41 \pm 2.73 \%$ (rangos obtenidos al dividir por el resultado de las mujeres), utilizando los tiempos de los ganadores; iii) $15.29 \pm 2.46 \%$ $16.93 \pm 2.87 \%$ (rangos obtenidos al dividir por el resultado de los hombres) y $18.05 \pm 3.02 \%$ $-20.38 \pm 3.45 \%$ (rangos obtenidos al dividir por el resultado de las mujeres), utilizando la media de los resultados totales (véase tablas 8,9 y 10).

En los porcentajes encontrados en el presente estudio para las pruebas de saltos, se puede observar valores de diferencia entre hombres y mujeres elevados en comparación con los valores correspondientes a las demás pruebas. Todos estos valores quedan por encima de 
los porcentajes encontrados por todos los estudios citados en la bibliografía, aunque estos estudios citados no presentan datos para las pruebas de salto específicamente.

Al comparar los porcentajes encontrados por las tres técnicas utilizadas entre sí, se observa que los porcentajes aportados por la curva característica son más altos que los aportados por las otras dos técnicas. Sin embargo, todos los valores porcentuales de diferencia entre hombres y mujeres hallados mediante las tres técnicas son mucho más altos que los valores de las demás pruebas analizadas. El único estudio que presenta datos para las pruebas de salto es el de Thibault et al.,(2010), que aunque señalen que con los records mundiales la diferencia con el paso de los años disminuyó desde el $30.1 \pm 8.52 \%$ al $17.5 \pm 1.11 \%$, en los datos específicos para las tres pruebas de salto analizadas en el presente estudio muestran un rango de $16.63 \%$ - 18.76\%. Este rango señalado en el estudio de Thibault et al., (2010) es el más alto de todas las pruebas de atletismo estudiadas, porcentajes que en el presente estudio son los más altos para todas las pruebas estudiadas y que se encuentran en el rango del $17.61 \%-22.11 \%$.

\subsection{Diferencias entre mujeres con hiperandrogenismo $y$ mujeres sin hiperandrogenismo.}

\subsubsection{Caster Semenya - 800 Metros}

Con el fin de analizar el rendimiento deportivo de la atleta sudafricana Caster Semenya y estudiar si su rendimiento se encuentra dentro de los rangos establecidos por la curva característica de la prueba de 800 metros femenino, además de la curva característica de la prueba, se han hallado las curvas de los rangos de confianza del 95\% y 99\%, como se puede observar en las figuras 7, 8, 9, 10 y 11. También, se han hallado los rangos de confianza del $95 \%$ y $99 \%$ para la curva característica de la prueba masculina.

Para una mejor comprensión de las figuras 7, 8, 9, 10 y 11 y los resultados presentados, es importante señalar que a la atleta en cuestión en la prueba celebrada en el Mundial de Atletismo de Berlín 2009 (véase figura 7), no se le había aplicado ninguna normativa IAAF y no había estado suspendida de la competición. Justo después de su victoria en el año 2009, Caster Semenya estuvo suspendida de la competición por un periodo de 11 meses (International Association of Athletics Federations, 2010). En el año 2010, Semenya 
regresó a la competición, después de que el Comité Médico de la IAAF estudiara su caso y le permitiera competir de nuevo, asumiendo la obligatoriedad de cumplir con la normativa de hiperandrogenismo de la IAAF (International Association of Athletics Federations, 2011a). En la competición del Mundial de Atletismo de Daegu 2011 y en los Juegos Olímpicos de Londres 2012 (véase figuras 8 y 9) Caster Semenya ocupó la segunda posición. Para explicar las figuras 10 y 11 que corresponden a los Juegos Olímpicos de Rio 2016 y la Liga Diamante Mónaco 2016, otra cuestión a tener en cuenta, es que la normativa IAAF de hiperandrogenismo se encuentra suspendida desde el 24 de julio de 2015, motivo por el cual ninguna atleta puede ser suspendida o retirada de la competición por este tema (Court of Arbitration for Sports, 2015).

Como se puede observar en la figura 8 (Mundial de Atletismo Daegu 2011) el rendimiento de la atleta sudafricana, se encuentra dentro de la curva del rango de confianza del $99 \%$. Por esta razón, su rendimiento deportivo en esta competición se puede establecer como un rendimiento característico para la prueba de 800 metros. Es importante observar, que el rendimiento de la atleta que ocupó la primera posición en esta prueba de 800 metros del Mundial de Atletismo del año 2011, tampoco se encuentra fuera de los rangos establecidos por la curva del rango de confianza del $99 \%$, siendo de igual manera un rendimiento característico para la prueba de 800 metros femenino.

En la figura 9 (Juegos Olímpicos Londres 2012) el rendimiento deportivo de Caster Semenya se encuentra tocando la curva característica de la prueba, como si este resultado estuviera predicho por la curva característica. En la prueba de los Juegos Olímpicos de Londres 2012, los resultados de todas las participantes se encuentran dentro de los rangos de la curva del $95 \%$ de confianza.

A diferencia de los resultados de los años 2011 y 2012, los resultados de Caster Semenya durante el Mundial de Atletismo de 2009 (figura 7), los Juegos Olímpicos de 2016 (figura 10) y la Liga Diamante Mónaco 2016 (figura 11), se encuentran por fuera de la curva del rango de confianza del 99\%. Es importante resaltar que en todas las pruebas específicas analizadas no hay ningún resultado que se encuentre por fuera de estos rangos establecidos por la curva de confianza del $99 \%$.

Teniendo en cuenta los resultados del presente estudio, podemos establecer que el rango de porcentaje de diferencia del rendimiento de Caster Semenya en las pruebas del Mundial de 
Atletismo de 2009, los Juegos Olímpicos de 2016 y la Liga Diamante Mónaco 2016 con la curva característica de la prueba femenina es del 1.24\% - 1.39\%. Si hacemos la comparación con la curva característica de la prueba masculina y sus rangos de confianza del $95 \%$ y $99 \%$ por encima de la curva, el rango de porcentaje de diferencia del resultado de Caster Semenya respecto al resultado correspondiente en la prueba masculina $\left(1^{\mathrm{a}}\right.$ posición) es de $11.17 \%$ - $11.75 \%$ para la curva característica de la prueba masculina; $10.02 \%$ - $10.18 \%$ para el rango del $95 \%$ de confianza por arriba de la prueba masculina; y $9.08 \%-9.77 \%$ para el rango del $99 \%$ de confianza por arriba de la prueba masculina.

Al comparar el resultado de la atleta en cuestión con el resultado de la atleta que ocupó la segunda posición en las pruebas anteriormente mencionadas, el porcentaje de diferencia del rendimiento deportivo fue de $2.08 \%$ para la prueba del 2009; $1.04 \%$ para los Juegos Olímpicos de 2016 y $0.78 \%$ para la prueba de la Liga Diamante Mónaco 2016.

Debemos recordar que la normativa de hiperandrogenismo de la IAAF del 2011 (International Association of Athletics Federations, 2011a) fue suspendida por el TAS, debido a que solo se establece que la diferencia del rendimiento deportivo entre las mujeres con hiperandrogenismo y las mujeres sin hiperandrogenismo es del orden del 3\% (Court of Arbitration for Sports, 2015) (parágrafo 256) . El TAS, referente a esta cuestión, llegó a la conclusión que este porcentaje del 3\% era significativamente menor que el porcentaje de la diferencia del 10 - 12\% en el rendimiento deportivo entre hombres y mujeres de élite. Con el análisis del presente estudio, solo teniendo en cuenta resultados deportivos se puede observar que el porcentaje de la diferencia del rendimiento de Caster Semenya respecto a la segunda clasificada se encuentra en el rango del $0.78 \%-2.08 \%$, lo cual es menor que el $3 \%$ citado en las medidas cautelares del caso Dutee Chand vs. IAAF\& AFI y no alcanza los porcentajes citados en la diferencia del rendimiento deportivo entre hombres y mujeres de élite. Adicionalmente, se comprueba en este caso específico que, aunque Caster Semenya se encuentre por fuera de los rangos de confianza del $99 \%$ por debajo de la curva característica de la prueba femenina, el porcentaje de diferencia existente entre esta atleta y el rango de confianza del $99 \%$ por encima de la curva característica de la prueba masculina es de $9.08 \%-9.77 \%$. 


\subsubsection{Dutee Chand - 200 Metros Femenino}

Para el análisis del rendimiento deportivo de la atleta india Dutee Chand, quien es la precursora de la suspensión de la normativa de hiperandrogenismo de la IAAF (International Association of Athletics Federations, 2011a), los datos disponibles son de pruebas en categorías juveniles, los cuales no se tuvieron en cuenta para el estudio de cálculo de las curvas características de la prueba de 200 metros femenino, por no ser eventos del Campeonato del Mundo de Atletismo ni de los Juegos Olímpicos.

Como se puede observar en las figuras 12, 13 y 14, las pruebas de 200 metros femeninos en la categoría juvenil en los eventos 16th Asian Junior Athletics 2014; 53rd Open National Athletcis Championship 2013 y 20th Asian Athletics Championship 2013, se pueden describir como carreras lentas respecto a la curva característica de la prueba absoluta de 200 metros femeninos.

Después de que el TAS suspendiera la normativa de hiperandrogenismo y se le permitiera competir a Dutee Chand, la atleta consiguió clasificarse para la prueba de 100 metros femenino para los Juegos Olímpicos de Rio 2016. Dutee Chand participó en la ronda clasificatoria de los 100 metros, en la serie $5^{a}$, ocupando la $7^{a}$ posición con un tiempo de 11.69 segundo (Rio 2016, 2016), quedando fuera de las semifinales y la ronda final de la prueba.

Uno de los objetivos específicos de esta tesis doctoral es estudiar la diferencia de rendimiento deportivo en mujeres con y sin hiperandrogenismo. Aunque, Dutee Chand sea la atleta que impugno la normativa ante el TAS y por ende la normativa de hiperandrogenismo se encuentre suspendida, con los datos analizados, no podemos concluir que exista una diferencia estadísticamente significativa en mujeres con y sin hiperandrogenismo, lo que daría sentido a la suspensión de la normativa IAAF por parte del TAS a partir de la reclamación interpuesta por la atleta Dutee Chand.

El resultado obtenido por Dutee Chand durante los Juegos Olímpicos de Río 2016, tampoco fue tenido en cuenta para calcular la curva característica de la prueba de 100 metros femenino, ya que solo se tuvieron en cuenta los resultados de las finales de las pruebas analizadas. Este resultado tampoco nos conduce a conclusiones acerca de la diferencia en su rendimiento deportivo, respecto al rendimiento deportivo de las otras participantes de la prueba. 
Por último, como se puede observar en las figuras 12, 13 y 14, debemos hacer énfasis en que, si dibujáramos la curva característica para las pruebas específicas presentadas en las figuras mencionadas, esta curva seguiría la misma tendencia de la curva característica de la prueba absoluta de 200 metros femeninos. Además, observando las gráficas ninguna de las atletas presenta un resultado que no pueda ser predicho (calculado) por la curva que se dibujaría para las pruebas específicas analizadas. 
6. CONCLUSIONES 



\section{Conclusiones}

\subsection{En relación con el objetivo de determinar la diferencias en el rendimiento deportivo entre hombres y mujeres.}

La diferencia de rendimiento deportivo entre hombres y mujeres en el atletismo de élite, utilizando las curvas características, los tiempos de los ganadores y las medias de los resultados totales, es la siguiente:

a) En las pruebas de velocidad (100m, 200m y 400m) la diferencia está en un rango de $8.23 \pm 1.02 \%-11.76 \pm 2.12 \%$.

b) En las pruebas de media y larga distancia $(800 \mathrm{~m}, 1500 \mathrm{~m}, 5000 \mathrm{~m}, 10000 \mathrm{~m}$ y maratón) la diferencia está en un rango de $10.35 \pm 3.26 \%-12.76 \pm 4.02 \%$.

c) En las pruebas de relevos $(4 \times 100 \mathrm{~m}$ y $4 \times 400 \mathrm{~m})$ la diferencia está en un rango de $9.75 \pm 2.93 \%-13.14 \pm 2.98 \%$.

d) En las pruebas de saltos (longitud, altura y triple) la diferencia está en un rango de $14.21 \pm 2.17 \%-25.04 \pm 4.36 \%$.

Por tanto, el presente estudio confirma que, mediante el análisis de resultados deportivos de Campeonatos del Mundo de Atletismo desde el año 1983 hasta el año 2015 y Juegos Olímpicos desde el año 1984 hasta el año 2016, el porcentaje de diferencia del 10\% - 12\% en el rendimiento deportivo entre hombres y mujeres aceptado por el Tribunal de Arbitraje Deportivo, en el caso Dutee Chand vs. Asociación Internacional de Federaciones de Atletismo (IAAF) y la Federación de Atletismo de la India (AFI), puede ser establecido como un porcentaje que indique la mínima diferencia en el rendimiento deportivo del atletismo de élite. Con la excepción de las pruebas de saltos, donde la diferencia es significativamente mayor a la mínima aceptada por el TAS. 


\subsection{En relación con el objetivo de determinar la diferencia entre mujeres con hiperandrogenismo y mujeres sin hiperandrogenismo.}

Los datos deportivos disponibles de la atleta Dutee Chand no permiten llegar a ninguna conclusión sobre una posible diferencia en su rendimiento deportivo respecto a otras atletas participantes en las mismas pruebas.

La diferencia de rendimiento deportivo entre la atleta Caster Semenya y otras atletas, antes de su suspensión de la competición en el año 2009 y después de la suspensión de la normativa de hiperandrogenismo de la IAAF del 2011, es la siguiente:

a) La diferencia está en un rango de $1.24 \%$ - 1.39\%, utilizando la curva característica de la prueba.

b) La diferencia está en un rango de $0.78 \%$ - 2.08\%, comparando sus resultados con la segunda clasificada en las pruebas específicas analizadas.

Por tanto, el presente estudio confirma que, mediante el análisis de resultados deportivos de Caster Semenya en la prueba de 800 metros femenino, el porcentaje de diferencia en el rendimiento deportivo respecto a otras mujeres no alcanzan el 3\% citado por el Tribunal de Arbitraje Deportivo, en el caso Dutee Chand vs. Asociación Internacional de Federaciones de Atletismo (IAAF) y la Federación de Atletismo de la India (AFI), como diferencia de rendimiento deportivo entre mujeres con y sin hiperandrogenismo.

\subsection{En relación con el objetivo de verificar si está justificada la normativa de hiperandrogenismo de la IAAF.}

Este estudio demuestra que:

a) La diferencia del rendimiento deportivo entre hombres y mujeres puede ser establecido en el rango del $10 \%$ - 12\% en el atletismo de élite. 
b) La diferencia del rendimiento deportivo entre mujeres con hiperandrogenismo y mujeres sin hiperandrogenismo no alcanza ni siquiera el $3 \%$, por lo que en ningún caso es equiparable a la diferencia del rendimiento deportivo entre hombres y mujeres.

Por tanto, en los términos enunciados por el TAS:

a) No está justificada la inelegibilidad de las mujeres con hiperandrogenismo con fundamento en una supuesta ventaja competitiva similar a la condición masculina.

b) Queda pendiente que desde cualquier otra ciencia se acredite la diferencia del rendimiento deportivo entre mujeres con y sin hiperandrogenismo en un rango masculino. 

7. LIMITACIONES Y FUTURAS LÍNEAS DE INVESTIGACIÓN 



\section{Limitaciones y futuras líneas de investigación}

\subsection{Pruebas de 1500 metros y más metros}

Una de las limitaciones detectadas en nuestro estudio está relacionada con la volatilidad de las marcas realizadas por los atletas en las finales de las carreras de 1500 o más metros durante los grandes campeonatos (mundiales y JJOO) que, sin duda, habrá afectado al diseño de las curvas correspondientes a estas pruebas.

La falta de estabilidad en las marcas de estas pruebas durante los campeonatos es debido al factor táctico propio de ellas que hace que las carreras puedan ser rápidas, de ritmo medio o muy lentas en base a las decisiones que tomen los participantes en cada carrera.

Por todo ello, creemos que para el análisis de estas pruebas en estudios futuros, no deberían tenerse en cuenta las marcas conseguidas en grandes campeonatos sino exclusivamente las marcas del ranking mundial del año correspondiente que serán, sin lugar a dudas, más fiables.

Afortunadamente, podemos excluir la prueba de $800 \mathrm{~m}$, clave en el presente estudio, de esta consideración ya que ésta muestra unos valores bastante estables en las marcas conseguidas a lo largo de todos los campeonatos.

\subsection{Número de casos}

Sin duda, una de las mayores limitaciones en el estudio de la presente tesis doctoral es el número de casos de mujeres con hiperandrogenismo. De los 30 casos totales que han sido investigados en aplicación de la normativa por parte de la IAAF, 12 eran casos de dopaje y de los 18 restantes: 7 tenían más de $10 \mathrm{nmol} / \mathrm{L}$ de testosterona en suero y fueron sometidas a tratamiento para reducir sus niveles de testosterona. De esas 18 posibles atletas que podían conformar el $100 \%$ de la muestra total, solo tenemos datos de 2 atletas que corresponden al $11.11 \%$. 


\subsection{Futuras líneas de investigación}

Llevar a cabo el mismo estudio de la presente tesis doctoral, incluyendo todos los casos de mujeres con hiperandrogenismo que han sido investigados por la Asociación Internacional de Federaciones de Atletismo.

Realizar el mismo estudio que se llevo a cabo en esta tesis doctoral y poder enlazarlo con estudios de resultados fisiológicos (como por ejemplo el nivel de testosterona en la sangre).

Analizar la diferencia de rendimiento deportivo entre hombres y mujeres en deportes diferentes al atletismo, utilizando la misma metodología utilizada es esta tesis doctoral. 
8. REFERENCIAS 

Alemán Ramírez, R., Céspedes Durán, L., Fernández Vaglio, R., Herrera Rodríguez, A., Sánchez Villalobos, N., Solar Del Valle, T., y Soto Zúñiga, M. (2013). Desórdenes del desarrollo sexual y cirugía correctiva. Medicina Legal de Costa Rica, 30 (2), 58-77.

American Association of Clinical Endocrinologists. (2001). Medical Guidelines for Clinical Practice for the Diagnosis and Treatment of Hyperandrogenic Disorders. Endocrine Practice, 7 (2), 120-134.

Asian Athletics Association. (07 de Julio de 2013). Results: Asian Athletics Championship 2013. Recuperado el 15 de Septiembre de 2016, de http://www.athleticsasia.org/index.php/results/asian-athletics-championships/21-asianathletics-championship-2013

Asian Athletics Association. (14 de Junio de 2014). Results: Asian Junior Athletics Championship 2014 . Recuperado el 15 de Septiembre de 2016, de http://www.athleticsasia.org/index.php/results/asian-junior-athletics-championships/69asian-junior-athletics-championship-2014

Associated Press. (18 de Diciembre de 2006). Indian runner fails gender test, loses medal. Recuperado el 15 de Agosto de 2016, de ESPN: http://www.espn.com/olympics/trackandfield/news/story?id=2701018

Athletics Federation of India. (10 de Septiembre de 2013). 53rd Open National Athletics Championships. Recuperado el 19 de Agosto de 2016, de http://indianathletics.in/?p=1347

Audí Parera, L., Gracia Bouthelier, R., Castaño González, L., Carrascosa Lezcano, A., Barreiro Conde, J., Bermúdez de la Vega, J., y otros. (2011). Anomalías de la diferenciación sexual. An Pediatr Contin, 9, 15-30.

Audí, L., Fernández-Cancio, M., Pérez de Nanclares, G., \& Castaño, L. (2006). Disgenesias gonadales y pseudohermafroditismo masculino. An Pediatr, 64 (Supl2), 23-27.

Ballantyne, K. N., Kayser, M., \& Grootegoed, J. A. (2012). Sex and gender issues in competitive sports: investigation of a historical case leads to a new viewpoint. Br J Sports Med, 46, 614-617.

Barr, M. L., \& Bertram, E. G. (1949). A Morphological Distinction between Neurones of the Male and Female, and the Behaviour of the Nucleolar Satellite during Accelerated Nucleoprotein Synthesis. Nature, 163 (4148), 676-677.

Bermon, S., Vilain, E., Fénichel, P., \& Ritzén, M. (2015). Women with hyperandrogenism in elite sports: scientific and ethical rationales for regulating. J Clin Endocrinol Metab, 100 (3), 828-830.

Bermon, S., Garnier, P. Y., Hirschberg, A. L., Robinson, N., Giraud, S., Nicoli, R., Baume, N.; Saugy, M.; Fénichel, P.; Bruce, S. J.; Henry, H.; Dollé, G.; Ritzen, M. (2014). Serum Androgen Levels in Elite Female Athletes. J Clin Endocrinol Metab, 99 (11), 4328-4335.

Botella Llusía, J. (1998). Los caracteres sexuales y su clasificación. En J. Botella Llusía, \& A. Fernández de Molina, La evolución de la sexualidad y los estados intersexuales (págs. 7784). Madrid: Ediciones Díaz de Santos, S. A. 
Burden, R. L., \& Douglas Faires, J. (2005). Numerical Analysis (8 ed.). Belmont, CA: Thomson Brooks/Cole.

Butler, M. (2015). IAAF Statistics Book - IAAF World Championships Beijing 2015. Monaco: IAAF Communications Department.

Campos Merlo, M. (2007). Identidad sexual y derecho. Estudio interdisciplinario del transexualismo. Pamplona: S.A. Eunesa. Ediciones Universidad de Navarra.

Cardinale, M., \& Stone, M. H. (2006). Is testosterone influencing explosive performance? J Strength Cond Res, 20 (1), 103-107.

Carlson, A. (2007). Chromosome Count. En J. O'Reilly, \& S. K. Cahn, Women and Sports in the United States: A Documentary Reader (págs. 103-110). Lebanon, NH: Northesatern University Press.

Centro canadiense para la ética en el deporte. (2012). Sport in Transition: Making Sport in Canada More Responsible For Gender Inclusivity. Ottawa.

Chapra, S., \& Canale, R. (2010). Numerical Methods for Engineers (6 ed.). Nueva York: Mc Graw Hill.

Coast, J. R., Blevins, J. S., \& Wilson, B. A. (2004). Do Gender Differences in Running Performance Disappear With Distance? Can J Appl Physiol, 29 (2), 139-145.

Court of Arbitration for Sports 24 de Julio de 2015. Dutee Chand v. Athletics Federation of India (AFI) \& The International Association of Athletics Federations (IAAF), CAS 2014/A/3759.

Crewther, B., Kilduff, L., Cook, C., Cunningham, D., Bunce, P., Bracken, R., y otros. (2012). Relationships between salivary free testosterone and the expression of force and power in elite athletes. J Sports Med Phys Fitness, 52 (2), 221-227.

de la Chapelle, A. (1986). The use and misuse of sex chromatin screening for "gender verification" of female athletes. JAMA, 256 (14), 1920-1923.

de la Chapelle, A. (1985). Why sex chromatin should be abandoned as a screening method for "gender verification" of female athletes. Summary of an oral presentation at the 2 nd International AmateurAthletic Federation Medical Congress, (págs. 49-53). Canberra.

Elsas, L. J., Ljungqvist, A., Ferguson-Smith, M. A., FRCPath, S, J. L., Genel, M., y otros. (2000). Gender verification of female athletes. Genet Med, 2 (4), 249-254.

Etter, F., Knechtle, B., Bukowski, A., Rüst, C., Rosemann, T., \& Lepers, R. (2013). Age and gender interactions in short distance triathlon performance. J Sports Sci, 31 (9), 996-1006.

Fardella B., C. (2001). Hiperplasia suprarrenal congénita. Rev. chil. pediatr, 72 (5), 408-415.

Ferguson-Smith, M. A., \& Ferris, E. A. (1991). Gender verification in sport: the need for change? Br J Sports Med, 25 (1), 17-20. 
Gregori Flor, N. (2015). Encuentros y des-encuentros en torno a las intersexualidades/DSD: Narrativas, procesos y emergencias. Tesis doctoral, Universidad de Valencia, Valencia.

Guttmann, A. (1988). The Cold War and the Olympics. Int J, 43 (4), 554-568.

Handelsman, D. J., \& Gooren, L. J. (2008). Hormones and Sport: physiology, pharmacology \& forensic science. Asian J Androl, 10 (3), 348-350.

Harper, J. (2015). Race Times for Transgender Athletes. Journal of Sporting Cultures and Identities, 6 (1), 1-9.

Havelock, E. (1904). Man and Woman: A Study of Human Secondary Sexual Characters (4 ed.). New York: The Walter Scott Publlishing Co., LTD.

Healy, M. L., Gibney, J., Pentecost, C., Wheeler, M. J., \& Sonksen, P. H. (2014). Endocrine profiles in 693 elite athletes in the postcompetition setting. Clin Endocrinol (Oxf, 81 (2), 294-305.

Heggie, V. (2010). Testing sex and gender in sports; reinventing, reimagining and reconstructing histories. Endeavour, 34 (4), 157-163.

Hughes, I., Houk, C., Ahmed, S., Lee, P., \& LWPES1/ESPE2, C. G. (2006). Consensus statement on management of intersex disorders. Arch Dis Child, 91 (7), 564-563.

Hunt, T. M. (2007). Sports, drugs and the Cold War: The conundrum of Olympic doping policy. Olympika: The International Journal of Olympic Studies, 19-41.

Hunt, T. M., Dimeo, P., Hemme, F., Mueller, \& A. (2014). The Health Risks of Doping during the Cold War: A ComparativeAnalysis of the Two Sides of the Iron Curtain. The International Journal of the History of Sport, 31 (17), 2230-2244.

International Association of Athletics Federations. (06 de Julio de 2010). Caster Semenya may compete. Recuperado el 16 de Agosto de 2016, de https://www.iaaf.org/news/iaafnews/caster-semenya-may-compete

International Association of Athletics Federations. (2016). Results. Recuperado el 02 de Agosto de 2016, de https://www.iaaf.org/results

International Association of Athletics Federations. (1 de Mayo de 2011a). IAAF Regulations Governing Eligibility of Females with Hyperandrogenism to Compete in Women's Competition. Recuperado el 16 de Agosto de 2016, de https://www.iaaf.org/news/iaafnews/iaaf-to-introduce-eligibility-rules-for-femal-1

International Association of Athletics Federations. (Mayo de 2011b). HA Regulations, Explanatory Notes. Recuperado el 16 de Agosto de 2016, de https://www.leichtathletik.de/fileadmin/user_upload/ImportedAttachments/Trafomat3/2012 135968_20110430053520_httppostedfile_haexplanatorynotes_eng_amg_30.04.2011_24295 .pdf 
International Association of Athletics Federations. (12 de Noviembre de 2006). IAAF Policy on Gender Verification. Recuperado el 14 de Agosto de 2016, de https://oii.org.au/wpcontent/uploads/2009/01/iaaf_policy_on_gender_verification.pdf

International Olympic Committee. (2016). Results. Recuperado el 01 de Agosto de 2016, de https://www.olympic.org/olympic-results

International Olympic Committe. (Noviembre de 2015). IOC Consensus Meeting on Sex Reassignment and Hyperandrogenism November 2015. Recuperado el 23 de Marzo de 2016, de https://stillmed.olympic.org/media/Document\%20Library/OlympicOrg/IOC/WhoWe-Are/Commissions/Medical-and-Scientific-Commission/EN-IOC-Consensus-Meetingon-Sex-Reassignment-and-

Hyperandrogenism.pdf\#_ga=1.123217675.1620386054.1473945126

International Olympic Committee. (2014). IOC Regulations on Female Hyperandrogenism .

Recuperado el 26 de Julio de 2016, de

https://stillmed.olympic.org/Documents/Commissions_PDFfiles/Medical_commission/IOC -Regulations-on-Female-Hyperandrogenism.pdf

International Olympic Committee. (22 de Febrero de 2012). IOC Regulations on Female

Hyperandrogenism. Games of the XXX Olympiad in London, 2012. Recuperado el 26 de Julio de 2016, de

https://stillmed.olympic.org/Documents/Commissions_PDFfiles/Medical_commission/201

2-06-22-IOC-Regulations-on-Female-Hyperandrogenism-eng.pdf

International Olympic Committee. (1996). Resolution of the 1st IOC World Conference on Women and Sport. Recuperado el 15 de Agosto de 2016, de https://stillmed.olympic.org/media/Document\%20Library/OlympicOrg/IOC/What-WeDo/Promote-Olympism/Women-And-Sport/The-IOC-Commitment/Advocacy-and-raisingawareness/1st-World-Conference-Lausanne-Resolutions-1996.pdf

Karkazis, K., Jordan-Young, R., Davis, G., \& Camporesi, S. (2012). Out of Bounds? A Critique of the New Policies on Hyperandrogenism in Elite Female Athletes. Am J Bioeth, 12 (7), 3 16.

Lacadena, J.-R. (1996). Citogenética. Madrid: Editorial Complutense.

Lager, G. (2011). Doping's Nemesis: Arne Ljungqvist. Chenltenham: SportsBooks Limited.

Le Meur, Y., Hausswirth, C., Dore, S., Bignet, F., Brisswalter, J., \& Bernard, T. (2009). Influence of gender on pacing adopted by elite triathletes during a competition. Eur J Appl Physiol, $106(4), 535-545$.

Le Meur, Y., Hausswirth, C., Dorel, S., Bignet, F., Brisswalter, J., \& Bernard, T. (2011). Erratum to: Influence of gender on pacing adopted by elite triathletes during a competition. Eur J Appl Physiol, 111 (6), 1231-1233.

Lepers, R. (2008). Analysis of Hawaii ironman performances in elite triathletes from 1981 to 2007. Med Sci Sports Exerc, 40 (10), 1828-1834. 
Lepers, R., \& Stapley, P. J. (2010). Differences in gender and performance in off-road triathlon. $J$ Sports Sci, 28 (14), 1555-1562.

Lerma González, H. D. (2012). Metodología de la Investigación: Propuesta, anteproyecto y proyecto ( $\left.4^{\mathrm{a}} \mathrm{ed}.\right)$. Colombia: Ecoe Ediciones.

Ljungqvist, A., Martínez-Patiño, M. J., Martínez-Vidal, A., Zagalaz, L., Díaz, P., \& Mateos, C. (2006). The history and current policies on gender testing in elite athletes. International SportMed Journal, 7 (3), 225-230.

Marañón, G. (1951). La evolución de la sexualidad y los estados intersexuales. Mexico: Ediciones Arcos.

Marín Fernández, B. (1996). Mujer y Deporte. Oviedo: Servicio de Publicaciones. Universidad de Oviedo.

Martínez Patiño, M. J., Mateos-Padorno, C., Martínez-Vidal, A., Sánchez Mosquera, A. M., García Soidan, J. L., Díaz Pereira, M., Touriño González, C. F. (2010). An approach to the biological, historical and psychological repercussions of genderverification in top level competitions. Journal of Human Sport and Exercise, 5 (3), 307-321.

Martinez-Patiño, M. J. (2005). Personal Account: A woman tried and tested. Lancet, S38.

Mendonca, B., Domenice, S., Arnhold, I. J., \& Costa, E. (2009). 46,XY disorders of sex development (DSD). Clin Endocrinol (Oxf), 70 (2), 173-187.

Mjelde, H. (1995). Official Report of the XVII Olympic Winter Games Lillehammer 1994 (Vol. 2). Lillehammer: Lillehammer: LOOC AS.

Mora, J. (29 de Enero de 1986). La federación retira la licencia de atleta a María Jose Martínez Patiño por tener cromosomas masculinos. El País .

Passarge, E. (2010). Genetica: Texto y Atlas. Madrid: Editorial Médica Panamericana.

Pieper, L. P. (2016). Sex Testing: Gender Policing in Women's Sports. Champaign, IL: University of Illinois Press.

Pujol Amat, P. (1992). Sexo genético: práctica actual y limitaciones de su uso como screening de feminidad en los Juegos Olímpicos. Apunts Med Esport, 29 (111), 39-46.

Rio 2016. (Agosto de 2016). Juegos Olímpicos Rio 2016. Recuperado el 29 de Septiembre de 2016, de Resultados 100 Metros Femenino: https://www.rio2016.com/es/atletismo-standings-at$100 \mathrm{~m}$-femenino

Riordan, J. (1988). The Role of Sport in Soviet Foreign Policy. Int J, 43 (4), 569-595.

Ritchie, R., \& Reynard, J. (2008). Intersex and the Olympic Games. J R Soc Med, 101 (8), 395399.

Ritzén, M., Ljungqvist, A., Budgett, R., Garnier, P., Bermon, S., Lindén-Hirschberg, A., y otros. (2015). The regulations about eligibility for women with hyperandrogenism to compete in 
women's category are well founded. A rebuttal to the conclusions by Healy et al. Clin Endocrinol (Oxf), 82 (2), 307-308.

Rüst, C. A., Rosemann, T., Lepers, R., \& Beat, K. (2015). Gender difference in cycling speed and age of winning performers in ultra-cycling - the 508-mile "Furnace Creek" from 1983 to 2012. J Sports Sci, 33 (2), 198-210.

Sader, M. A., McGrath, K. C., Hill, M. D., Bradstock, K. F., Jimenez, M., Handelsman, D. J., y otros. (2005). Androgen receptor gene expression in leucocytes is hormonally regulated: implications for gender differences in disease pathogenesis. Clin Endocrinol (Oxf), 62 (1), 56-63.

Sakamoto, H., Nakanoin, K., Komatsu, H., Michimoto, T., Takashima, E., \& Furuyama, J. (1988). Femininity Control at the XXth Universiade in Kobe, Japan. Int J Sports Med, 9 (3), 193195.

Sánchez, F. J., Martínez-Patiño, M. J., \& Vilain, E. (2013). The new policy on hyperandrogenism in elite female athletes is not about 'sex testing'. J Sex Res, 50 (2), 112-115.

Settin, A., Elsobky, E., Hammad, A., \& Al-Erany, A. (2008). Rapid Sex Determination Using PCR Technique Compared to Classic Cytogenetics. Int J Health Sci (Qassim), 2 (1), 49-52.

Simpson, J. L., Ljungqvist, A., Ferguson-Smith, M. A., de la Chapelle, A., Elsas, L. J., Ehrhardt, A. A., y otros. (2000). Gender Verification in the Olympics. JAMA, 284 (12), 1568-1569.

Sparling, P., O'Donnell, E. M., \& Snow, T. K. (1998). The gender difference in distance running performance has plateaued:an analysis of world rankings from 1980 to 1996. Med Sci Sports Exerc, 30 (12), 1725-1729.

Strachan, T., Read, A. P. (2006). Genética Humana (3 ${ }^{\mathrm{a}}$ ed.). Mexico D.F: McGraw-Hill Interamericana.

Teetze, S., \& Torres, C. R. (2016). Drug Testing, Sex Verification, and the 1967 Pan-American Games. The International Journal of the History of Sport, 33 (1-2), 127-146.

Thibault, V., Guillaume, M., Berthelot, G., El Helou, N., Schaal, K., Quinquis, L., y otros. (2010). Women and men in sport performance: The gender gap has not evolved since 1983. Journal of Sports Science and Medicine, 9 (2), 214-223.

Tucker, R., \& Collins, M. (2010). The science of sex verification and Athletic Performance. Int J Sports Physiol Perform, 5 (2), 127-139.

Valdivia Moral, P. A., Molero López-Barajas, D., Campoy Aranda, T., \& Lara Sánchez, A. J. (2003). La coeducación como instrumento para la integración en la actividad física y el deporte. En M. L. Zagalaz Sánchez, A. J. Lara Sánchez, J. Cachón Zagalaz, \& G. Torres Luque, El deporte como vehículo de integración (págs. 69-82). Sevilla: Wanceulen Editorial Deportiva S.L.

Vázquez, B. (2002). La mujer en ámbitos competitivos: el ámbito deportivo. FAISCA. Revista de Altas Capacidades, 9, 56-69. 
Veldhuis, J., Frystyk, J., Iranmanesh, A., \& Ørskov, H. (2005). Testosterone and Estradiol Regulate Free Insulin-Like Growth Factor I (IGF-I), IGF Binding Protein 1 (IGFBP-1), and Dimeric IGF-I/IGFBP-1 Concentrations. J Clin Endocrinol Metab, 90 (5), 2941-2947.

Voet, D., Voet, J. G., \& Pratt, C. W. (2007). Fundamentos de Bioquímica: La vida a nivel molecular. Buenos Aires: Editorial Médica Panamericana.

Wells, C. (2010). Diagnosing Sex-Gender Verification and the IOC. En R. K. Barney, J. E. Forsyth, \& M. K. Heine, Rethinking Matters Olympic: Investigations Into the Sociocultural Study of the Modern Olympic Movement (pág. 517). London: International Centre for Olympic Research, University of Western Ontario.

Wells, C., \& Darnell, S. C. (2014). Caster Semenya, Gender Verification and the Politics of Fairness in an Online Track \& Field Community. Sociol Sport J, 31 (1), 44-65.

Yamaguchi, A., Fukushi, M., Kikuchi, Y., Aparicio, J., \& Wakisaka, A. (1992). A Simple Method for Gender Verification Based on PCR Detection of Y-Chromosomal DNA and Its Application at the Winter Universiade 1991 in Sapporo City, Japan. Int J of Sports Med, 13 (4), 304-307. 

9. ANEXOS 

ANEXO I:

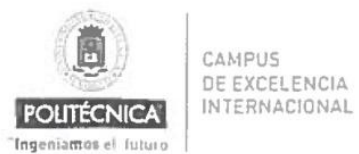

\section{INFORME QUE EMITE EL COMITÉ DE ÉTICA \\ DE LA UNIVERSIDAD POLITÉCNICA DE MADRID}

A petición de la Vicerrectora de Investigación, Innovación y Doctorado de la Universidad Politécnica de Madrid,

Dạ Asunción Gómez Pérez, de un dictamen sobre los aspectos éticos del Proyecto "Controles de sexo, género, hormonales y la inelegibilidad de las mujeres con hiperandrogenismo en el deporte femenino de alto nivel", cuyo investigador principal es D. Jonathan Andrés Ospina Betancurt, del Departamento de Deportes de la Facultad de Ciencias de la Actividad Física y del Deporte - INEF. El Comité emite el siguiente informe:

A la vista de la información del contrato enviada, el investigador firmante asegura que los datos que se analizan son públicos. La información que revelen los resultados de los análisis deberá protegerla el investigador, siendo conocedor de los procesos y protocolos que deben cumplir relativos a la protección de datos según Ley Orgánica 15/1999, de 13 de diciembre, Real Decreto 1720/2007, de 21 de diciembre y Ley 41/2002, de 14 de noviembre, el equipo de investigación asume la responsabilidad de la adopción de las medidas de seguridad y se compromete a respetar la confidencialidad de los datos personales.

Por lo tanto, no hay inconveniente en informar favorablemente la propuesta, recomendando el efectivo cumplimiento de los compromisos declarados.

$Y$ para que asi conste, firmo el presente informe en Madrid a 21 de noviembre de dos mil dieciséis.
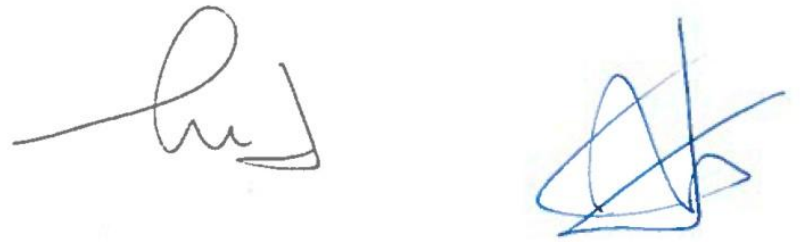

Da Ernestina Menasalvas

Juan Carlos Dueñas 



\section{ANEXO II: \\ Resumen de las pruebas testificales y su valoración por el TAS en el asunto Dutee Chand vs. AFI \& IAAF (CAS 2014/A/3759)}

La impugnación de la normativa sobre hiperandrogenismo de la IAAF se fundamentó, a los efectos que resultan relevantes para esta investigación, en tres argumentos principales: (i) es una normativa discriminatoria contra las mujeres deportistas y contra los deportistas que tienen características físicas naturales particulares; (ii) es una normativa que se basa en el error fáctico de asumir que existe una relación entre la testosterona y el rendimiento deportivo y (iii) es una normativa desproporcionada respecto de cualquier objetivo legítimo a perseguir.

En la vista oral, toda vez que no hubo controversia entre las partes en relación con el primer argumento, toda la actividad probatoria, consistente en las testificales de diferentes expertos en la materia, se centró en las cuestiones relativas a (i) la vinculación entre los andrógenos y el rendimiento deportivo

\section{La vinculación entre los andrógenos y el rendimiento deportivo.}

\section{I.1. La actividad probatoria de la impugnante}

La impugnante sostuvo en defensa de su pretensión que son falsas las dos premisas en las que se fundamenta la normativa sobre hiperandrogenismo -(i) un elevado nivel de testosterona endógena aporta a las atletas femeninas una ventaja competitiva; y (ii) la medicina es capaz en la actualidad de establecer un distinto nivel de testosterona para los atletas masculinos y femeninas-, argumentando que (i) no existe una relación de causalidad entre los niveles de testosterona y el rendimiento deportivo; (ii) la testosterona endógena producida naturalmente- no tiene el mismo efecto fisiológico que la testosterona exógena aportada al cuerpo desde fuentes externas-; y (iii) la medicina no es capaz en la actualidad de establecer que exista un distinto nivel de testosterona para los atletas de ambos sexos. 
La prueba propuesta por la impugnante en defensa de sus argumentos consistió en los testimonios de (i) el profesor Richard Holt, (ii) la Dra. Sari van Anders y (iii) la Dra. Katrina Karkazis.

\section{I.1.1. Testimonio del profesor Richard Holt.}

Richard Holt es un médico, profesor de diabetes y endocrinología de la Universidad de Southampton, que ha sido asesor de numerosas agencias anti-dopaje, incluyendo la Agencia Mundial, la Agencia de Estados Unidos y la Agencia de Reino Unido. Elaboró un informe pericial escrito en cooperación con el profesor Peter Sønksen, otro médico experto en endocrinología, que fue presentado el 14 de noviembre de 2014. El contenido del citado informe pericial y del testimonio oral del profesor Holt queda ampliamente reflejado en los parágrafos 135 a 158 de la decisión arbitral.

El profesor Holt expuso que la normativa sobre hiperandrogenismo carece de rigor científico, pues parte de dos defectos científicos para sustentar la idea de que un elevado nivel de testosterona endógena en las atletas femeninas les confiere una ventaja competitiva: (i) la testosterona endógena no explica la diferencia en el rendimiento deportivo entre varones y mujeres y (ii) no hay pruebas convincentes de que la testosterona endógena mejora el rendimiento deportivo en atletas femeninas, incluyendo aquellas con hiperandrogenismo.

El profesor Holt apoya sus conclusiones principalmente en (i) los resultados obtenidos de los denominados datos de Moscú y Daegu; y (ii) el estudio realizado por Healy et al., (2014) en el marco de un reciente proyecto multinacional de investigación destinado a desarrollar un test de abuso de hormona de crecimiento en el deporte (Healy et al., 2014). Sobre las muestras utilizadas en este estudio asume la crítica de que no se habían obtenido para propósitos médicos y que no se habían recogidos conjuntamente datos clínicos, admitiendo también que era posible que alguna de las mujeres con altos niveles de testosterona pudieran haber estado tomando medicamentos. Sin embargo, en contraposición, destaca la circunstancia de que todos los participantes habían hecho una declaración sobre que no estaban tomando medicamentos y, dado que el estudio se llevó a cabo de manera voluntaria y anónima, en su opinión, era probable que estuvieran diciendo 
la verdad. Por otra parte, el estudio tiene el aval de haber sido publicado en una prestigiosa revista científica revisada por pares.

Desde una perspectiva metodológica, el profesor Holt reconoció que la mayor diferencia entre su análisis y el de los expertos de la IAAF fue si incluir valores atípicos en la definición del rango de referencia normal para los niveles de testosterona endógena. En su opinión, los valores atípicos deben ser incluidos a menos que haya una buena razón para excluirlos y, en este caso, (i) los atletas de alta competición son, por definición, valores atípicos; y (ii) los datos no tienen un fin de diagnóstico clínico sino el de establecer el intervalo de referencia en el rendimiento deportivo, lo que tiene una función diferente y bastante independiente. Igualmente señala que los niveles de testosterona no se miden generalmente en individuos sanos normales, por lo que no hay suficientes muestras para determinar si las mujeres con más de $10 \mathrm{nmol} / \mathrm{L}$ de testosterona endógena tienen un trastorno, y que no todas las Anomalías de la Diferenciación Sexual (ADS) requieren atención clínica por lo que algunas mujeres con altos niveles de testosterona pueden no necesitar visitar nunca a un endocrinólogo.

El contenido principal del testimonio del profesor Holt puede resumirse en las siguientes consideraciones:

a) El diferente IMM de varones y mujeres es uno de los factores causales de las diferencias de rendimiento deportivo entre ambos sexos y está en consonancia con las diferencias en los registros mundiales entre los deportistas de ambos sexos. A esos efectos destaca que en el estudio de Healy et al., (2014) en que se comparan 24 variables en atletas de alta competición de ambos sexos, incluyendo los niveles hormonales y la grasa corporal, se encontró que el IMM de una mujer es, en promedio, en términos proporcionales y absolutos, mucho más baja que la de un varón, existiendo una diferencia de $10 \mathrm{~kg}$ de promedio entre el IMM de ambos sexos. Igualmente, hay otros factores que pueden influir en el rendimiento atlético como son los genéticos, psicológicos o sociológicos.

b) Es una hipótesis razonable establecer que la testosterona es uno de los factores que explican la diferencia de masa muscular entre ambos sexos, pero hay otros factores 
que también pueden ser importantes, como son los diferentes niveles de la hormona del crecimiento, que afecta al desarrollo de la masa corporal, lo que puede aportar una explicación alternativa o adicional. A esos efectos, señala que en el estudio Healy et al., (2014) no se establece una correlación entre los niveles de testosterona y el IMM en ambos sexos, ya que el IMM está condicionado en gran medida por la estatura y la masa, ambas determinadas genéticamente.

c) Las diferencias en el rendimiento deportivo no son causadas por los diferentes niveles de testosterona endógena en cada sexo, sino por otros factores, ya que (i) existe una superposición en los niveles de testosterona en ambos sexos y (ii) no pueden identificarse unos niveles normales de testosterona para establecer rangos para cada uno de los sexos que determinen un umbral a partir del cual puedan afirmarse la existencia de un superior rendimiento deportivo. El profesor Holt acepta un rango de referencia para las mujeres de menos de $2.7 \mathrm{nmol} / \mathrm{L}$ y para los hombres entre 8.4 y $29 \mathrm{nmol} / \mathrm{L}$, pero señala que la testosterona varía con la edad y que no hay datos suficientes para definir un intervalo de referencia para los atletas de alta competición.

A esos efectos, destaca que los resultados del estudio Healy et al., (2014) muestran un muy amplio rango de niveles de testosterona en deportistas de alta competición de ambos sexo, ya que (i) 11 de las 234 atletas femeninas tenían un nivel de testosterona endógena por encima de $8 \mathrm{nmol} / \mathrm{L}$; (ii) 32 de las 234 , lo que representa el $17 \%$, tenían un límite superior al rango de referencia femenino de $2.7 \mathrm{nmol} / \mathrm{L}$; y (iii) el $16.5 \%$ de los deportistas de alta competición masculinos tenían valores de testosterona en sangre por debajo de $8.4 \mathrm{nmol} / \mathrm{L}$. También pone de manifiesto que en el estudio Bermon et al., (2014), el percentil del 99\% para testosterona en mujeres era de 3,08 nmol/L, con exclusión de las mujeres con ADS para las que el nivel medio era de $18.3 \mathrm{nmol} / \mathrm{L}$. Igualmente, expone que los datos de Daegu revelaron que había 13 atletas femeninas no dopadas con niveles de testosterona por encima de $3.08 \mathrm{nmol} / \mathrm{L}$ (el valor citado por los expertos de la IAAF como el límite superior de la "gama femenina"); 4 hombres con niveles de testosterona por debajo de $3.08 \mathrm{nmol} / \mathrm{L}$ y 198 hombres con testosterona por debajo de $10 \mathrm{nmol} / \mathrm{L}$ (Healy et al., 2014). Y que los datos de Moscú, después de eliminar los atletas dopados, 
establecían que 6 mujeres tenían niveles de testosterona por encima de 3,08 $\mathrm{nmol} / \mathrm{L} ; 2$ hombres tenían niveles de testosterona por debajo de $3.08 \mathrm{nmol} / \mathrm{L}$ y 131 hombres tenían testosterona por debajo de $10 \mathrm{nmol} / \mathrm{L}$ (no existe estudio publicado en una revista científica para estos datos).

El profesor Holt afirma que estos datos entran en conflicto con la hipótesis de que es posible distinguir entre hombres y mujeres a partir de la testosterona en sangre y que, si bien, en promedio, los hombres tienen la testosterona más alta que las mujeres, hay algunas mujeres con alta testosterona y algunos hombres, incluso entre los atletas de alta competición, con bajos niveles de testosterona.

d) Es arbitrario establecer como elemento determinante de una eventual ventaja competitiva el umbral de $10 \mathrm{nmol} / \mathrm{L}$ de testosterona en sangre y la sensibilidad a los andrógenos. A esos efectos, el profesor Holt señala como elementos relevantes que (i) los datos de Daegu ponen de manifiesto que no todas las mujeres con un rango superior a $10 \mathrm{nmol} / \mathrm{L}$ tenían un diagnóstico clínico de ADS o mostraban ser casos de dopaje; (ii) en cuanto a la prueba de insensibilidad a los andrógenos, diversas condiciones hormonales pueden causar resistencia hormonal, siendo la clínica, endocrina y evaluación molecular de la insensibilidad a los andrógenos muy imprecisa, pues hay varios cientos de mutaciones de los receptores de andrógenos y ciertos receptores tienen un efecto mayor que otros; y (iii) si bien no hay ninguna duda de que los atletas que se dopan con testosterona exógena experimentan mejoras en su rendimiento, no existe una correlación demostrada entre la testosterona endógena y el IMM, ya que la testosterona exógena y endógena funcionan de manera diferente dentro de un sistema endocrinológico extraordinariamente complejo.

e) La regulación sobre hiperandrogenismo de la IAAF carece del necesario sustento científico. El profesor Holt hace una comparación entre la evolución de las pruebas de la hormona del crecimiento y esta regulación sobre hiperandrogenismo, señalando que las pruebas de la hormona del crecimiento se desarrollaron durante la década de 1990, pero que no se llevaron a cabo hasta el año 2012 y, durante el período de intervención, los científicos trabajaron duro para establecer la prueba 
científica necesaria para justificar la aplicación de un sistema de ensayos de hormona de crecimiento. Sostiene que el estado actual de la evidencia científica en relación con el papel de la testosterona endógena sobre el rendimiento deportivo es similar al estado de los conocimientos sobre los efectos de la hormona del crecimiento en la década de 1990, por lo que el actual estado de demostración es rudimentario y hay un largo camino por recorrer para conseguir el necesario sustento científico.

\section{I.1.2. Testimonio de la Dra. Sari van Anders.}

Sari van Anders es profesora asociada titular de psicología y estudios de la mujer en la Universidad de Michigan y ha publicado un gran número de artículos en revistas sometidas a revisión sobre temas relacionados con la testosterona. Tiene una particular experiencia de investigación en el campo de la neuroendocrinología social, en el que se examina la relación entre las hormonas y el comportamiento social. Elaboró un informe pericial por escrito presentado el 14 de noviembre de 2014. El contenido de ese informe y de su testimonio oral queda ampliamente reflejado en los parágrafos 159 a 171 de la decisión arbitral.

La Dra. van Anders expone que las tres razones por las que la normativa sobre hiperandrogenismo no es sólida científicamente son que (i) la testosterona es dinámica, lo que significa que los individuos tienen sus propios rangos de testosterona que varían dependiendo de una amplia gama de factores; (ii) la testosterona endógena no define masculinidad o feminidad; y (iii) no existen normas científicas para establecer unos niveles de testosterona en mujeres y hombres sanos, en parte debido a que estas normas no reflejarían la naturaleza dinámica de los niveles individuales de testosterona. A esos efectos, de su testimonio cabe destacar las siguientes consideraciones:

a) Los efectos de la testosterona en el cuerpo humano son distintos para cada individuo y variables dependiendo de diversos factores. Así, expone que los tres factores que influyen en el efecto de la testosterona endógena en el cuerpo de una persona son: (i) los niveles de testosterona; (ii) la funcionalidad del receptor de andrógenos; y (iii) el recuento y ubicación del receptor de andrógenos. Indica que 
la funcionalidad del receptor de andrógenos, si bien es estática para cada individuo, varía entre los diferentes individuos y que tanto los niveles de testosterona como el recuento y ubicación del receptor de andrógenos además de variar también para cada persona, son dinámicos, ya que cambian en respuesta a factores internos, ambientales y sociales en cada individuo.

b) Existe un gran número de factores con impacto directo en la variabilidad del nivel de testosterona en cada individuo. La Dra. van Anders cita la estación del año; la hora del día; los patrones y duración del sueño; la edad; el uso de medicamentos, de drogas y la salud; los niveles de estrés; la composición corporal, masa muscular y peso; el ejercicio; la competición; el estado civil y la actividad sexual; situación familiar; menstruación; o el uso de anticonceptivos hormonales. También afirma que la mayoría de las investigaciones sobre la testosterona se ha realizado sobre hombres de ascendencia europea en el ámbito urbano y que no está claro si esos resultados pueden generalizarse a otros grupos de personas.

c) No existe ninguna prueba científica que apoye la afirmación de que la testosterona endógena es el factor causal que garantiza el rendimiento deportivo. Afirma que lo que demuestra la investigación científica es lo contrario, ya que hay deportistas de alta competición de ambos sexos con bajos niveles de testosterona, algunas atletas femeninas que usan anticonceptivos hormonales con bajo índice de andrógenos y otras con SIA completo o parcial. Igualmente, defiende que, debido a que la testosterona es dinámica y varía notablemente, no es posible establecer un rango normal para cada sexo, existiendo un considerable solapamiento de rangos entre ambos sexos. También indica que la hipótesis de que el nivel de testosterona permite diferenciar el rendimiento deportivo en ambos sexos es una suposición falsa y problemática, ya que, si bien la testosterona puede aparecer como un factor relevante, es posible que haya otros factores, como la socialización de géneros durante la pubertad, que puede explicar esa. También recuerda que en el estudio de Sader et al., (Sader et al., 2005) encontró que, en promedio, la expresión del receptor de andrógenos fue sistemáticamente mayor en varones jóvenes sanos que en mujeres jóvenes sanas. Del mismo modo, argumenta que las mujeres con 
hiperandrogenismo, que tienen niveles de testosterona dentro del rango masculino, no rinden del mismo modo que los hombres con ese nivel de testosterona.

d) Un alto nivel de testosterona en las mujeres no implica necesariamente una anormalidad. La Dra. van Anders rechaza la afirmación de que las mujeres sanas no tienen niveles de testosterona endógena de $10 \mathrm{nmol} / \mathrm{L}$, ya que los altos niveles de andrógenos no son por sí anormales o evidencian de un problema de salud, pues aunque haya mujeres que requieran una atención clínica, también puede haber mujeres en perfecto estado de salud con altos niveles de andrógenos que no requieran una atención médica endocrinológica. A esos efectos señala que hay una serie de posibles ADS que aun provocando niveles elevados de testosterona de forma natural, no revisten importancia clínica y no requerirían tratamiento médico.

e) La evaluación sobre in/sensibilidad a los andrógenos se basa en juicios subjetivos que no deberían jugar ningún papel en el diagnóstico clínico. Afirma que la valoración de las características físicas de virilización en el proceso de evaluación sobre sensibilidad a los andrógenos importa normas culturales sobre, por ejemplo, la profundidad de la voz, lo que implica juicios subjetivos acerca de la apariencia de un atleta.

f) Existe una diferencia entre los efectos fisiológicos de la testosterona exógena y endógena, por lo que no resulta posible generalizar los efectos de un nivel alto de testosterona exógena a los de la testosterona endógena. La profesora van Anders expone que es conocido que la testosterona exógena afecta el deseo sexual, mientras que la testosterona endógena no lo hace, señalando que las dos fuentes de testosterona implican diferentes medios de distribución, con diferentes consecuencias para la actividad neuronal. Igualmente, indica que la testosterona exógena a veces tiene el efecto opuesto de la testosterona endógena. Así, con cita del estudio de (Sader et al., 2005), recuerda que mientras la testosterona endógena aumenta la sensibilidad de unión de los receptores de andrógenos, la exógena lo disminuye. Igualmente, expone que mientras en el supuesto de un grupo de sujetos transexuales de mujer a hombre, a los que se les administró testosterona exógena, su nivel del receptor de andrógenos fue notablemente menor que la de los hombres 
jóvenes sanos; mujeres que habían sido expuestas a testosterona endógena a través de un trasplante de médula ósea mostraron un nivel de receptor de andrógenos comparable al de los varones jóvenes sanos, que es muy superior a la de las mujeres jóvenes sanas. De ello deduce que los efectos de la testosterona endógena y exógena pueden ser opuestos. Por último, también hace referencia al estudio de Crewther et al., (2012) para sustentar que un aumento de la testosterona endógena no implica la misma mejora del crecimiento del músculo que la provocada por un aumento de la testosterona exógena.

\section{I.1.3. Testimonio de la Dra. Katrina Karkazis.}

Katrina Karkazis es una investigadora en el campo de la bioética de la Universidad de Stanford. Esta doctorada en antropología médica y cultural y ha publicado libros y trabajos en revistas científicas sobre aspectos sociales y culturales de las enfermedades, ética clínica y de la investigación, tratamiento médico para menores intersexuales y tratamiento de mujeres deportistas con hiperandrogenismo. Elaboró un informe pericial escrito presentado el 13 de noviembre de 2014. El contenido de dicho informe y de su testimonio oral queda reflejado en los parágrafos 172 a 174 de la decisión arbitral.

La Dra. Karkazis reconoció que no era médico y que no había tenido experiencia en diagnóstico o tratamiento médico, pero que tenía experiencia clínica con atención a personas intersexuales. En su testimonio expuso su oposición a la normativa sobre hiperandrogenismo criticando tanto sus bases científicas como su justificación desde una perspectiva de equidad, con fundamento en el artículo del que es coautora: "Out of bounds? A critique of the new policies on hyperandrogenism in elite female athletes" (Karkazis et al., 2012). En este artículo se rebate la vinculación entre la testosterona y el rendimiento deportivo, negando la existencia de evidencias de que los atletas más exitosos tengan un nivel de testosterona más alto que los menos exitosos y destacando que mientras que los estudios clínicos muestran que la testosterona ayuda a aumentar la masa muscular, la fuerza y la resistencia, de ello no se concluye que el aumento de la testosterona endógena tenga como consecuencia un mayor rendimiento deportivo. Los individuos tienen respuestas drásticamente diferentes a la testosterona, que es un elemento más en un complejo sistema neuroendocrino que se retroalimenta. Este trabajo destaca que casi todas 
las investigaciones sobre la testosterona y el atletismo se han llevado a cabo con hombres y que mientras se afirma que hay una diferencia de 10 veces en los niveles de testosterona endógena de ambos sexos, las diferencias de rendimiento deportivo son significativamente más pequeñas.

\section{I.2. La actividad probatoria de la IAAF.}

La IAAF sostuvo en defensa de su pretensión que hay evidencias científicas respecto de que (i) la testosterona es un elemento determinante del rendimiento deportivo y que la diferencia en el nivel de testosterona es el factor más relevante para explicar la diferencia de rendimiento en los deportistas masculinos y femeninas; (ii) los efectos fisiológicos de la testosterona endógena y exógena son los mismos; y (iii) es posible identificar un rango femenino para niveles normales de testosterona, ya que las atletas femeninas no tienen niveles de testosterona más allá del rango establecido a menos que sufran una anomalía ADS o hayan sido objeto de dopaje.

La prueba propuesta por la IAAF en defensa de sus argumentos consistió en los testimonios de (i) el profesor Martin Ritzen y la profesora Angelica Linden Hirschberg, (ii) el doctor Stéphane Bermon y (iii) el profesor Arne Ljungqvist.

\section{I.2.1. Testimonio de los profesores Martin Ritzen y Angelica Linden} Hirschberg.

Martin Ritzen es profesor emérito en el Departamento de salud de las mujeres y los niños del Instituto Karolinska en Estocolmo. Es un especialista en el campo de la endocrinología pediátrica desde hace más de 40 años y ha publicado numerosos trabajos científicos sobre reproducción masculina y diferenciación sexual. Por su parte, Angelica Linden Hirschberg es profesora de ginecología y obstetricia en el Instituto Karolinska y consultora sénior en el Departamento de ginecología y obstetricia del Hospital universitario Karolinska. Ha publicado un gran número de trabajos científicos sobre anomalías en el desarrollo sexual, los efectos del tratamiento con testosterona, anticonceptivos orales y otras cuestiones sobre endocrinología ginecológica. Ambos son miembros del grupo de 14 expertos responsable de revisar los casos planteados a la IAAF en aplicación de la normativa sobre 
hiperandrogenismo. Ambos han realizado un informe pericial fechado el 30 de enero de 2015. El contenido de dicho informe y del testimonio oral conjunto de estos profesores queda reflejado en los parágrafos 175 a 203 de la decisión arbitral.

En el informe se expone el proceso del desarrollo sexual y las condiciones que causan el hiperandrogenismo femenino tanto durante el desarrollo fetal como en la mujer adulta. Durante el desarrollo fetal, la gónada primitiva tiene el potencial de convertirse en testículos, ante la presencia de ciertos genes, o en ovarios, en ausencia de ellos. El testículo segrega la testosterona y la hormona anti-Mülleriana (AMH) y estas hormonas, a su vez, generan sus respectivos receptores para estimular el desarrollo de los órganos internos y externos masculinos. Posteriormente, la testosterona se convierte en dihidrotestosterona (DHT) que hace que los genitales externos se desarrollen de forma masculina. En ausencia de testosterona, porque los testículos no pueden generarla, o si el receptor no funciona siendo el feto insensible a la testosterona y la DHT, o si la testosterona no se puede convertir a DHT por alguna razón, los genitales externos no masculinizan completamente. En esos casos, a un bebé se le puede asignar un género femenino al nacer, incluso si es portador de los cromosomas sexuales masculinos (XY). Por otro lado, si un feto con cromosomas femeninos (XX) está expuesto a hormonas androgénicas sus genitales externos serán masculinizados. Algunas ADS pueden suponer el nacimiento de una mujer con cromosomas XY y testículos no descendidos, pero que son funcionales. También hay una serie de casos en que se puede causar hiperandrogenismo en mujeres adultas, como son el síndrome de ovario poliquístico (SOP); hiperplasia suprarrenal congénita (HSC); 5 alfa-reductasa deficiencia de tipo 2; insensibilidad completa a los andrógenos (SIA); insensibilidad parcial a los andrógenos (SIA Parcial); DSD ovotesticular; y la deficiencia de la aromatasa.

Estos profesores rechazan las afirmaciones de que (i) la normativa sobre hiperandrogenismo carece de soporte científico; y (ii) el tratamiento contemplado en esa normativa es perjudicial para las atletas con hiperandrogenismo. Respecto de esto último destacan que el tratamiento consiste en tomar anticonceptivos orales que es el sistema más simple y rápido para reducir los niveles de testosterona, siendo generalmente bien tolerado y con pocos efectos secundarios. 
Sobre el fundamento científico de la normativa sobre hiperandrogenismo consideran (i) que el profesor Holt y la Dra. van Anders habían interpretado erróneamente la finalidad de la normativa sobre hiperandrogenismo, ya que deja claro que la relevancia que se da al nivel de testosterona no lo es para establecer una distinción entre sexos sino para identificar atletas femeninas que, debido a una condición especial, tienen niveles funcionales de testosterona en sangre que, por lo general, sólo aparecen en los varones; y (ii) que si bien es indubitado que existe una variedad de factores físicos y psicológicos que contribuyen al éxito deportivo, el alto nivel de testosterona es el factor más importante para explicar la diferencia de rendimiento físico entre ambos sexos. De ese modo, en relación con la influencia de la testosterona en el rendimiento deportivo, ambos profesores destacan los siguientes aspectos:

a) Antes de la pubertad, ambos sexos tienen niveles similares de testosterona y una composición corporal también similar. Al inicio de la pubertad, el cuerpo masculino produce significativas cantidades de testosterona en los testículos, mientras que el cuerpo femenino normalmente no lo hace. El aumento de la testosterona provoca el crecimiento de la lipólisis, la síntesis de proteínas y el crecimiento de la fibra muscular, lo que supone que los niños ganan significativamente más masa muscular que las niñas. Tomando en consideración que los hombres adultos tienen un promedio de aproximadamente diez veces más testosterona que las mujeres adultas, eso supone una significativa ventaja física para los hombres. Además, la testosterona provoca aumentos en el tejido óseo y los glóbulos rojos y tiene influencia sobre ciertos patrones de comportamiento, como es el mecanismo de la competitividad, lo que ayuda a una mejora del rendimiento deportivo. Por su parte, la exposición a niveles masculinos de testosterona provoca virilización en las mujeres con una sensibilidad normal en sus receptores de andrógenos. Esto ocurre si los cromosomas de una mujer son XY o XX y surgen elevados niveles de testosterona de los testículos no descendidos o por trastornos suprarrenales u ováricos. Esta virilización tiene un número de síntomas que incluyen la profundización de la voz, atrofia de mama, aumento del crecimiento del vello corporal, acné, aumento de volumen muscular, amenorrea y clitoromegalía.

b) La testosterona es un factor determinante del IMM, que a su vez determina la fuerza, por lo que esta hormona es el mejor factor de discriminación del rendimiento deportivo 
entre ambos sexos. No existe duda de que las atletas femeninas con más de $10 \mathrm{nmol} / \mathrm{L}$ de testosterona tendrán una ventaja significativa respecto de aquellas con niveles normales de testosterona. Esta opinión es ampliamente sustentada en la comunidad científica, existiendo una serie de estudios que establecen una probada vinculación entre los niveles de testosterona endógena y el rendimiento, como el realizado por Cardinale y Stone (2006), que demostró una correlación entre la concentración de testosterona en la sangre y la fuerza explosiva de los atletas de ambos sexos.

c) Existe una relación comprobada entre el uso de testosterona exógena y el aumento de la fuerza y el rendimiento deportivo. A esos efectos, citan un trabajo de Bermon et al., (2015) en el que se acredita que de las 156 atletas femeninas que actualmente cumplen sanciones por dopaje, 100 lo era por uso de esteroides anabólicos androgénicos, y 57 de esos 100 por testosterona o compuestos relacionados con ella. Los autores de este estudio concluyeron que "es poco probable que muchas atletas femeninas dopadas mantuvieran su uso prohibido, aunque detectable, si no tuviera un efecto de aumento del rendimiento". Igualmente, ambos profesores afirman que no hay ninguna diferencia bioquímica entre la testosterona endógena y exógena y que una vez que la testosterona exógena entra en el torrente sanguíneo, la molécula es la misma y los receptores de andrógenos no puede distinguir entre ambas.

El profesor Ritzen sugirió que no había evidencia positiva para sustentar la teoría del profesor Holt y la Dra. van Anders de que los altos niveles de testosterona exógena afectan a la homeostasis del cuerpo de manera diferente en que lo hace la testosterona endógena. Afirma que si bien en los niveles inferiores y superiores es difícil demostrar una relación entre la testosterona y la masa muscular, en un aumento de la dosis de la testosterona desde 3 a 5 o $10 \mathrm{nmol} / \mathrm{L}$, la curva de respuesta que diferencia la masa muscular entre la mujer media y la que tiene un nivel de $10 \mathrm{nmol} / \mathrm{L}$ de testosterona es grande. El profesor Ritzen declara que, si bien no hay datos que lo acrediten, era esperable un mismo resultado en aplicaciones de la testosterona endógena.

d) La selección de un umbral de $10 \mathrm{nmol} / \mathrm{L}$ de testosterona en sangre en la normativa sobre hiperandrogenismo se justifica porque los niveles de testosterona de las atletas femeninas sanas de alta competición en situación de descanso siempre están muy por 
debajo $10 \mathrm{nmol} / \mathrm{L}$. A esos efectos citan estudios basados en datos de población general y de deportistas de alta competición, entre estos últimos, una publicación de Bermon et al., (Bermon et al., 2014) en el que se analizaron los niveles de testosterona en los atletas que participan en el Campeonato Mundial de Atletismo 2011 en Daegu. En este estudio se mostraba que si de las atletas de sexo femenino se excluían las que tenían ADS o estaban dopadas, los niveles de testosterona nunca llegan a $10 \mathrm{nmol} / \mathrm{L}$. El percentil 99\% para el grupo femenino fue de $3.08 \mathrm{nmol} / \mathrm{L}$, muy por debajo del límite de $10 \mathrm{nmol} / \mathrm{L}$. Tres atletas femeninas no diagnosticadas de ADS ni controladas positivamente en el control antidoping tenían niveles de testosterona que excedían del límite. Sin embargo, opinan que estas atletas eran altamente sospechosas de doparse, aunque no hubiera podido probarse totalmente. Igualmente, sostienen que la mayoría de las atletas femeninas de alta competición tienen niveles de testosterona endógena entre 0.1 y $3.08 \mathrm{nmol} / \mathrm{L}$ y que la gama normal para la población masculina comienza alrededor de los $10.5 \mathrm{nmol} / \mathrm{L}$.

Ambos profesores refutan la afirmación de la Dra. van Anders de que incluso si fuera posible establecer distintos rangos de testosterona para ambos sexos, la selección de un límite de $10 \mathrm{nmol} / \mathrm{L}$ es insostenible, argumentando que (i) aunque los niveles de testosterona sean diferentes para cada individuo y variables en cada uno de ellos atendiendo a factores internos, sociales o ambientales, esas variaciones están incluidas en la media de las cohortes publicadas; (ii) no existen pruebas de variaciones significativas entre los grupos étnicos; y (iii) si bien los niveles de testosterona pueden variar en cada individuo, no ocurre de manera extrema, de modo que la probabilidad de que una mujer sana alcance los $10 \mathrm{nmol} / \mathrm{L}$ es prácticamente cero. En relación con ello, refutan la sugerencia del profesor Holt de que es posible que las mujeres sanas con altos niveles de testosterona no se presentan para una atención médica, señalando la profesora Hirschberg que a menos que no tengan sensibilidad a los andrógenos entonces tendrían síntomas de virilización, lo que disminuiría la probabilidad de que no requirieran esa atención médica.

Igualmente, rechazan la opinión del profesor Holt sobre la existencia de una superposición en los rangos normales de testosterona de ambos sexos. Afirman que, sin perjuicio de las situaciones anormales de hiperandrogenismo, que causa altos 
niveles de testosterona, y de sobre-entrenamiento, que causa niveles anormalmente bajos de testosterona, por lo general hay una diferencia clara entre los niveles de testosterona de ambos sexos.

Por tanto, concluyen que no hay fundamento para atacar la selección de un umbral de $10 \mathrm{nmol} / \mathrm{L}$, al que solo se le puede achacar que es demasiado generoso y puede llevar a falsos negativos. Reconocen que la normativa sobre hiperandrogenismo del COI no especifica un límite inferior y lo achacan a que el COI considera que el rango normal masculino puede estar por debajo de $10 \mathrm{nmol} / \mathrm{L}$. A pesar de estar de acuerdo con esa apreciación desde un punto de vista científico, destacan que la normativa de la IAAF tiene la ventaja de establecer un criterio objetivo claro.

e) El profesor Ritzen explica que la decisión de utilizar el umbral de $10 \mathrm{nmol} / \mathrm{L}$ parte del nivel medio de testosterona en mujeres con SOP, que es de $4.5 \mathrm{nmol} / \mathrm{L}$, sumando una desviación estándar de tres puntos $(7.5 \mathrm{nmol} / \mathrm{L})$, lo que ya sólo se aplicaría aproximadamente a 16 atletas de 1000, y que para garantizar que la normativa sólo se aplica a las atletas femeninas con hiperandrogenismo se propuso añadir una desviación extra de dos punto, que dio como resultado el nivel de $10 \mathrm{nmol} / \mathrm{L}$, coincidente con los niveles clínicos normales de rango de testosterona masculina.

\section{I.2.2. Testimonio del doctor Stéphane Bermon.}

Stéphane Bermon es el actual presidente de la Sociedad internacional de ejercicio e inmunología. Ha sido miembro de la Comisión médica y anti-doping de la IAAF, desde enero de 2006 y en 2009 formó parte del grupo de trabajo responsable de revisar las políticas de la IAAF tras el caso Caster Semenya. Ha realizado un informe pericial fechado el 29 de enero de 2015. El contenido de dicho informe y de su testimonio oral queda reflejado en los parágrafos 204 a 215 de la decisión arbitral.

El Dr. Bermon señala que en la alta competición los atletas masculinos superan ampliamente en sus resultados a las atletas femeninas y que, utilizando datos de todos los eventos directamente comparables, la diferencia media de rendimiento entre los dos es del $12.64 \%{ }^{23}$. Las evidencias disponibles establecen que esta diferencia no es atribuible a la 
nutrición, sino al hecho de que los atletas masculinos son típicamente más rápidos, fuertes y altos, y tienen una mayor ratio músculo-peso que las mujeres. Esa diferencia surge como resultado de la mayor masa muscular y una mayor potencia que los varones desarrollan durante la pubertad que, a su vez, es provocada principalmente por el efecto anabólico y androgénico de unos destacados niveles más altos de testosterona que los varones comienzan a producir desde la pubertad. De ese modo, en relación con la influencia de la testosterona en el rendimiento deportivo, destaca los siguientes aspectos:

a) Discrepa con las críticas a la base científica del Reglamento sobre hiperandrogenismo, citando dos estudios de la IAAF con muestras amplias ${ }^{24}$ que establecen que el rango normal de testosterona endógena en las mujeres, incluyendo a las atletas de alta competición, es mucho más baja, con una severa desviación estándar, que el límite establecido por la IAAF. Además, se refiere a las circunstancias de que (i) las atletas femeninas de alta competición de la República Democrática alemana experimentaron enormes mejoras inmediatas en su rendimiento deportivo después de recibir testosterona exógena; (ii) las atletas femeninas siguen utilizando testosterona exógena de manera ilícita para mejorar su rendimiento deportivo; (iii) Las mujeres con ADS están desproporcionadamente representadas en la alta competición atlética en comparación con la población general; (iv) una serie de estudios establecen una relación positiva entre los niveles de testosterona y la fuerza explosiva; y (v) las atletas con hiperandrogenismo que han recibido tratamiento para suprimir sus niveles de testosterona no han podido, en su retomo a la competición, obtener sus mejores resultados previos al tratamiento.

b) Cuestiona el estudio de Healy et al., (2014) tanto desde un punto de vista metodológico como respecto de la capacidad de excluir el dopaje o el hiperandrogenismo en las atletas femeninas y el hipoandrogenismo en los atletas masculinos en los datos manejados.

En relación con los datos de Daegu, destaca que después de la eliminación de las diez atletas con niveles anormalmente elevados de testosterona por dopaje o ADS, el 99\% de las restantes habían dado unos niveles de testosterona por debajo de 3,08 
nmol/L. Nueve atletas estaban por encima de ese nivel. Seis de ellas tenían niveles de testosterona entre 3 y $4 \mathrm{nmol} / \mathrm{L}$. De esas seis, una era un atleta con un ADS que estaba autorizada para competir, pero que no habían sido muy diligente con el tratamiento médico prescrito. Dos más habían sido sancionadas previamente por uso exógeno de testosterona. Una cuarta daba otros resultados que dieron lugar a una sospecha de dopaje. La quinta tenía un perfil muy específico que daba lugar a un riesgo de $98 \%$ de dopaje. La sexta se había retirado en 2012 y no existía ninguna información adicional sobre ella. Las otras tres atletas con valores entre 10 y 12 $\mathrm{nmol} / \mathrm{L}$ provenían de un país sospechoso con una prevalencia especialmente alta de dopaje. Una tenía un perfil de la orina sospechosa; otra tenía un perfil de ferritina muy alta, lo que era un fuerte indicador de dopaje; y la tercera tenía en sus muestras dos indicadores de uso de testosterona exógena.

El Dr. Bermon pone de manifiesto que los datos de Daegu revelan una sobrerepresentación de las mujeres con ADS en la población de mujeres deportistas de alta competición y que ello era consistente con el hecho de que las mujeres con SOP, que tienen niveles elevados de testosterona, también están sobre representadas en la población femenina. Los datos de Daegu muestran una tasa de incidencia del hiperandrogenismo de 7.1 por cada 1000 mujeres atletas, siendo, por el contrario, la tasa de incidencia en la población general de alrededor del 1 por cada 20000. Por tanto, la tasa de incidencia en deportistas es de aproximadamente 140 veces mayor que en la población general.

Por su parte, en relación con los datos de Moscú, indica que dentro del grupo de atletas femeninas había dos casos con niveles atípicamente altos de testosterona de 28 y $43 \mathrm{nmol} / \mathrm{L}$ y que había motivos fundados para creer que estas atletas tenían alguna ADS. Además, había tres atletas dopadas con resultados de entre 7 y 11 $\mathrm{nmol} / \mathrm{L}$. Una vez que se eliminaron estos cinco casos, los niveles de testosterona obtenidos de las atletas femeninas fueron más o menos los mismos que en la población general. También indicó que había un significativo número de atletas varones con niveles de testosterona por debajo de $10 \mathrm{nmol} / \mathrm{L}$. En algunos casos era consecuencia de hipogonadismo, ya fuera como resultado del uso de esteroides anabólicos, sobre-entrenamiento u otra condición médica subyacente. 
c) Aporta dos razones para justificar que no se hagan test a los varones para identificar altos niveles de testosterona como son que (i) solo hay dos categorías de competición, femenina y masculina, y no una tercera separada para los varones con un rendimiento deportivo anormalmente alto; y (ii) la curva de respuesta en varones con altos niveles de testosterona no determina una ventaja particular de la misma manera que se produce en las mujeres.

d) Reconoce que las pruebas de la vinculación entre la testosterona y el rendimiento deportivo eran indirectas y que no era posible una prueba directa y que no ha existido una adecuado análisis de correlación entre resultados deportivos y niveles de testosterona por falta de datos.

e) Ratifica (i) que el umbral de $10 \mathrm{nmol} / \mathrm{L}$ se seleccionó sobre la base de que era una desviación estándar de 5 puntos respecto de los niveles de testosterona típicos de las mujeres con SOP; (ii) que si se toman en consideración los valores atípicos hay un leve solapamiento entre los rangos de ambos sexos; y (iii) que la testosterona no debe considerarse de forma aislada, ya que la evaluación clínica de virilización es igualmente importante para determinar la insensibilidad total o parcial a los andrógenos.

\section{I.2.3. Testimonio del profesor Arne Ljungqvist.}

Arne Ljungqvist ha sido un atleta internacional de alta competición antes de ejercer como médico. Ha sido el Presidente de la Comisión Médica y Antidopaje de la IAAF desde 1980 a 2004 y de la Comisión Médica del COI desde 2003 a 2014. También ha ejercido distintos puestos en la Agencia Mundial Antidopaje -de la que ha sido vicepresidente- incluyendo la presidencia de su Comité de salud, médico y de investigación. Ha realizado un informe pericial fechado el 29 de enero de 2015. El contenido de dicho informe y de su testimonio oral queda reflejado en los parágrafos 216 a 228 de la decisión arbitral.

El profesor Ljungqvist sostiene que la diferencia de rendimiento deportivo entre ambos sexos se debe en gran parte al hecho de que a partir de la pubertad los testículos del varón 
producen niveles mucho más altos de testosterona que los ovarios de una mujer. La testosterona afecta a todo el cuerpo, en particular aumentando el tamaño del músculo y la capacidad de transportar oxigeno de la sangre. Por esa razón algunos deportistas de ambos sexos se auto administran ilícitamente testosterona para aumentar su rendimiento deportivo.

Discrepa con los argumentos de que (i) no es distinto el rango de testosterona en ambos sexos, citando un trabajo del que es coautor con el profesor Ritzen (Ritzén et al., 2015) en el que se refuta el trabajo de Healy et al., (2014); y de que (ii) no hay pruebas de que la testosterona endógena mejore el rendimiento, destacando que la lista de sustancias prohibidas se refiere tanto a la administración de hormonas exógenas sintéticas como a la de sustancias que promueven la producción y liberación de las hormonas endógenas, incluyendo la testosterona.

Afirma que (i) no es posible cuantificar la magnitud de la ventaja atlética disfrutada por una atleta particular sobre la base de una evaluación de virilización física; (ii) la existencia de niveles de testosterona en atletas femeninas superiores a los $10 \mathrm{nmol} / \mathrm{L}$ no les permite participar en competiciones masculinas, como tampoco niveles de testosterona en atletas varones menores de $3 \mathrm{nmol} / \mathrm{L}$ les permite competir en la categoría femenina; y (iii) no existe ninguna otra norma de exclusión aplicable a otros rasgos genéticos o características biológicas, tales como el tamaño de la mano.

El profesor Ljungqvist expone, en relación con la adopción de la normativa sobre hiperandrogenismo, que no era partidario de las pruebas de verificación de género y que participó en las discusiones en Miami 2010 (explicada en el apartado 1.2.7 de esta tesis doctoral), sobre la adopción de la nueva normativa, destacando los siguientes aspectos: (i) la reglamentación fue adoptada después de muchas reuniones de consenso; (ii) la IAAF consideró que tenía una responsabilidad para con las atletas, incluyendo su protección frente a las especulaciones sobre su sexo; (iii) la IAAF ha estado continuamente buscando un test que, estando desarrollado conforme a la mejor ciencia disponible, tuviera la menor perturbación posible para las atletas; (iv) el proceso que condujo a la actual regulación se centró originalmente en las atletas con ADS; (v) había una preocupación de que los varones no compitieran en categorías femeninas; (vi) se aceptó la posición de que las 
mujeres con SIA no tiene ninguna ventaja competitiva y las mujeres con SIA parcial solo tiene una ventaja de menor importancia. Considera que sólo las mujeres con un nivel de testosterona en el rango masculino con unos receptores de andrógenos totalmente funcionales cuentan con una ventaja competitiva, pero esto tendría que ser evaluado caso por caso.

El profesor Ljungqvist afirma que los presupuestos de la normativa sobre hiperandrogenismo son científicamente válidos, dentro del estado actual del conocimiento y que, cuando la competición se divide en dos categorías sexuales, pero existe una población de intersexuales, los científicos con los que ha consultado dicen que estas regulaciones son lo mejor que se puede conseguir. Considera que no existe una exclusión para otros rasgos genéticos particulares porque es perfectamente aceptable tener una diversidad de características naturales dentro de un mismo grupo de competición siempre que no afecte a características que afecten a la definición de una persona como varón o mujer.

\section{I.3. La valoración de la actividad probatoria por el TAS.}

El TAS expone la valoración de la actividad probatoria desarrollada sobre las bases científicas de la normativa sobre hiperandrogenismo en los parágrafos 454 a 488 de la decisión arbitral.

El TAS, de manera preliminar, no objeta la independencia e imparcialidad de los expertos que testimoniaron a propuesta de la IAAF, a pesar de que todos ellos participaron en la elaboración de la normativa sobre hiperandrogenismo, argumentado que si bien sus opiniones son favorables a proporcionar una base científica al Reglamento impugnado, lo hacen actuando como profesionales expertos independientes.

El TAS constata que no existe controversia entre las partes en admitir que el IMM contribuye a la fuerza y, en última instancia, al rendimiento deportivo; pero que hay un desacuerdo en los efectos de la testosterona en el desarrollo de esa masa muscular, lo que plantea una controversia respecto de (i) si la testosterona tiene ese efecto y (ii) si hay una 
diferencia entre la testosterona endógena y exógena, cuyo análisis aborda de una manera separada.

\section{I.3.1. La relación entre la testosterona y el rendimiento deportivo.}

El TAS afronta, en primer lugar, la valoración que le sugiere el debate existente respecto de las conclusiones del estudio Healy et al., (2014) sobre la influencia de la testosterona en el desarrollo de la masa muscular. A esos efectos, el TAS pone de manifiesto que mientras el profesor Holt había concluido en su testimonio oral que el estudio Healy demostraba que, tomando en consideración todas las variables demográficas y hormonales, la testosterona tenía una correlación menor que otros factores en el IMM (Healy et al., 2014), en otros estudios se había llegado a la conclusión opuesta. Así, el TAS cita el trabajo de los profesores Hirschberg y Ritzen y del doctor Bermon (Ritzén et al., 2015), quienes destacaron las graves limitaciones metodológicas del estudio Healy respecto de la técnica usada para la medición de testosterona y en la toma de muestras de sangre de los atletas, que se hizo cuando los niveles de testosterona en los hombres son propensos a ser menores y cuando los niveles de testosterona en las mujeres tienden a permanecer sin cambios o a un aumento moderado. Igualmente critican que el estudio Healy carece de la discusión sobre el razonamiento subyacente que respalda sus conclusiones y no establece cuál es el mejor predictor del IMM. En atención a todo ello, el TAS considera mejor fundamentada esta refutación del estudio Healy, por no proporcionar una base razonada para rechazar la correlación entre la testosterona y el rendimiento deportivo o sugerir una causa alternativa.

El TAS destaca, en segundo lugar, que los profesores Hirschberg y Ritzen explicaron que el IMM es una clave determinante de la fuerza y que es claro que el IMM está a su vez muy influido por los niveles de testosterona. Antes de la pubertad, no hay una diferencia significativa entre los sexos en la composición corporal entre hombre y mujeres, siendo durante la pubertad cuando los hombres aumentan significativamente su masa muscular en relación con las mujeres. Esta correlación, en la opinión de estos autores, se explica por el aumento de los niveles de testosterona durante la pubertad masculina. Por otra parte, ambos profesores señalan que Veldhuis et al., (2005) también encontraron que cantidades fisiológicas de testosterona estimulan de acumulación de tejido muscular aumentando el volumen muscular total. De ello, infieren que la testosterona es un factor significativo en el 
índice de masa muscular, que a su vez determina la fuerza, y, por tanto, que esta hormona es el mejor factor para diferenciar el rendimiento deportivo entre hombres y mujeres. Frente a ello, el TAS constata que si bien el profesor Holt relacionó la diferencia entre masa muscular masculina y femenina con posterioridad a la pubertad no directamente con la testosterona sino con la hormona del crecimiento, ese rechazo de la vinculación entre masa muscular y la testosterona sólo representa una hipótesis que no está respaldada de pruebas científicas.

El TAS afirma que el estudio Harper (2015) si bien se basa en una muestra de pequeño tamaño apoya la conclusión de que (i) la testosterona es un factor de diferenciación apropiada entre los atletas de ambos sexos y (ii) una disminución de la testosterona endógena reduce la capacidad atlética, como también lo hace la reducción de la testosterona exógena.

El TAS expone que, si bien la impugnante se basó en el argumento expuesto en el trabajo de Karkazis et al., publicado en el American Journal of Bioethics (Karkazis et al., 2012) sobre que la diferencia de 10 veces en los niveles de testosterona endógena entre ambos sexos no se traduce en una igual diferencia de rendimiento deportivo, ese argumento no puede ser tomado en consideración, ya que representa una opinión sociológica, lo que no equivale a un conocimiento y evidencia científica y clínica. Se basa en la observación de solapamiento en los resultados de las carreras en las competiciones masculinas y femeninas y no está respaldada por estudios o análisis científicos. No obstante, supone un cuestionamiento sobre la correlación directa entre los niveles de testosterona y la cuantificación del rendimiento deportivo.

El TAS constata que la impugnante rebate la posición de la IAAF de que la testosterona es el mejor predictor del rendimiento deportivo, enfatizando la existencia de anomalías en los efectos fisiológicos de testosterona como es el SIA. Frente a ello, destaca que la segunda fase del test de inelegibilidad es, precisamente, determinar la in/sensibilidad a los andrógenos.

Del mismo modo, el TAS afirma que también es una mera hipótesis que no se basa en la evidencia científica el argumento de que si la testosterona es el elemento más relevante del 
rendimiento deportivo, los atletas masculinos con bajos niveles de testosterona no debían demostrar un alto rendimiento atlético ni éxito deportivo. Así, destaca la respuesta aportada por el Dr. Bermon de que los niveles bajos de testosterona podrían explicarse por hipogonadismo o por un sobre-entrenamiento sin una recuperación adecuada.

Por lo que se refiere a la polémica sobre las diferentes conclusiones que se alcanzaron por cada uno de los expertos en relación con los datos de Moscú y Daegu en cuanto a una eventual yuxtaposición en los rangos de testosterona endógena en ambos sexos, el TAS sostiene que las discrepancias se deben a la forma en que los expertos trataron los valores atípicos en el estudio, siendo algunos partidarios de incluir esos valores y otros de excluirlos. En relación con ello, afirma que, a pesar de la relevancia de ambos estudios por la amplitud de su muestra, la circunstancia de la superposición de los niveles de testosterona entre ambos sexos no resulta relevante por no afectar a la cuestión controvertida en el caso del efecto de tales niveles en el rendimiento deportivo.

El TAS concluye de todo ello que la impugnante no ha cumplido con la carga probatoria que le correspondía de que no existe una relación entre la testosterona y el rendimiento deportivo.

\section{I.3.2. La diferencia entre la testosterona endógena y exógena.}

El TAS expone la valoración de la actividad probatoria desarrollada sobre la diferencia entre la testosterona endógena y exógena en los parágrafos 473 a 488 de la decisión arbitral.

El TAS constata que ningún estudio ha establecido, con un nivel apropiado de certeza, la existencia de una base científica para llegar a una conclusión definitiva sobre la existencia o no de un diferente efecto de la testosterona endógena y exógena. Así, en relación con las conclusiones del estudio Sader et al., (2005) sobre la existencia de efectos de la testosterona exógena opuestos en algunos casos a los de la testosterona endógena, el TAS afirma que no es una evidencia convincente, ya que (i) el profesor Ritzen señaló que el estudio mide el nivel de los receptores de andrógenos de leucocitos, que es relevante para la enfermedad cardiovascular, pero que no pueden ser generalizados de forma automática a 
los efectos que las hormonas exógenos y endógenos tienen sobre los músculos o el cerebro; y (ii) las limitaciones metodológicas planteadas por el profesor Ritzen y reconocidas por el profesor Holt arrojan dudas sobre la validez de las conclusiones de la Dra. van Anders que son una extrapolación del estudio Sader.

En relación con las conclusiones de la doctora van Anders, basada en el estudio de Crewther et al., (2011) de que un aumento de la testosterona endógena no conduce a la misma mejora del crecimiento muscular que el de la testosterona exógena, el TAS da prevalencia a la opinión de los profesores Hirschberg y Ritzen, por ser su campo específico de especialidad, de que la Dra. van Anders malinterpreta los resultados de ese estudio. En este trabajo se examinan los efectos a corto plazo de la testosterona exógena y endógena en el sistema neuromuscular, concluyéndose que la contribución exacta de la testosterona endógena para el entrenamiento de resistencia sigue siendo poco clara.

El TAS pone de manifiesto que la IAAF ha presentado como un estudio que acredita la vinculación entre los niveles de testosterona endógena y el rendimiento deportivo el realizado por Cardinale \& Stone (2006). Este estudio examinó los niveles de testosterona y la capacidad de salto en velocistas femeninas y jugadores de voleibol. El estudio encontró específicamente que la relación positiva observada entre los niveles de testosterona y de salto vertical indicó que esta hormona juega un papel crucial en la función neuromuscular. Por lo tanto, los profesores Hirschberg y Ritzen sostuvieron que este estudio demostraba una correlación positiva entre la concentración de testosterona en la sangre y la fuerza explosiva en ambos sexos. También constata el TAS que el profesor Holt muestra su conformidad en que este estudio establece una correlación entre los niveles de testosterona endógena y el rendimiento, pero señaló que correlación no significa causalidad, afirmando que cualquier diferencia de resultados puede ser causada por otras diferencias entre las disciplinas deportivas o una coincidencia. En atención a ello, el TAS concluye que esta afirmación de que otras diferencias pueden justificar la diferencia de capacidades entre las velocistas y el salto de los jugadores de voleibol es meramente especulativa.

El TAS también rechaza, por ser hipótesis no probadas, (i) la afirmación de la Dra. van Anders del distinto camino de metabolización de la testosterona endógena y exógena; (ii) la evidencia clínica del Dr. Bermon de su participación personal en 30 casos de mujeres 
con hiperandrogenismo con quien la IAAF había tratado en virtud de la normativa sobre hiperandrogenismo, en que se pone de manifiesto que de las siete atletas con niveles de testosterona funcional superior a $10 \mathrm{nmol} / \mathrm{L}$ que se sometieron a un tratamiento para reducir esos niveles por debajo de $10 \mathrm{nmol} / \mathrm{L}$, las siete experimentaron una disminución en su rendimiento deportivo; y (iii) la afirmación del Dr. Bermon, basada en su experiencia de que, para una diferencia entre $1.5 \mathrm{nmol} / \mathrm{L}$ y $15 \mathrm{nmol} / \mathrm{L}$, se estima una mejora del $3 \%$ en el rendimiento deportivo.

Por tanto, el TAS concluye que las pruebas aportadas sobre si la testosterona endógena y exógena tienen los mismos o diferentes efectos en el cuerpo no permite llegar a una conclusión u otra, ya que no hay datos aceptables para validar correctamente cualquiera de las hipótesis. De ese modo, teniendo que aplicar las reglas sobre la carga de la prueba, el TAS establece que la impugnante no ha demostrado que existe una diferencia entre los efectos de la testosterona endógena y exógena.

\section{La desproporcionalidad de la normativa sobre hiperandrogenismo.}

\section{II.1. La actividad probatoria de la impugnante}

La impugnante sostuvo en defensa de su pretensión que la normativa sobre hiperandrogenismo (i) persigue un objetivo ilegítimo como es la búsqueda de la igualdad de condiciones en la competición y (ii) causa daños desproporcionados en la consecución de cualquier objetivo legítimo.

La prueba propuesta por la impugnante en defensa de sus argumentos consistió en los testimonios de (i) la Dra. Katrina Karkazis; (ii) Sr. Paul Melía; y (iii) Sra. Madeleine Pape.

\section{II.1.1. Testimonio de la Dra. Katrina Karkazis.}


La Dra. Karkazis, cuyo testimonio es detalladamente recogido en los parágrafos 251 a 266 de la decisión cautelar, fundamenta su oposición a la normativa sobre hiperandrogenismo en los siguientes aspectos:

a) Estigmatiza y genera perjuicios a las atletas que son investigadas por sospecha de hiperandrogenismo. La Dra. Karkazis argumenta que esta normativa se fundamenta en que la segregación sexual en el deporte implica que todos los competidores pueden (y deben) ser científicamente clasificados como varones o mujeres y, sin embargo, esa clasificación resulta insuficiente para esta normativa ya que indaga más allá del estatus legal sexual de un individuo como varón o mujer para establecer un criterio adicional que determine si una atleta puede competir en pruebas de atletismo femenino. De ese modo, sostiene que si bien esta normativa busca alejarse del anterior enfoque de verificación de género, afirmando que la testosterona es un marcador científicamente válido para la segregación de sexos, existe una percepción generalizada de que esta normativa implica también una verificación de género, ya que (i) la determinación sexual no es una tarea sencilla al existir al menos seis distintos marcadores de sexo -cromosómico, gonadal, hormonal, características sexuales secundarias, genitalidad externa y genitalidad interna (explicados en el apartado 1.1.1)- ninguno de los cuales son decisivos. Eso determina una variabilidad mucho más compleja que la categorización binaria de sexos. (ii) La propia normativa establece la segregación sexual en la competición deportiva como la razón de su existencia, que es la misma de las anteriores pruebas de verificación de género.

En relación con lo anterior, sostiene que la aplicación de esta normativa resulta estigmatizante. Los medios de comunicación a menudo sugieren que el fin de la investigación es determinar si una atleta ostensiblemente masculina no es, de hecho, una mujer, máxime cuando establece que las mujeres con hiperandrogenismo suelen mostrar rasgos masculino y capacidades atléticas poco comunes en relación al resto de competidoras femeninas, lo que puede ser valorado como signos de una subyacente o verdadera masculinidad. Igualmente, pone de manifiesto que la previsión de que cualquier persona puede plantear dudas acerca de una atleta al director médico de la IAAF crea el riesgo de que haya investigaciones que se desencadenen a partir de campañas de rumores y 
la posibilidad de que se filtre información privada sobre la salud. Así, destaca que la propia IAAF ha estado involucrada en la divulgación de información sobre las atletas investigadas, ya que, por ejemplo, en 2008, un trabajador de la IAAF confirmó a la prensa que la atleta Caster Semenya estaba bajo investigación. También destaca que una investigación puede afectar a la visión de la atleta sobre su propia identidad y a sus relaciones familiares, con su deporte y con la comunidad en general, lo que se ve agravado en casos de repercusión mediática, pudiendo generar la ruptura de relaciones familiares, la pérdida de empleo e incluso intentos de suicidio.

b) Es injusta comparada con el tratamiento que se da al resto de variaciones fisiológicas que afectan el rendimiento deportivo. La Dra. Karkazis también critica el hecho de que esta normativa trata de forma diferente el hiperandrogenismo que a otros rasgos físicos naturales que no son objeto de restricciones en cuanto a su elegibilidad. Cita como ejemplos (i) los corredores y los ciclistas que tienen algunas condiciones mitocondriales raras que les dan una mayor capacidad aeróbica y resistencia contra la fatiga; (ii) los jugadores de baloncesto con acromegalia, que les dota de un tamaño excepcionalmente grande de manos y pies; (iii) la proporción de jugadores de béisbol con una visión perfecta es significativamente más alta que en la población general; y (iv) aquellos atletas que tienen variaciones genéticas que les permite incrementar la eficiencia y tamaño de su masa muscular y de su flujo sanguíneo a los músculos esqueléticos. Señala que, siendo el hiperandrogenismo una condición natural, no hay ninguna razón para tratarlo de manera diferente a cualquier otra variación biológica excepcional.

c) Afecta de manera desproporcionada a las mujeres del hemisferio sur. Destaca que son las mujeres pobres del hemisferio sur las que parecen ser la población más afectada por esta normativa, lo que aumenta la preocupación sobre la falta de consentimiento informado, ya que las mujeres procedentes de entornos socioeconómicos menos favorecidos pueden verse afectadas en mayor medida por las presiones adicionales que se derivan del hecho de que sus familias, los equipos y sus países pueden ser especialmente dependientes de su capacidad de competir. 
d) Provoca que mujeres sanas puedan verse coaccionadas a someterse a intervenciones médicas perjudiciales con el fin de ser elegibles para competir. La Dra. Karkazis afirma que, conforme a su experiencia, el consentimiento informado es a menudo insuficiente en la toma de decisiones médicas relacionadas con el hiperandrogenismo y que existe el riesgo de que las atletas con hiperandrogenismo se sometan de manera coaccionada y con el fin de recuperar su elegibilidad a un complejo tratamiento médico para reducir la testosterona que pueden conllevar graves efectos secundarios sobre su salud que disminuyen la calidad de vida e implican significativos riesgos físicos.

\section{II.1.2. Testimonio del Sr. Paul Melia}

Paul Melia es el Presidente y Oficial Jefe ejecutivo del Centro canadiense para la ética en el deporte (CCES, en sus siglas en inglés), que es la agencia nacional antidoping de Canadá y tiene encomendada la protección de la integridad en el deporte frente a otras amenazas poco éticas y la promoción de que el deporte sea justo, seguro y abierto a todos. Ha realizado un informe pericial escrito fechado el 14 de noviembre de 2014. El contenido de dicho informe y de su testimonio oral queda reflejado en los parágrafos 267 a 273 de la decisión arbitral.

El sr. Melia expone las siguientes razones por las que el CCES considera que la normativa sobre hiperandrogenismo resulta objetable desde perspectivas morales, éticas y legales:

a) La normativa resulta discriminatoria por razones de sexo. Somete a las atletas femeninas a una restricción que no existe para los hombres ya que no se ha establecido un nivel de testosterona producida de forma natural por encima del cual se considera que un hombre pueda tener una ventaja injusta para competir contra otros hombres. Igualmente, señala que puede resultar discriminatoria por razones de condición física ya que, por ejemplo, no se prohíbe a una mujer con gigantismo jugar al baloncesto femenino sobre la base de que su altura está en el rango de la masculina. 
b) La normativa resulta desproporcionada. La preocupación de que las atletas hiperandrogénicas ponen en peligro la integridad del deporte no está respaldada por la evidencia científica o la historia. El predecesor de la normativa sobre hiperandrogenismo -la política de verificación de sexo- ya dio lugar a situaciones de estigmatización, humillación y perjuicios emocionales de las atletas a las que se les aplicó, por lo que, frente a una posibilidad real de ser sometido a una investigación de esta naturaleza, las mujeres atletas pueden verse disuadidas de continuar con su carrera deportiva.

c) La normativa resulta injusta. Tiene un diferente nivel de cumplimiento en cada país. A esos efectos, destaca que en Canadá el CCES tiene serias reservas sobre la conveniencia y legalidad de su aplicación y se negaría a participar en cualquier prueba o procedimiento para su aplicación.

El sr. Melia también hace referencia a las conclusiones de un informe elaborado por el CCES en 2012 titulado "Sport in Transition: Making Sport in Canada More Responsible for Gender Inclusivity" (Centro canadiense para la ética en el deporte, 2012), centrado en la aplicación de las políticas de verificación de sexo para atletas intersexuales y transexuales. En ese informe se concluye que la investigación científica no pudo identificar las concretas características típicamente sexuales que confieren una ventaja competitiva, dado que entre 200 y 300 genes afectan al rendimiento deportivo y resulta demasiado limitado identificar de manera concluyente un solo marcador. El estudio concluyó que "el mayor y potencialmente más injusto perjuicio sería continuar marginando o excluyendo a las atletas con variaciones del desarrollo sexual". Las pruebas de sexo históricamente han sido utilizadas para hacer frente a una amenaza prácticamente inexistente a la equidad de la competición, mientras que "los daños reales que experimentan las atletas sometidas a tales pruebas han sido severos, y en unos pocos casos, catastróficos" (parágrafo 272).

\section{II.1.3. Testimonio de la Sra. Madeleine Pape.}

Madeleine Pape es una antigua atleta olímpica que participio en los 800 metros en representación de Australia. En la actualidad está desarrollando un doctorado en la Universidad de Wisconsin y se define como una apasionada defensora de la igualdad de 
género en el deporte. Su testimonio oral fue prestado el 25 de febrero de 2015 y su contenido aparece reflejado en los parágrafos 349 a 356 de la decisión arbitral.

La sra. Pape describe su experiencia de competir contra Caster Semenya en el Campeonato Mundial de Atletismo en Berlín en 2009, exponiendo que después de haber oído que el sexo de Semenya estaba siendo investigado por la IAAF, se había sentido enfadada cuando Semenya ganó la carrera de manera tan destacada. Ella consideraba que Semenya tenía una ventaja competitiva sobre otras atletas como resultado de poseer ciertos rasgos biológicos asociados con la masculinidad (incluyendo niveles masculinos de testosterona endógena). Esos sentimientos estaban reforzados por los comentarios de atletas de ambos sexos que describían a Semenya como un varón. Esa percepción evolucionó de forma muy significativa como resultado de sus estudios y su compromiso con las críticas de las ciencias sociales sobre las relaciones de género y la sexualidad. En particular, su apreciación de la naturaleza compleja y no binaria de los sexos ha dado lugar a una revisión sustancial de sus puntos de vista, que estaban basados en una profunda convicción de que la división de los atletas en categorías sexuales era simple y fundamentada en un conocimiento científico incontrovertible.

La sra. Pape expone las siguientes razones por las que considera que la normativa sobre hiperandrogenismo resulta objetable:

a) La normativa sobre hiperandrogenismo equivale a las pruebas de verificación de sexo y son percibidos como tales por la comunidad deportiva, toda vez que toman como referencia (i) un nivel de testosterona en las mujeres en rangos masculinos y (ii) presentación de signos físicos y externos de virilización.

b) Resulta problemático establecer como finalidad legítima de esta normativa la búsqueda de una igualdad de condiciones en la competición ya que (i) el deporte es intrínsecamente injusto y hay innumerables factores aleatorios que afectan al rendimiento deportivo como son la estatura, la visión, la capacidad aeróbica y la resistencia, el crecimiento muscular, métodos de capacitación; acceso a entrenamiento más tecnificados; posibilidad de acceder a complementos alimenticios; y (ii) la complejidad de la evidencia científica o el grado de 
divergencia de opiniones entre los propios expertos en relación con los efectos de la testosterona en el rendimiento deportivo. A ello añade que esta normativa, al centrarse en un solo rasgo biológico, se muestra incapaz de apreciar que hay una interacción compleja y dinámica entre la biología humana y el contexto social y las estructuras dentro del cual operan los seres humanos.

\section{II.2. La actividad probatoria de la IAAF}

La IAAF sostuvo en defensa de su pretensión que la normativa sobre hiperandrogenismo (i) persigue el objetivo legítimo de mantener la equidad en las competiciones deportivas, garantizando que las atletas femeninas puedan competir en igualdad de condiciones; y (ii) es necesaria y proporcionada para la consecución de ese objetivo, ya que sus beneficios superan cualquier daño y justifican el efecto discriminatorio que implica.

La prueba propuesta por la IAAF en defensa de sus argumentos consistió en los testimonios de (i) el profesor Thomas Murray; (ii) el profesor Arne Ljungqvuist; (iii) el doctor Stéphane Bermon; (iv) la profesora María José Martínez Patiño; (v) la Sra. Joanna Harper; y (vi) la Sra. Paula Radcliffe ${ }^{25}$.

\section{II.2.1. Testimonio del profesor Thomas Murray.}

El profesor Murray es un académico sénior en materia de bioética. Es presidente emérito de Centro Hastings y profesor visitante de la Escuela de medicina de la Universidad Nacional de Singapur. Desde su fundación en 2004 ha dirigido el Grupo de revisión ética de la Agencia Mundial Antidopaje (WADA). Ha realizado un informe pericial escrito fechado el 30 de enero de 2015. El contenido de dicho informe y de su testimonio oral queda reflejado en los parágrafos 274 a 289. Sus afirmaciones más destacadas fueron que:

a) La esencia del deporte de competición es establecer una competencia con resultado incierto determinado por los factores que son apreciados y valorados por el deporte, como son, por ejemplo, el talento y la dedicación, y no por otros factores. Ello hace inevitable que se establezcan reglas para asegurar esa equidad como son la delimitación de las categorías, las conductas admisibles e inadmisibles y definir lo que es justo e injusto. 
b) Cada deporte tiene el derecho a decidir qué valores quiere promover y lo que es injusto se decide, en gran medida, por la comunidad de los atletas como reflejo de un entendimiento común de lo que se considera que es el espíritu deportivo, lo que excluye la posibilidad de reglas arbitrarias.

c) Existen una serie de factores que se utilizan comúnmente para dividir las competiciones en diferentes categorías, como la edad o el peso, con el fin de garantizar que no existe una enorme ventaja. Es un reto constante para los deportes decidir qué variaciones son suficientemente importantes como para justificar categorías separadas que den oportunidades similares a los atletas. Así, la estatura no se utiliza como una regla de elegibilidad, a pesar de conferir ventajas claras en algunos deportes, ya que los atletas no parecen considerar que se trate de una ventaja injusta o que desvirtúe las características esenciales que se valoran en ese deporte.

d) El consenso sobre la existencia de categorías sexuales supone una protección de la competición femenina vinculada a razones de equidad. Por tanto, existe una obligación ética de garantizar que las atletas no tienen que competir contra otras atletas con ventajas de rendimiento comúnmente asociados con los hombres. De hecho, la inexistencia de esta normativa podría presionar a algunas atletas a recurrir al dopaje con andrógenos anabólicos exógenos con el fin de nivelar la ventaja de las competidoras que tienen niveles naturalmente altos de testosterona endógena.

e) El establecimiento de una línea arbitraria como es el umbral de $10 \mathrm{nmol} / \mathrm{L}$ puede resultar justificada si satisface las condiciones de (i) ser útil o necesaria para permitir una competición equitativa; (ii) ser razonable y ajustada de conformidad con las alternativas disponibles. La normativa de hiperandrogenismo satisface ambas, ya que (i) tiene por objeto garantizar una competición equitativa para las mujeres que carecen de las ventajas de rendimiento que normalmente disfrutan los atletas masculinos; y (ii) los datos científicos y clínicos no refutan claramente la justificación de este nivel de testosterona. 
f) La testosterona endógena se puede distinguir de la ventaja aportada por otros rasgos físicos naturales en función de la distinción entre (i) aquellas variaciones que cada deporte considera que forman parte del talento natural que pueden desempeñar un papel en la determinación de un superior rendimiento y (ii) las que, como la edad, peso, etc., sirven al deporte para establecer clasificaciones separadas con el fin de asegurar competiciones equitativas. Además, tampoco es relevante el hecho de que, por ser una producción natural, no se está engañando a nadie, pues una situación de inequidad puede producirse sin intención de hacer trampa como sucede con un atleta que ingiere sin saberlo una sustancia que mejora su rendimiento.

g) El Reglamento de hiperandrogenismo no es discriminatorio para las mujeres por no aplicarse a los varones, ya que su finalidad es impedir que haya que competir con atletas con ventajas hormonales masculinas; no existen evidencias de una correlación entre los niveles de testosterona y un mejor rendimiento deportivo entre los hombres; y no existe una demanda de regulación sobre ese particular en las competiciones masculinas.

h) Las pruebas de verificación de género o sexo resultaban insostenibles por la finalidad de asignar de forma inequívoca una condición sexual u otra. El Reglamento de hiperandrogenismo, precisamente, implica un cambio sustancial. Acepta que cualquier persona que se identifica a sí misma como una mujer pueda competir en la categoría femenina con la única limitación del criterio de elegibilidad de testosterona endógena.

i) Las presiones o coerción sobre una atleta femenina hiperandrogénica para que elija entre someterse a un tratamiento médico para reducir el nivel de testosterona o renunciar a competir en eventos femeninos deriva de exigencias de equidad y no es excesiva, innecesaria ni injusta.

\section{II.2.2. Testimonio del profesor Arne Ljungqvist.}

El profesor Ljungqvist, cuyo testimonio es detalladamente recogido en los parágrafos 290 a 299 de la decisión arbitral cautelar, expone: 
a) Las diferencias evidentes de rendimiento deportivo según el sexo de los atletas han llevado a la general aceptación de que debe haber categorías separadas por sexos. Sin esa categorización la esencia del deporte, caracterizada como la igualdad de condiciones que lleva a la verdadera igualdad de oportunidades, se vería comprometida en perjuicio de las atletas femeninas en el deporte de élite.

b) Las pruebas de verificación de sexo tienen su origen en, al menos, la década de 1960 por la preocupación general de que algunos países podrían tratar de ganar más medallas haciendo pasar a atletas masculinos por mujeres, lo que condujo a las iníciales pruebas consistentes en un mero examen físico de la anatomía de la atleta femenina, que fue rápidamente sustituido por pruebas de cromatina sexual para determinar si un atleta tenía cromosomas XX o XY. Esas pruebas se basaban en la suposición de que todas las atletas femeninas tenían cromosomas $\mathrm{XX}$, mientras que todos los atletas masculinos tenían cromosomas XY. Posteriores avances científicos y médicos mostraron que esa división binaria no resultaba correcta ante la presencia de personas intersexuales. La IAAF abandonó formalmente en 1991 la práctica de las pruebas de verificación de sexo sistemáticas, reservándose los exámenes médicos a casos concretos en que se planteaban dudas. El COI mantuvo el carácter sistemático de los exámenes para la participación en los Juegos Olímpicos hasta el año 1999.

c) La Comisión Médica del COI convocó en 2003 un grupo de expertos para revisar las normas y procedimientos relativos a la reasignación de sexo en el deporte, dando lugar a la Declaración del Consenso de Estocolmo que estableció que un atleta que ha sufrido un cambio de sexo de hombre a mujer era elegible para competir en la categoría femenina (i) si la reasignación se produjo antes de la pubertad; o (ii) si la reasignación se produjo después de la pubertad, cuando las gónadas se han eliminado y el atleta se ha sometido a terapia de reemplazo hormonal durante un período de tiempo suficiente para eliminar la ventaja derivada de la exposición anterior a los niveles masculinos de testosterona. 
d) El caso de Caster Semenya en 2009 demostró los problemas de continuar con una política de controles ad hoc en esta área. Así, a principios de 2010, la IAAF y el COI tuvieron una reunión conjunta de expertos para abordar las restricciones de elegibilidad de las atletas intersexuales y con trastornos del desarrollo sexual. Hubo consenso en que las cuestiones relativas a las ADS no estaban vinculadas con el sexo o la verificación de género sino con la forma de tratar justamente a los atletas con altos niveles de andrógenos. La Comisión Médica del COI recomendó al COI que adoptara reglas para determinar la elegibilidad de los atletas hiperandrogénicas para competir en las categorías femeninas, dando lugar en 2012 a los Reglamentos sobre hiperandrogenismo para los Juegos Olímpicos de 2012 en Londres y en 2014 para los Juegos Olímpicos de Invierno de 2014 en Sochi.

e) La normativa sobre hiperandrogenismo del COI hace constar expresamente que no tiene por objeto la determinación del sexo y se limita a establecer un procedimiento para la apertura de las investigaciones sobre los presuntos casos de hiperandrogenismo en los Juegos Olímpicos. En tales casos, un grupo de expertos compuesto por un genetista, un ginecólogo y un endocrinólogo debe evaluar el caso para determinar: (i) si la atleta es hiperandrogénica; y (ii) en caso afirmativo, si la condición confiere una ventaja competitiva. Al contrario que el Reglamento de la IAAF, los del COI no establecen un umbral de elegibilidad específica de 10 nmol/L, ya que el COI considera que algunas atletas pueden disfrutar de una ventaja de rendimiento incluso con concentraciones de testosterona endógena en suero inferior a $10 \mathrm{nmol} / \mathrm{L}$.

f) Una serie de factores como la financiación, la nutrición, los métodos de formación $\mathrm{y}$ entrenamiento son relevantes en el rendimiento deportivo pero no es posible compararlos con la ventaja derivada de los altos niveles de testosterona natural.

\section{II.2.3. Testimonio del doctor Stéphane Bermon.}

El Dr. Bermon, cuyo testimonio es detalladamente recogido en los parágrafos 300 a 318 de la decisión arbitral cautelar, expone: 
a) El Reglamento de hiperandrogenismo es necesario. Hay datos que sugieren que, sin esta normativa, pruebas como las carreras de media distancia podrían llegar a ser dominadas por las atletas con hiperandrogenismo, alentando el dopaje de otras atletas para ser capaces de competir a ese nivel.

b) El Reglamento de hiperandrogenismo no resulta desproporcionado, ya que (i) no implica dudas sobre la sexualidad de las atletas con hiperandrogenismo, pues rechaza expresamente el concepto de pruebas de sexo y verificación de género; (ii) limita la posibilidad de promover la investigación de una atleta por parte del Médico Director de la IAAF alentándola solo cuando haya motivos razonables basados en una fuente fiable; (iii) no está basado en estereotipos de género, pues los indicadores de virilización no se utilizan para determinar que atletas deben ser sometidas a investigación sino, cuando ya se ha iniciado, para establecer la funcionalidad de la testosterona con fundamento en la Medical Guidelines for the linical Practice for the Diagnosis and Treatment of Hyperandrogenic Disorders de la Asociación Americana de Endocrinólogos Clínicos (2001); (iv) establece normas claras sobre la necesidad de una estricta confidencialidad, de modo tal que fuera de la IAAF nadie conoce la identidad de las atletas, su nacionalidad, o incluso el número de casos investigados; (v) el eventual tratamiento médico para el hiperandrogenismo es independiente de la elegibilidad para competir en pruebas de atletismo femenino, sin perjuicio de que el hiperandrogenismo puede implicar riesgos graves para la salud, por lo que es importante su identificación y diagnostico tempranos; (vi) establece la necesidad del consentimiento informado y se ha obtenido de todas las atletas sometidas a investigación.

c) El límite de testosterona establecido en el Reglamento de hiperandrogenismo es muy conservador al establecer un umbral muy por encima del rango normal de la mujer. La media del nivel de testosterona para mujeres deportistas es de 0.69 nmol/L y el percentil 99 para las atletas de sexo femenino es de $3.08 \mathrm{nmol} / \mathrm{L}$. Por lo tanto, el Reglamento de hiperandrogenismo incorpora un margen significativo que asegura que sólo se aplican a las atletas con una ADS o atletas dopadas. En su experiencia, de los 30 casos que había tratado con arreglo a la normativa sobre hiperandrogenismo, 12 eran casos de dopaje y de los 18 restantes: 7 tenían más de 
$10 \mathrm{nmol} / \mathrm{L}$ de testosterona en suero y fueron sometidas a tratamiento para reducir sus niveles de testosterona, experimentando todas ellas una disminución en el rendimiento deportivo con una extensión variable. Aproximadamente la mitad volvió a un alto nivel de competencia internacional, y las restantes no repitieron su nivel inicial de rendimiento y se retiraron. El resto de casos está en curso. Algunas de las atletas experimentaron efectos secundarios menores después del tratamiento quirúrgico, que fueron tratados con éxito mediante el uso de anticonceptivos orales.

d) Competir con altos niveles de testosterona endógena es intrínsecamente injusto al suponer una ventaja muy importante. Por lo general en el atletismo es necesario entre 10 y 15 años de entrenamiento especializado para alcanzar el nivel de campeón del mundo. Sin embargo, las atletas hiperandrogénicas pueden lograr este nivel de rendimiento en menos de un año.

e) Es posible que en el futuro los atletas debieran ser clasificados con otros rasgos genéticos que impliquen situaciones ventajosas.

f) No resulta necesario someter a los atletas a este mismo régimen de elegibilidad porque solo hay dos categorías sexuales de competición y si bien hay algunos atletas masculinos con niveles inusualmente altos de testosterona endógena eso no les aporta la misma ventaja de rendimiento sobre sus compañeros que las que aporta a las atletas femeninas.

g) No es fácil determinar la sensibilidad a los andrógenos y las evaluaciones no pueden establecer un porcentaje específico del grado de insensibilidad, por eso el Grupo Médico de la IAAF da a las atletas el beneficio de la duda.

h) Los resultados del estudio de Daegu determinan que sin los valores atípicos existe una diferencia definitiva en los niveles de testosterona en la gama normal entre ambos sexos. El 99 \% de las mujeres está por debajo de $3.08 \mathrm{nmol} / \mathrm{l}$. Los valores en varones por debajo de $4 \mathrm{nmol} / \mathrm{L}$ se vinculan con hipogonadismo por el uso de esteroides anabólicos, por exceso de entrenamiento o por otra condición médica. 


\section{II.2.4. Testimonio de la profesora María José Martínez Patiño.}

La profesora Martínez Patiño es una antigua atleta de alto nivel. Es entrenadora nacional de atletismo y profesora en la Facultad de Ciencias de la Educación y Deportes de la Universidad de Vigo (España). Desde 2013 participa como experta independiente en la Comisión Médica del COI en el seguimiento de la regulación sobre hiperandrogenismo. Ha realizado un informe pericial escrito fechado el 30 de enero de 2015. El contenido de dicho informe y de su testimonio oral queda reflejado en los parágrafos 319 a 325 de la decisión arbitral, destacando los siguientes aspectos:

a) Durante su carrera como atleta de élite juvenil fue sometida a pruebas de verificación de género. En 1985 falló en la prueba del corpúsculo de Barr y fue declarada inelegible para la competición femenina a causa de una enfermedad genética relacionada con sus cromosomas. Experimentó una situación de crítica pública, su información médica privada se dio al conocimiento público y su condición de mujer fue cuestionada. Recurrió con éxito su inhabilitación y finalmente se le permitió continuar compitiendo en pruebas femeninas de atletismo. La experiencia fue triste y dolorosa con consecuencias personales importantes y duraderas.

b) El Reglamento de hiperandrogenismo se podría mejorar en algunos aspectos, sobre todo en las áreas de la confidencialidad, la privacidad y la educación, pero apoya su espíritu y enfoque. Tiene como finalidad garantizar la igualdad en el deporte al permitir que las atletas puedan competir en igualdad de condiciones, tomando en consideración tanto a las mujeres que se ven afectadas por la regla de elegibilidad como las que no son hiperandrogénicas y desean una competición equitativa.

c) Es primordial preservar la confidencialidad de las atletas. Es un área en que la IAAF y el COI pueden y deben mejorar, siendo necesario un régimen disciplinario cuando se viola la confidencialidad. Además, los psicólogos deben participar cuando las mujeres sean investigadas con arreglo a esta normativa, ya que si bien el proceso de someterse a la investigación médica no causa un impacto psicológico adverso, si lo hace el cuestionamiento de la condición femenina de la atleta. 


\section{II.2.5. Testimonio de la Sra. Joanna Harper.}

Joanna Harper es una física médica. Durante 30 años ha estado compitiendo en carreras en categoría masculina y después de completar un proceso de transición de género, desde 2005 está compitiendo en categoría femenina. El contenido de su testimonio escrito, fechado el 22 de enero de 2015, queda reflejado en los parágrafos 326 a 333 de la decisión arbitral, destacando los siguientes aspectos:

a) Su experiencia personal de supresión de la testosterona como parte de la terapia de transición de hombre a mujer es que ella era notablemente más lenta en el plazo de un mes desde el comienzo del tratamiento, lo que persistió después de someterse a una gonadectomía. Ese mismo resultado es el obtenido de cotejar los datos de otras siete corredoras transgénero, quienes tenían tiempos mucho más lentos compitiendo como mujeres que como varones. Las diferencias de tiempo eran tan grandes que sus actuaciones clasificadas por edades (un método estadístico de comparación de los tiempos de carrera para los hombres y mujeres de todas las edades) permanecieron prácticamente constantes. Los resultados del estudio han sido publicados en Journal of Sporting Cultures and Identities (Harper, 2015), concluyendo que, al menos para carreras de larga distancia, la manipulación de los niveles de testosterona es suficiente para cambiar el rendimiento en competiciones deportivas de una persona en su transición de sexo masculino a sexo femenino.

b) $\mathrm{Su}$ experiencia y la de otras mujeres deportistas sugieren que los efectos de la testosterona endógena y exógena en el rendimiento deportivo es muy similar, por lo que los estudios que vinculan la testosterona exógena a un mayor rendimiento deportivo tienen una aplicación significativa de las enormes ventajas hormonales de las que disfrutan algunas mujeres intersexuales.

c) Los extremos y rápidos cambios que las mujeres transgénero experimentan en su velocidad con la supresión de la testosterona indican su importancia en el rendimiento deportivo, por lo que no es razonable comparar las ventajas de la testosterona con los aportados por otras características físicas, tales como las manos 
más grandes. La testosterona es, sin lugar a dudas, el único factor diferencial del rendimiento deportivo entre sexos y, por tanto, el nivel de testosterona funcional es el mejor criterio para determinar la elegibilidad en las competiciones femeninas. De ese modo, la mejor manera de lograr la igualdad de condiciones para las atletas es exigir que todas ellas sean hormonalmente similares.

d) No es correcto que las mujeres intersexuales se vean obligadas a someterse a cirugía para poder continuar participando en las competiciones deportivas. Sin embargo, los efectos nocivos de la terapia hormonal farmacológica no son tan graves, ya que en su experiencia de haberse sometido a 18 meses de supresión química de la testosterona no tuvo ningún efecto adverso a excepción de algunos efectos diuréticos, que es lo mismo que le han trasmitido otras atletas con la misma experiencia.

\section{II.2.6. Testimonio de la Sra. Paula Radcliffe.}

Paula Radcliffe es una consumada corredora de élite de pruebas de largas distancias. Ha ganado medallas de oro en los Campeonatos europeos y mundiales y en los de Juegos de la Commonwealth, teniendo el actual record del mundo femenino en los 10 y 25 kilómetros en ruta y en la maratón. Ha sido miembro de la Comisión de Atletas de la IAAF desde 2009. Participó como representante de los atletas de la IAAF en la revisión de la normativa sobre hiperandrogenismo del COI en 2013. El contenido de su testimonio, fechado el 26 de enero de 2015, queda reflejado en los parágrafos 334 a 340 de la decisión arbitral, destacando los siguientes aspectos:

a) Las atletas necesitan sentir que están compitiendo en igualdad de condiciones y que la competencia es justa, por eso existen multitud de regulaciones deportivas para garantizar la equidad, que van desde normas contra el engaño deliberado, como son las antidopaje, o el uso de criterios de edad, peso y sexo para establecer categorías que permitan garantizar que el éxito está determinado solo por el talento y la dedicación, y no por una ventaja injusta. Al existir una gran diferencia de rendimiento deportivo entre ambos sexos en la alta competición, si compitieran 
conjuntamente no sería equitativo, porque los hombres siempre superarían a las mujeres.

b) El Reglamento de hiperandrogenismo no tiene como objetivo ni la determinación del género o sexo ni evitar el engaño deliberado. Su finalidad es preservar una competición justa desde un punto de vista deportivo, para lo que se centra en un aspecto que es el que establece las significativas diferencias de rendimiento entre los sexos como es el nivel de testosterona. De ese modo, la presencia de atletas con niveles de testosterona en un rango masculino hace que la competición no sea equitativa. Muchos otros atletas comparten este punto de vista como demuestra la reacción existente al caso de Caster Semenya en que muchas atletas sintieron que ella tenía una ventaja injusta.

\section{II.3. La valoración de la actividad probatoria por el TAS.}

El TAS expone la valoración de la actividad probatoria desarrollada sobre la alegada desproporcionalidad de la normativa sobre hiperandrogenismo en los parágrafos 500 a 532 de la decisión arbitral, comenzando con una serie de consideraciones generales para centrarse después en el estudio de la eventual justificación de la regla de elegibilidad.

\section{II.3.1. Consideraciones generales:}

El TAS, resumiendo la posición general sobre la cuestión planteada, acepta como punto de partida que (i) el Reglamento de hiperandrogenismo es discriminatorio por razones de género y de condición física; (ii) esta discriminación es contraria a la Carta Olímpica y la Constitución de la IAAF; (iii) debe ser declarada nula si no puede justificarse como una respuesta razonable y necesaria para la consecución de un fin legítimo; y (iv) la carga de acreditar que el Reglamento de hiperandrogenismo es un medio proporcionado para alcanzar el objetivo legítimo de garantizar la equidad en la competición femenina corresponde a la IAAF.

El TAS, resumiendo la posición mantenida por las partes, identifica que la IAAF establece como argumentos en defensa de la normativa sobre hiperandrogenismo que (i) es 
consustancial al deporte la igualdad de condiciones, para lo que resulta necesario establecer categorías por sexos, siendo exigida esa misma igualdad por las atletas en la categoría femenina mediante la exclusión de aquellas que tienen ventajas de rendimiento deportivo por contar con niveles masculinos de hormonas; y (ii) la testosterona proporciona el mejor criterio para justificar la existencia de categorías de competición diferenciadas por sexos y también la igualdad de condiciones dentro de la categoría femenina. Por el contrario, la impugnante sostiene que si bien es un objetivo legítimo una competición equitativa, el Reglamento de hiperandrogenismo no es necesario para alcanzar dicho objetivo.

El TAS, atendiendo a la posición de la IAAF, considera que (i) resulta dificultoso desde una perspectiva científica, ética y legal el conciliar una regla de elegibilidad que tiene que combinar la existencia de un sistema binario sexual de competición con la realidad biológica de que el sexo en los seres humanos es un proceso continuo en que no existe una delimitación clara y singular entre hombres y mujeres; (ii) la IAAF ha buscado diligentemente crear un sistema de reglas que sean justas, objetivas y fundadas en la mejor ciencia disponible para proteger la equidad en el deporte dentro del respeto de los derechos de todos los atletas; (iii) la intención era, tras reconocer que las normas anteriores eran defectuosos y con una base científica débil, crear un nuevo conjunto de reglas que reflejaran el estado actual de la ciencia y evitar los problemas de las anteriores políticas de verificación de género mediante un amplio proceso de consultas en que destaca la posición favorable mantenida por el colectivo de las atletas; y (iv) el Reglamento de hiperandrogenismo se aplica de manera confidencial y cuidadosa, dando el beneficio de la duda a las atletas, y permitiendo que se proporcione la atención debida cuando se revela alguna situación médica que requiera tratamiento.

El TAS acepta que el Reglamento de hiperandrogenismo tiene el objetivo legítimo de garantizar una competencia leal y la igualdad de condiciones dentro de la categoría femenina. Sin embargo, teniendo en cuenta las consecuencias que se derivan de su aplicación y su carácter discriminatorio, es necesario que, además, quede acreditado que establece unas reglas que son un medio eficaz y proporcionado para alcanzar ese objetivo de garantizar la equidad. 
El TAS expone que las cuestiones sobre las que las partes están de acuerdo son que (i) es razonable y proporcionado dividir las competiciones en categorías masculina y femenina; (ii) debe haber un criterio objetivo para controlar esta división; (iii) las pruebas de género no son un criterio adecuado; (iv) una atleta no deja de ser mujer por poseer altos niveles de testosterona y un aumento de la masa muscular que le aporten una ventaja competitiva; (v) es la ley la que determina si una persona es una mujer; (vi) el reconocimiento legal como mujer no varía en la mayoría de países, aunque exista un pequeño número de ellos en que el género esté determinado exclusivamente por una proceso de auto-identificación; (vii) el nivel de testosterona endógena y la sensibilidad a la testosterona puede proporcionar un criterio adecuado para dividir ambos sexos, aunque hay mujeres con ADS, con altos niveles de testosterona endógena funcional que permanecen como mujeres; (viii) no hay una categoría separada de intersexuales en la que se pueda competir; (ix) el Reglamento de hiperandrogenismo sólo se aplica a las mujeres; (x) la inelegibilidad de una atleta por aplicación de esta normativa no le permite competir en categoría masculina; (xi) los criterios de un nivel de testosterona endógena de $10 \mathrm{nmol} / \mathrm{L}$ con un grado de virilización se basan en la mejor información científica disponible sobre los rangos típicos de testosterona en hombres y mujeres y las indicaciones físicas de sensibilidad a los andrógenos.

\section{II.3.2. La justificación de la regla de elegibilidad.}

El TAS opina que la distinción entre hombre y mujer es legal pero que los niveles de testosterona endógena son un indicador biológico clave de la diferencia entre sexos. También destaca que la normativa sobre hiperandrogenismo no usa el criterio del nivel de testosterona endógena como criterio diferencial entre sexos, ya que no se utiliza para determinar si un atleta debe competir en categoría masculina o femenina. El uso de este criterio lo es para establecer una categoría de atletas femeninas no elegibles dentro de la competición femenina. De ahí que sea necesario analizar con especial cuidado la necesidad y la proporcionalidad de esta restricción.

La existencia de dos únicas categorías sexuales en la competición determina que juntas deban abarcar la totalidad de los atletas que deseen competir. Las atletas con altos niveles de testosterona endógena pueden incluir mujeres con características intersexuales. La existencia de una población intersexual y su representación en el atletismo femenino 
determina que haya que aceptar que estas atletas pueden tener características que abarquen una amplia gama, desde las que están dentro del rango normal femenino a las que están dentro del rango normal masculino. La cuestión es determinar si resulta razonable y proporcionado que una atleta femenina -que solo es elegible para competir como mujerpuede ser sometida a una valoración que la excluye de las competiciones femeninas cuando tiene, de forma natural, características estrechamente asociadas con ventajas competitivas masculinas. En ese contexto, el TAS opina que cada atleta debe tener la oportunidad de competir en una de las dos categorías sexuales y no se le debe impedir competir en cualquiera de ellas como consecuencia de características naturales. Una regla que impidiera competir en esas circunstancias es la antítesis del principio fundamental del Olimpismo de que "toda persona debe tener la posibilidad de practicar deporte sin discriminación de ningún tipo". Igualmente sucede con una regla que impusiera como condición para competir someterse a una intervención médica que inhibiera o redujera el efecto de una característica genética individual de origen natural. Este tipo de reglas solo son válidos si se ha establecido claramente que son un medio necesario y proporcionado para alcanzar una competición leal.

El TAS no discute que siendo apropiada la segregación sexual en la competición deportiva, resulte necesario un control que dé lugar a decisiones difíciles cuando la naturaleza no establece una división en estas categorías de manera tan simple. En relación con ello, el TAS argumenta que si el Reglamento de hiperandrogenismo está destinado a proteger a las atletas de tener que competir contra otras que disfrutan de una ventaja competitiva similar a la que tiene los varones; entonces la premisa que sustenta esta normativa es que algunas atletas tienen una ventaja competitiva sobre otras mujeres que es similar a la ventaja de rendimiento de la que gozan los atletas masculinos. De ese modo, el TAS considera que cuando una atleta es reconocida legalmente como mujer se le debe permitir competir en categoría femenina salvo que sus niveles naturalmente altos de andrógenos les confieran una ventaja significativa de rendimiento comparable con la ventaja de rendimiento que tiene los atletas masculinos respecto de las femeninas. En consecuencia, el TAS considera que la cuestión relevante es determinar si las atletas con niveles de testosterona endógena de, al menos, $10 \mathrm{nmol} / \mathrm{L}$ y con sensibilidad a los andrógenos tienen una ventaja competitiva suficientemente clara y significativa sobre el resto de competidoras como para excluirlas de la competición. 
El TAS considera que no se han mostrado evidencias del efecto cuantitativo que sobre el rendimiento deportivo femenino tienen los niveles de testosterona endógena superiores a $10 \mathrm{nmol} / \mathrm{L}$, lo que determina que en la actualidad no hay suficientes pruebas sobre el grado de ventaja que las mujeres con hiperandrogenismo funcional tienen respecto del resto de mujeres. Por tanto, no queda acreditado que una atleta con un nivel de testosterona por encima de $10 \mathrm{nmol} / \mathrm{L}$ tenga una ventaja similar a la de un atleta masculino, que debería ser del 10 al $12 \%$, y no otra, relativamente marginal, del $1 \%$.

El TAS destaca que en 2014 los profesores Ritzen y Hirschberg y el doctor Bermon publicaron un artículo, junto con otros varios autores, titulado "Serum Androgen Levels in Elite Female Athletes", que fue publicado en la revista Journal of Clinical Endocrinology and Metabolism (Bermon et al., 2014), en que se examinaron los rangos de testosterona masculina y femenina revelada por los datos de Daegu, concluyendo (i) la ausencia de evidencias directas en cuanto a la magnitud de la ventaja de rendimiento que las mujeres hiperandrogénicas tenían como resultado de sus niveles de andrógenos; y (ii) que la sobrerepresentación de atletas hiperandrogénicas en la alta competición era una evidencia indirecta de la ventaja aportada por el alto nivel de testosterona. El TAS también pone de manifiesto la declaración oral del Dr. Bermon en que este afirmó que según su experiencia y sus datos no publicados una atleta con sensibilidad a los andrógenos y un nivel de 15 $\mathrm{nmol} / \mathrm{L}$ de testosterona endógena experimentaría una ventaja de rendimiento de aproximadamente el $3 \%$ respecto de una atleta con un nivel del $1,5 \mathrm{nmol} / \mathrm{L}$ de testosterona endógena. Igualmente confirmó que la IAAF no había analizado los datos de Daegu para tener en cuenta cualquier correlación entre los niveles de testosterona y la clasificación de las atletas, pero que no estaba seguro de que pudiera hacerse por las exigencias técnicas de ese análisis. En atención a ello, el TAS destaca que la ventaja de rendimiento de aproximadamente el 3\% sugerido por el Dr. Bermon es significativamente menor que el 10 a $12 \%$ de diferencia entre el rendimiento de una atleta masculino y otro femenina a que se refiere la IAAF; el 10\% al que se refieren los profesores Ritzen y Hirschberg en su informe conjunto de expertos; o el $12.64 \%$ que se establece en el informe del Dr. Bermon. Estos datos demuestran que la IAAF reconoce que la ventaja de rendimiento de las mujeres con hiperandrogenismo respecto de las atletas que no lo tienen puede ser de un orden diferente a la ventaja de los varones sobre las mujeres. 
El TAS considera que la falta de pruebas sobre la determinación cuantitativa de la mejora de rendimiento deportivo por unos mayores niveles de testosterona endógena es una cuestión determinante, ya que, mientras un $10 \%$ de diferencia en el rendimiento deportivo justifica la segregación de la competición por sexos, un $1 \%$ de diferencia no puede justificar la inelegibilidad de las atletas para competir en categoría femenina ante la presencia de muchas otras variables relevantes que afectan también al rendimiento deportivo.

El TAS valora que la prohibición del uso de testosterona exógena por sus efectos potenciadores de rendimiento no implica que unos altos niveles de testosterona endógena aporten una ventaja tan significativa que implique una desigualdad de condiciones en la competición femenina. Hay muchas características de la biología humana que no tienen ningún efecto sobre la elegibilidad de un atleta cuando se producen de forma natural, pero cuya inducción artificial está prohibida por mejorar el rendimiento como son la hormona de crecimiento humana y la adrenalina, cuya administración exógena está prohibida por el Código de la WADA.

EL TAS determina que la IAAF no ha dado cumplimiento a la carga que le correspondía de probar que el Reglamento de hiperandrogenismo cumpla su objetivo pretendido, pues la evidencia es que no hay datos suficientes para establecer o refutar la hipótesis de que esta normativa solo declara inelegibles a las mujeres que tienen una ventaja competitiva del mismo nivel que los hombres.

Las conclusiones del TAS, en atención a las pruebas desarrolladas en el procedimiento, son que no se puede concluir que (i) las atletas hiperandrogénicas con sensibilidad a los andrógenos tengan una ventaja de rendimiento respecto del resto de atletas de tal magnitud que sea necesario y proporcionado para mantener la equidad en la competición su separación de la competición femenina a menos que se sometan a tratamiento; y (ii) si bien los niveles más altos de testosterona endógena pueden aumentar el rendimiento deportivo, la ventaja que aportan sea más significativa que la derivada de las numerosas variables que afectan al rendimiento deportivo como pueden ser la nutrición, el acceso a los servicios de formación de especialistas y de entrenamiento, y otras variaciones genéticas y biológicas. 
Por lo tanto, es necesaria una prueba más consistente de la relación cuantitativa entre los niveles de andrógenos en las mujeres hiperandrogénicas y un mayor rendimiento deportivo para que la IAAF pueda cumplir con su responsabilidad de establecer que el Reglamento de hiperandrogenismo es una normativa necesaria y proporcionada para alcanzar el objetivo pretendido. 



\title{
NOTAS
}

\begin{abstract}
${ }^{1}$ Este concepto hace referencia al mito greco-latino de Hermafrodito, hijo de Hermes (Mercurio) y Afrodita (Venus), quien por obra de los dioses queda fundido en un solo cuerpo con el de la ninfa Sálmacis, dando origen a un solo ser de doble sexo para nunca más ser separados, de modo tal que "ya no eran dos formas, sino una forma doble, de la que no se podía decir si era hombre o mujer, pues no parecía ninguno y parecía los dos" (Ovidio Nasón, 1994, pág. 175). Otra de las versiones es la recogida por Fausto-Sterling (FaustoSterling, 2000, pág. 50) donde explica que Afrodita y Hermes tuvieron un hijo dotado con los atributos de ambos progenitores, los cuales indecisos por su masculinidad o feminidad, deciden llamarlo Hermafrodito.
\end{abstract}

${ }^{2}$ En ese sentido puede citarse la SentenciaT-622/14 de la Corte Constitucional Colombiana, que usa el término en múltiples ocasiones. No obstante, aunque utiliza una terminología errónea y desactualizada, resuelve de manera positiva a favor del menor que solicita una cirugía de reasignación de sexo, ordenando a la entidad prestadora de salud llevar a cabo todas las medidas oportunas para resolver la situación en cuestión y exhortando al Ministerio de Salud y Protección Social de Colombia, para que elabore guías y protocolos oficiales para el tratamiento de las personas nacidas en condición intersexual de obligatorio cumplimiento. http://www.corteconstitucional.gov.co/relatoria/2014/T-622-14.htm (Sentencia T-622/14, 2014)

${ }^{3}$ Así, Gregori Flor (Gregori Flor, 2015) recuerda que Platón defendía que en un principio existían tres sexos mujer, hombre y hermafrodita-, de modo tal que en su diálogo El Banquete (siglo IV a. C) hace relatar a Aristófanes el mito de Andrógino, conforme al cual existían tres tipos de seres humanos: unos provistos de dos cuerpos masculinos, otros formados por dos cuerpos femeninos y una tercera categoría constituida por los hombres-mujeres o andróginos. En el siglo I, Galeno argumentaba que los hermafroditas no pertenecían ni al sexo masculino, ni al femenino, sino a un sexo intermedio.

${ }^{4}$ Marañón incluye la homosexualidad como un estado intersexual. Esta situación estuvo incluida en el Manual diagnóstico y estadístico de los trastornos mentales de la Asociación americana de psiquiatría, hasta su segunda versión en el apartado de desviaciones sexuales. En la $3^{\text {a }}$ edición de dicho manual (DSM-III) la homosexualidad resulta excluida, pero la "Disforia de Género" sigue estando clasificada en la edición actual (DSM-V).

${ }^{5}$ Un locus es la localización cromosómica única que define la posición de un gen individual o la secuencia de ADN. (Strachan \& Read, 2006, pág. 641)

${ }^{6}$ Normalmente en la literatura médica se las identifica por sus siglas en inglés CAIS (Androgen Insensitivity Syndrome complete) y PAIS (Androgen Insensitivity Syndrome Partial).

${ }^{7}$ Se puede consultar la evolución de las mujeres en los JJOO tanto de invierno como de verano en las tablas del documento preparado por el COI. Factsheet Women in the Olympic Movement. Junio de 2016. Disponible en:

https://stillmed.olympic.org/Documents/Reference_documents_Factsheets/Women_in_Olympic_Movement. pdf (Consulta el 16 de agosto de 2016).

${ }^{8}$ Este record, como se explica en la propia página web del COI en su sección de resultados, no fue reconocido por la IAAF. Véase los resultados de la prueba de 100 metros lisos mujeres, en los JJOO de Berlín 1936. 100 Women, Ranking. Disponible en: https://www.olympic.org/berlin-1936/athletics/100mwomen(Consulta el 16 de agosto de 2016).

${ }^{9}$ En la página web del COI en su sección de resultados, se puede comprobar que en los JJOO de Londres 1948 en la prueba de 200 metros lisos, no aparece ningún registro de la atleta Foekje Dilema. Quien aparece como vencedora de la prueba es la también neerlandesa Fanny Blankers-Koen con un registro de 24.4 segundos. Disponible en: https://www.olympic.org/london-1948/athletics/200m-women (Consulta el 12 de agosto de 2016).

${ }^{10}$ Traducción propia.

${ }^{11}$ Véase el perfil de la atleta Tamara Press en la página web del COI. Disponible en: https://www.olympic.org/tamara-press (Consulta el 16 de agosto de 2016). 
${ }^{12}$ Véase el perfil de la atleta Irina Press en la página web del COI. Disponible en:
https://www.olympic.org/irina-press (Consulta el 16 de agosto de 2016).

${ }^{13}$ Este extremo no puede establecerse como oficialmente confirmado, ya que en la página web de resultados del COI aparece como ganadora de dos medallas olímpicas en los JJOO de Tokio 1964, en la pruebas de 100 metros lisos con una marca de 11.6 segundos y en la prueba de relevos 4x100 metros con una marca de equipo 43.6 segundos. Disponible en: https://www.olympic.org/ewa-klobukowska (Consulta el 10 de agosto de 2016). Igualmente en su biografía del Comité Olímpico Polaco aparecen todos sus registros, sus tres records mundiales $y$ el hecho de ser ganadora de dos medallas olímpicas. Disponible en: http://www.olimpijski.pl/pl/bio/976,klobukowska-ewa.html (Consulta el 10 de agosto de 2016).

${ }^{14}$ Un caso singular, por no haber sido resultado directo de las pruebas de verificación de sexo, lo representa la historia de la esquiadora austriaca Erika Schinegger. Antes de los JJOO de Invierno en Grenoble 1968 fue sometida a una revisión de rutina en el hospital de Innsbruck junto con el resto de los miembros de su delegación. En esa revisión fue informada de que tenía órganos sexuales masculinos y, por tanto, que no resultaba elegible para las competiciones deportivas femeninas. La esquiadora, que había sido campeona mundial de esquí alpino en 1966 en Chile, fue apartada del equipo austriaco y nunca más volvió a competir en categoría femenina. En el mismo año que fue notificada de sus órganos sexuales internos masculinos, Erika se sometió a una cirugía de reasignación de sexo y empezó a competir con el nombre de Erik Schinegger (Pieper, 2016, pág. 75; Wrynn, 2004).

${ }^{15}$ En el informe oficial de los JJOO de Invierno de 1968 en Grenoble, publicado en forma de libro, la cuestión de los controles de sexo se aborda en el apartado "Inspecciones Anti-Doping" y de una manera muy escueta. "la Comisión Médica realizará dos labores en los juegos i) los controles de sexo de las mujeres y ii) las inspecciones anti-doping". De esta última, sí desarrolla de manera detallada la técnica a utilizar, pero de los controles de sexo no comenta nada al respecto. Rapport officiel Xèmes Jeux Olympiques d'hiver. (1969). Disponible en: https://www.olympic.org/grenoble-1968 (Consulta el 10 de agosto de 2016).

16 "La atleta antes mencionada se ha sometido a un examen médico autorizado. El resultado fue cromatina sexual positiva. Esto satisface los requisitos de la IAAF para competir en eventos atléticos femeninos" (traducción propia).

${ }^{17}$ Lindsay Parks Pieper obtuvo una beca del Comité Olímpico Internacional y del Centro de Estudios Olímpicos, lo que le dio acceso a documentos archivados y no publicados por el COI. La mayoría de esos documentos son cartas a los miembros de las diferentes comisiones del COI y memorandos internos de la organización. La información obtenida para documentar el punto referido al que denomina "The Danish Protest" la obtuvo de "A memorándum on the Use of Sex Chromatin Investigation of Competitions in Women's Division of the Olympic Games" February 3, 1972, Box 105, Commissions, IOC Commissions and Committees-Medical Commission, 1970-1973 Folder, Brundage Colletion” (Pieper, 2016, pág. 82).

${ }^{18}$ La marca de SanthiSoundarajande 2:03.16 minutos, disponible en:

http://web.archive.org/web/20061210225943/http://www.doha-

2006.com/gis/Sports/AT/IGATResults800m.aspx?rscid=1-008-008-E-00001 (consulta el 15 de agosto de 2016), donde se recoge el registro de la final de la prueba de 800 metros en los Juegos Asiáticos de Doha 2006. El registro de los Juegos Asiáticos 2006 no está disponible en la página web del Consejo Olímpico de Asia http://www.ocasia.org/

19 El perfil de la atleta Santi Soundarajan se puede consultar en la página de la IAAF. Disponible en: https://www.iaaf.org/athletes/india/soundarajan-shanti-210467 (consulta el 15 de agosto de 2016).

${ }^{20}$ Datos oficiales del Mundial de Atletismo en Berlín 2009 de la página web de la IAAF. Disponible en: https://www.iaaf.org/results/iaaf-world-championships-in-athletics/2009/12th-iaaf-world-championships-inathletics-3658/women/800-metres/final/result (consulta el 15 de agosto de 2016).

${ }^{21}$ La IAAF publicó un comunicado de prensa de 6 líneas, en el cual explicaba que la investigación que se había iniciado en el 2009 a la atleta Caster Semenya había concluido, notificando que la IAAF aceptaba las conclusiones del panel de expertos y la atleta podía competir con efectos inmediatos. También se aclaró que 
no se haría público detalles de la investigación y no se harían comentarios futuros acerca del tema. Disponible en: https://www.iaaf.org/news/iaaf-news/caster-semenya-may-compete (consulta el 16 de agosto de 2016).

${ }^{22}$ Se hace relación a datos desde el año 1891 hasta el año 2008 y se informa en el artículo (Thibault, y otros, 2010) que se obtuvieron para el deporte del atletismo de la página oficial del COI en su sección de resultados, se puede considerar un error de los autores. Ya que los primeros JJOO de la era moderna se llevaron a cabo en el año 1896 y consultando la propia página de resultados del COI, se puede confirmar que existen datos disponibles desde el año 1986 https://www.olympic.org/olympic-results

${ }^{23}$ El método utilizado y presentado por el Dr. Bermon para establecer esta diferencia media de rendimiento no han sido publicado en ninguna revista científica. En el apartado 2.1 se explica cuál fue el método utilizado por el doctor Bermon para establecer este porcentaje.

${ }^{24}$ En la decisión de medidas cautelares no se especifican los estudios a los que el Dr. Bermon hace referencia. En la correspondencia mantenida por el autor de esta tesis doctoral y la Dra. Hirschberg se pudo determinar que uno de los estudios es el denominado "Dague Study" (Bermon et al., 2014) y el otro es un estudio que se llevó a cabo en el Mundial de Atletismo de 2015 en Beijing, cuyos resultados no han sido hechos públicos.

${ }^{25}$ Se omite la referencia al testimonio de Nick Davies, Secretario General de la IAAF, quien había sido también su Director de comunicación desde 2002, que prestó declaración, expuesta en los parágrafos 341 a 348 de la decisión arbitral, sobre la revelación que hizo confirmando la investigación de la atleta Caster Semenya y que no resulta relevante para esta investigación. 